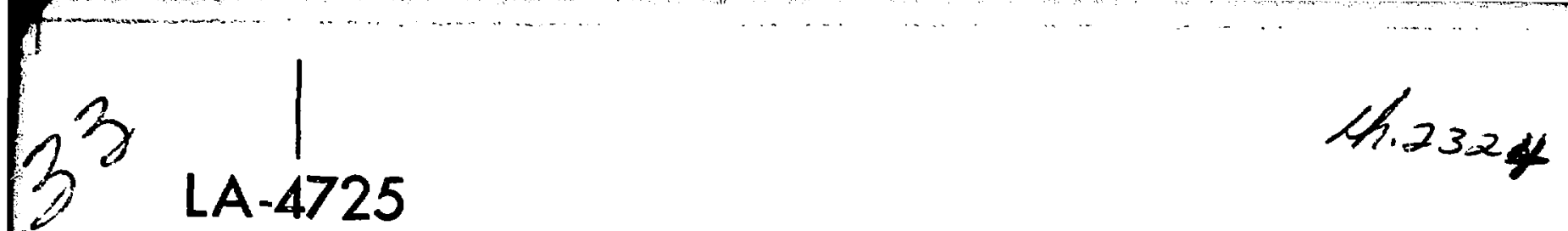

$11^{130}$
MASTER

\title{
An Evaluation of the
}

Neutron and Gamma-Ray Production

Cross Sections for Nitrogen 
This report was prepared as an account of work sponsored by the United States Government. Neither the United States nor the United States Atomic Energy Commission, nor any of their employees, nor any of their contractors, subcontractors, or their employees, makes any warranty, express or implied, or assumes any legal liability or responsibility for the accuracy, completeness or usefulness of any information, apparatus, product or process disclosed, or represents that its use would not infringe privately owned rights.

Printed in the United States of America. Available from

National Technical Information Service

U. S. Department of Commerce

5285 Port Royal Road

Springfield, Virginia 22151

Price: Printed Copy \$3.00; Microfiche $\$ 0.95$ 


\title{
An Evaluation of the
}

\section{Neutron and Gamma-Ray Production Cross Sections for Nitrogen}

by

\author{
P. G. Young
}

D. G. Foster, Jr.

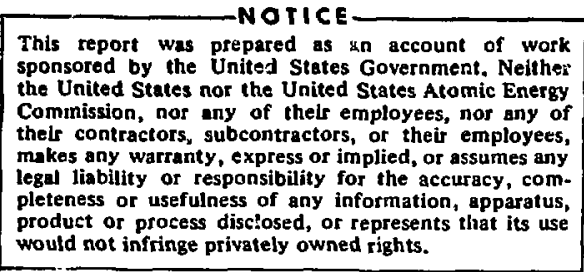

Work supported by The Defense Nuclear Agency. 
CONTENTS

ABSTRACT

1. INTRODUCTION 1

2. GENBRAL FaAtURES OF tHE EVALUATION 1

3. NEUTRON AND PHOTON-PRODUCTION CROSS SECTIONS AND SECONDARY-ENERGY DISTRIBTUIONS 3

3.1 Total Crosa Section 3

3.2 The ${ }^{14} \mathrm{~N}(\mathrm{n}, \gamma)^{15} \mathrm{~N}$ Gross Section 10

3.3 Neutron Inelastic--Scattering Cross Sertions 13

3.3.1 The ${ }^{14} \mathrm{~N}\left(\mathrm{n}, \mathrm{n}^{\prime}\right)$ and ${ }^{14} \mathrm{~N}\left(\mathrm{n}, \mathrm{n}^{\prime} \gamma^{\prime}\right.$ Cross Sections
for $\mathrm{E}_{\mathrm{X}}\left({ }^{1.4} \mathrm{~N}\right)<8.5 \mathrm{MeV}$

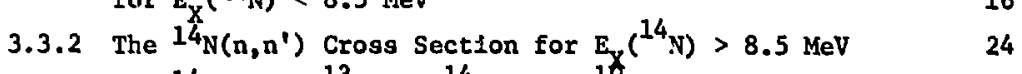

3.3.3 The ${ }^{14} \mathrm{~N}\left(n, n^{\prime} p\right){ }^{13} \mathrm{C}$ and ${ }^{14} \mathrm{~N}\left(n, n^{\prime} \mathrm{a}\right){ }^{1 f_{B}}$ Cross Sections 26

3.4 The ${ }^{14} \mathrm{~N}(\mathrm{n}, \mathrm{p}){ }^{14} \mathrm{C}$ and ${ }^{14} \mathrm{~N}(\mathrm{n}, \mathrm{pr}){ }^{14} \mathrm{C}$ Cross sections 27

3.5 The ${ }^{14} N(n, d){ }^{13} c,{ }^{14} N(n, d \gamma){ }^{13} c$, and ${ }^{14} N\left(n, n^{\prime} p \gamma\right)^{13} c$ Cross Sections 30

3.6 The ${ }^{14} \mathrm{~N}(\mathrm{n}, \mathrm{t}){ }^{12} \mathrm{C}$ and ${ }^{14} \mathrm{~N}(\mathrm{n}, \mathrm{t} \gamma)^{12} \mathrm{C}$ Cross Sections 32

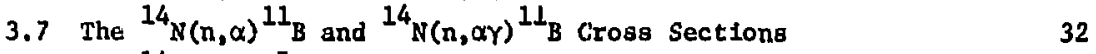

3.8 The ${ }^{14} \mathrm{~N}(\mathrm{n}, 2 \alpha)^{7}$ L1 Cross Section 39

3.9 The ${ }^{14} \mathrm{~N}(\mathrm{n}, 2 \mathrm{n})^{13} \mathrm{~N}$ Cruss Section and Energy Diatris :Ion 41

3.10 The Elastic-Scattering Crosg Section 41

4. NEUTRON ANGULAR DISTRIBUTIONS 44

4.1 Elestic-Scattering Angular Distributions 44

4.1.1 Elastic Angular Distributions for $E_{n}<8 \mathrm{MeV} \quad 44$

4.1 .2 Elastic Angular Distributions for $E_{n}>8 \mathrm{MeV} \quad 49$

4.2 Inelastic Neutron Angular Dlstributions 51

4.3 Angular Distributions for the ${ }^{14} \mathbb{N}(n, 2 n)^{13} \mathbb{N}$ Reaction 55

5. PHOTON ANGULAR DISTRIBUTIONS

6. DISCUSSION

ACKNOWLEDGMENTS $\quad 58$

REFERENCES

APPENDIXES

A. Compound-Nucleus Reaction-Theory Calçulations 63

B. Resonance-Theory Parameterization 65

C. Legerdre Coefficlents and Angular Dlstributions for
Neutron Inelastic Scattering 
AN EVALUATION OF THE NEUTRON AND

GAMMA-RAY-PRODUCTION CROSS SECTIONS FOR NITROGEN

by

P. G. Young and D. G. Foster, Jr.

ABSTRACT

This report describes a complete evaluation of the neutron cross sections of $14 \mathrm{~N}$ from $10^{-5} \mathrm{eV}$ to $20 \mathrm{MeV}$, lncluding photonproduction cross sections and energy and angular distributions of secondary neutrons and photons. The recommended data are based mainly on experiment, augmented by calculations from nuclear models where appropriate. The evaluated data are available on magnetic tape in ENDF/B(III) format.

\section{INTRODUCTION}

All neutron-1nduced reactions with $14 \mathrm{~N}$ have been evaluated for the neutron energy region from $10^{-5} \mathrm{eV}$ to $20 \mathrm{MeV} .^{*}$ The evaluation includes energy and angular distributions for secondary neutrons and photons, as well as neutron- and photon-proriuction cross sections. The evaluated data are in ENDF/B (III) format as MAT 1133 and have been provided to the Radiation Shielding Information center at Oak Ridge and to the National Neutron Cross Section Center at Brookhaven.

The evaluation is based primarily upon experimental measurements. All avallable experimental information for neutron-induced reactions with nitrogen was complled for the study. Our bibllography is reasonably complete for measurements reported before the fall of 1970, but not all of $1 t$ is included in this report. The evaluation was completed around the end of 1970. Since then several new resuits have appeared in the Iiterature, and we corment on the most Important of these In the text. We also comment on areas that might be improved, either in light of new information or because of oversights in the original evaluation.

* Because natural nitrogen consists of $99.63 \% 14 \mathrm{~N}$ and only $0.37 \% 15 \mathrm{~N}$, it can be treated as $14 \mathrm{~N}$ for most practical applications.
The mora general features of the study are reviewed in Sec. 2. The detailed considerations that went into the evaluation are described in Secs. 3 5. Section 3 is devoted to cross sections, Sec. 4 to neutron angular distributions, and Sec. 5 to secondary-photon angular distributions. Sec. 3 also gives implicit information on neutron and photon energy distrlibutions, because all $\left(n, n^{\prime}\right)$ reactions are represented as discrete level-excitation cross sections and all gamma rays are given as discrete transitions. In addition, explicit information on $(n, 2 n)$ energy distributions is given in Sec. 3 , Finally, Sec. 6 includes a capsule summary of est1mated uncertainiles in the evaluated quantities, together with a brief discusston of areas where the evaluation might be improved.

\section{GiNERAL FEATURES OF THE EVALUATION}

The neutron-induced reactions with ${ }^{14} \mathrm{~N}$ that have two or three outgoing particles are summarized In Table $I$, together with the reaction Q-values* and thresholds. The most important reactions are also shown schematically in Fig. 1. The "E scales at the right and left boundaries of FIg. 1

*All Q-values in this evaluation are from the 1964 mass tables of Mattauch et al. (Ma65). A new set of mass tables (Wa71) has recently become available. 
indicate laboratory neutron energy and can be used to determine the thresholds for the various reactions. The energies associaied with the level diagrams are in the center-of-mass system. Guing from left to right, the following processes are represented: ${ }^{14} \mathrm{~N}\left(\mathrm{n}, \mathrm{n}^{1}\right)^{14} \mathrm{~N},{ }^{14} \mathrm{~N}(\mathrm{n}, \mathrm{np})^{13} \mathrm{C},{ }^{14} \mathrm{~N}(\mathrm{n}, \mathrm{p})^{14} \mathrm{c}$, ${ }^{14} \mathrm{~N}(\mathrm{n}, \mathrm{d}){ }^{13} \mathrm{C},{ }^{14} \mathrm{~N}(\mathrm{n}, \mathrm{t})^{12} \mathrm{C},{ }^{14} \mathrm{~N}(\mathrm{n}, \alpha)^{11} \mathrm{~B},{ }^{14} \mathrm{~N}(\mathrm{n}, 2 \alpha)^{7} \mathrm{Li}$, and ${ }^{14} N(n, 2 n)^{13} N$.

TABLE I

Q-VALUE AND THRESHOLD

FOR SEVERAL NITRGGEN REACTIONS

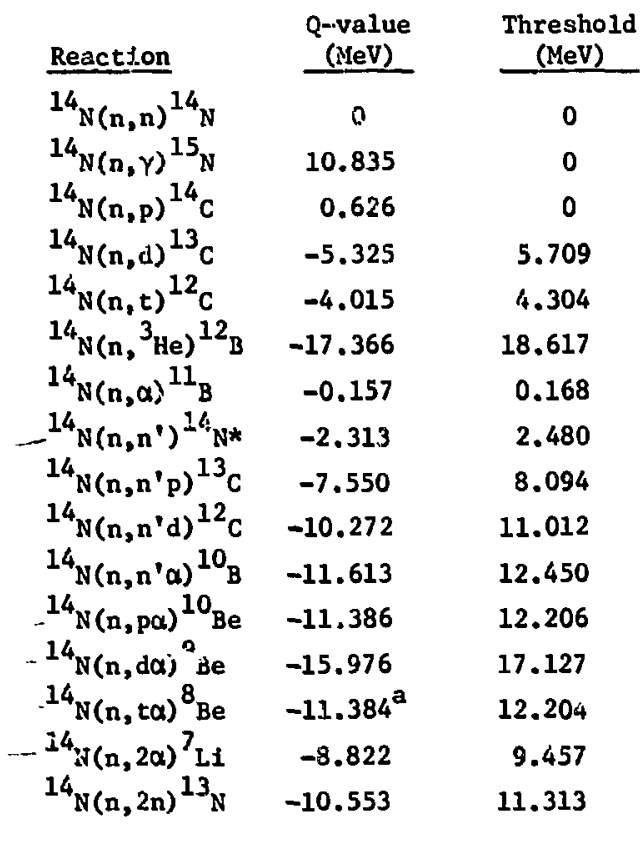

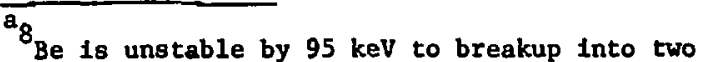
alpha particles.

We determined the cross sections for the $\left(n, p_{0}\right)$, $\left(n, d_{0}\right),\left(n, t_{0}\right),\left(n, \alpha_{0}\right),(n, 2 \alpha)$, and $(n, 2 n)$ reactions from direct experimental measurements. The excitation cross sections for the various gamma-ray-producing levels, which are mostly the levels shown below the thresholds for particle emission in Fig. 1, are also based largely on exporimental measurements. For the higher levels, we used Hauser-Feshbach (Ha52) and evaporation-model calculations to supplement the measuremenis. We determined the total cross section over the entire energy region from experimental data. Below $10 \mathrm{MeV}$, the elastic cross section was obtained by subtracting the sum of the nonelastic partials from the total cross section. At higher energles, however, the nonelastic cross section be- comes less and less certain owing to uncertainty in the $\left(n, n^{\prime}\right)$ cross section to highly excited levels of ${ }^{14} \mathrm{~N}$. Therefore, above $10 \mathrm{MeV}$ we joined the elastic cross section smoothly to the elastic measurements, and adjusted the $\left(n, n^{n}\right)$ cross section to the particle-unstable states (predominantly the $(n, n p)$ reaction), so that the nonelastic partial cross sections sumed to the correct total nonelastil cross section.

The gross features of the evaluated cross sections are shown in Figs. 2-5. Fig. 2 gives the total, elastic, $(n, p)$, and $(n, \gamma)$ cross sections from $10^{-11}$ to $0.1 \mathrm{MeV}$. The $(n, p)$ reaction accounts for most of the neutron ebsorption at these energies. Figure 3 gives an overview of the structure in the total, elastic, and nonelastic cross sections in the SieV region. Figure 4 show the $(n, y),(n, \infty)$, $(n, 2 \alpha)$, and $(n, 2 n)$ cross sections over the MeV region. We obtained the $(n, \alpha)$ cruss section by aumming the discrete $(n, \alpha)$ excitation cross sections for the first 11 states of ${ }^{11_{B}}$. The $(n, \gamma)$ reaction is relatively unimportant at these energies, whereas the $(n, \alpha)$ cross section is ressonably large over much of the MeV region. The $(n, 2 \alpha)$ renction also becomes Important at higher energies. Finally, Fig. 5 compares the $\left(n, n^{\prime}\right),(n, p),(n, d)$, and $(n, t)$ cross sections in the $\mathrm{HeV}$ region. The $\left(n, n^{\prime}\right)$ cross section is the sum of all $\left(n, n^{\prime}\right)$ reactions and includes the $\left(n, n^{\prime} p\right),\left(n, n^{\prime} d\right)$, and $\left(n, n^{\prime} \alpha\right)$ processes. The $(n, p),(n, d)$ and $(n, t)$ cross sections result from suming the excltation cross sections to particle-stable levels for these reactions and are seen to have relatively small cross sections at energies above $\sim 6 \mathrm{MeV}$.

We determined the elastic angular distributions below $8 \mathrm{keV}$ from a single-level resonance-theory analysis that incorporated resonance energies and total widths from our analysis of the total cross section and reaction widths from our analysis of the partial cross sections. With the resonance paraneters fixed, we obtained the $\ell=0$ and $l=1$ potential phase shifts by fitting the available angular-distribution measurements. A total of 33 resonances are included in the analysis. From 8 to $15 \mathrm{MeV}$, we determined the elastic angular distributions by fitting the available measurements with Legendre expansions, and above $15 \mathrm{MeV}$ we used optical-model calculations to estimate the angular 

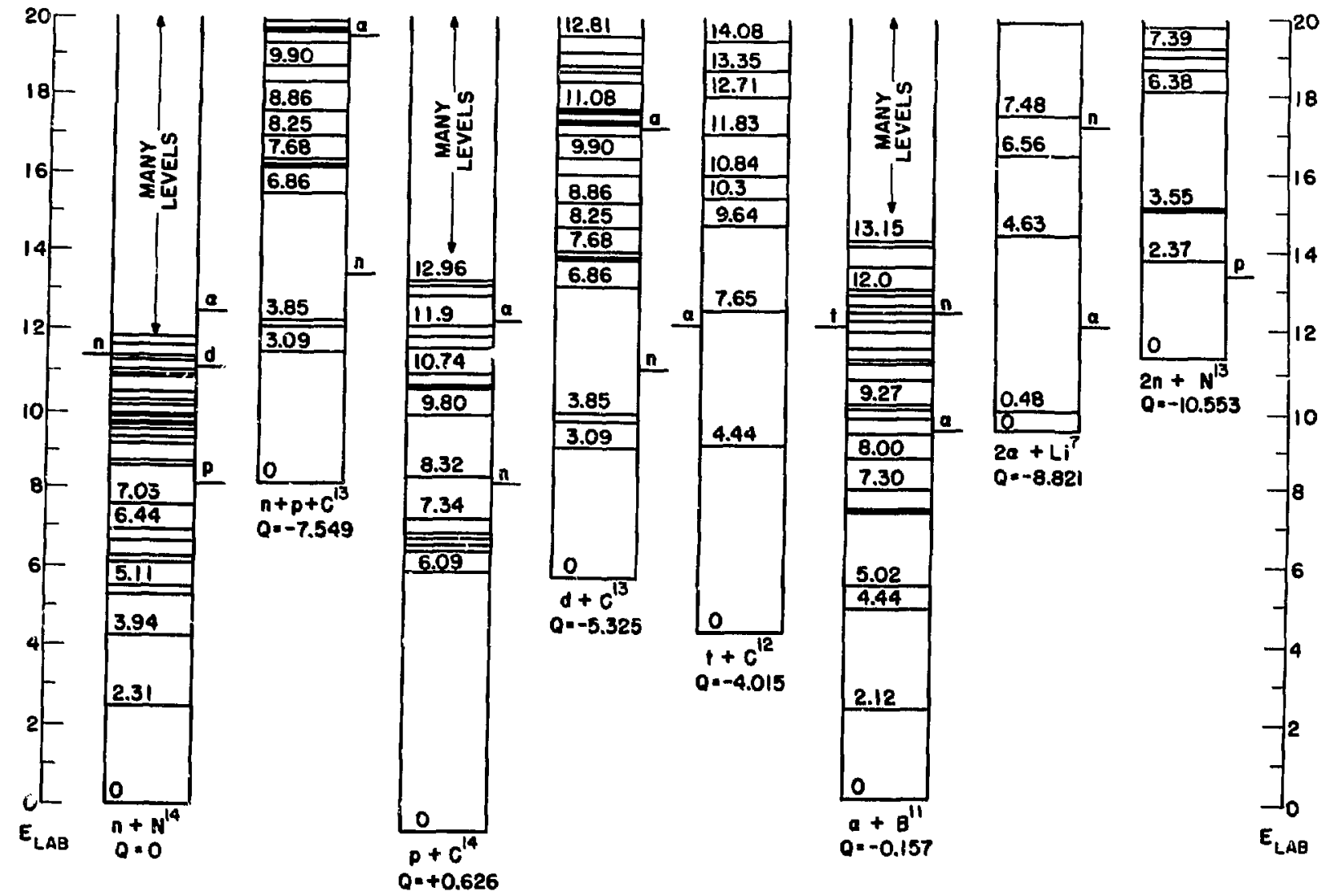

Fig. 1. Composite energy-level diagram for the residual nuclei of mafor interest in thia evaluation. Except for the "E $E_{1}$ " scales, the energtes are in the center-of-mass system, and all energies are in MeV. The separation energies for secondary-particle emission are show by short lines at the side of each diagram.

distributions. The inelastic neutron angular distributions are based almost entirely upon measured $\left(p, p^{\prime}\right)$ angular distribtuions, ma'-ing use of an equivalence theorem due to Lutz and Anderson (Lu66) and Anderson et al. (An67) which is based upon the charge symmetry of puclear forces.

\section{NEUTRON AND PHOTON-PRODUCTION CROSS SECTIONS AND SECONDARY-ENERGY DISTRIBUTIONS \\ 3.1 Total Cross Section}

We constructed the free-atom total cross section in the eV region from the scattering and absorption cross sections - The ahsorption cross section was assumed to have a $1 / v$ energy dependence and was based upon a measurement of the thermal $(n, Y)$ cross section by Jurney and Motz (Ju63) and upon a composite of four measurements of the thermal (n,p) cross section (Co49, Ba49, ${ }^{*}$ Cu51, , Ha61). We assumed the scattering cross section to be constant at these energies and obtained $1 t$ by fitting a straight line as a function of $\mathrm{E}_{\mathrm{n}}^{-\frac{1}{2}}$ to Melkonian's (Me49) time-of-f1ight total-cross-section measurement between 1 and $79 \mathrm{eV}$, augmented by a single point at $0.0253 \mathrm{eV}$ derived from the absorption cross section and an estimate of the scattering cross section. Two iterations of this procedure were maje to obtain the scattering cross section, and the results are summarized for $E_{n}=0.0253 \mathrm{eV}$ in Table II. In this way we found that molecular effects in $\mathrm{N}_{2}$ gas are perceptible in the total cross section at all energies below $2 \mathrm{ev}$, in approximate agreement with Melkonian's original conclusions (Me49).

These results have been renormalized to a boron $(n, \alpha)$ cross section of $759 b$ for thermal neutrons. 


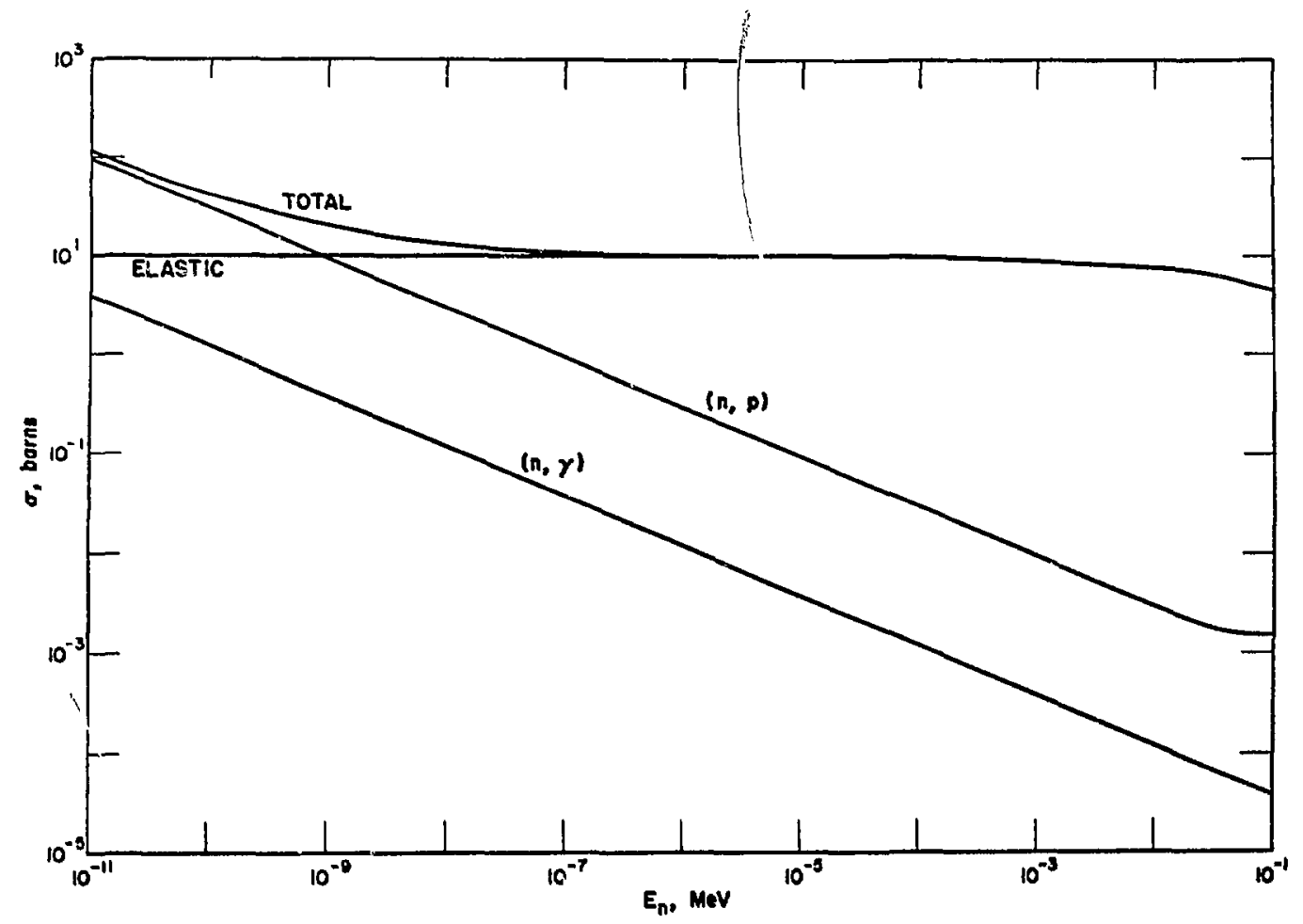

Fig. 2. Evaluated total cross section and 1ts constituent partial cross sections from $10^{-11}$ to $10^{-1} \mathrm{MeV}$.

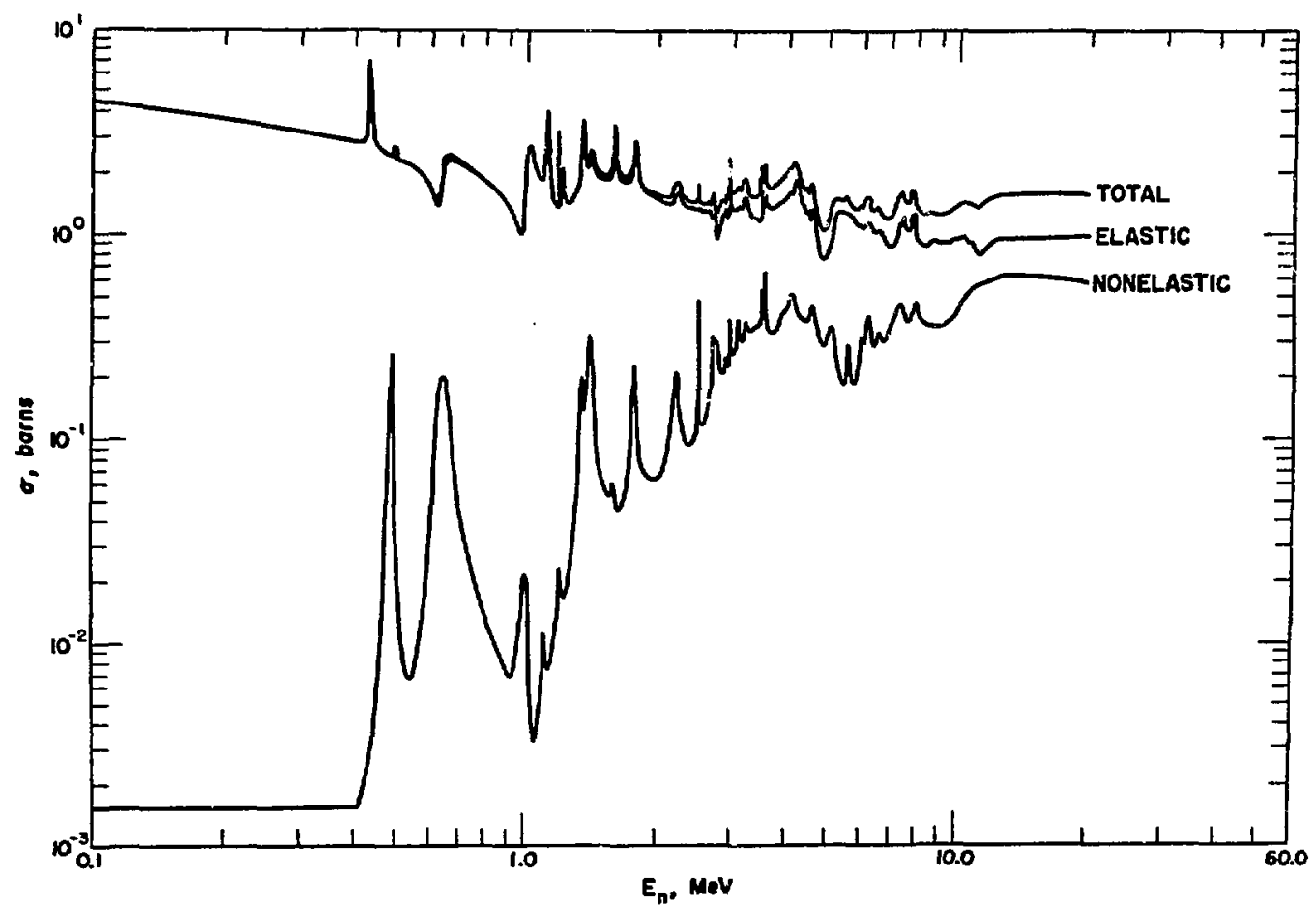

Fig. 3. Evaluated total cross section and its constituent elastic and nonelastic cross sections from 0.1 to $20 \mathrm{MeV}$. 


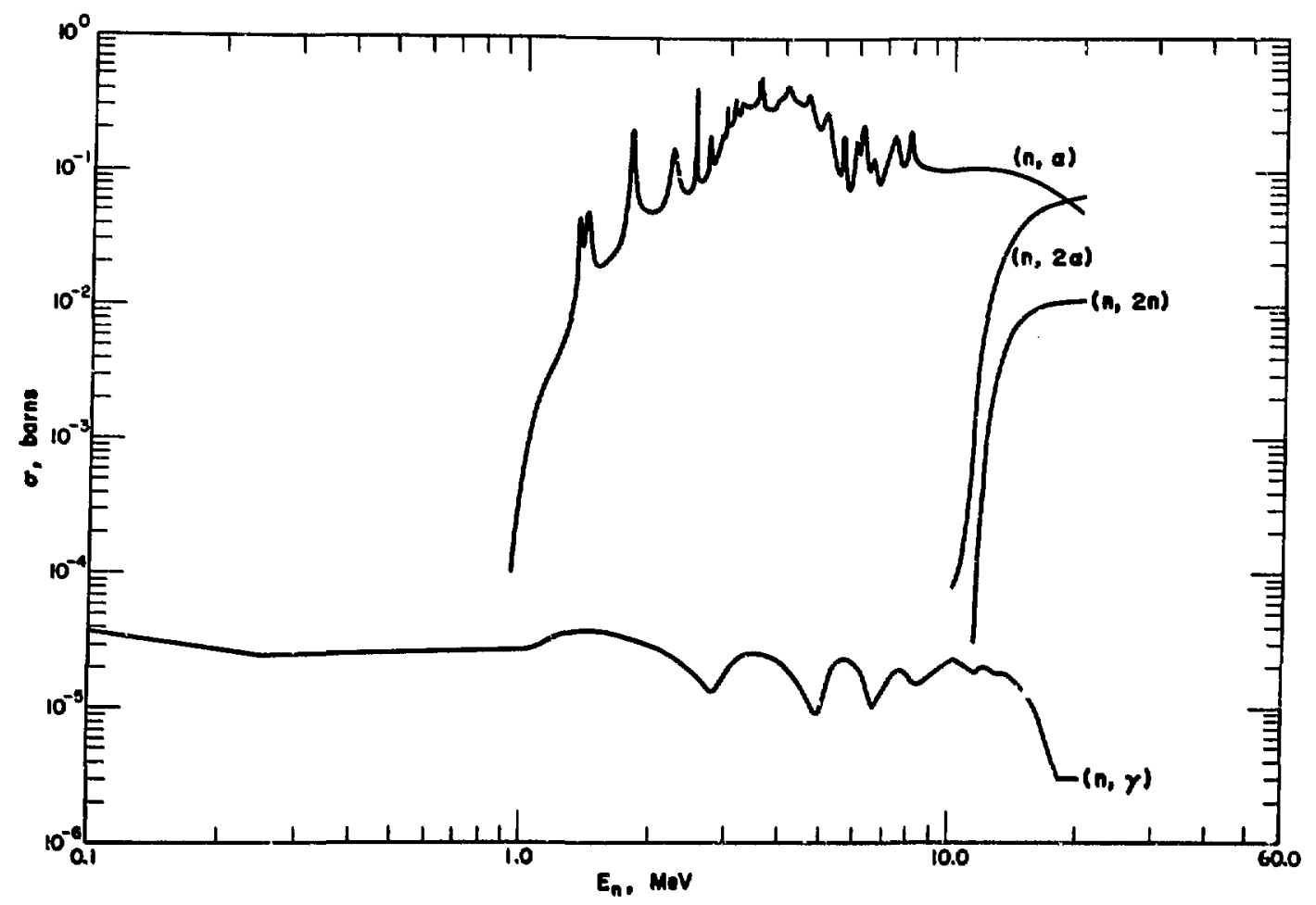

Fig. 4. Evaluated $(n, \gamma),(n, \alpha),(n, 2 \alpha)$, and $(n, 2 n)$ cross sections from 0.1 to $20 \mathrm{MeV}$.

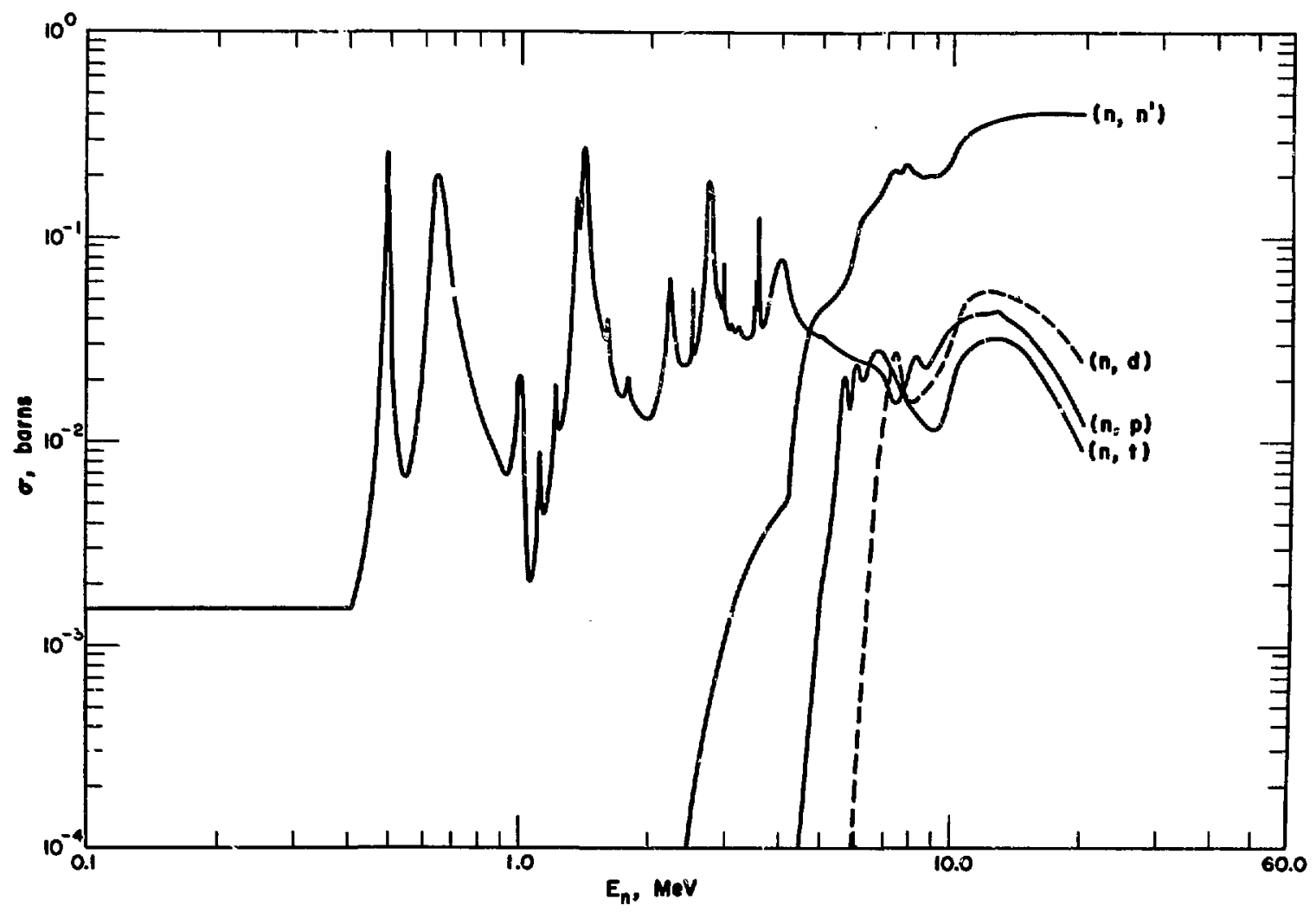

Fig. 5. Evaluated cross sections from 0.1 to $20 \mathrm{MeV}$ for Inelastic scattering and the ( $n, p)$, ( $n, d)$, and ( $n, t)$ reactions. As discussed in the text, the $\left(n, n^{\prime}\right)$ cross section includes $\left(n, n^{\prime} p\right),\left(n, n^{\prime} d\right)$, and $\left(\hat{n}^{\prime}, n^{\prime} \alpha\right)$ reactions. 
Accordingly, we 1ncluded only the total cross-section data between 1.3 and $79 \mathrm{eV}$ in the fit. Aside from any unknown systematic errors in the total or absorption cross sections, the extrapolation of the total cross section to $10^{-5} \mathrm{eV}$ is accurate to within $5 \%$.

TABLE II

$2200-\mathrm{m} / \mathrm{sec}$ CROSS SECTIONS OF NITROGEN

\begin{tabular}{|c|c|c|c|}
\hline Reaction & $\begin{array}{c}\sigma \\
\text { (barns) } \\
\end{array}$ & $\begin{array}{c}\Delta \sigma^{\mathrm{a}} \\
\text { (barns) } \\
\end{array}$ & Reference \\
\hline$(n, p)$ & 1.819 & 0.036 & $\mathrm{Co} 49, \mathrm{Ba} 49, \mathrm{CuS1}, \mathrm{Ha} 61$ \\
\hline$(n, y)$ & 0.075 & 0.0075 & Ju63 \\
\hline Absorption & 1.834 & 0.037 & Sum of $(n, \gamma)$ and $(n, p)$ \\
\hline Scattering & 9.957 & 0.040 & Present Analysis \\
\hline Total & 11.851 & 0.054 & Present Analysis \\
\hline
\end{tabular}

a Does not include estimates of systematic errors. SeE Sec. 6 for more realistic error estimmes.

The evaluated total cross section from $10^{-5} \mathrm{eV}$ to $10 \mathrm{keV}$ is compared to the avallable measurements In Flg. 6. Melkonfan's data below $0.3 \mathrm{eV}$, which are severely influenced by molecular effects, have been omitted from $\mathrm{F}_{\mathrm{g}}$. 6. Above $80 \mathrm{eV}$, we fitted a quadratic in $\log E_{\text {i }}$ to Melkonian's data from 85 to $653 \mathrm{eV}$ and to cur evaluated composite (described below) from 10 to $20 \mathrm{keV}$. Nelkonian's two points above $653 \mathrm{eV}$ are clearly inconsistent with the other measurements and have been liscarded.

The foundation for the evaluated total cross section in the $\mathrm{MeV}$ region is the recent time-offlight measurements by Heaton et al. (He70) at the National Bureau of Standards, Carlson and Cerbone (Ca70) at Gulf General Atomic (GGA), and Foster and Glasgow (Fo71) at Hanford. These three measurements, which span the energy region from 0.5 to $25 \mathrm{MeV}$, are in such dramatically good agreement (better than $0.5 \%$ on $:: a$ average after allowance for differences in resolution) that we discarded nine older measurements between 2 and $15 \mathrm{MeV}$. The Heaton and Carlson energy scales agree to within $\pm 0.5 \mathrm{keV}$ at all energies where a close comparison can be made. We therefore used the tIme-of-flight energy scale to correct the energy scales of the older measurements that overlap it at the low-energy end. Further, the time-of-flight measurements served as a standard for judging the quality of the older measurements that overlapped at lower energies.
Between 10 and $500 \mathrm{keV}$, the measurements of Hinchey et al. (Hi52) and Huddleston and Mooring (Hu61) are flanked by two unpublished measurements (B159, B162) from Duke which disagree by $8 \%$ in their overlap region. However, a composite of these four measurements, after normalization to their weighted average, provides a substantial overlap with the time-of-flight measurements by Heaton et al. (He70) and Carlson and Cerbone $(\mathrm{Ca} 70)$, and the composite agrees with the heaton data to within a few tenths of one percent. We therefore used this composite for the evaluated total cross section from 10 to $500 \mathrm{keV}$. Figure 7 compares the evaluated and experimental data from 10 to $410 \mathrm{keV}$ before normalization.

The only significant disagreement in the timeof-flight measurements occurs at the low-energy end of the Heaton (He70) and Carlson ( $\mathrm{Ca} 70$ ) measurements, roughly from 0.5 to $0.7 \mathrm{MeV}$. This difference, which Is a maximum of $5 \%$ at $500 \mathrm{kev}$, arises from dead-time errors in the high-intensity time-of-flight systems and is always greatest at the lowest energy. The error in the Heaton (He70) data is intrinsically larger, but the correction is more accurately known. Because the Heaton data agree 80 well with the normalized composite of the Hinchey (H152), Huvdleston (Hu61), and Bilpuch (B159, B162) messurements at lower energies, we based our evaluated curve from 0.5 to $0.75 \mathrm{HeV}$ entirely on the Heaton (He70) reaults. Additional NRS measurements (made after this part of the evaluation was completed) directed specifically at resolving this discrepancy indicate that our composite should be lowered by $1.5 \%$ at $500 \mathrm{keV}$, which would reduce the discrepancy between the GGA and NBS measurements to $3.5 \%$.

The total-cross-section results from 0.4 to $0.7 \mathrm{MeV}$, including the unnormalized data, are shown In Fig. 8. This energy region includes the first three resonances in nitrogen at 434, 493, and 647 $\mathrm{keV}$. We found the energy of the lowest resonance to be $\$ 33.6 \pm 0.4 \mathrm{keV}$ after correcting the energy scales of the lower-energy measurements to agree with the Heaton (He7O) and Carlson (Ca70) time-offlight data. The second resonance at $493 \mathrm{keV}$ has a rather small neutron width $\left(\Gamma_{n} / \Gamma \sim 0.3\right)$ and is seen more clearly in the $(n, p)$ reaction than in the total cross section. This point is better illustrated in Fig. 3 where the firat peak in the nonelastic cross section is entirely due to the 493$\mathrm{keV}$ resonance in the $(n, p)$ cross section. 


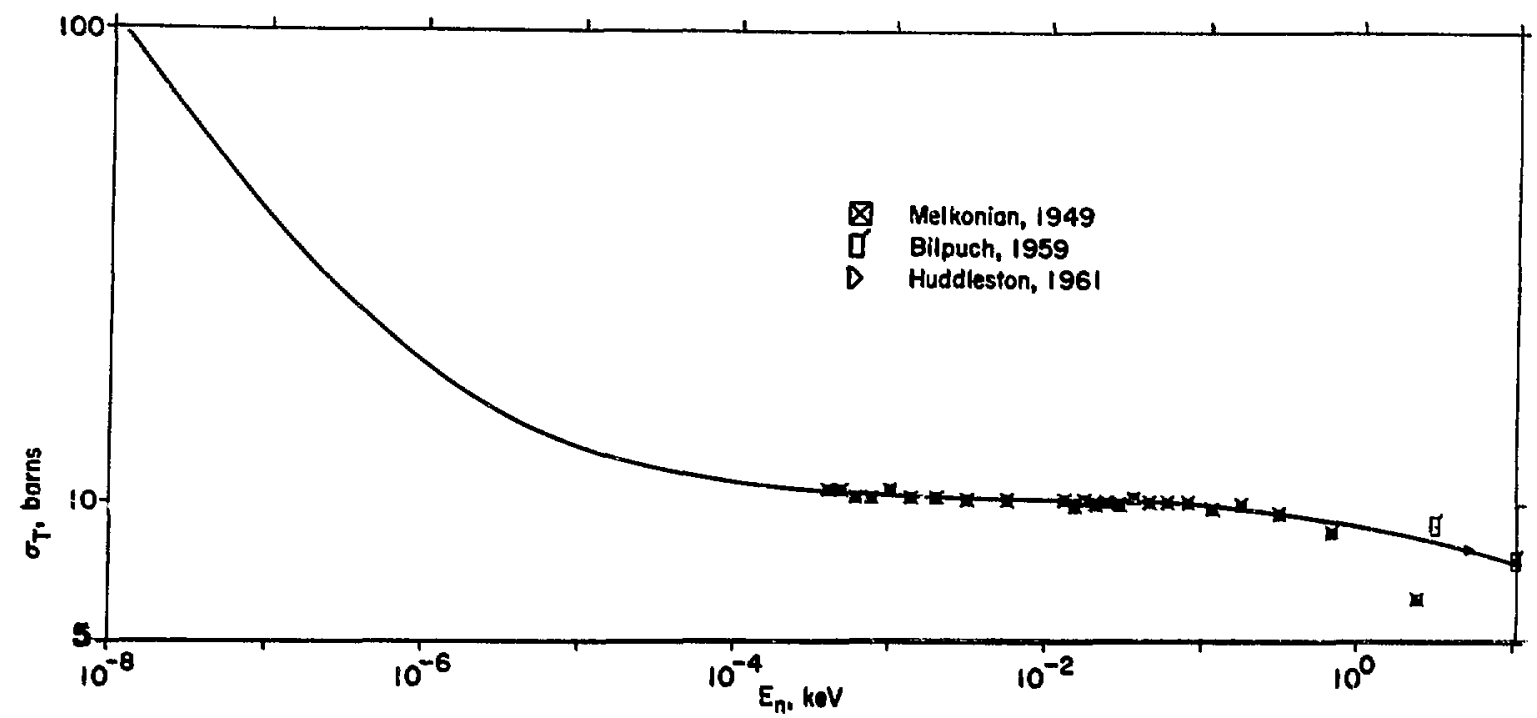

Fig. 6. Evaluated total cross section below $10 \mathrm{keV}$ with the data on which $1 \mathrm{t}$ is based.

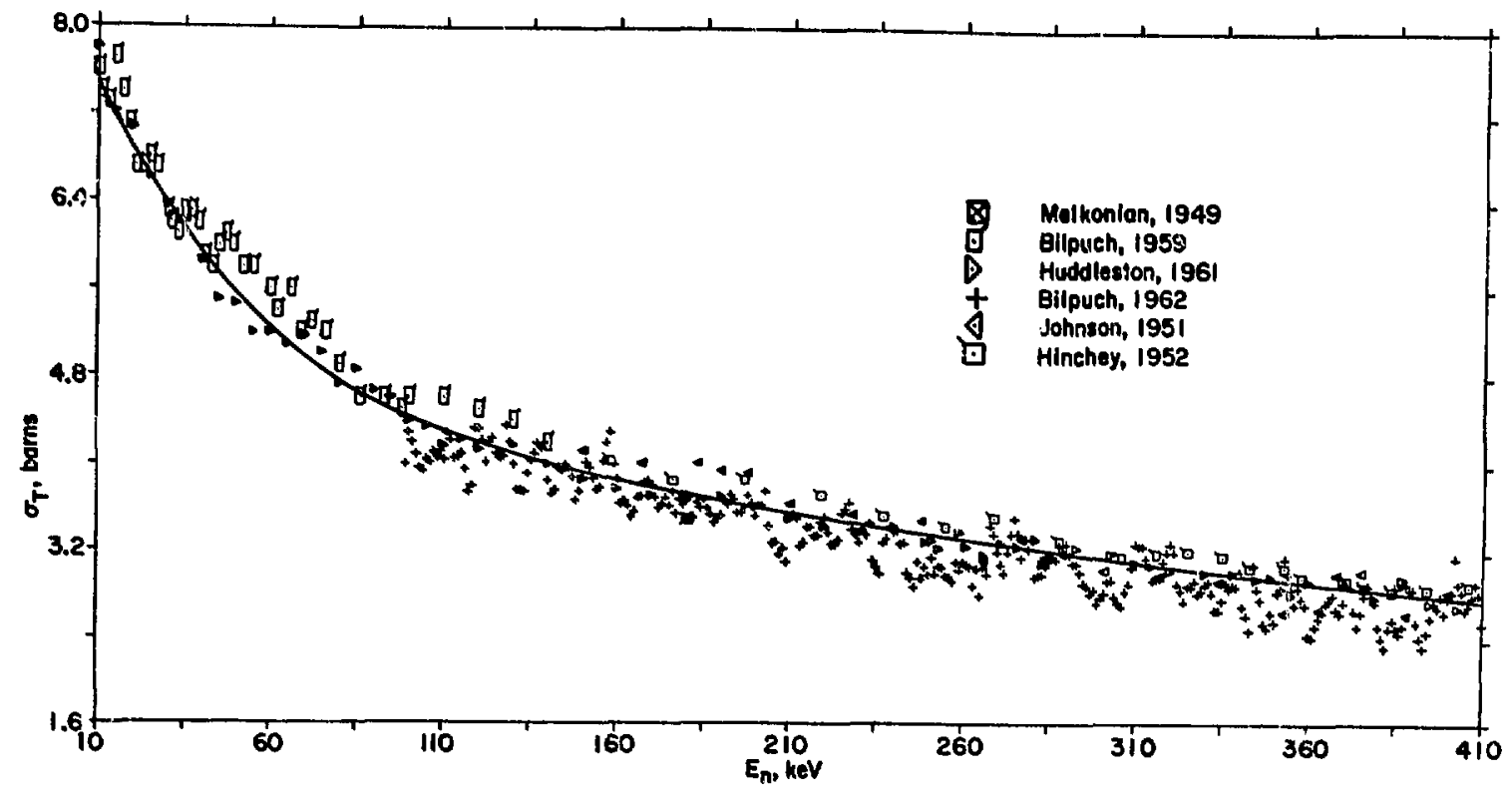

Fig. 7. Evaluated total cross section from 10 to $410 \mathrm{keV}$ with the measurements on which $1 \mathrm{t}$ 1s based.

For smoothing purposes, we have represented the peaks in the total cross section up to about $8 \mathrm{MeV}$ by single-level Breit-Wigner fits above straightline backgrounds. These fits elso served to estabIish resonance energies and widths for other parts of the evaluation. Where the cross section is smooth, that is, between resonances and at energies $>8 \mathrm{MeV}$, we genersted the evaluated curve by sliding polynomlal fits to the composite experimental data.

From 0.75 to $25 \mathrm{MeV}$, we used a composite of the three time-of-flight measurements by Heaton et al.
(He70), Car1son and Cerbone (Ca70), and Foster and Glasgow (Fo71) to represent the total cross section. The evaluated curve was obtained by smoothing the composite results, as described above. Generally, we used the Carlson data alone to fit the BreitWigner shapes over sharp structure because these data have the best resoiution; the Heaton results, on the other hand, dominate the composite at other energies because of their better preciston. There was serious disagreement between some of the older measurements and the time-of-flight composite, with 
differences of up to $20 \%$. Most of the older data between 4 and $15 \mathrm{MeV}$ lie systematically higher than the composite. The evaluated total cross section from 0.7 to $30 \mathrm{MeV}$ is compared to all available experimental measurements in Figs. 9-18. Again, we shcw als of the data in their original (unnormalized) form. We estimate the accuracy of the evaluated total in this energy region to be $\sim 1 \%$ except near fine structure.

Pronounced structure is observed in the total cross section up to about $8 \mathrm{MeV}$. A complete description of the resonances in the total cross section is given in Sec. 4.1.1, which deals with the resonance-theory analysis used to obtain the elastic angular distributions. Evidence for this structure is seen in most of the figures, but perhaps the best example ocsurs in Fig. 10 which shows the 1.116-. $1.184-, 1.209-, 1.349-$, and 1.406-MeV resonances. The sharp structure in this figure, particularly the 1.184-MeV resonance (width $=2.1 \mathrm{keV}$ ), illustrates the excellent agreement between the energy scales of the Heaton (He70) and Carlson ( $\mathrm{Ca} 70$ ) measurements, as well as the superior energy resolution of the
Carlson measurements. These points are also illustrated in Fig. 13 which includes several resonances over the energy region 2.65 to $3.375 \mathrm{MeV}$. The Foster and Glasgow time-of-flight data (Fo71) in Fig. 13 have poorer resolution than either the Heaton or Carlson measurements.

Examples of disagreement between older measurements and the recent time-of-filght results (Ca70), He70, Fo71) occur in all figures, but the most apparent involve the data of Johnson et al. (Jo51) in Fig. 9, the data of Johnson et al. (Jo52, Jo68) in F1g. 12, the data of Johnson et al. (Jo68) and Meler et al. (Me53) In Figs. 13 and 14, and the data of Nereson and Darden (Ne54) and Becker and Barschall (BeS6) in Figs. 14-16. Most of these data are falrly old, and the differences are not too surprising. Examples of extremely good agreement between older measurements and the recent time-of-flight data are the Coon measurement (Co52) at $14.1 \mathrm{MeV}$ In Fig. 17 and the Peterson et al. measurements (Pe60) above $15 \mathrm{MeV}$ in Fig. 18. The time-of-flight data of Foster and Glaggow (Fo71) begin in Fig, 12 near $2.3 \mathrm{MeV}$. The statistics In these data are poor at the low-energy end, and

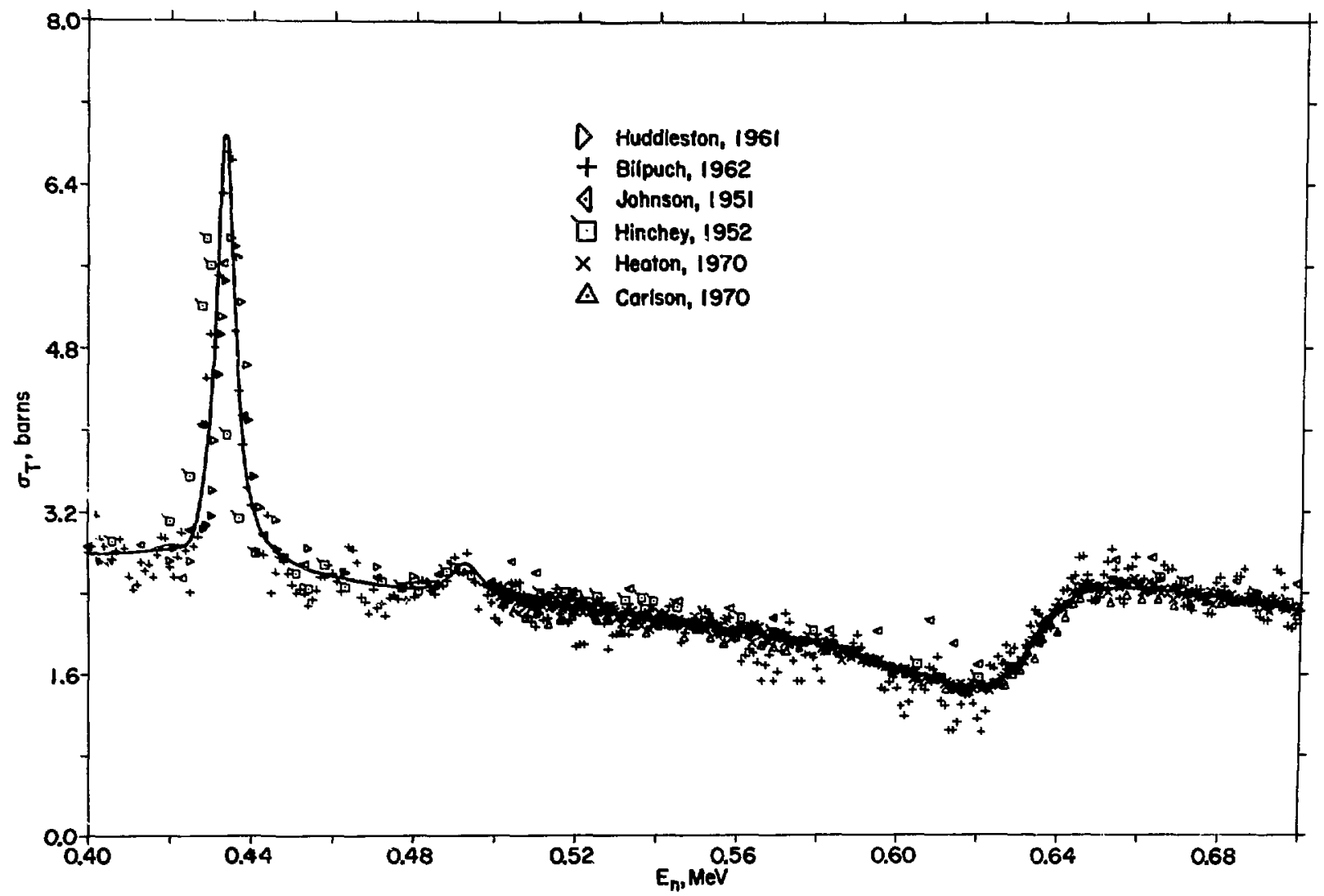

FIg. 8. Evaluated total cross section from 400 to $700 \mathrm{keV}$ with the data on which it is based. 
the results seem somewhat lower than the Heaton (He70) and Carlson (Ca70) measurements near $2.4 \mathrm{MeV}$. At energles above $2.7 \mathrm{MeV}$, however, the three timeof-flight measurements agree very well.

Figure 16 gives the total cross section from 6 to $9 \mathrm{MeV}$, which spans the energy region of the famous nitrogen discrepancy. This discrepancy, which was pointed out by Stewart (St69) and Dickens and Perey (D169), occurs because the elastic cross sec- tion obtained near $8 \mathrm{MeV}$ by subtracting the sum of the nonelastic partial cross sections from the total cross section lies some $200 \mathrm{mb}$ higher than the elastic measurement by Bauer et al. (Ba67). This problem is discussed further in Sec. 3.10. In Fig. 16, the time-of-flight measurements of Heaton (He70), Carlson (Ca70), and Foster (Fo71) again agree rea-' sonably well, and, although some of the older data (Be56, Ne54) disagree with the evaluated curve,

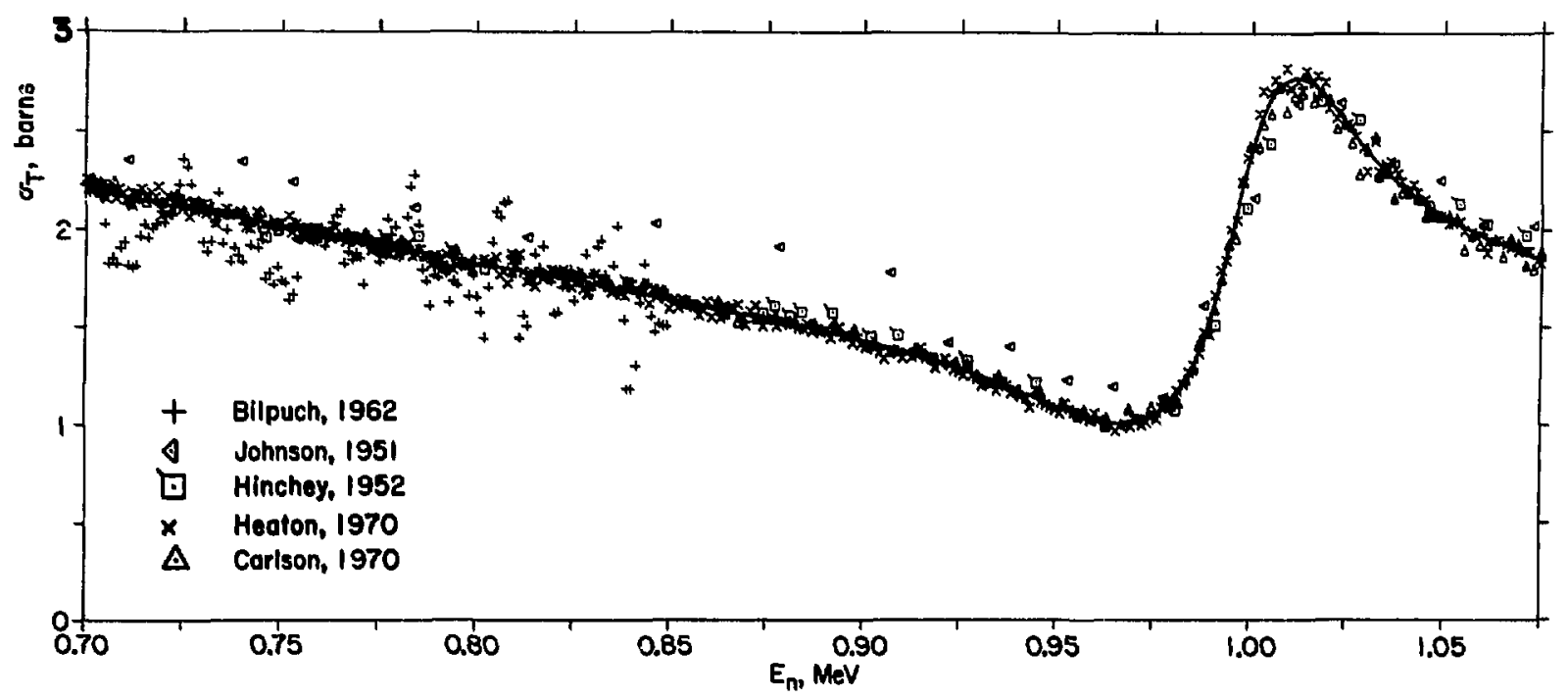

Fig. 9. Measured and evaluated total cross section between 0.7 and $1.1 \mathrm{MeV}$.

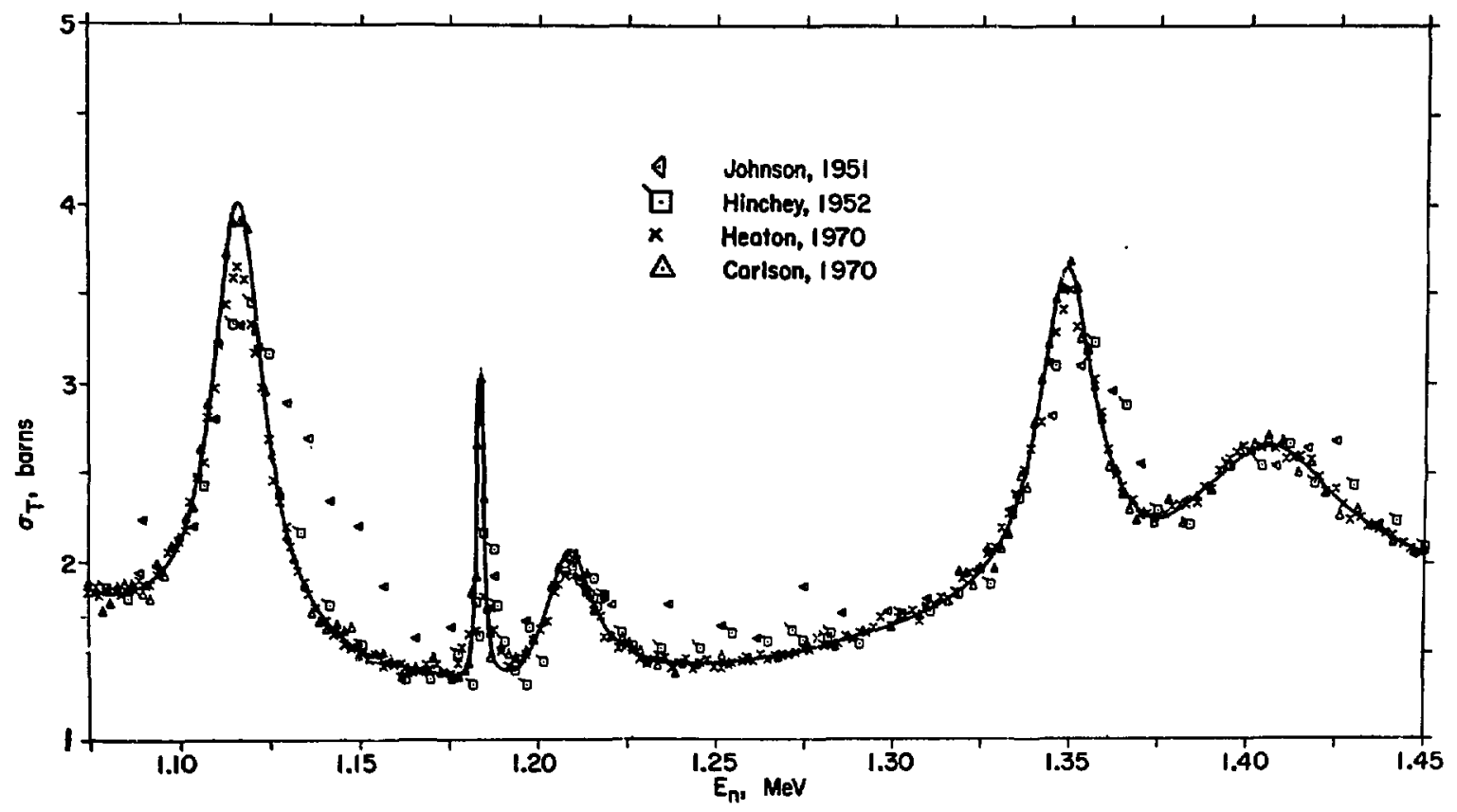

FIg. 10. Measured and evaluated total cross section between 1.1 and $1.45 \mathrm{MeV}$. 
these earlier measurements are generally higher than the evaluation which is in the wrong direction to explain the discrepancy in the cross sections.

The Carlson ( $\mathrm{Ca} 70$ ) measurement ends at $9 \mathrm{MeV}$ (FIg. 16), and near this energy the statistics in the data are poor. The Foster (Fo71) and Heaton (He70) results agree well up to $15 \mathrm{MeV}$ where the Foster measurement ends (Fig. 17). The Heaton measurement continues to $25 \mathrm{MeV}$ and is seen to agree well with the older Peterson measurement (Pe60) above 15 MeV (Fig. 18). We extended the evaluated total cross section to $150 \mathrm{MeV}$ by fitting all avallable measurements above $24 \mathrm{MeV}$ with a cubic in $\log E_{n}$; these results are presented in Fig. 19. The worst statistical uncertainty in the fit is less than $2 \%$ near $45 \mathrm{MeV}$.

\subsection{The ${ }^{14} \mathrm{~N}(n, y)^{15} \mathrm{~N}$ Cross Section}

The thermal $(n, \gamma)$ cross section for nitrogen has been measured as $80 \pm 20$ mb by Bartholomew (Ba57) and as $75 \pm 7.5 \mathrm{mb}$ by Jurney and Motz (Ju63). The 75-mb value was accepted for this evaluation. The energy dependence of the $(n, y)$ cross section is assumed to be $1 / \mathrm{v}$ up to $250 \mathrm{keV}$, as the ff.rst resonance In nitrogen does not occur unt1l $434 \mathrm{keV}$.

The $(n, \gamma)$ reaction is the inverse of the nuclear photoeffect and is expected to exhibit the photonuclear giant resonance near $\mathrm{E}_{\mathrm{n}}=11 \mathrm{MeV}$. Because of lack of experimental data In the MeV region, we

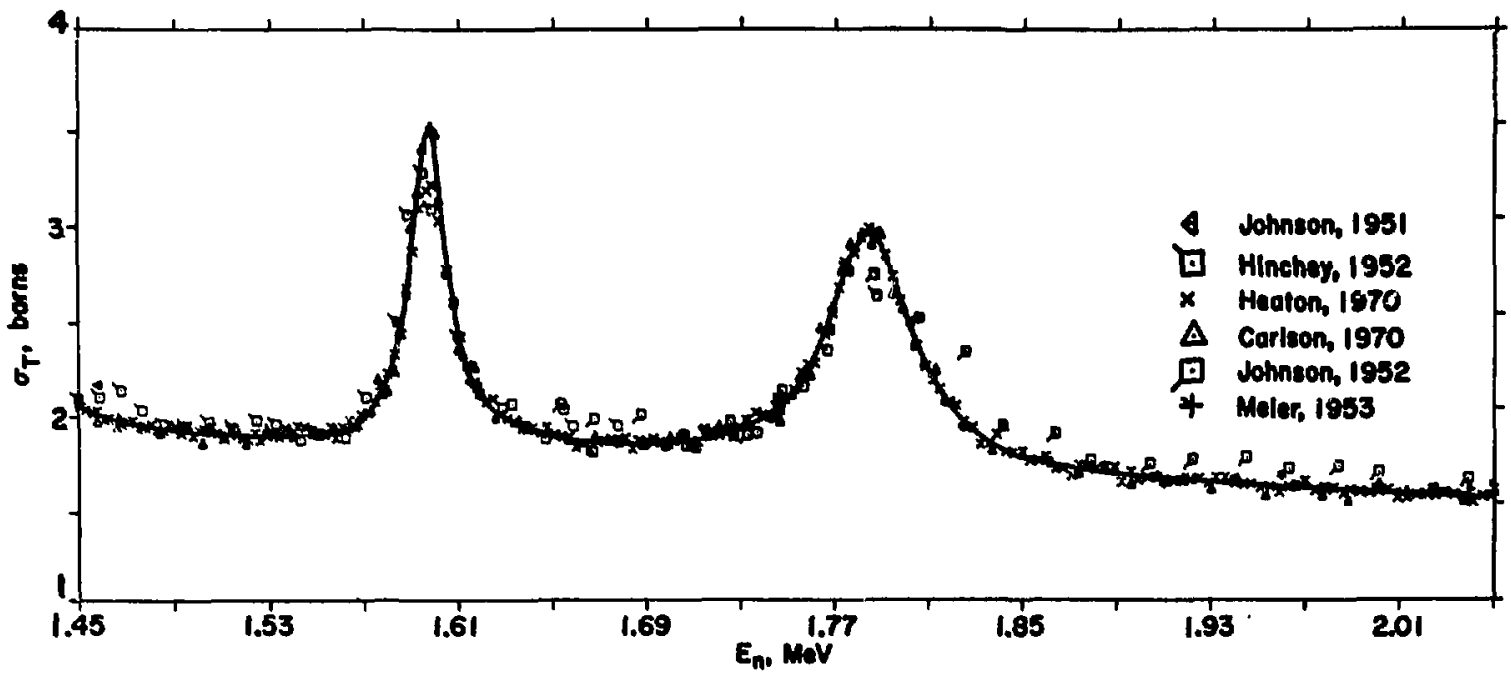

Fig. 11. Measured and evaluated total cross section between 3.45 and $2.05 \mathrm{MeV}$.

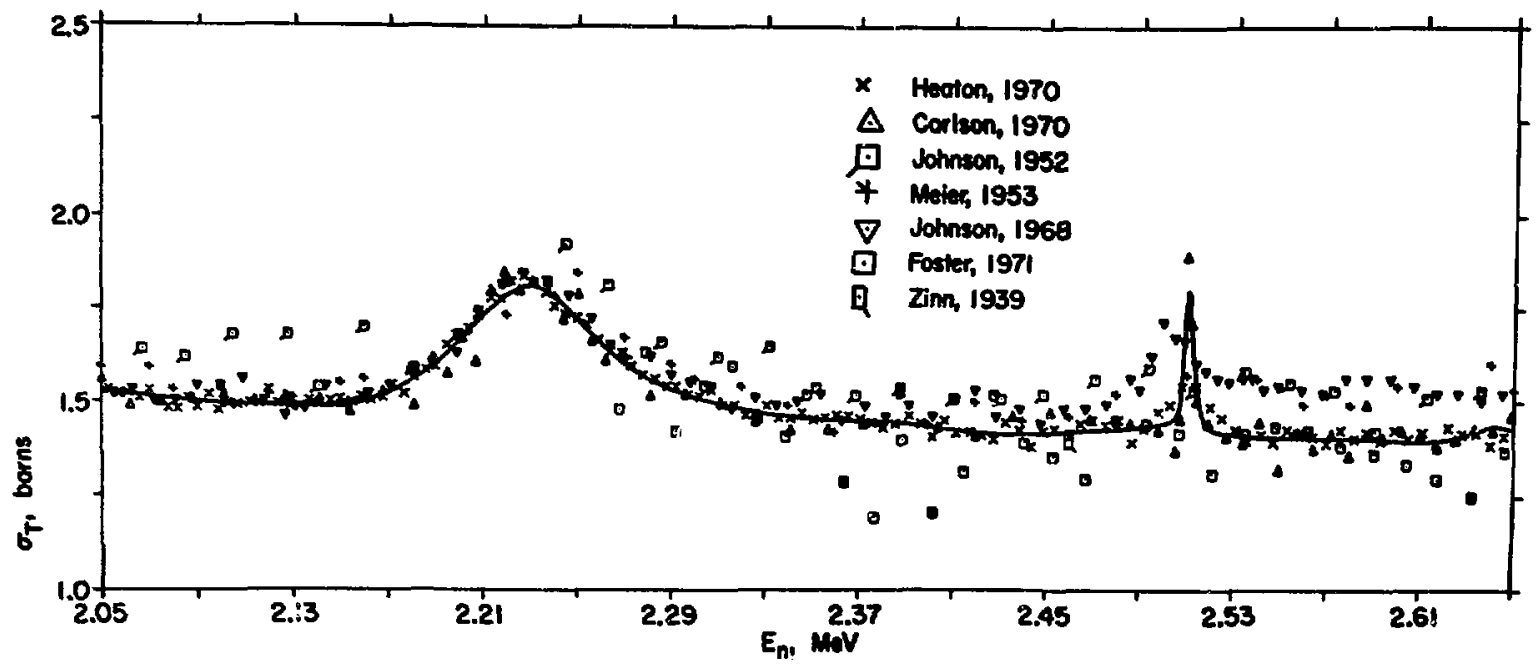

Fig. 12. Measured and evaluated total cross section between 2.05 and 2.65 MeV. 
assume that the cross section for the ${ }^{14} \mathrm{~N}(\mathrm{n}, \gamma){ }^{15} \mathrm{~N}$ reaction is equal to the cross section for the ${ }^{14} \mathrm{~N}(\mathrm{p}, \gamma)^{15} \mathrm{o}$ charge-conjugate reaction. Th1s assumption is made because the $(n, \gamma)$ and the $(p, \gamma)$ reactions excite the same isospin states, and $15_{\mathrm{N}}$ and 150 are mirror nuclet. In addition to adjusting the $(n, y)$ and $(p, y)$ data to the same excitation energies In the compound nucleus, we have introduced a linear shift in the neutron-energy scale which decreases from about $2 \mathrm{MeV}$ near $E_{n}=1 \mathrm{MeV}$ to zero near $E_{n}=$ $15 \mathrm{MeV}$. Th1s realigment of the energies in the mirror nuclet matches the observed structure in the $(p, \gamma)$ cross section below the giant resonance to groups of peaks in the neutron total cross section.
The best avallable evidence on the $(p, \gamma)$ reaction in this region comes from measurements by Kuan et al. $(K u 70)$. The $(p, \gamma)$ cross section is 6 to 8 times greater :han the $(n, \gamma)$ cross section extrapolated from thermal. The evaluated ${ }^{14} \mathrm{~N}(n, \gamma)$ cross section from $10^{-11}$ to $20 \mathrm{MeV}$ is shown in Fig. 20.

We obtained the capture gamma-ray energy spectrum at thermal-neutron energy by evaluating a decay scheme for the particle-stable levels of ${ }^{15} \mathrm{~N}$, using charged-particle data as well as direct $(n, y)$ spectrum measurements. The results of this analysis are shown schematically in Fig. 21. The primary transition probabilities and level-branching ratios are based mainly upon the ${ }^{14} \mathrm{~N}(\mathrm{n}, \gamma)$ spectrum measurements

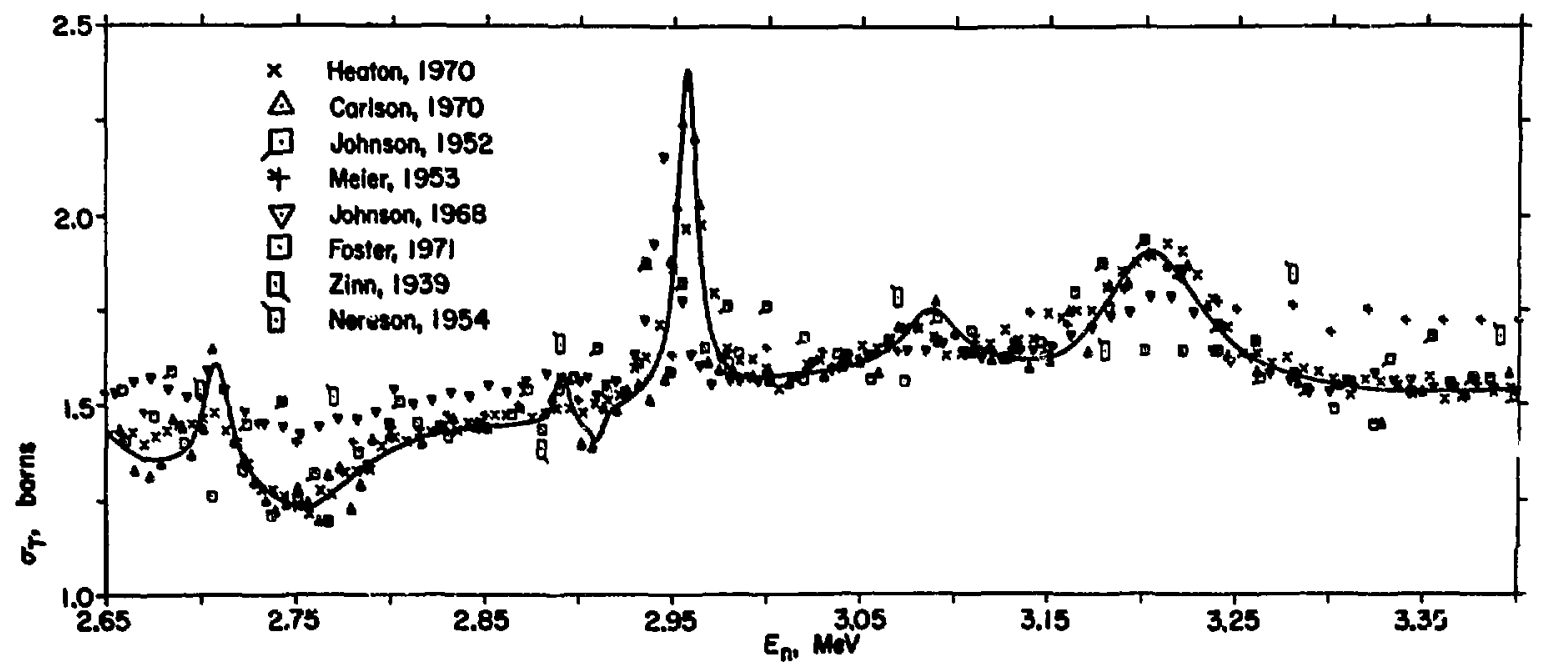

Fig. 13. Measured and evaluated total cross sectioti between 2.65 and 3.4 MeV. The weak structure at 2.9 $\mathrm{HeV}$ is barely significant statistically.

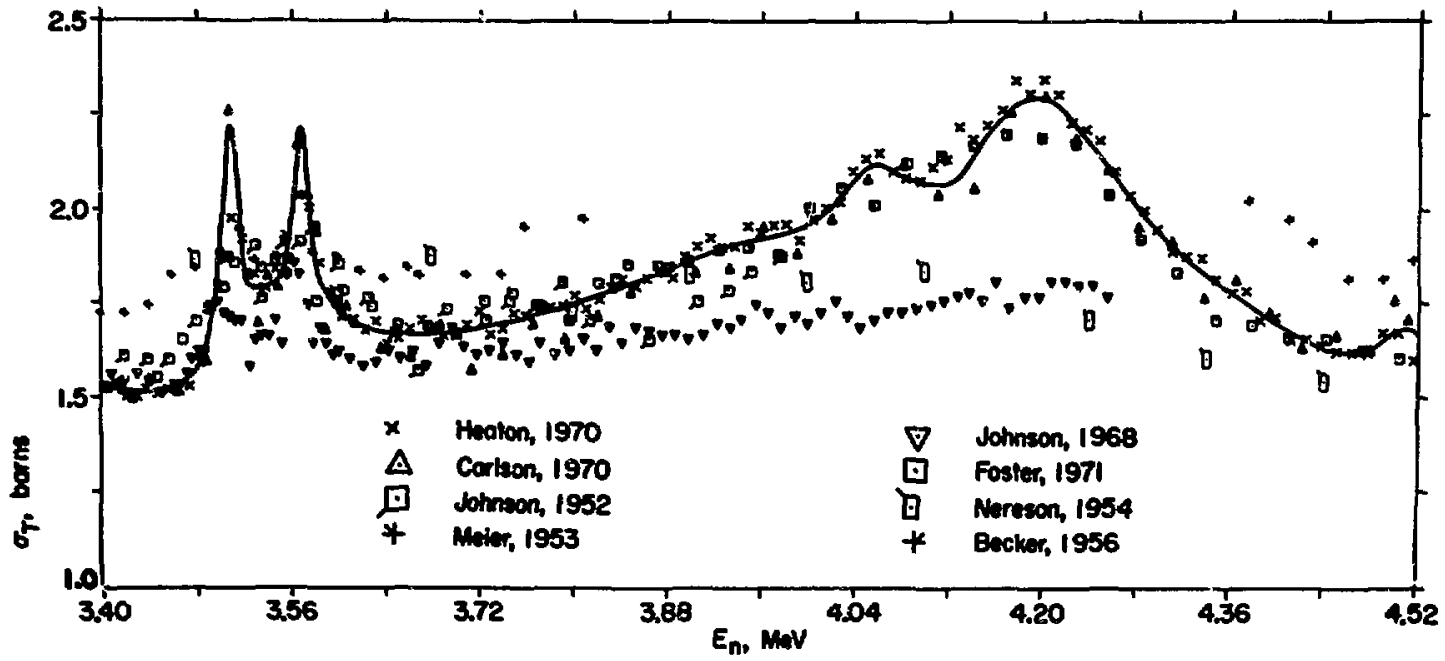

F18. 14. Neanured and evalueted total cross section from 3.4 to $4.5 \mathrm{MeV}$. 
by Jonsson and Hardell (jo69), Thomas et a1. (Th67), and Motz et a1. (Mo62), together with ${ }^{13} \mathrm{C}\left({ }^{3} \mathrm{He}, \mathrm{py}\right){ }^{15} \mathrm{~N}$ colncidence measurements by Phillips et al. (Ph67), ${ }^{14} \mathrm{C}(\mathrm{p}, \gamma){ }^{15} \mathrm{~N}$ measurements by Slefken et al. (S169), ${ }^{13} \mathrm{C}\left({ }^{3} \mathrm{He}, \mathrm{pY}\right){ }^{15} \mathrm{~N}$ measurements by Warburton et al. (Wa66), and the ${ }^{14} \mathrm{~N}(\mathrm{~d}, \mathrm{p \gamma})^{15} \mathrm{~N}$ and ${ }^{13} \mathrm{C}\left({ }^{3} \mathrm{He}, \mathrm{pr}\right)^{15} \mathrm{~N}$ studies of Warburton et a1. (Wa65a). We obtained branching information for the $9.15 \mathrm{meV}$ doublet from Greenwood's $14 N(n, \gamma)$ measurement (Gr68), as well as from Jonsson and Hardell (Jo69). The excitation energies In Fig. 21 are from measurements by Greenwood (Gr68), Jonsson and Hardell (Jo69), Gallman et a1. (Ga66), and Warburton et al, (Wa66), In decreasing order of emphasis.

In Table III, we compare the evaluated capture gamma-ray spectrum to measurements by kotz et al. (Mo62), Thomas et al. (Th67), Jonsson and Hardell (Jo69), and Orphan et al. (0r70). The column labeled $E_{Y}$ contains the transition energy without correction for the energy of the recoiling ${ }^{15}$ nucleus. Thomas et al. (Th67) tabulate the recoll eirergy, which is a maximum of $4.2 \mathrm{keV}$ for the $10.835 \mathrm{MeV}$ transition, for the various 11nes. The total multiplicity of the evaluated thermal spectrum is 2.166. In Table III the evaluated spectrum and the

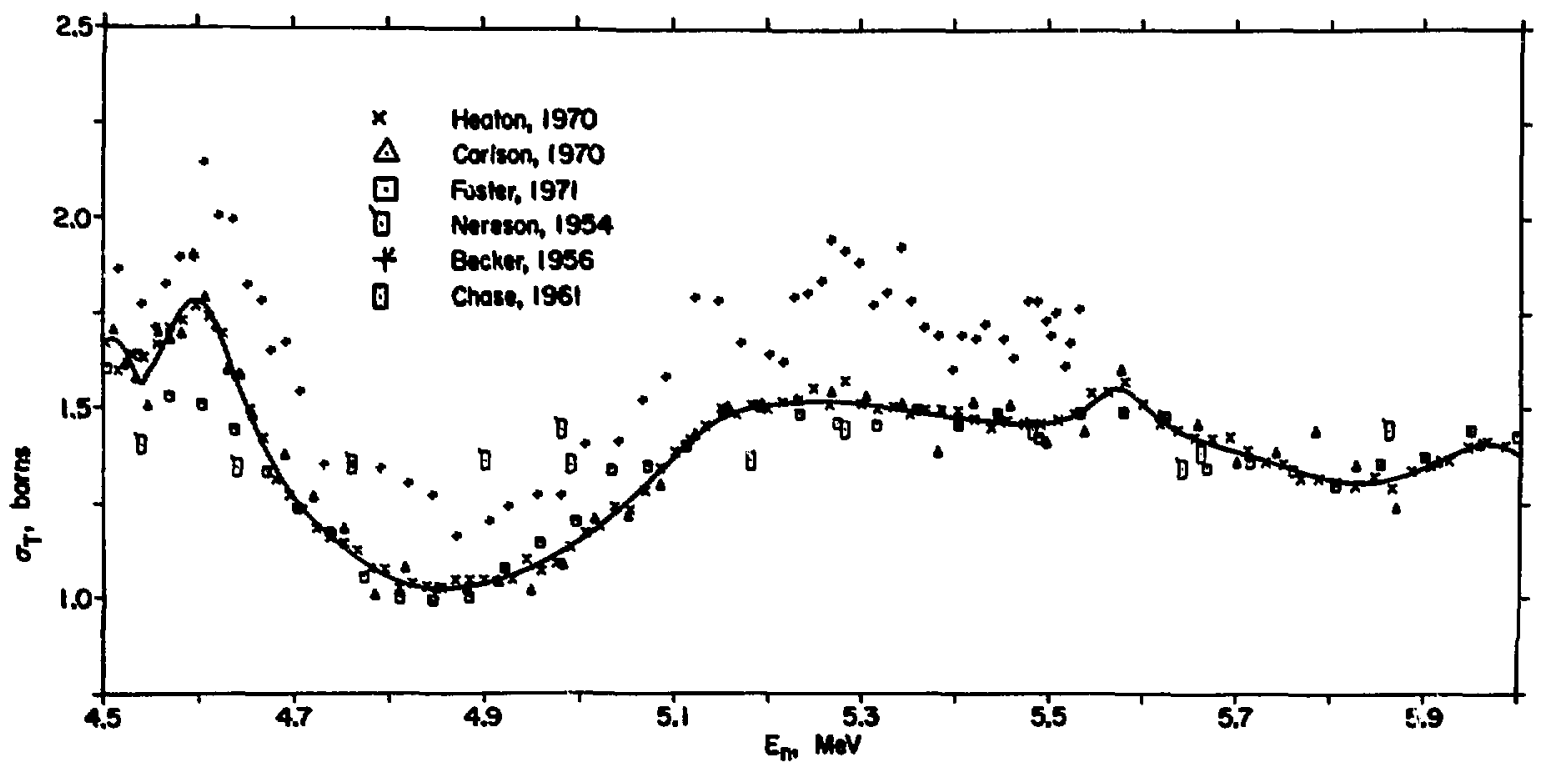

Fig. 15. Measured and evaluated total cross section from 4.5 to $6.0 \mathrm{MeV}$.

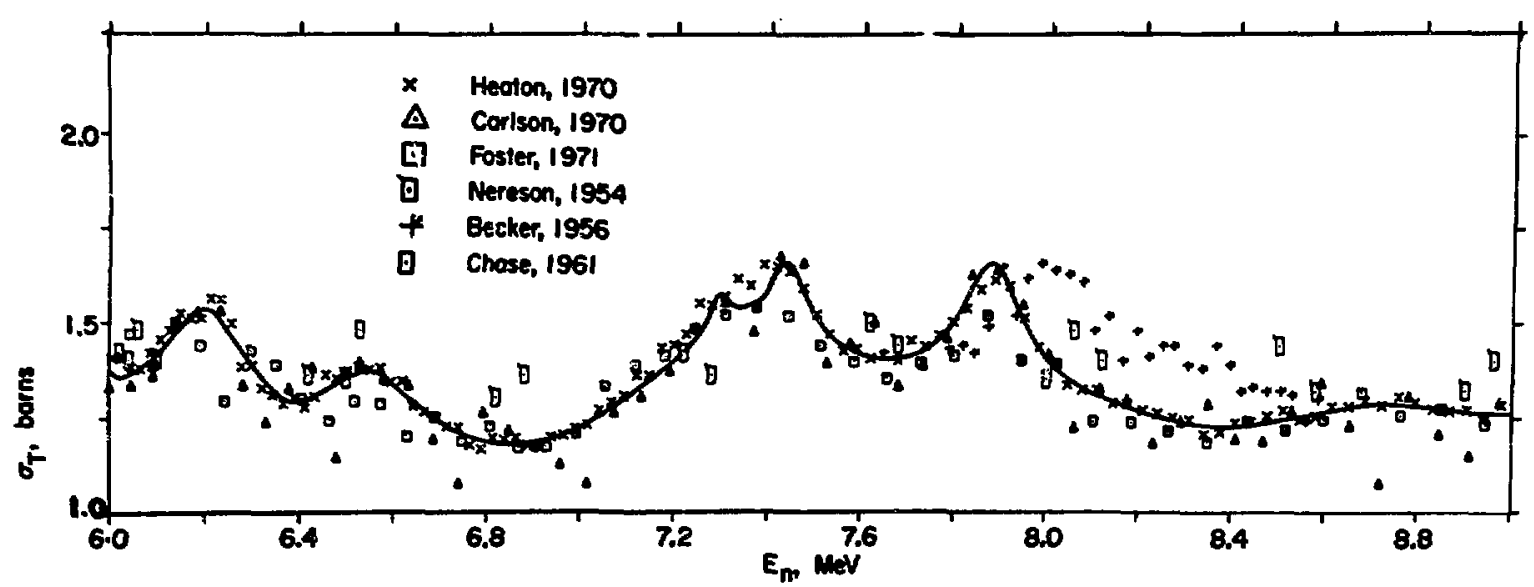

Fig. 16. Measured and evaluated total cross section between 6 and $9 \mathrm{MeV}$. The sma11 peak near $7.3 \mathrm{MeV}$ is probably not atatistically significant. 
measurements by Motz et al. (Mo62), Thomas et al. (Th67), and Jonsson and Hardell (Jo69) agree reasonably well. The measurements by orphan et al. (Or70) for some of the lines (for example, $E_{Y}=1.8849$, 2.523, and 5.2701 MeV) differ significantly from the other experimental data. Further, Orphan reports several reasonably strong lines (not included in Table III) that were not seen in the other measurements. The evaluated $(n, y)$ spectrum and cross section are reasonably consistent with Maerker and Muckenthaler's (Ma69) thermal-neutron measurements.

The thermal spectrum is assumed to hold up tc a neutron energy of $250 \mathrm{keV}$. Again, we belleve this is a reasonable assumption because the first resonance in nitrogen does not occur unt1l $434 \mathrm{keV}$. From $250 \mathrm{keV}$ to $1 \mathrm{MoV}$, the thermal spectrum is phased into a single ground-state transition, and at all higher energies the spectrum 18 assumed to consist. of a aingle ground-atate transition. Th1s behavior 18 suggested by the ${ }^{14} N(p, \gamma)$ messurements by Kuan et al. (Ku70) who observed no significant transition to oth- er than the ground state. The evaluated capture cross section and spectrum imply that $14-\mathrm{MeV}$ neutrons produce $24-\mathrm{MeV}$ photons with a cross section of $15 \mu \mathrm{b}$.

\subsection{Neutron Inelastic-Scattering Cross Sections}

The usual procedure in neutron cross-section evaluations is to separate inelastic neutron scattering Into cross sections to discrete levels of the target nucleus and to a continuum of levels. In the former case, the $\left(n, n^{\prime}\right)$ cross sections to Ind1vidual levels are tabulated separately as functions of Incident neutron energy, with separate angular distributions provided for each level. In the continuum case, a composite energy distribution is given at each incident energy to represent inelastic neutrons from a continuum of states (gemerally highly excited) of the target nucleus, and each distribution is given an average angular distribution.

We have departed from this procedure in that we have specified all inelastic scattering as $\left(n, n^{\prime}\right)$ resctions to discrete states or groups of states,

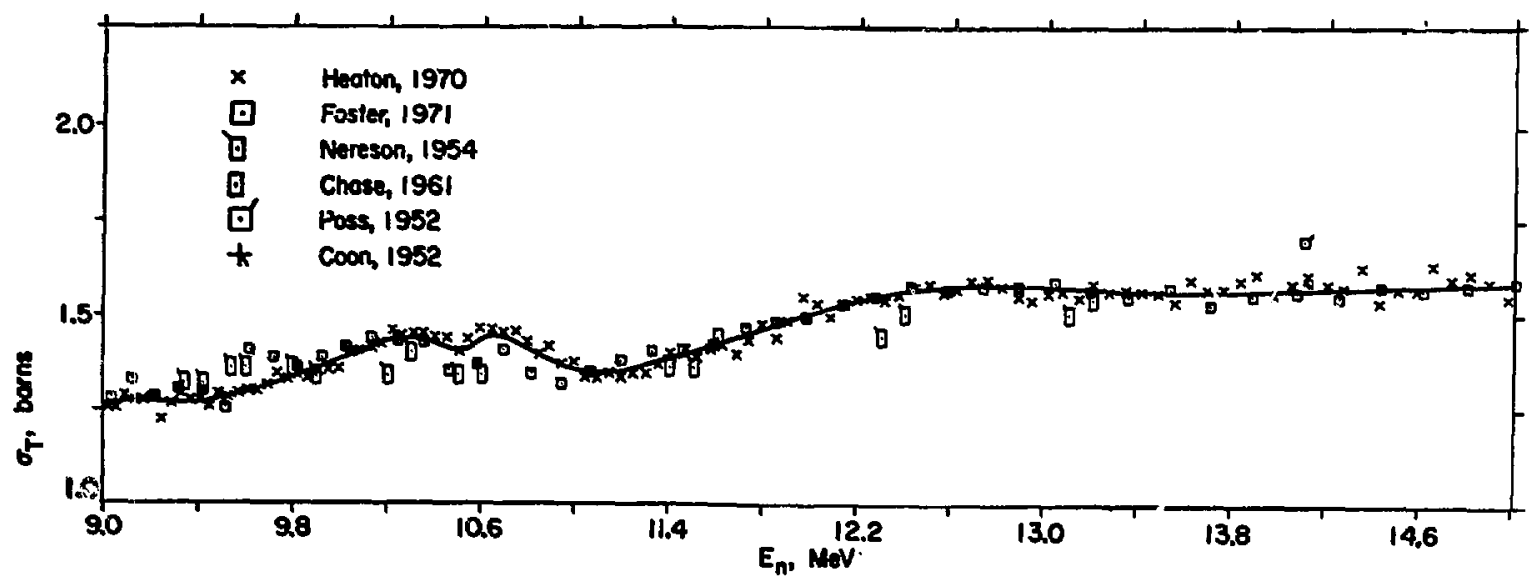

Fig. 17. Measured and evaluated total cross section between 9 and $15 \mathrm{MeV}$. The structure in this region appears to match that deduced for the inverse photonuclear giant resonance (Sec. 3.2 and Fig. 20).

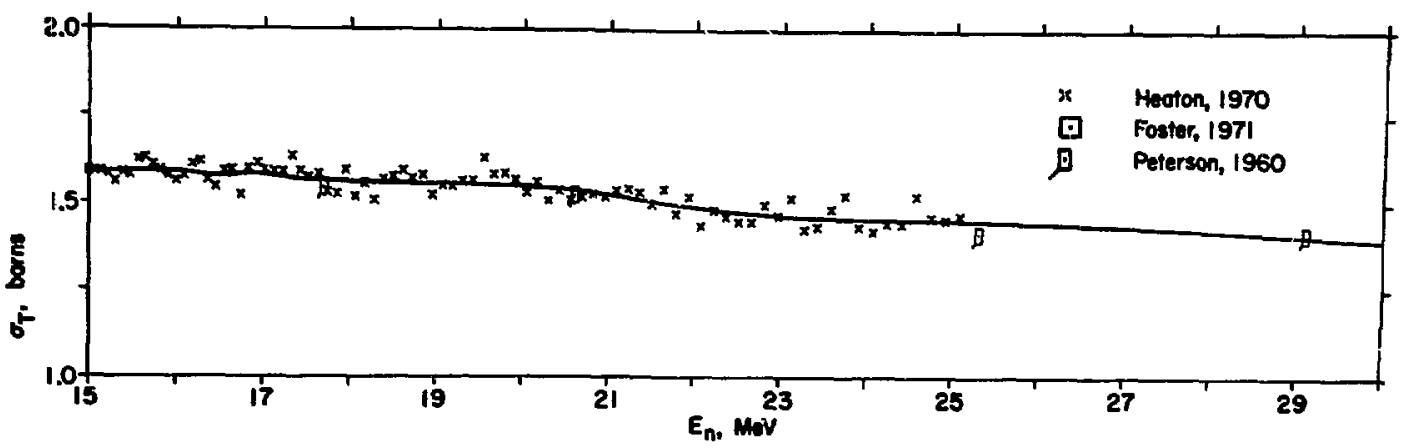

Fig. 18. Measured and evaluated total cross section from 15 to $30 \mathrm{MeV}$. 


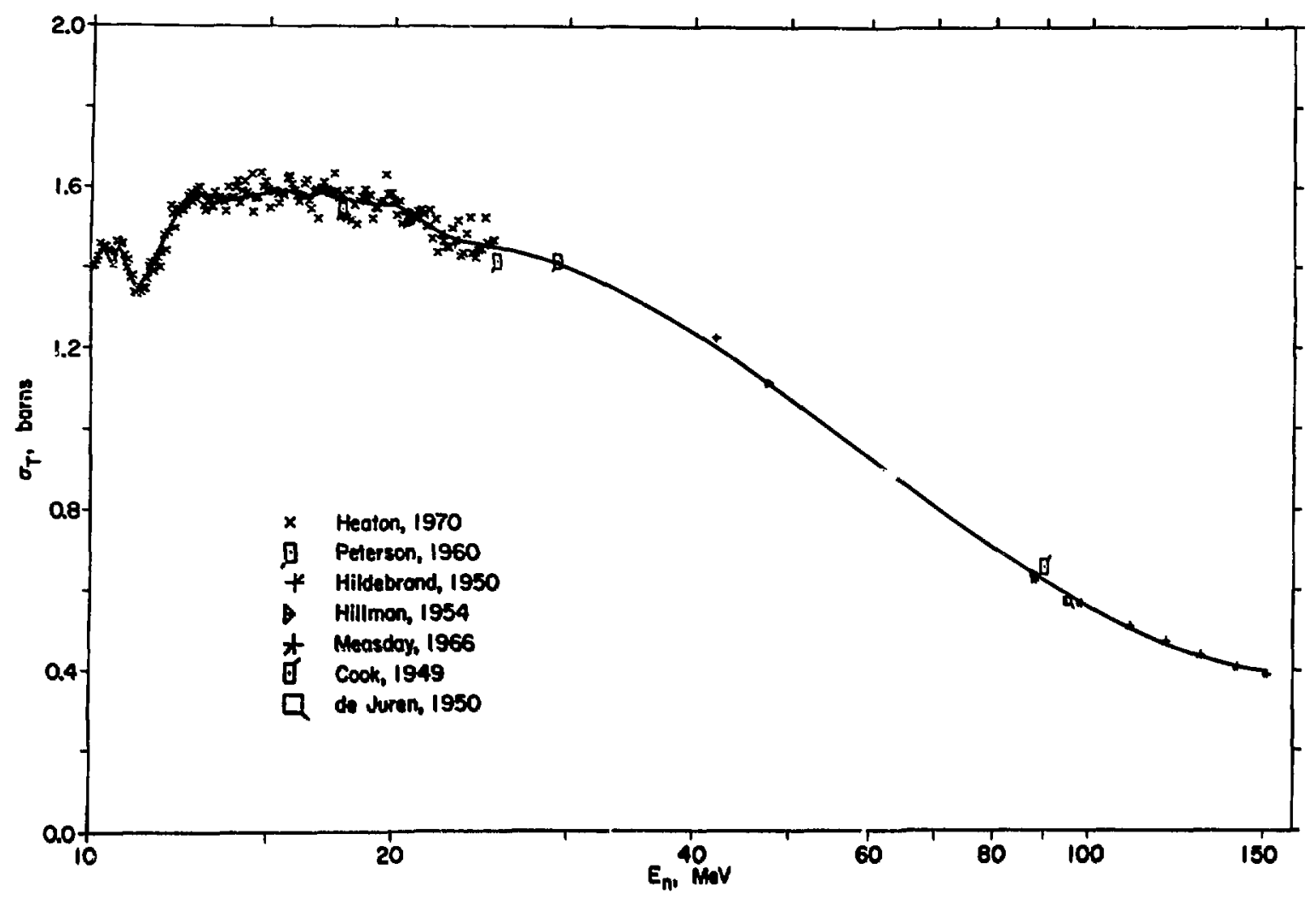

Fig. 19. Measured and evaluated total cross section from IC to $150 \mathrm{MeV}$.

and do not use an $\left(n, n^{\prime}\right)$ continuum representation. This approach allows more accurate representation of the energy-angle relationships of outgoing neutrons without actually incorporating complicated energyangle correlations like those, for example, provided for in File 6 of ENDF/B. The use of average angular distributions for composite energy spectra is 1imited because angular distributions of inelastic neutrons can be strong functions of outgoing neutron energy, particularly for the lighter elements. Because the largest effects occur at the lowest outgoing neutron energies, this problem is made more important by the fact that $\left(n, n^{\prime}\right)$ energy distributłons frequently peak at relatively low outgoing neutron energles. A more accurate representation of the outgolng neutrons is clearly attained by allowing the $\left(n, n^{2}\right)$ reactions for different excitation levels of the residual nucleus to have different angular distributions.

A crude example of the above effect is shown in Fig. 22 where relative angular distributions in the laboratory frame of reference are shown for the
${ }^{14} \mathrm{~N}\left(\mathrm{n}, \mathrm{n}^{\prime}\right)^{14} \mathrm{~N}^{\text {* }}$ reaction to fictitious states in ${ }^{14} \mathrm{~N}$ between 10- and 13-MeV excitation for 14- $\mathrm{MeV}$ incident neutron energy. The angular distributions are assumed to be 1sotropic in the center-of-mass system, so the departure from lsotropy of the laboratory distributions is due entirely to center-of-mass motion. The different excitation energies correspond approximately to different outgoing laboratory neutron energles. The angular distributions vary appreciably with excitation energy, and, although we do not regard the effect as severe In this case, It Is clearly significant even for a nucleus as heavy as nitrogen.

We evaluated the $\left(n, n^{\prime}\right)$ cross sections as a function of neutron energy in two stages:

1. We evaluated the excitation cross sections to the first 12 levels of ${ }^{14} \mathrm{~N}\left(\mathrm{E}_{\mathrm{X}}<8.5 \mathrm{MeV}\right)$ from threshold to $20 \mathrm{MeV}$, mainly using $\left(n, n^{\prime} \gamma\right)$ experimental data together with the level-decay scheme for ${ }^{14} \mathrm{H}$.

2. We estimated the relative $\left(n, n^{\prime}\right)$ cross sections to states in ${ }^{14} \mathrm{~N}$ above $8.5-\mathrm{MeV}$ exc1- 


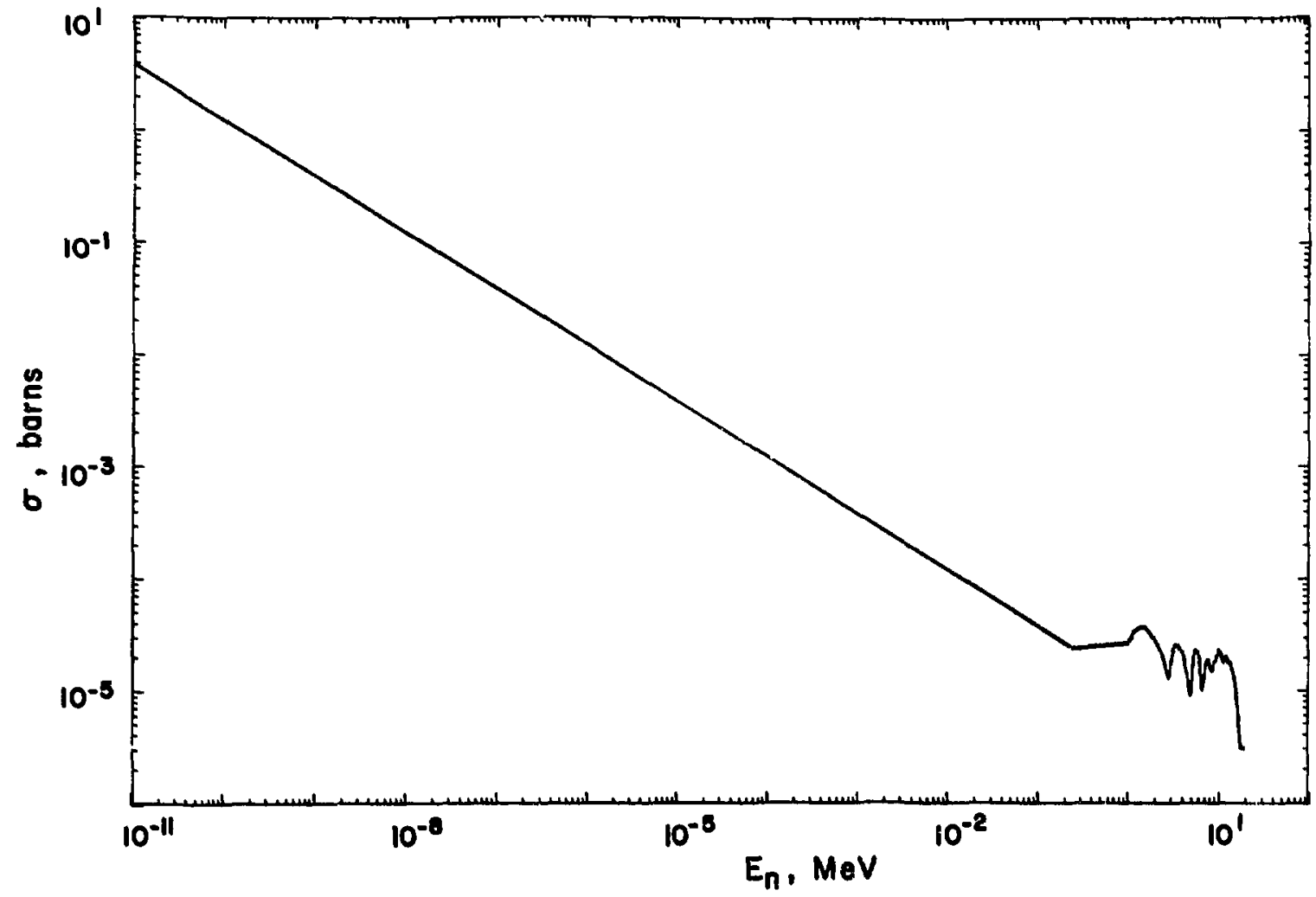

F1g. 20. Evaluated cross section for radiative capture from $10^{-5}$ eV to $20 \mathrm{MeV}$.

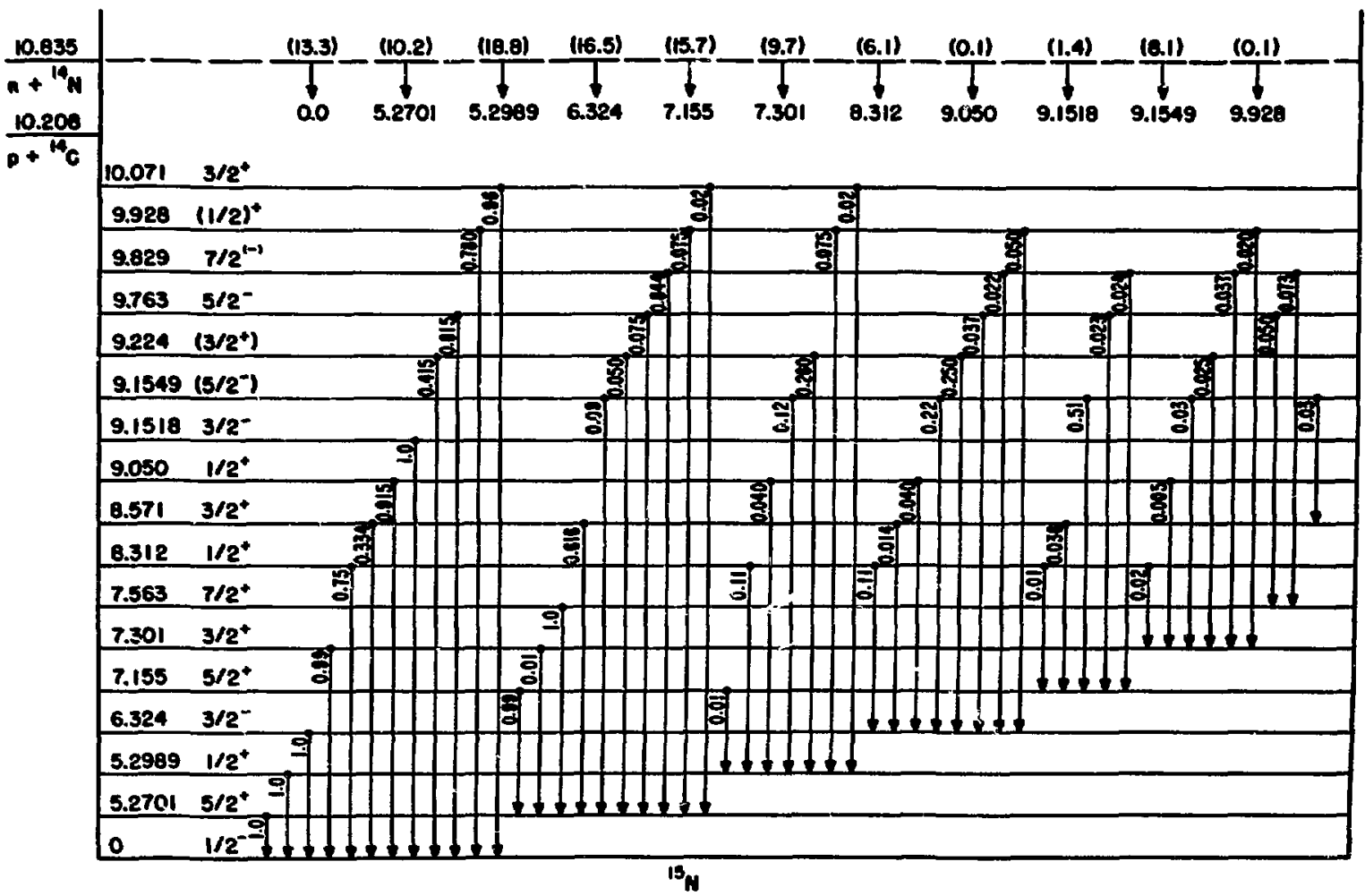

F1g. 21. Decay scheme and branching ratios for thermal radiative capture. The numbers in parentheses at the top of the diagram are transitions per 100 captures to the designated states. 


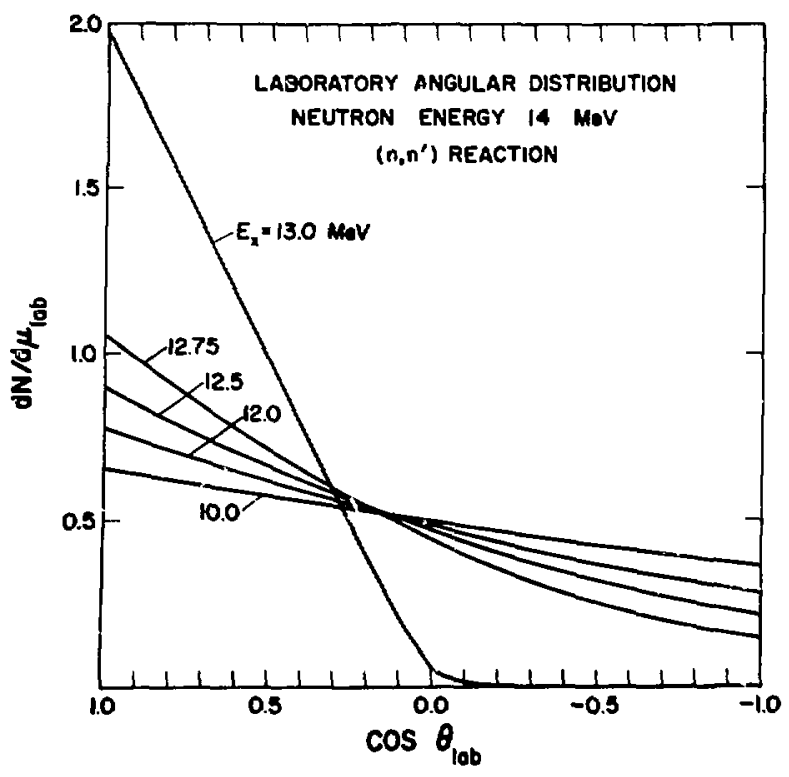

F1g. 22. Calculated angular distributiong in the 1aboratory aystem correaponding to 1sotropic inelastic scattering in the c.in. system for $14-\mathrm{MeV}$ incident neutrons and final states of excitation energy $E$ in $14 \mathrm{~N}$. The curves are normalized so that the area under each 18 unity.

tation energy from Hauser-Feshbach (Hz52) and evaporation-wodel calculations, and normalized the composite at all incident neutron energies so that the sum of the partial reaction cross sections agreed with the evaluated elastic and total cross sections. We grouped the $\left(n, n^{\prime}\right)$ cross sections into $0.5-\mathrm{MeV}-$ wide excitation bins and repreaented them as some 20 discrete $\left(n, n^{\prime}\right)$ reactions to ficitious levels at the average excitation eneczies of the bins. This information replaces the more-usual continum representation.

3.3.1 The ${ }^{14} N\left(n, n^{\prime}\right)$ and ${ }^{14} N\left(n, n^{\prime} \gamma\right)$ Crons Sections for $\mathrm{B}_{2}(14 \mathrm{~N})<8.5 \mathrm{MeV}$

Except for limited data near $14 \mathrm{MeV}$ (Ba63, Bo62, An64), no direct measurements of $\left(n, n^{\prime}\right)$ cross sections were avallable when we completed this evaluation. * Consequently, we based the $\left(n, n^{\prime}\right)$ excitation cross sections to all states in ${ }^{14} \mathrm{~N}$ below an excitation energy of $8.5 \mathrm{MeV}$ almost entirely upon

* Some data have subsequently become avallable from measurements at 9 and $11 \mathrm{MeV}$ by Nellis et al. (Ne71). ganma-ray production measurement 8 . The decay scheme for ${ }^{14} N$, which relates the $\left(n, n^{\prime}\right)$ excitation cross sections to the gamma-ray production measurements, Is given In FIg. 23. We took the level energies, spins, and parities from Ajzenberg-Selove's compilation (Af70). The branching ra: 10 s were obtalned mainly from Carlson's ${ }^{10} \mathrm{~B}\left({ }^{6} \mathrm{LI}, \mathrm{d} Y\right)^{14} \mathrm{~N}$ colncidence measurements ( $\mathrm{Ca} 66)$, the ${ }^{12} \mathrm{C}\left({ }^{3} \mathrm{He}, \mathrm{PY}\right)^{14} \mathrm{~N}$ measurements by Gorodetzky et al. (Go66), and the ${ }^{12} \mathrm{C}\left({ }^{3} \mathrm{He}, \mathrm{PY}\right)^{14} \mathrm{~N}$ measurements by Warburton et al. (We64, Wa65), although several other sources also provided Input (see $A j 70$ for a compllation of the measured branching rat1os).

Unfortunately, we did not become aware of the recent work by Young, Phill1ps, and Marion (Yo59) until the Afzenberg-Selove (Af70) compilation, which cites their results, appeared in 1 to final form late in 1970. Because our $\left(n, n^{\prime}\right)$ cross-section evaluation was already complete, we did not include the Young results in Fig. 23. Dolng so would generally lower the total $\left(n, n^{\prime}\right)$ cross section by at most a few percent, with a maximum decrease of perhaps 5-10\% for the ( $\left.n, n^{\prime}\right)$ level-excitation crose sections to the 5.106- and 5.834-MeV levels. In view of the

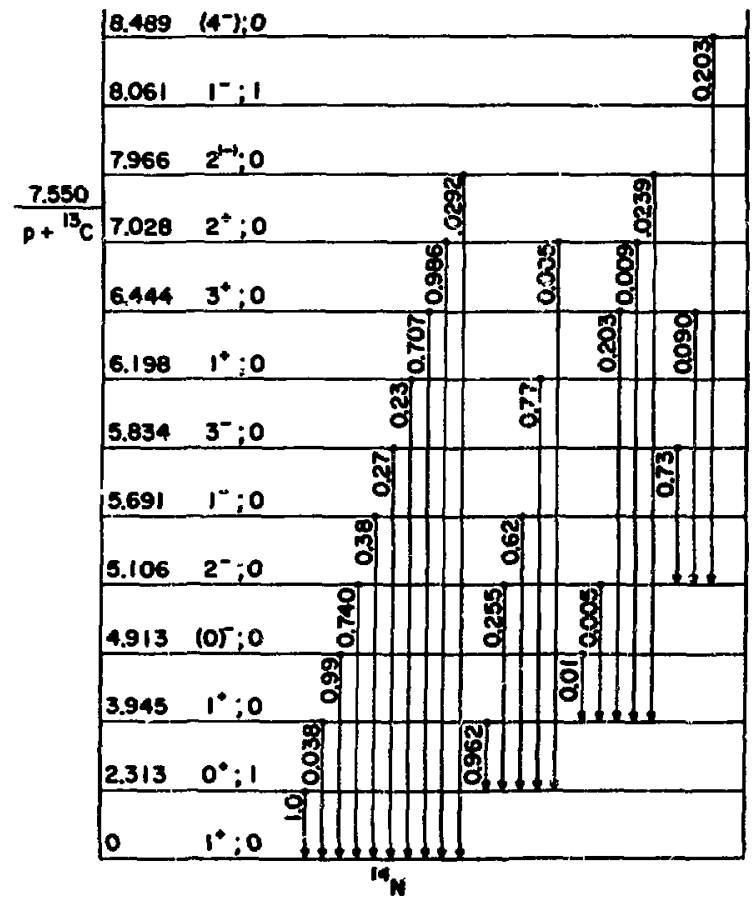

Fig. 23. Decay scheme for ${ }^{14} \mathrm{~N}$ used in interpret ing the $\left(n, n^{\prime} \gamma\right)$ measurenents. The levels are labeled with their 1sospin as well as ordinary spin and parity. Note that the encrgy scale is distorted. 
TABLE III

CAPTURE GAMMA-RAY SPECTRUM FOR THERMAL NEUTRONS ON NITROGE:

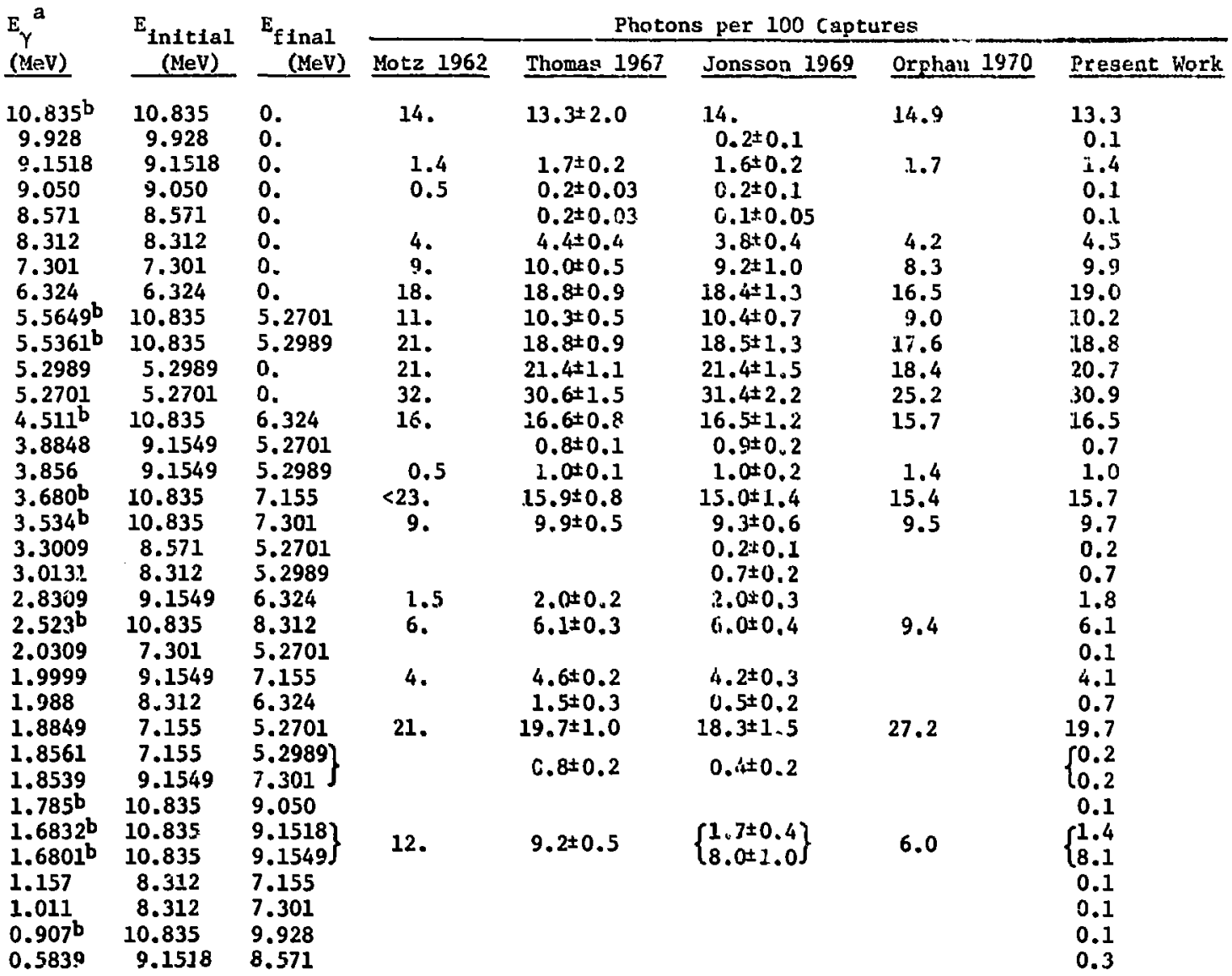

alo correction has been made for the energy of the recoliling ${ }^{15} \mathrm{~N}$ nucleus.

brimary transitions.

overall uncertainty in the $\left(n, n^{\prime}\right)$ cross sections, we do not regard the omission of the Young branchingratio information as serious.

The branching ratios shown in Fig. 23 for states above the $p+{ }^{13} \mathrm{C}$ threshold at $7.55 \mathrm{MeV}$ have been multiplied by the probability that the levels decay by gamme-ray emission, taken to be the ratio of the gamma-ray width to the total wid:h for each leve1. The largest uncertainty in Fig. 23 is for the branches from the 7.966-MeV level. There the ratio of the two branches is well known, but the relative probability of photon emission is unknown. In the evaluation, we assumed that the $7.966-\mathrm{MeV}$ level decays 5.37 by garma emission. This assumption, coupled with Dickens and Perey's $(n, x y)$ measurements (D169) for the 7.966-MeV line, suggests an $\left(n, n^{\prime}\right)$ excitation cross section somewhat larger than that predicted by Hauser-Feshbach cajculations. However, the analysis by Hebbard and Vogl (He60), who studied the ${ }^{13} \mathrm{C}(\mathrm{p}, \mathrm{p})$ and ${ }^{13} \mathrm{C}(\mathrm{p}, \gamma)$ reactions, suggests that the 7.966-MeV level decays by gamma emission less than $1 \%$ of the time, which leads to a much larger $\left(n, n^{\prime}\right)$ cross section for this level when it is combined with Dickens and Perey's $(n, x y)$ results (Di69). The $\sim 5 \%$ value we used is therefore a compronise between these considerations.

We surveyed the states in ${ }^{14} \mathrm{~N}$ above the $\mathrm{p}+{ }^{13} \mathrm{c}$ threshold to determine whether these particle-unstible levels make aignificant contributions to the $(n, x y)$ cross sections. We made this study using the gamma-

\footnotetext{
These calculations are discussed in detail in Appendix A.
} 
ray and total widths compiled by Afzenberg-Selove (Aj 70) together with the experimental results of Gallmann et al. (Ga67). In addition to the contributions from the 7,966- and $8.489-\mathrm{MeV}$ states shown In Fig. 23, we found the states at 8.963 and 9.172 $\mathrm{MeV}$ in ${ }^{14} \mathrm{~N}$ to have gamma-ray decay probabilities of $19.6 \%$ and $9.1 \%$, respectively. Almost all the remalning states above the $p+{ }^{13} \mathrm{C}$ threshold have total widths in the $\mathrm{keV}$ range. Because the largest gamma-ray widih in the Ajzenberg-Selove compilation is $43 \mathrm{eV}$, we expect the $\left(n, n^{\prime} \gamma\right)$ contribution from chese higher states to be negligible. We therefore assumed that no ganma rays result from states in ${ }^{14} \mathrm{~N}$ above an excitation energy of $8.5 \mathrm{MeV}$. We es-timate the siaximum $(n, x y)$ contributions from the 8.963- and 9.172-MeV Ievels, which we did not include in the evaluation, to be $\sim 3 \mathrm{mb}$ for the $8.963-$ $+6.444-\mathrm{MeV}$ transition and $\sim 0.5 \mathrm{mb}$ for the $9.172-+$ O-MeV cransttion near a neutron energy of $13 \mathrm{MeV}$. Table IV sumnarizes the gama rays from $\left(n, n^{\prime}\right)$ reactions that appear in our evaluation. The brackets Indicate transitions that were combined into one $(n, x y)$ cross section.

\section{TABLE IV} GAMRA RAYS FROM ${ }^{14} N\left(n, n^{\prime} \gamma\right)^{14} N$ REACTIONS

\begin{tabular}{|c|c|c|}
\hline $\begin{array}{l}\mathrm{E}_{\mathrm{Y}} \\
(\mathrm{MeV})\end{array}$ & $\begin{array}{c}\text { E }_{\text {Injitial }} \\
(\mathrm{MeV}) \\
\end{array}$ & $\begin{array}{c}E_{\text {final }} \\
(\mathrm{MeV}) \\
\end{array}$ \\
\hline $\begin{array}{l}7.966 \\
7.028 \\
6.444 \\
6.198 \\
5.834 \\
5.691 \\
5.106\end{array}$ & $\begin{array}{l}7.966 \\
7.028 \\
6.444 \\
6.198 \\
5.834 \\
5.691 \\
5.106\end{array}$ & $\begin{array}{l}0 \\
0 \\
0 \\
0 \\
0 \\
0 \\
0\end{array}$ \\
\hline 4.913 & $\left\{\begin{array}{l}4.913 \\
7.028\end{array}\right.$ & $\left.\begin{array}{l}0 \\
2.313\end{array}\right\}$ \\
\hline 3.98 & $\left\{\begin{array}{l}7.966 \\
3.945\end{array}\right.$ & $\begin{array}{l}3.945 \\
0\end{array}$ \\
\hline 3.885 & 6.198 & 2.313 \\
\hline 3.38 & $\left\{\begin{array}{l}8.489 \\
5.691\end{array}\right.$ & $\left.\begin{array}{l}5.106 \\
2.313\end{array}\right\}$ \\
\hline 2.793 & $\left\{\begin{array}{l}7.028 \\
5.106\end{array}\right.$ & $\left.\begin{array}{l}3.945 \\
2.313\end{array}\right\}$ \\
\hline $\begin{array}{l}2.499 \\
2.313 \\
1.622\end{array}$ & $\begin{array}{l}6.444 \\
2.313 \\
3.945\end{array}$ & $\begin{array}{l}3.945 \\
0 \\
2.313\end{array}$ \\
\hline 0.728 & $\left\{\begin{array}{l}5.106 \\
5.913\end{array}\right.$ & $\left.\begin{array}{l}5.106 \\
3.945 \\
3.945 \\
5.106\end{array}\right\}$ \\
\hline
\end{tabular}

Most of the ${ }^{14} \mathrm{~N}(\mathrm{n}, 2 \gamma)$ experimental data are from measurements performed at one angle; Table $V$ is a summary of the angles and detectors used in the varfous meagurements considered in the evalua- tion. Except for some of tho results of Morgan et al. (Mo64), the experimental (n...xy) data described here are single-angle measurements multiplied by $4 \pi$. This procedure should not lead $\mathrm{t}$ large errors for nitrogen because at most energles the, 55 and $125^{\circ}$ measurements by Dickens and Perey (D169) and Orphan and Hoot (Or69) were emphasized in the evali. uation. * Near $15 \mathrm{MeV}$ we stressed Nyberg's (Ny69) $80^{\circ}$ measurements; many of the gamma-ray angular distributions are 1sotropic within $10 \%$ at these energies (Bu71; also see Mo64). The Morgan results (Mo64) that we give for the 1.632-, 2.124-, 2.313-, 3.684-, 3.854-, and 5.1-MeV gamma rays were obtained by integrating the measured angular distributions; all other gamma-ray cross sections from this source are $90^{\circ}$ measurements multiplied by $4 \pi$.

\section{TABLE V}

SUMMARY OF GAMMA-RAY PRODUCTION MEASUREMENTS USED IN THE EVALUATION

\begin{tabular}{|c|c|c|c|}
\hline Reference & $\begin{array}{c}\text { Measurement } \\
\text { Angleg }\end{array}$ & $\begin{array}{l}\text { Neutron } \\
\text { Energy } \\
\text { Range } \\
(\mathrm{MeV}) \\
\end{array}$ & Detector \\
\hline $\begin{array}{l}\text { Bostrom, } 1959 \\
\text { Buchanan, a } 1969 \\
\text { Clayeux, } 1969 \\
\text { Conde , } 1968 \\
\text { Dickens, } 1969 \\
\text { Engesser, } 1967 \\
\text { Hall, } 1959 \\
\text { Maslov, } 1968 \\
\text { Morgan, a } 1963 \\
\text { Morgan, a } 1964\end{array}$ & $\begin{array}{l}77^{\circ} \\
55^{\circ} \\
90^{\circ} \\
55^{\circ} \\
55^{\circ}, 90^{\circ} \\
90^{\circ} \\
90^{\circ} \\
90^{\circ} \\
90^{\circ} \\
30^{\circ}-140^{\circ} \\
\text { (8 angles) }\end{array}$ & $\begin{array}{c}4.2 \\
14.8 \\
14.1 \\
4.5-7.0 \\
5.8-11.0 \\
14.7 \\
4.7-8.1 \\
14.1 \\
14.8 \\
14.8\end{array}$ & $\begin{array}{l}\mathrm{NaI} \\
\mathrm{NaI} \\
\mathrm{Ge}(\mathrm{LI}) \\
\mathrm{Ge}(\mathrm{LI}) \\
\mathrm{Ge}(\mathrm{LI}) \\
\mathrm{NaI} \\
\mathrm{CsI} \\
\mathrm{NaI} \\
\mathrm{NaI} \\
\mathrm{NaI}\end{array}$ \\
\hline $\begin{array}{l}\text { Nyberg, } 1969 \\
\text { Orphan, } 1969\end{array}$ & $\begin{array}{r}80^{\circ} \\
125^{\circ}\end{array}$ & $\begin{array}{l}15.0 \\
2-16\end{array}$ & $\begin{array}{l}\mathrm{Ge}(\mathrm{LI}) \\
\mathrm{Ge}(\mathrm{LI})\end{array}$ \\
\hline
\end{tabular}

$a_{\text {The }} 1963$ and 1964 Morgan data are largely superseded by the 1969 Buchanan results but are included for completeness. These data were obtained using a NaI anticolncidence shield.

We wish to emphasize that the Morgan measurements (Mo63,Mo64) and the Buchanan results (Bu69) were all obtrined by Texas Nuclear Corporation (TNC), and the 1969 reference apparently supersedes the

\footnotetext{
*If a photon angular distribution can be represented by an expression of the form $\sigma(\mu)=a_{0}+a_{2} P_{2}(\mu)$, where $\mu$ is the cosine of the reaction angle and $P_{2}(\mu)$ is the $l=2$ Legendre polynomial, then the Integrated cross section is identically equal to $4 \pi$ times the differential cross section at 54.7 or $125.3^{\circ}$ (zeros of the second Legendre polynomial). This is true for many of the gamma rays from nitrogen.
} 
earlier results. Accordingly, we largely ignorad the 1963 and 1964 data in our evaluation of the $(n, x y)$ cross sections; however, for completeness we included these results in our figures. After we completed the evaluation, a new compllation of TNC results ( $B u 7 i$ ), which supersedes the three previous comminications, became available. The new compilation inclides a reanalysis of the nitrogen $(n, x y)$ measurements, and the results for some lines differ significantly from Buchanan's 1969 compilation. The new cross sections, which are not included in our f1gures, are generally higher than the older values and usually agree better with the evaluation. We have included specific comments in the text where we consider the new TNC results most significant. The $2.313-\mathrm{MeV}$ level of ${ }^{14} \mathrm{~N}$ is a $\mathrm{T}=1$ level with $J^{\pi}=0^{+}$. Consequently, the $\left(n, n^{\prime}\right)$ cross section to this level is relatively small, and there is little direct information about its magnitude. Further, the $(n, x y)$ cross section for the $2.313-\mathrm{MeV}$ photon, which results from the decay of this level, is composed malnly of cascade contributions from the higher 3.945-, 5.106-, 5.691-, and 6.198-MeV levels (Fig. 23). Consequencly, we based the evaluated $\left(n, n^{\prime}\right)$ cross section for the 2.313-MeV level mainly upon $\left(p, p^{\prime}\right)$ measurements to this level by Oda et al. (Od60), Hansen et al. (Ha70), Freemantle et al. (Fr54), and Borell et al. (Bo68), augmented by the $\left(n, n^{\prime} \gamma\right)$ measurements and a single $\left(n, n^{\prime}\right)$ measurement at $14 \mathrm{MeV}$ by Bauer et al. (Ba63).* Our decision to use $\left(p, p^{+}\right)$measurements in the absence of $\left(n, n^{\prime}\right)$ data results from arguments by Lutz and Anderson (Lu66) and Anderson et a1. (An67) which are based upon charge symmetry of the nuclear two-body force (see Sec. 4.2 for further discussion). Indeed, we allowed the avallable $\left(p, p^{\prime}\right)$ results to influence our evaluation of the $\left(n, n^{\prime}\right)$ cross sections for some of the stronger transitions in energy regions where $(n, x y)$ measurements were lacking or were in disagreement.

The evaluated $\left(n^{\prime}, n^{\prime} \gamma\right)$ cross section for the 2.313-MeV gamma ray is compared to the avallable measurements in Fig. 24. As noted above, the curve is determined mainly by cascade contributions from higher levels and is not very sensitive to the small $\left(n, n^{\prime}\right)$ cross section to the $2.313-\mathrm{MeV}$ level. The evaluated curve and the measurements in Fig. 24 agreo reasonably well, although we blased our evaluation of the $\left(n, n^{\prime} \gamma\right)$ data somewhat in the righ direction to try to reconcile the "discrepancy" in the cross sections near 8-MeV neutron energy (St69, Di69). This problem is discussed further in Sec. 3.10 .

\# The $\left(n, n^{\prime}\right)$ measurement by Bobyr et al. (Bo62) is more than an order of magnitude higher than the other measurements and is not included here.

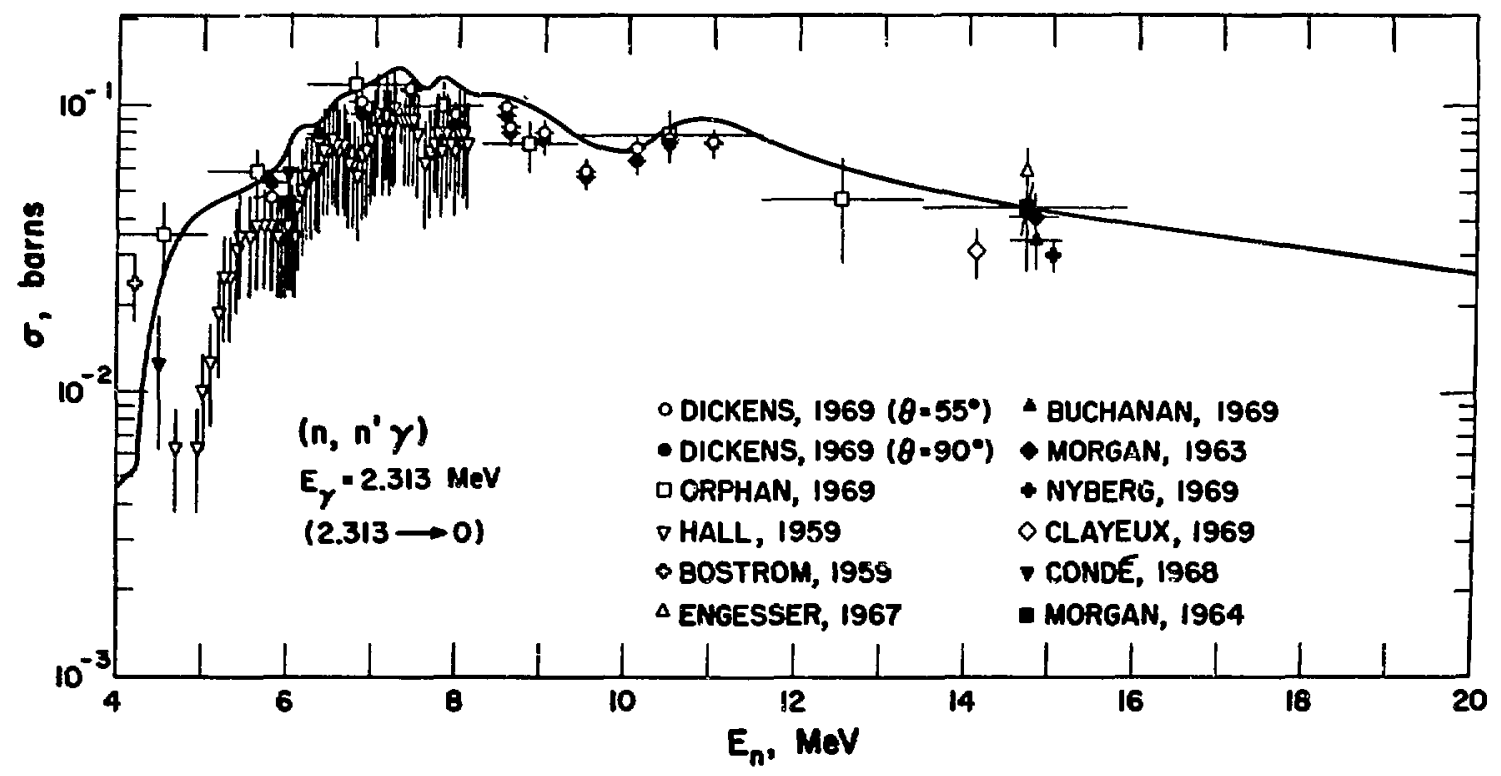

Fig. 24. Measured and evaluated photon-production cross section from 4 to $20 \mathrm{MeV}$ for the 2.313-MeV gana ray. 
The gamma-ray production cross sections for the 1.632- and 4.913-MeV gamma rays are given in FIg. 25. We used the experimental data shown in the figure to estimate the $\left(n, n^{\prime}\right)$ cross sections to the 3.945- and 4.913-MeV levels in ${ }^{14} \mathrm{~N}$, incorporating also, of course, the decay scheme given in Fig. 23. We have combined a small contribution $(<0.2 \mathrm{mb})$ from the $7.028-+2.313-\mathrm{MeV}$ transition $\left(E_{\gamma}=4.715 \mathrm{MeV}\right)$ into the $\left(n, n^{\prime} \gamma\right)$ cross section for the 4.913-MeV gamma ray. The evaluated $\left(n, n^{\prime}\right)$ cross section (19 mb) for the 3.945-MeV level near $14 \mathrm{MeV}$ agrees well with the direct $\left(n, n^{\prime}\right)$ measurement $(19 \mathrm{mb})$ by Bauer et al. (Baf3). The extensions of both evaluated curves from 15 to $20 \mathrm{MeV}$ are simple extrapolations of tine lower energy results. This is true of all $\left(n, n^{\prime} \gamma\right)$ results shown.

The evaluated $\left(n, n^{\prime} \gamma\right)$ cross sections for the 2.793- and 5.106-MeV gamma raya are compared to the available measurementa in Fig. 26. Both these gamtha rays rosult from decay of the $5.100^{\circ}-\mathrm{MeV}$ level.
We determined the evaluated $\left(n, n^{\prime}\right)$ excitation cross section to this level mainly from the 5.106-MeV gamma-ray measurements. The good agreement of the eva1uated curve with the 2.793-MeV measurements supports the branching ratios used for this level and the $\left(n, n^{\prime} \gamma\right)$ experimental data for both these photons. The new TNC compilation (Bu71) gives a point at 14.8 $\mathrm{MeV}$ for the 2.793-MeV photon which agrees closely with the curve.

The gama-ray production cross sections fir the 3.378- and 5.691-MeV gamma rays are gitven In FIg. 27. Both of these gamma rays result from decay of the 5.691-MeV level. We based the evaluated curves in the figures pi:imarily upon measurements of the 3.378-MeV gamra ray, which is the predominant branch In the decay. The cross section for the $3.378-\mathrm{MeV}$ photon also iucludes a small contribution from the 8.489- + 5.106-MeV transition $\left(E_{\gamma}=3.383 \mathrm{MeV}\right)$. The 3.378- and 3.383-MeV photons are close enough in energy so that they were certainly unresolved

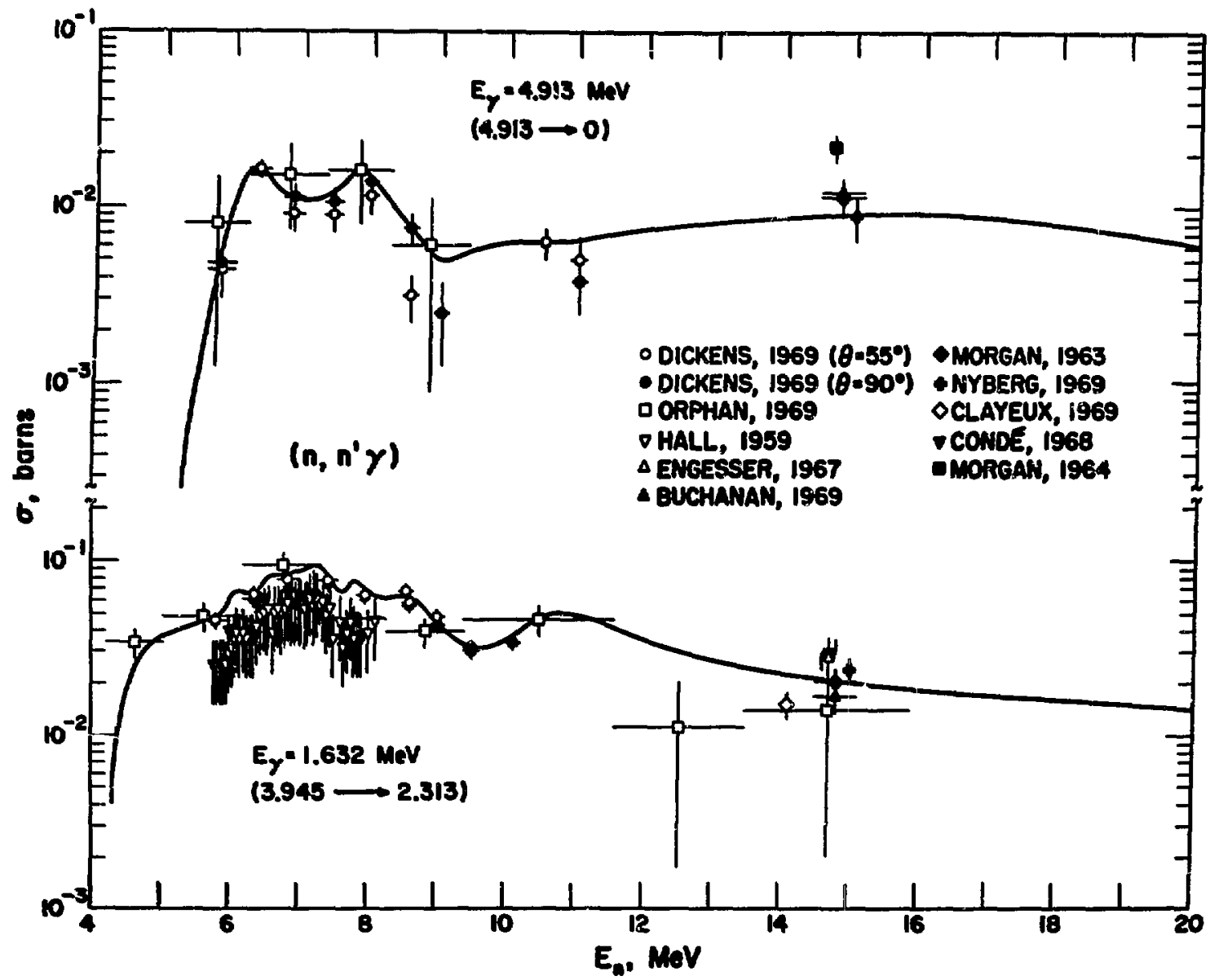

F1g 25. Measured and evaluated photon-production cross sections for the predominant gamm raye from the second and third excited states in $14 \mathrm{~N}$. 


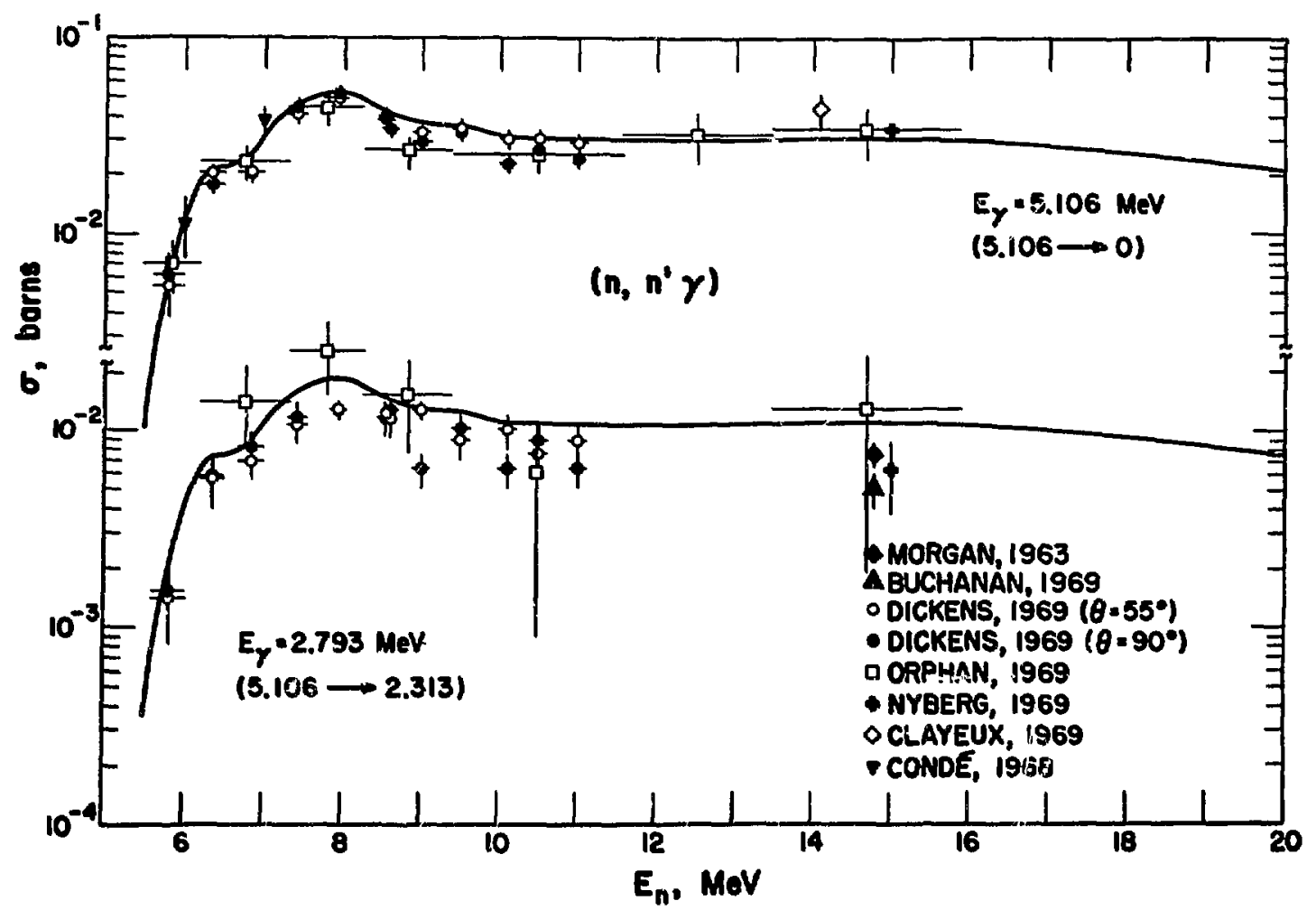

Fig. 26. Measured and evaluated photon-production cross sections for the predominant gamma rays from the 5,106- MeV level in $14 \mathrm{~N}$.

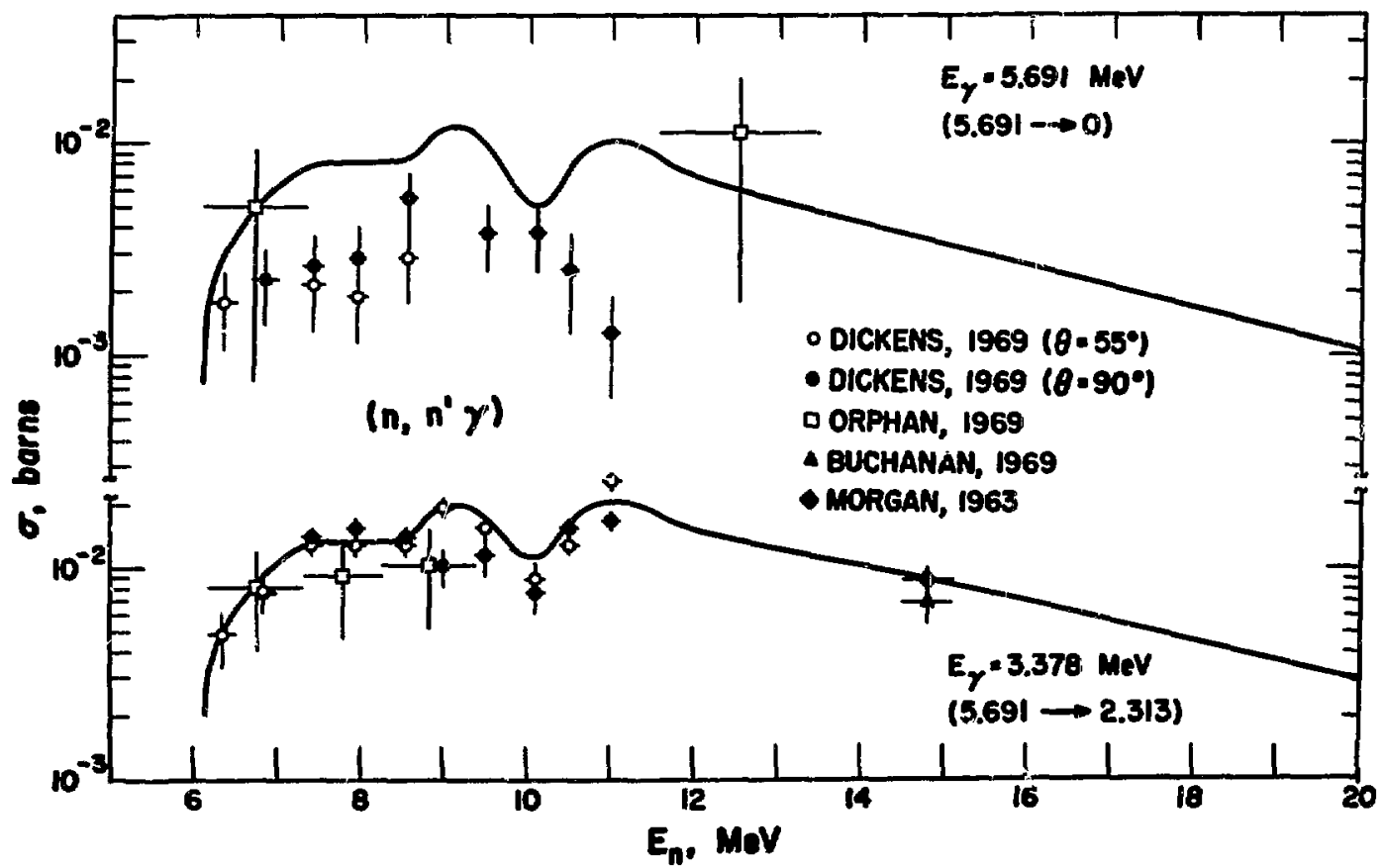

F18. 27. Massured and evaiuated photon-production cross gections for two gamma rays from the 5.691-HeV level in 14\%. 
In the measurements made with NaI detectors and probably unresolved in the Ge(LI) measurements as well. The lack of agreement between the evaluated curve and most of the 5.691-MeV experimental data may reflect an error in the branching ratios used or a problem in the measurements. The latter 1s more probable, and the problem probably 11 es in the 5.691$\mathrm{MeV}$ data because most of the measured cross sections for chis photon are quite small ( - a few mb).

The $\left(n, n^{\prime} \gamma\right)$ cross sections for the 0.728 - and 5.834-MeV gamma rays from the 5,834-MeV level are given in Fig. 28. The evaluated curves and, consequently, the evaluated excitation cross section, are based mainly upon the $0.728-\mathrm{HeV}$ gammg-ray data." Again, the agreement of the evaluated curve with the 5.834-MeV gama-ray experimental data gives us confidence in the branching ratios used for this level and in the experimental data for both the 0.728 - and 5.834-MeV photons.

"The new TNC compilation (Bu71) gives a 14.8-KoV point for the $0.728-$ MeV line which is $10 \mathrm{mb}$ higher than the curve.
The $\left(n, n^{\prime} Y\right)$ measurements used in deterwining the excitation cross section for the 6.198-HeV level are shown in F.g. 29. In this case, experimental data are available only for the 3.885-MeV game ray. The shape of the evaluated curve to $14 \mathrm{MeV}$ is based upon a tauser-Feshbach calculation (described in Append1x A). The evaluated cross section for the weaker 6.198-MeV gama ray 18 also included In Fig. 29.

The evaluated cross sections for the 2.499- and 6.444-KeV gamn raye from the 6.444- MeV level in $14 \mathrm{~N}$ are compared to experiment in FIg. 30. The predominant branch is the ground-atate transition, and the $\left(n, n^{\prime}\right)$ excitation cross section to this level is based upon the $\left(n, n^{\prime} Y\right)$ measurements for the 6.444MeV photon. As discussed above, the earlier INC date (Ho63, Ho64) have been cupereeded by more recent results, so we Ignored the olngle Korgan datum near $15 \mathrm{MeV}$ in our eveluntion of the crose section for the 6.444-KeV photon. The new TWC compllation (Bu71) cites $24 \mathrm{mb}$ for the Interval $\mathrm{E}_{\gamma}=6.0$ to 6.5 MeV which is much more consistent with our results.

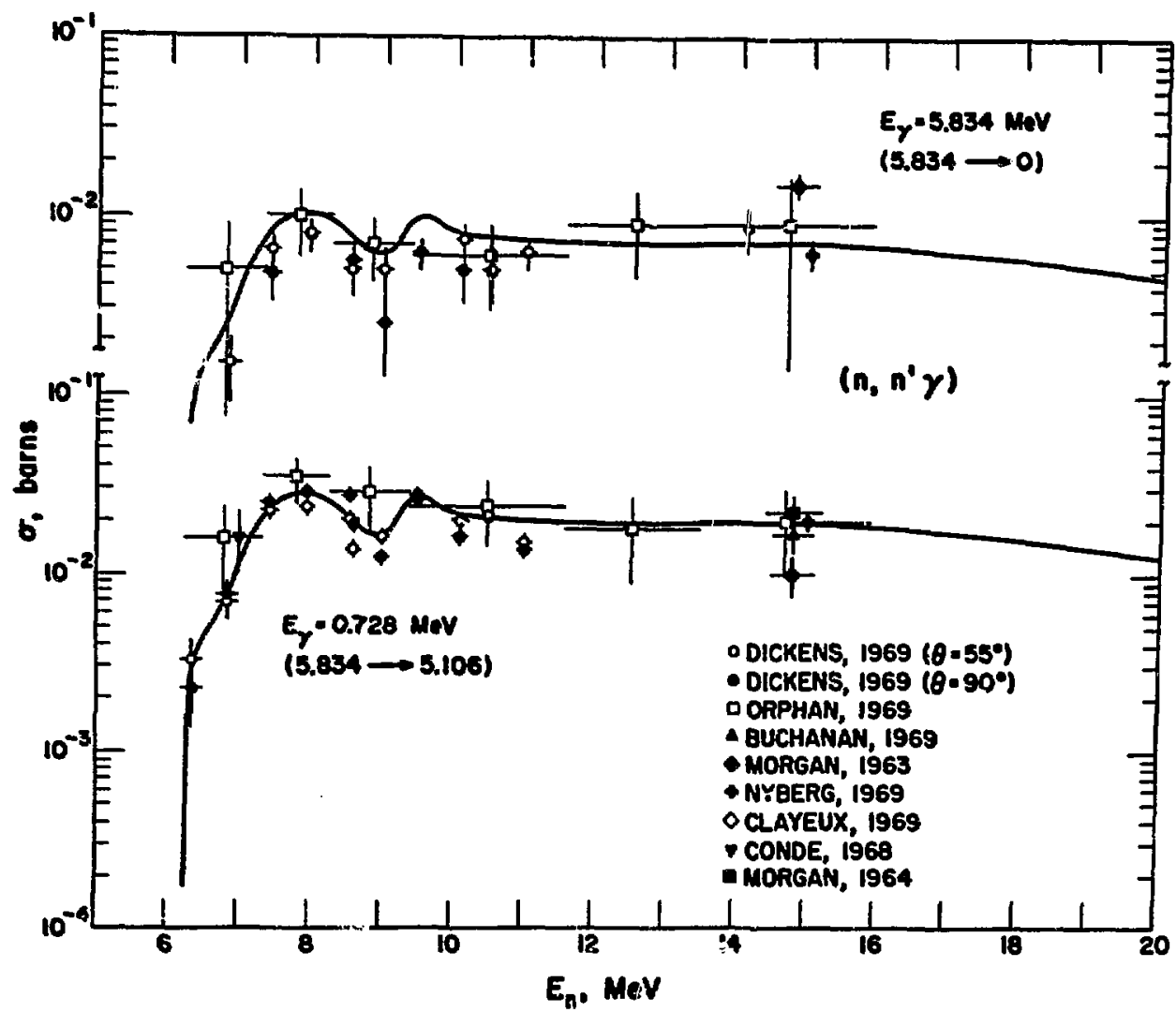

Fig. 28. Seasured and evaluated photon-production crosil wections for two gamne rays from the 5.834-HeV level in $14 \mathrm{~N}$. 


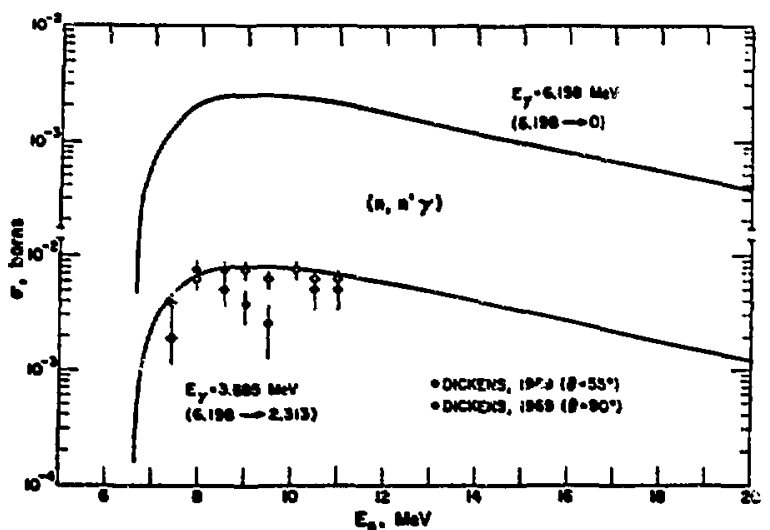

F18. 29. Measured and evaluated photon-production crose gection for the $3.885-\mathrm{MeV}$ gawn ray from the 6.198- Yev level in $14 \mathrm{~N}$, together with the evaluated crose section for the unobearved 6.198-KeV gaman traneition to the ground atate.

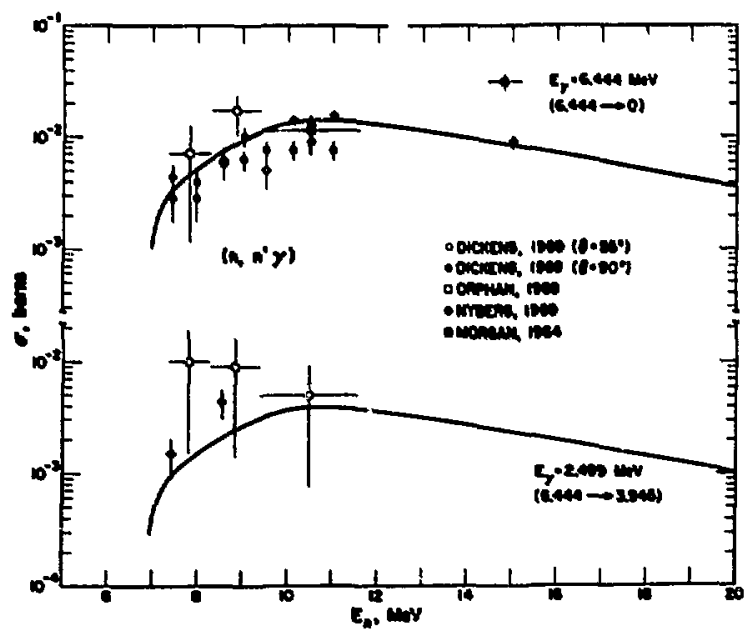

F18. 30. Measurad and avaluated photon-production crose esctione for the predominant gama raye from the $6.444-\mathrm{keV}$ level in $14 \mathrm{k}$.

F1gure 31 showe the $\left(n, n^{\prime} \gamma\right)$ crose sections for the 7.028- and 7.966-1/eV game rays. The shape of the evaluated curve up to $14 \mathrm{HeV}$ for the 7.966-2/eV IIne 18 based agein upon a Hauser-Feshbach calculat1on, es described In Appendix A. We determined the $\left(n, n^{\prime}\right)$ excitation crose sections to the 7.028and 7.966-MeV levels from these date.

Finally, F1g. 32 gives the gama-ray production crose sectione for gama rays of 3.98- and 1.25-KeV energy. The 3.98-MeV line 18 a composite of the 3.945- $\rightarrow 0-$ and 7.966- $+3.945-\mathrm{MeV}$ trans1tlons, and the 1.25-MeV gama 18 a su of the contributions from the 5.106- + 3.945-, and 6.444- $\rightarrow$
5.106-MeV transitions. The curves were computed from the evaluated level-excltation cross sections to the four levels involved.

The ${ }^{14} \mathrm{~N}\left(n, n^{\prime}\right)$ level-excltation cross sections that result from the foregoing analysis are presented In Figs. 33-35. Figure 33 gives the cross sections for the 2.313- and 3.945-NeV levels up to $\mathrm{E}_{n}=5$ MeV, F18. 34 contains the results for levels with $E_{x}<6 \mathrm{MeV}$ for $E_{n}=5$ to $20 \mathrm{MeV}$, and $F I_{8}$. 35 gives the cross sections for $6<E_{x}<8.5 \mathrm{NeV}$ out to $E_{n}=$ $20 \mathrm{MeV}$. The cross sectlons for the 8.061- and 8.489MeV levels in F1g. 35 are based entirely upon the Hauser-Feshbach calculations. There are no exper1mental $\left(n, n^{\prime}\right)$ nor $(n, x y)$ data for there two levels; however, the Integrated $\left(p, p^{\prime}\right)$ measurements by hansen et al. (Ha70) nt $\mathrm{E}_{\mathrm{p}}-14.6 \mathrm{MeV}$ 1Le approximately $35 \%$ below the evaluation for the 8.061-MeV level and within a few percent for the $\left(n, n^{\prime}\right)$ cross section to the $8.489 \mathrm{meV}$ level.

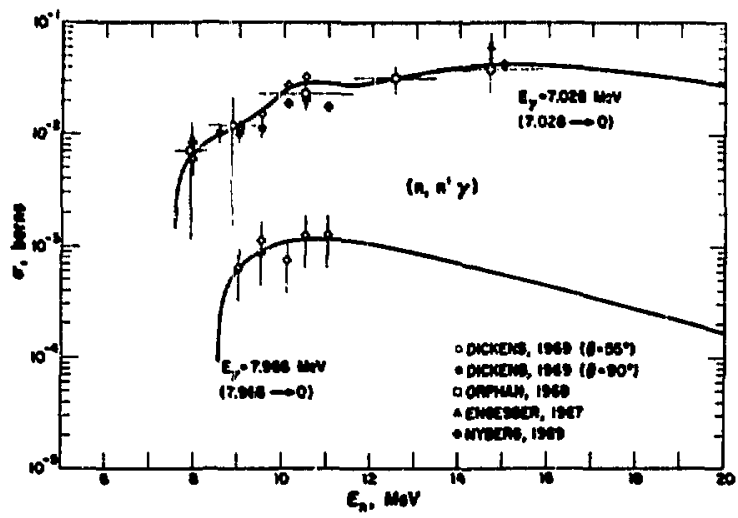

F18. 31. Measured and evaluated photon-production cross sections for the ground-state gamma rays from the $7.028-$ and $7.966-\mathrm{NeV}$ levels in $14 \mathrm{k}$.

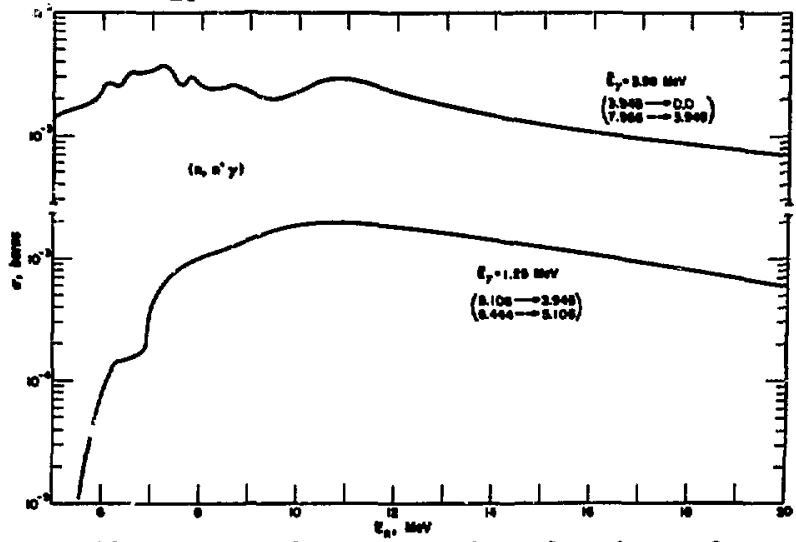

Fig. 32. Evaluated crose sectlons for the production of two weak photon doublets followIng inelastic scattering from ${ }^{14} \mathrm{~N}$. 


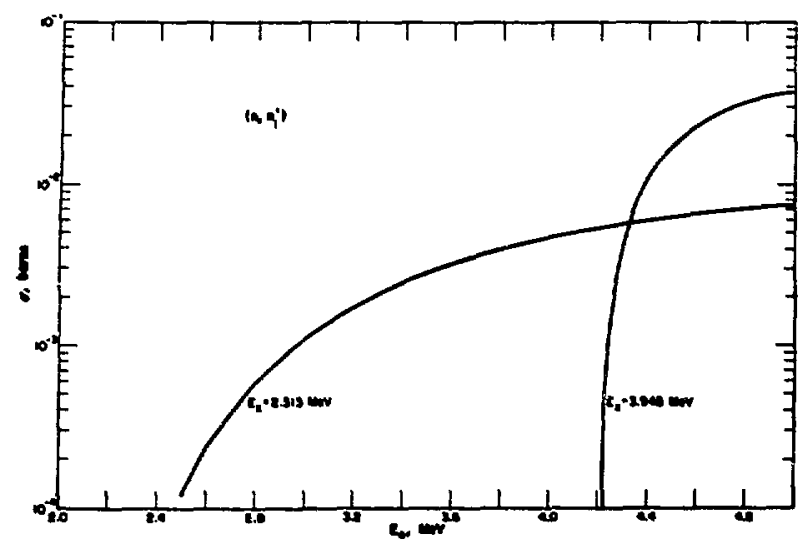

Fig. 33. Evaluated cross sections up to $5 \mathrm{MeV}$ for inelastic scattering to the firat two excited atates in $14 \mathrm{~N}$.

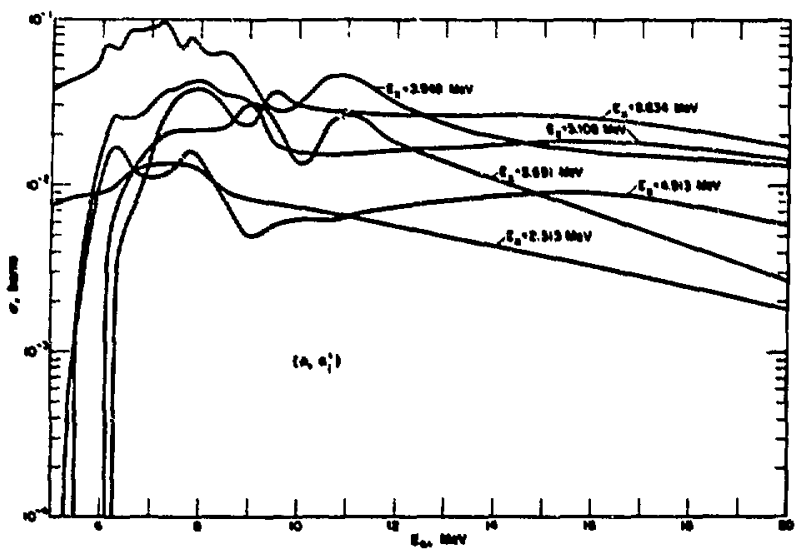

F1g. 34. Evaluated cross sections from 5 to $20 \mathrm{MeV}$ for Inelatic acattering to levela in $14 \mathrm{~N}$ with $E_{x}<6$ HeV.

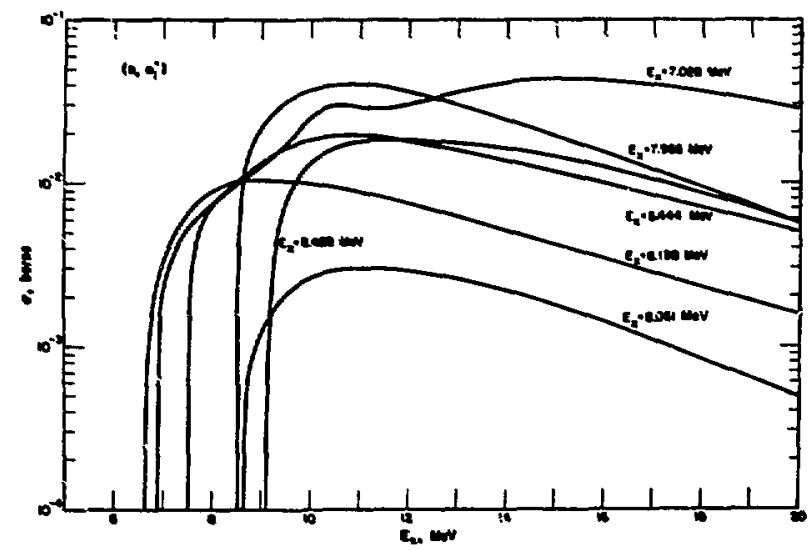

Fig. 35. Evaluated cross sections for Inelastic scattering to levelo in $14 \mathrm{~N}$ wich $E_{x}$ between 6 and $8.5 \mathrm{MeV}$.

\subsubsection{The ${ }^{14} N\left(n, n^{\prime}\right)$ Crose Section for $E_{X}\left({ }^{14} N\right)>$ $8.5 \mathrm{MeV}$}

As noted previously, at neutron energies above 9 to $10 \mathrm{MeV}$ many new levels in ${ }^{14} \mathrm{~N}$ becoue avallable for $\left(n, n^{\prime}\right)$ reactions, Because almost no experimental Information is avallable on the cross aections to these highly excited levels, It becomes increasingly difficult to estimate all the reaction crose sections at these energies. Therefore, in the 10to $12-\mathrm{MeV}$ region the elastic cross section, which Was obtained at lower energies by subtracting the sum of the partial reaction cross sections from the total cross section, was joined amoothly to the available elastic neasuremente, and we obtained a nonelasic crosa aetion by aubtracting the evaluated elastic from the total crose section. At neutron energles above $10 \mathrm{MaV}$ wa adjuoted the $\left(n, n^{\prime}\right)$ crose section to levels in ${ }^{14} \mathrm{~N}$ with $\mathrm{E}_{x}>8.5 \mathrm{HeV}$ so that the total $\left(n, n^{\prime}\right)$ crose aection and the evaluated $(n, \gamma),(n, p),(n, d),(n, t),(n, \alpha),(n, 2 \alpha)$, and $(n, 2 n)$ croes sectione $a i= \pm 0$ the correct nonelastic cross gection.

Inplicit in the above procedure is the asamption that neutrons from ${ }^{14} w(n, p)^{14} c^{*}(n)^{13} c$ and ${ }^{14} \mathrm{~N}(n, d){ }^{13} C^{*}(n){ }^{12} \mathrm{C}$ reactions are adequately repreaented in this way (or can be neglected), because these processes are lumped Into the $\left(n, n^{\prime}\right)$ reactions. We feel that this assumption is reasonable because the $(n, p)$ and $(n, d)$ cross sectione to highly excited atates in ${ }^{14} \mathrm{C}$ and ${ }^{13} \mathrm{C}$ are undouhtedly quite small. A second Implied assumption is that the ${ }^{14} N(n, t) 3 \alpha$ cross section is negligible; this approxImation 18 supported by the measurement by Hösner et al. (Ho67) at $15.7 \mathrm{MeV}$ which gives a value of $0.8 \pm 0.5 \mathrm{mb}$ for the $(n, t) 3 \alpha$ cross section. No similar problem arises for the $(n, a)$ reaction to highly excited states of ${ }^{11_{B}}$ because these states decay mainly by alpha emission and are Included in our estimate of the $(n, 2 \alpha)$ cross section.

We generated the spectrum of Inelastic neutrons from $\left(n, n^{\prime}\right)$ reactions to states in ${ }^{14} \mathrm{~N}$ above $8.5-$ MeV excitation energy in three steps:

(1) We estimated the relative $\left(n, n^{\prime}\right)$ cross sections to levels between $8.5-$ and 13-MeV excitation energy from Hauser-Feshbach calculations. At these excitation energies, the level structure of ${ }^{14} \mathrm{~N}$ is reasonably well understood, and spin and parity assignments have been made for most 
of the levels. We performed the calculations, described in more detall in Appendix A, with the code JANE (Fe68), employing some 50 levels in ${ }^{14} \mathrm{~N}$ and using the level Information compiled by Afzenberg-Selove (Aj70).

(2) For excitation energiee greater than $13 \mathrm{MeV}$, we estimated the $\left(n, n^{\prime}\right)$ energy distributions from a simple evaporation model using the expression

$$
\sigma_{n, n},(\varepsilon) \propto \varepsilon \exp [-\varepsilon / T],
$$

where $\varepsilon$ is the outgoing neutron energy in the center-of-mass system. We chose the nuclear temperature $T$ so that the shape calculated from this expression agreed with the Hauser-Feshbach calculation below $E_{X}=1.3 \mathrm{MeV}$. The temperatures we used are given by

$$
T=0.307 \sqrt{\mathrm{E}}(\mathrm{MeV}) \text {, }
$$

where $\mathrm{E}$ is the laboratory neutron energy in $\mathrm{MeV}$. We normalized the evaporation energy spectra at each Incident neutron energy to match the $\left(n, n^{\prime}\right)$ cross sections cslculated from Hauser-Feshbach theory for $8.5 \mathrm{MeV}<\mathrm{E}_{x}<13 \mathrm{MeV}$.

(3) The final step was to nocmalize the composite Hauser-Feshbach nuclesr-temperature energy spectrum for $E_{x}>8.5 \mathrm{MeV}$ so that all the reaction cross sections sunimed to the proper nonelastic cross section at all Incldent neutron energles, as described earlier.

We grouped the inelastic cross oections resultIng from this treatment Into 0.5-MeV-wide excitationenergy bins and represented them as $\left(n, n^{\prime}\right)$ reactions to fictitloue levels at $8.75,9.25,9.75, \ldots, 18.25$ MeV. The reeulte are shown in Figs. 36-39. The curves become more ayatematic for $E_{x}>13 \mathrm{MeV}$ where we used the evaporation-model calculations.

The only experimental result available to use In checking our evaluation of $\left(n, n^{\prime}\right)$ cross sections for levels with $\mathrm{E}_{X}>8 \mathrm{MeV}$ is the $14-\mathrm{MeV}$ neutronspectrum measurement by Anderson and McClure (An64). These results, which have been renormalized to give an Integrated cross section of $0.54 \mathrm{~b}$ (St65), * are compared in Fig. 40 to a histogram constructed from our evaluated $\left(n, n^{\prime}\right)$ cross sectlons. We determined the evaluated results above $E_{n}^{c}=4.2 \mathrm{MeV}$ from the various $\left(n, n^{\prime} \gamma\right)$ measurements and from the $\left(n_{b} n^{\prime}\right)$

*This renormalization is a rough correction for multiple-scattering effects. A detalled calculation was not made.

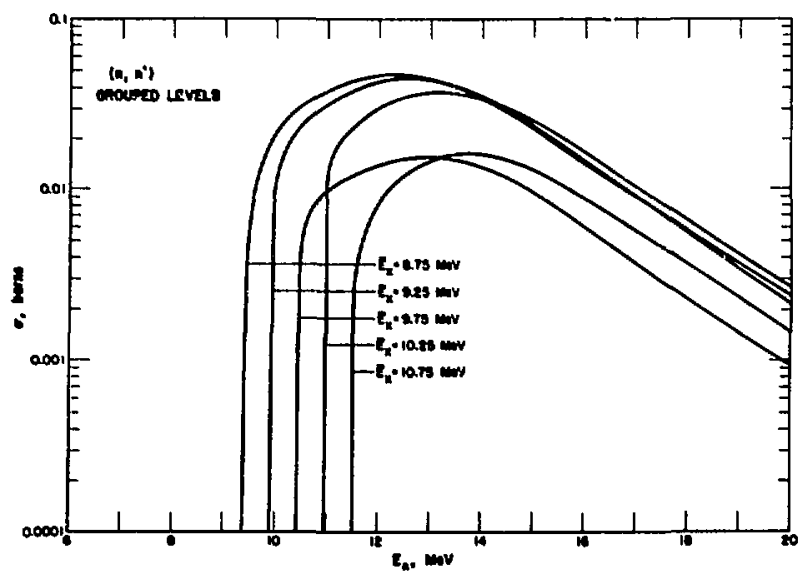

F18. 36. Evaluated cross sections for Inelastic gcattering to groups of known levels in $14 \mathrm{~N}$ with $\mathrm{E}$ between 8.5 and $11 \mathrm{MeV}$. Each half-MeV if excitation energy is represented as a single fictitious level.

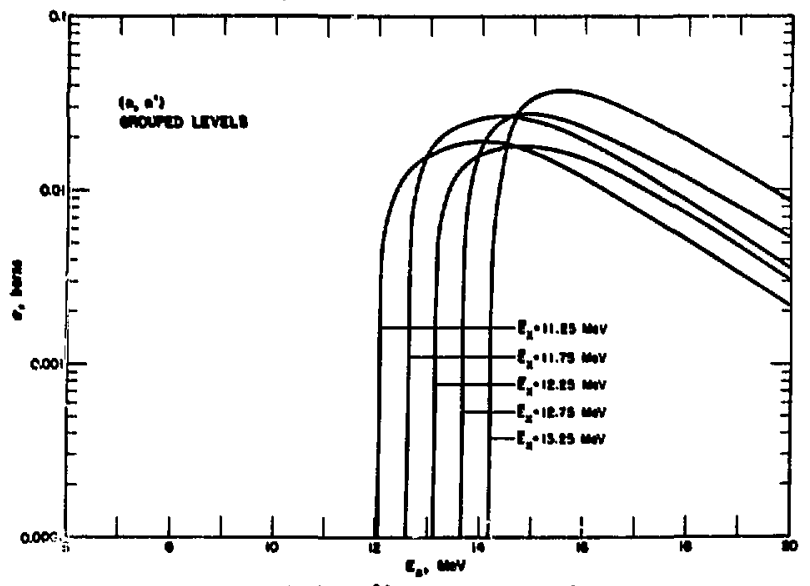

F18. 37. Evaluated $\left(n, n^{\prime}\right)$ crose sections to groups of levels in $14 \mathrm{~N}$ between 11 and $13.5 \mathrm{MeV}$.

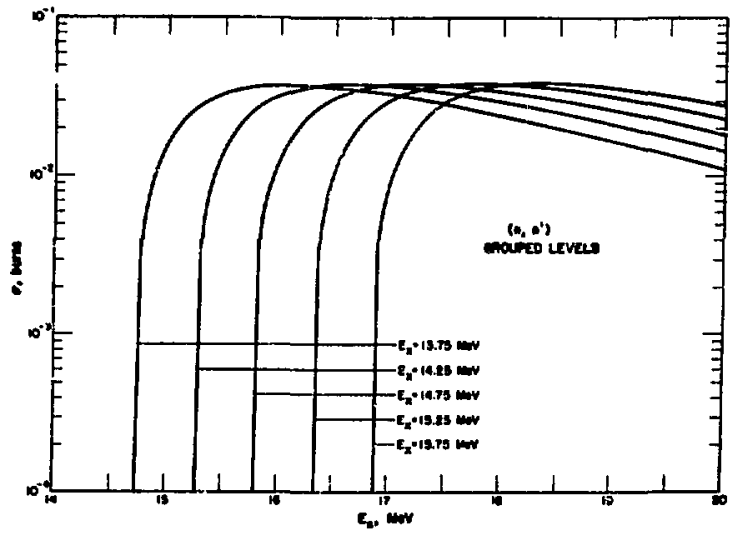

Fig. 38. Evaluated $\left(n, n^{\prime}\right)$ cross sections to groups of levels in $14 \mathrm{~N}$ between 13.5 and $16 \mathrm{MeV}$. 


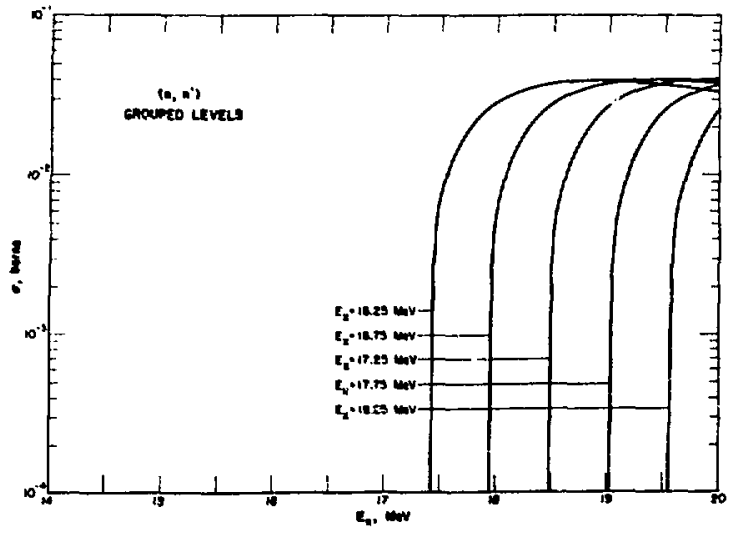

F1g. 39. Evaluated $\left(n, n^{\prime}\right)$ crose sections to groups of levels in $14 \mathrm{~N}$ between 16 and $18.5 \mathrm{MeV}$.

messurement at $14 \mathrm{MeV}$ by Bauer et al. (Ba63), as described in Sec. 3.3.1. The evaluated spectrum below $E_{n}^{c}=4.2 \mathrm{MeV}$ reaulte from our renormalized Hauser-Feshbach calculations, as discuesed above. The gapa in the histogram are regione where there are no levels in ${ }^{14} \mathrm{~N}_{i}$ the fact that the measured spectrum does not dip near the gaps indicates that the resolution of the meaeuremente was falrly broad.

The agreement betwoen evaluation and meagurement is only fair, and aignificant differences occur for $E_{n}^{c}<2 \mathrm{MeV}$. The difference may indicate that the level structure of ${ }^{14} \mathrm{~N}$ for $8.5<E_{X}<13 \mathrm{MeV}$ is not adequately known; however, the problem may very well be in the measurement because the experimental uncertainties are probably greatest at the lowest neutron energies. A second difficulty in the comparIson is that the total $\left(n, n^{\prime}\right)$ cross section from the measurement is $0.54 \pm 0.11 \mathrm{~b}$ (St65), whereas the evaluated total $\left(n, n^{\prime}\right)$ cross section is 0.4 b. If the measured value of $0.54 \mathrm{~b}$ is ancepted, the elastic cross section at $14 \mathrm{MeV}$ (described in Sec. 3.10) must be decreased substantially $(\sim 0.14 \mathrm{~b})$, and this 18 difficult to reconcile with most of the elastic measurements. If we assume that the measured spectrum is wrong below $E_{n}^{c}=2.3 \mathrm{MeV}$ and compare the integrated cross sections for the evaluated and measured spectra only for $E_{n}^{c}>2.3 \mathrm{MeV}$, the difference between the evaluated and measured values decreases from roughly 30 to $20 \%$.

3.3.3 The ${ }^{14} N\left(n, n^{\prime} p\right)^{13} C$ and ${ }^{14} N\left(n, n^{\prime} \alpha\right)^{10} B$ Cross Sec-

\section{tions}

States at high excitation energies in ${ }^{14} \mathrm{w}$ decay predominantly by proton, deuteron, and alpha emiasion, corresponding to the ${ }^{14} \mathrm{~N}\left(\mathrm{n}, \mathrm{n}^{\prime} \mathrm{p}\right)^{13} \mathrm{c},{ }^{14} \mathrm{~N}\left(\mathrm{n}, \mathrm{n}^{\prime} \mathrm{d}\right)^{12} \mathrm{c}$, and ${ }^{14} N\left(n, n^{\prime} \alpha\right){ }^{10}$ reactions with threaholds at 8.09 , 11.01, and $12.45 \mathrm{MeV}$, respectively. In this evaluetion we assume that levels above 8.5-MeV excitation in ${ }^{14} \mathrm{~N}$ decay entirely by emieation of either protons or alpha particles. Because there is virtually no available experimental information on these processea, we have very crudely divided the $\left(n, n^{\prime}\right)$ cross sections into $\left(n, n^{\prime} p\right)$ and $\left(n, n^{\prime} \alpha\right)$ components by assuming that states in ${ }^{14} \mathrm{~N}$ emit particles with decay probabilities proportional to $(2 s+1)(2 J+1) \Delta E_{c}$, where 8 is the apin of the emitted particle, $J$ is the spin

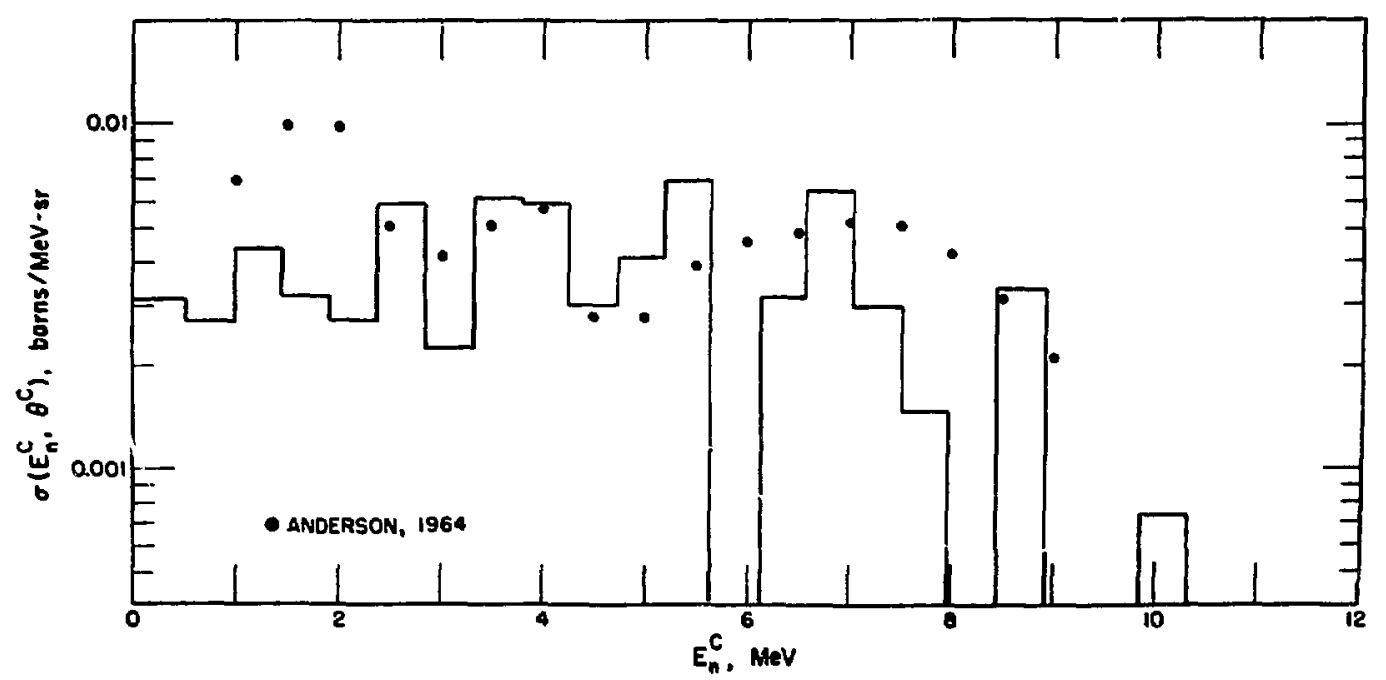

F1g. 40. Menaured and evaluated secondary-neutron spectra in the c.m. system for 14-MeV (lab) Inc1dent neutrons. 
of the new state, and $\Delta E_{c}$ is the center-of-mass energy released in the reaction. He performed this calculation using all the states avallable for particle decay. The resulting $\left(n, n^{\prime} p\right)$ and $\left(n, n^{\prime} \alpha\right)$ cross sections are given In Fig. 41 together with the total $\left(n, n^{\prime}\right)$ and $\left(n, n^{\prime}{ }^{\prime}\right)$ cross sections, where the latter $1 \mathrm{~s}$ defined to be the $\left(n, n^{\prime}\right)$ cross section that results In photon emission. We have corabined the $\left(n, n^{\prime} d\right)$ cross section, which 18 relatively small, Into our estimate for the $\left(n, n^{\prime} p\right)$ cross section.

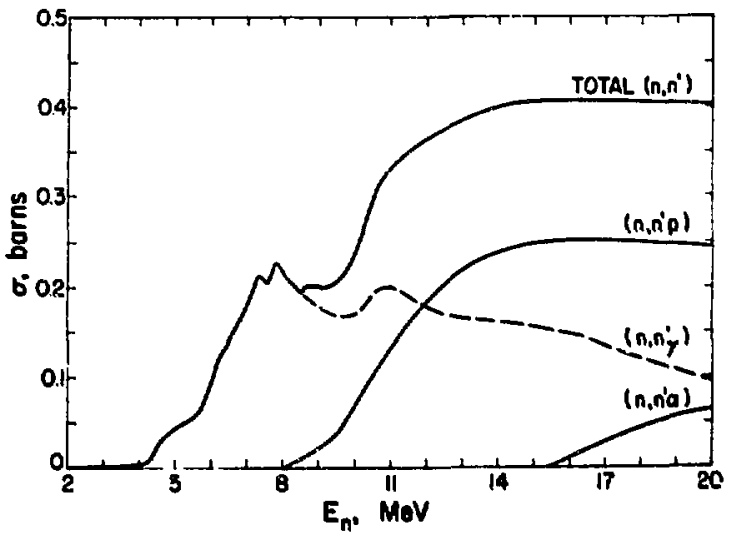

Fig. 41. Total inelastic-scattering cross section and Its constituent photon- and chargedparticle-entssion crose bections. This curve 1a compounded from the results shown In Fige. 34-39.

The $\left(n, n^{\prime} p\right)$ and the $\left(n, n^{\prime} \alpha\right)$ cross sections are Included in the END:/B evaluation by flagging certain of the $\left(n, n^{\prime}\right)$ level-excitation cross sectlons In File 3 as decaying by wther proton or alpha emission. Because the number of discrete levels allowed by the format is limited, this representation necesarily produces artificlal structure in the $\left(n, n^{\prime} p\right)$ and $\left(n, n^{\prime} \alpha\right)$ cross sections. This structure 18 not included in Fig. 41.

3.4 The ${ }^{14} \mathrm{~N}(\mathrm{n}, \mathrm{p})^{14} \mathrm{C}$ and ${ }^{14} \mathrm{~N}(\mathrm{n}, \mathrm{p},)^{14} \mathrm{C}$ Cross Sections

We evaluated the thermal $\left(n, p_{0}\right)$ cross section to be $1.819 \pm 0.036 \mathrm{~b}$ from a compostte of measuremanta by Coon and Nobles (Co49), Batchelor and Flowers (Ba49), Gïer et al. (Cu51), and Hanna et al (Ha61). The uncertainty in the thermal value if based upon the quoted errore in the messurements. The $\left(n, p_{0}\right)$ cross section 18 ascumed to vary as $1 / \mathrm{v}$ up to $10 \mathrm{keV}$ and 18 then joined anothly to nessurements by GIbbons and Macklin (G159) and Johnson and Barschall (Jo50) between 0.03 and $0.3 \mathrm{MeV}$. These cesults are given In Fig. 42. Again, we feel that the $1 / v$ assumption up to $10 \mathrm{keV}$ is reasonable because the first resonance does not occuí unt $11434 \mathrm{keV}$.
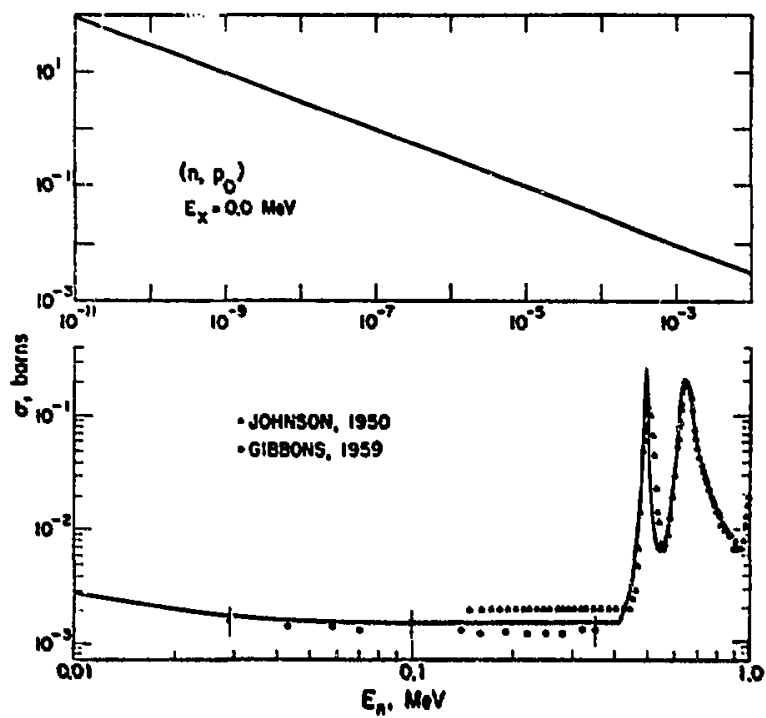

F18. 42. Measured and eveluated $(n, p)$ grone aection to the ground atate of ${ }^{14} \mathrm{C}$ from $10^{-5}$ eV to $1 \mathrm{MeV}$. The top figure 1 s baced on a composite of four measurements at thermal energy (not shown).

The $\left(n, p_{0}\right)$ cross section up to $6 \mathrm{MeV}$ is shown In $\mathrm{Fig}$. 43. In the regions between resonances, the curve 18 a smooth fit to the measured data, with greatest emphasis placed on the results of Johnson (Jo50) and Gabbard et al. (Ga59) * up to $4 \mathrm{MeV}$. Over many of the sharper resonances, we obtalned the curve from a Brelt-Wigner shape using the resonance energy and width from the total-cross-section analysis and normalizing the area under the curve to the $\left(n, p_{0}\right)$ measurements.

At neutron energies from 4 to $13 \mathrm{MeV}$, we used the mesurement of the Inverse ${ }^{14} \mathrm{C}(\mathrm{p}, \mathrm{n}){ }^{14} \mathrm{~N}$ reaction by Wong et al. (Wo67) to determine the $\left(n, p_{0}\right)$ cross section. The results from 6 to $20 \mathrm{MeV}$ are given In F18. 44. Because of the paucity of experimental Information, the structure in the $\left(n, P_{0}\right)$ cross section in this energy region is largely unknown.

Also shown In Fig. 44 are the $(n, p)$ excitation cross sections for the $81 x$ particle-atable excited levele of ${ }^{14} \mathrm{C}$, with the firat, second, and fourth levels combined Into one curve. Except for $\left(n, p_{5}\right)$,

*All the results of Gabbard et al. (Ge59) have been increased $20 \mathrm{x}$ to account for a calibration error (Ga53). 


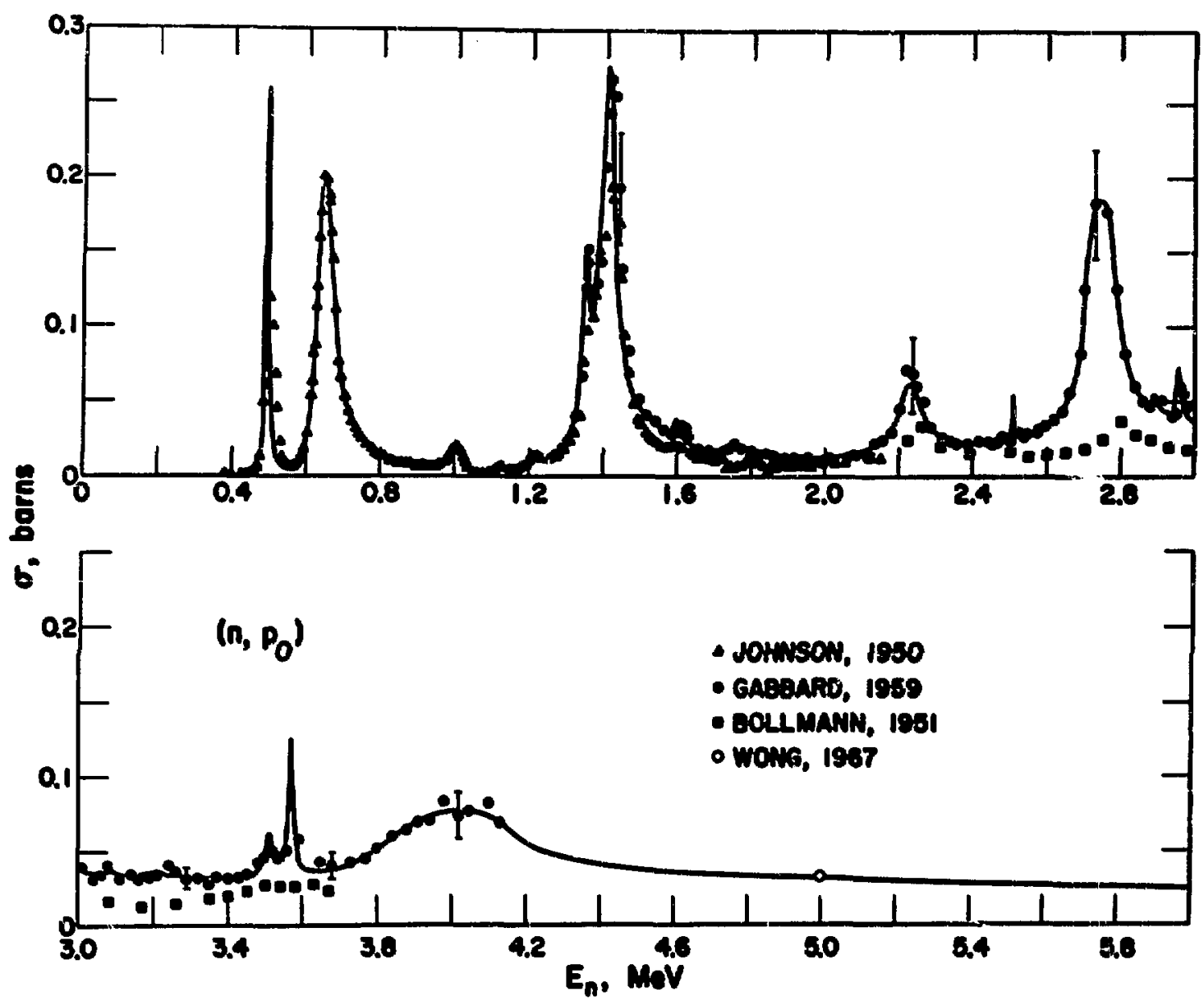

F1g. 43. Evaluated crose section for the $\left(n, p_{0}\right)$ reaction from $400 \mathrm{keV}$ to 6 weV, with the westiurenants on which it is based.

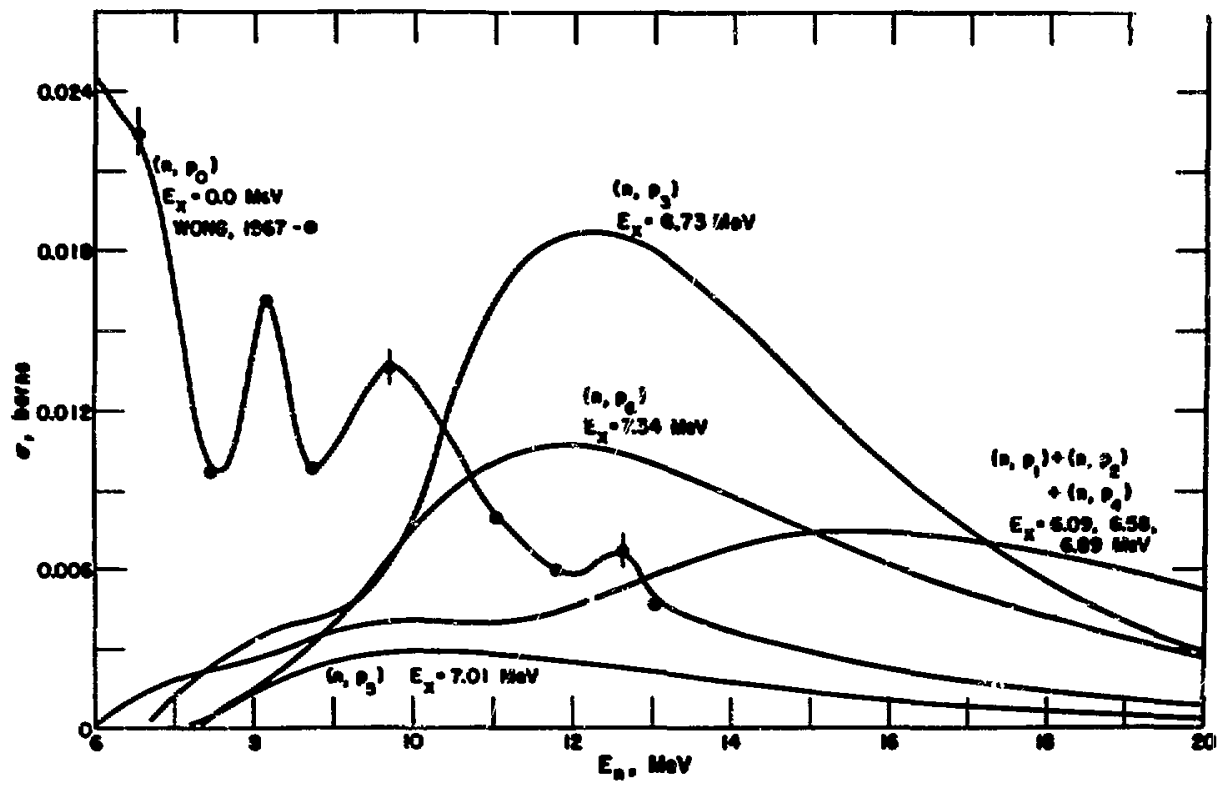

F18. 44. Evaluet crose sections from 6 to $20 \mathrm{yeV}$ for the $(n, p)$ reaction co the olx particle-stable excited states in ${ }^{14} \mathrm{C}$, together with the $\left(n, p_{0}\right)$ croes section and the date on which it is based. 
we obtained the excited-level excitation cross sectlons from measurements of gamma-ray production cross sections, together with the decsy scheme for ${ }^{14} \mathrm{C}$, as described below. We obtained the curve for $\left(a, p_{5}\right)$ from a compouid-nucleus reaction-theory calculation, as described in Appendix $A$. We adjusted the calculated shape for $\left(n, p_{5}\right)$ by the same factir required to produce agreement between the calculated shape of $\left(n, p_{6}\right)$ and the $(n, p Y)$ measurements for the 1.242-MeV gamma ray from the aixth excited state of ${ }^{14} c$. The $\left(n, p_{5}\right)$ crose section is relatively small, In qualitative agreement with the fact that. a 7.012MeV gaxma ray is not observed in the gamma-ray production measuremente.

The decay scheme for ${ }^{14} \mathrm{C}$, which relates the $(n, p)$ level excitation crose sections to the gammaray production seasurenente, 18 given in Fig. 45. The branching ratios are a composite of ${ }^{13} \mathrm{c}(\mathrm{d}, \mathrm{p}){ }^{14} \mathrm{C}$ measurements by Aburger et al. (A166), ${ }^{12} \mathrm{C}(\mathrm{t}, \mathrm{p})^{14} \mathrm{c}$ measuremente by Bell ot al. (Be68), and Crrloon'a $9_{\mathrm{Be}}\left({ }^{7} \mathrm{LI}, \mathrm{d}\right){ }^{14} \mathrm{C}$ aeacurements $(\mathrm{Ca66})$. The level energles, spins, and parities are from Ajrenberg-Selove"s energy-levej. compllation for $A=13-15(A j 70)$. The 6.583- and 6.894-Mav levelo decay entirely to the 6.095-xeV level in ${ }^{14} \mathrm{C}$. Thereforo, because we had determined the $(n, F)$ level excitation cross sections fron $(n, p \gamma)$ beasurenents, we conblned the $\left(n, p_{1}\right)$, $\left(n, p_{2}\right)$, and $\left(n, p_{4}\right)$ excitation cross sections in the evaluation. Table VI 1s a sumary of the gamma-ray transitions fncluded in the evalustion. Two of the tramsitions have been combined, as Indicated.

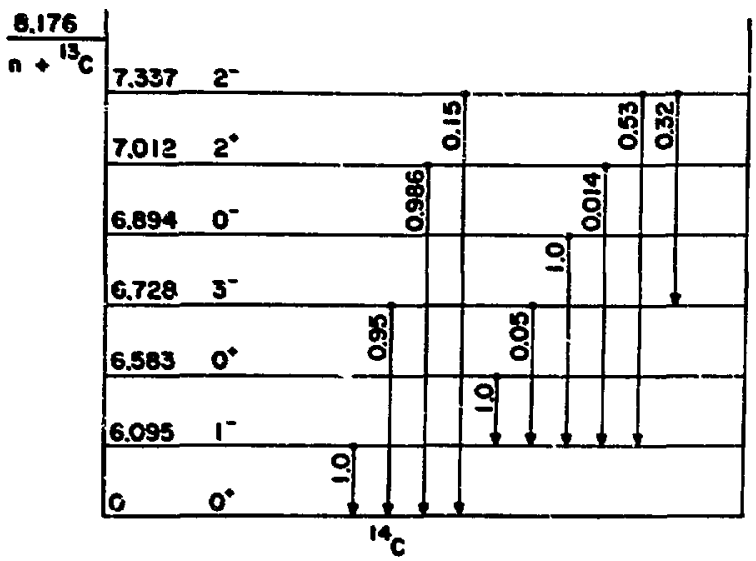

Fig. 45. Decay acheme for ${ }^{14} \mathrm{C}$ used in correlating the $(n, p y)$ crose sections with the levelexcitation crose eections. Note that the energy scale is grossly distorted.
TABLE VI

GAMMA HAYS FROM ${ }^{14} \mathrm{~N}(n, \mathrm{p} Y)$ REACTIONS

\begin{tabular}{|c|c|c|}
\hline $\begin{array}{l}\mathrm{E}_{\mathrm{Y}} \\
(\mathrm{MeV})\end{array}$ & $\begin{array}{c}E_{\text {Initial }} \\
\text { (MeV) }\end{array}$ & $\begin{array}{r}E_{\text {final }} \\
(\mathrm{MeV})\end{array}$ \\
\hline $\begin{array}{l}7.337 \\
7.012 \\
6.728 \\
6.095\end{array}$ & $\begin{array}{l}7.337 \\
7.012 \\
6.728 \\
6.095\end{array}$ & $\begin{array}{l}0 \\
0 \\
0 \\
0\end{array}$ \\
\hline 1.242 & $\left\{\begin{array}{l}7.337 \\
7.012\end{array}\right.$ & $\left.\begin{array}{l}6.095 \\
6.095\end{array}\right\}$ \\
\hline $\begin{array}{l}0.634 \\
0.609\end{array}$ & $\begin{array}{l}6.728 \\
7.337\end{array}$ & $\begin{array}{l}6.095 \\
6.728\end{array}$ \\
\hline
\end{tabular}

Neutron emission is possible for ${ }^{14} \mathrm{C}$ states above $8.176-\mathrm{MeV}$ excitation energy, and we have assumed that all states $1_{i}$ - ${ }^{14} \mathrm{C}$ above this energy decay entirely by particle emission. This assumption is oupported by the fact that none of the levela in ${ }^{14} \mathrm{C}$ In this energy region have signjficant ratios of photon width to total width in elthe. charged-particleor neutron-induced reactions (AJ70). We do not give the $(n, p n)$ cross section proceeding through these highly excited levels in ${ }^{14} \mathrm{C}$ explicitly in the evaluation, but it is included roughly in our estimates of $\left(n, \mathrm{H}^{\prime}\right)$ cross sections to levels in ${ }^{14} \mathrm{~N}$ that decay by putoton emission (see Sec. 3.3.3). of the ${ }^{14} \mathrm{~N}$ $(n, p){ }^{14} C^{*}(n)^{13} C$ and ${ }^{14} N\left(n, n^{\prime}\right)^{14} N^{*}(p)^{13} C$ processes, the latter is expected to dominate. The total $(n, p)$ cross section shown in F1g. 5 was obtalned by summing the $(n, p)$ level excitation cross sections for the first seven levels of ${ }^{14} \mathrm{C}$.

In F1g. 46, the evaluated ( $\left.n_{3}, \mathrm{p}\right)$ cross sections for the 6.094- and 6.728-MeV gamma rays are compared to the avallahle measurements. He determined the excitation cross sections off the 6.094- and 6.728MeV levels from these curves. Tt.s curves are based primarily upon measurements by Dickens and Perey (D109), Orphan et al. (0r69), and Nyberg et al. (Ny69).

The $(n, p Y)$ cross sections for the 0.609-, 0.634-, 1.242-, 7.012-, and 7.337-MeV garma rays are ziven In F1g. 47. The $0.634-\mathrm{MeV}$ line is determined from the 6.728- $\mathrm{MeV}$ data of Fig. 46 using the decay scheme of FIg. 45. The 0.609- and 7.337-MeV lines are determined by the curve through the $E_{\gamma}=1.242-\mathrm{NeV}$ measurements, and we obtalned the 7.012-MeV line from the calculated $\left(n, p_{5}\right)$ excitation cross section discussed previously. 


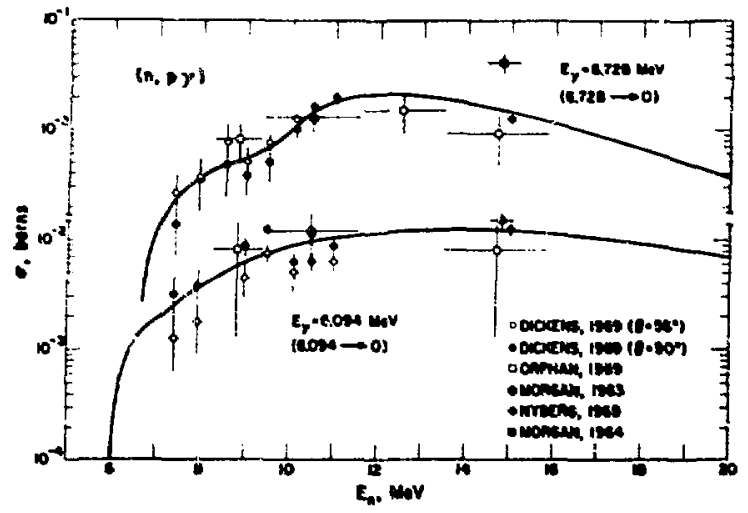

F1g. 46. Measured and evaluated crose sectlons for the griund-atate garma rays from de-excitation of the 6.094- and 6.728-MeV levels In $14 \mathrm{C}$.

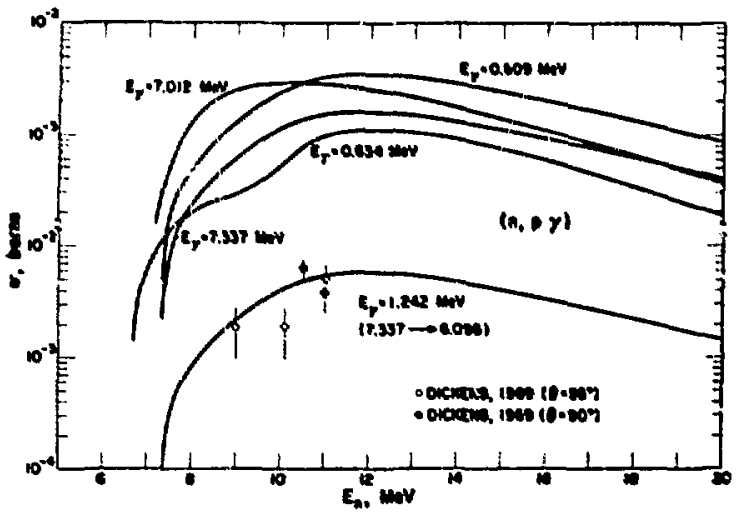

F1g. 47. Evaluated crose aections for vome of the weaker $(n, p Y)$ gawn raye.

3.5 The ${ }^{14} \mathrm{~N}\left(\mathrm{n}_{2} \mathrm{~d}, \mathrm{2}^{13} \mathrm{c},{ }^{14} \mathrm{~N}(\mathrm{n}, \mathrm{d} Y)^{13} \mathrm{c}\right.$, and ${ }^{14} \mathrm{~N}\left(\mathrm{n}, \mathrm{n}^{\prime} \mathrm{pr}\right)$

\section{${ }^{13} \mathrm{C}$ Cross Sections}

The threshols for the ${ }^{14} \mathrm{~N}\left(\mathrm{n}, \mathrm{d}_{0}\right)^{13} \mathrm{C}$ reaction occurs at $5.71 \mathrm{MeV}$. In F18. 48, the evaluated curve lor the $\left(n, d_{0}\right)$ crase section from threshold to 20 fiev is compared to the ayallable measureaneats. The exparimental data of Chase et al. (Ch61) and Benenson and Yaramis (Be63) conelet of ${ }^{13} \mathrm{C}(d, n)^{14} \mathrm{~N}$ measurements that have been converted to ${ }^{14} \mathrm{~N}\left(\mathrm{n}, \mathrm{d}_{0}\right)$ cross sections by means of the reclprocity theorem for nuclear reactions (B152). The single point at 14 MeV is a composite of ${ }^{14} \mathrm{~N}\left(n, d_{0}\right)$ angular-dietribut1on zeasurements by Fessenden and Maxeon (Fe67), Carlson (Ca57), MLljanic et a1. (M168), zatzick and Marson (za63), and Lindsay and Velt (L167). We de-emphasized iln:leay and Yeit's measurewents because they lie roughly a factor of 2 below the othar date. From these messurements, we estinate the $\left(n, d_{0}\right)$ cross section at $14 \mathrm{MeV}$ to be $20 \neq 4 \mathrm{mb}$. A gnooth extrapolation of the evaluated curve was ande from 14 to $20 \mathrm{MeV}$.

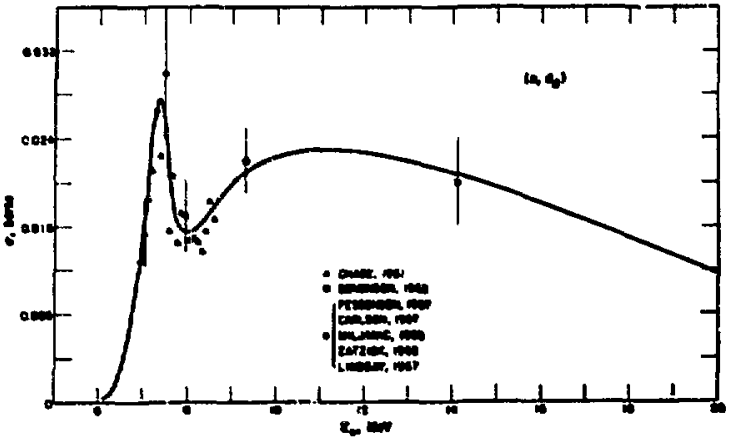

F18. 48. Wanured and evaluared $(n, d)$ croos esctlons to the ground atate of ${ }^{13} \mathrm{C}$. The 14-HeV point is a compoutte of five seaeureanents.

The level-decay sehene for ${ }^{13} \mathrm{C}$, whlch relates tine gamax-ray production resaurcante to the $\left(n_{0} d\right)$ and $(n, n p)$ level-axcitation crose anctionn, is given In F18. 49. We took the level onergien, opina, and parities from the Ajsenberg-Selove (N70) \& - 23-15 energy-level conpllation. Tho branchins ratios are

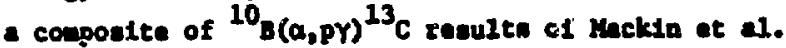
(Ka56), P1xley et al. (P160), and Kane at al. (Ka60), and the ${ }^{12} \mathrm{C}(1, \mathrm{PY})^{13} \mathrm{C}$ renulte of Corodetzky at al. (Go66). Table VII gives a list of the ganan raye that can reault from de-excitation of ${ }^{13} \mathrm{C}$ levels. In this evaluation, we sosuse that lovels in ${ }^{13} \mathrm{C}$ above the $n+{ }^{12} c$ thremold at $4.947 \mathrm{MaV}$ decay entirely by particle calesion. We obtained the total $(\mathrm{n}, \mathrm{d})$ croes section shown in Ffs. 5 by ouming the $(r, d)$ axcitation croses sections for the four atetes given in F18. 49.

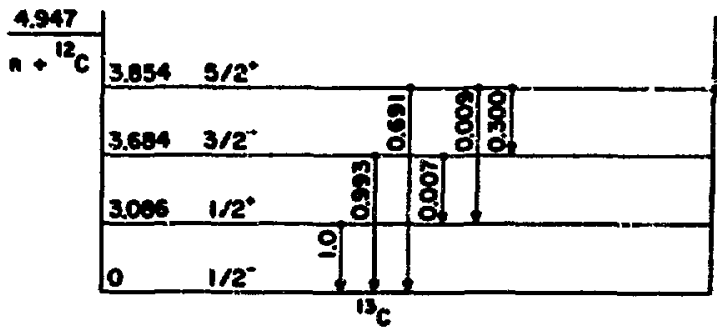

F18. 49. Dexey schene for ${ }^{13} \mathrm{~g}$ uaed in Interpreting the $(n, d \gamma)$ and $(n, n p y)$ ctous sectioas. Hote that the exersy scele is sroushy distorted. 
TABLE VII

Gavey BAYS FROH ${ }^{14} \mathrm{~d}\left(\mathrm{xl}_{\mathrm{i}}, \mathrm{d}\right)^{13} \mathrm{c}$ AND ${ }^{14} \mathrm{~N}(\mathrm{n}, \mathrm{np})^{13} \mathrm{C}$ REACTIONS

\begin{tabular}{|c|c|c|}
\hline 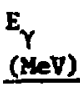 & $\begin{array}{c}E_{\text {Initial }} \\
\text { (KeV) }\end{array}$ & $\begin{array}{r}E_{\text {final }} \\
(\mathrm{HeV}) \\
\end{array}$ \\
\hline $\begin{array}{l}3.854 \\
3.684 \\
3.086\end{array}$ & $\begin{array}{l}3.854 \\
3.684 \\
3.086\end{array}$ & $\begin{array}{l}0 \\
0 \\
0\end{array}$ \\
\hline 0.68 & $\left\{\begin{array}{l}3.854 \\
3.684\end{array}\right.$ & $\left.\begin{array}{l}3.086 \\
3.086\end{array}\right]$ \\
\hline 0.170 & 3.854 & 3.684 \\
\hline
\end{tabular}

In evalunting the $(n, x y)$ crose section, one wet realize thet levela in ${ }^{13} \mathrm{C}$ can be excited by $(n, n p)$ reactiose as well a by $\left(n_{0}, d\right)$ reactions. To eatinnte the $(\mathrm{n}, \mathrm{d})$ arcication crose sections, we assued that the ahapes of the excttintion crecs aectlone vere elatler to $(n, p)$ croes sectione for alIlar Q-values, a calculated ustas compound-nucleus renction theory (Appoudix A). We then nortallat these calculated shapas so shat they resulted in $(n, x y)$ crose sectione that agreed with neasuresents around 10 key. Nithough the threshold for the (n,Dpr) reaction is $9.02 \mathrm{MVV}$, ubbetatinl contributions froe this cource are not expected for an MV or so above the threobold.

the eatimated the excitetion of ${ }^{13} \mathrm{C}$ levele through $(n, n p)$ renctions by rouphly dividing the $\left(n, n^{\prime}\right)$ crose section to particle-inntable levels in 14 sons the various atates that can be reached in 13. (awotron ateion), ${ }^{13} \mathrm{c}$ (proton miesion), ${ }^{12} \mathrm{c}$

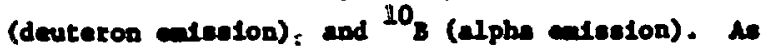
desertbed in Sec. 3.3.3, wa ade this celculation anmintas the decay protsbllitles to be proportionsl to $(2 s+1)(2 J+1) \Delta t_{c}$, where the oybole have the ereve venting at in Sec. 3.3.3. We then normallzed the rewulting ( $n, n_{p}$ ) excitation functions for the three excled levels of ${ }^{13} \mathrm{C}$ by a compa factor $(\sim 0.8)$ so thet the wor of the $(n, d)$ and $(n, n p)$ excltation crove sectione renuled in $(n, x y)$ crose eectlone that agreed better with mavaurements near 14 HeV, where the (n, npY) coneributione are dontnant.

Plgure 50 showe the reoults of thlo annilyse for the $\left(n_{0} d_{1}\right)$ crose enction and for the $(n, 2 y)$ crose eaction for the 3.006 -ith gere ray, the ra-

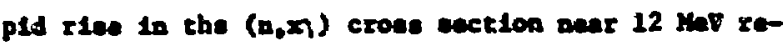
cults fron the ( $n$, np $)$ contribution. The dieagrear-

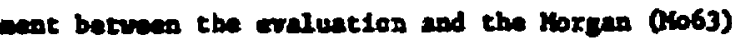

and Buchanan (Bu69) experimental rasults In FIg. 50 1s largely ellainated by the recentily reviaed TiC compliation (Bu71). The new reault, which aupersedes the older data, is $14 \mathrm{mb}$ at $14.8 \mathrm{KeV}$, In reasomble agrecent with the $18 \mathrm{ab}$ evaluated reault.

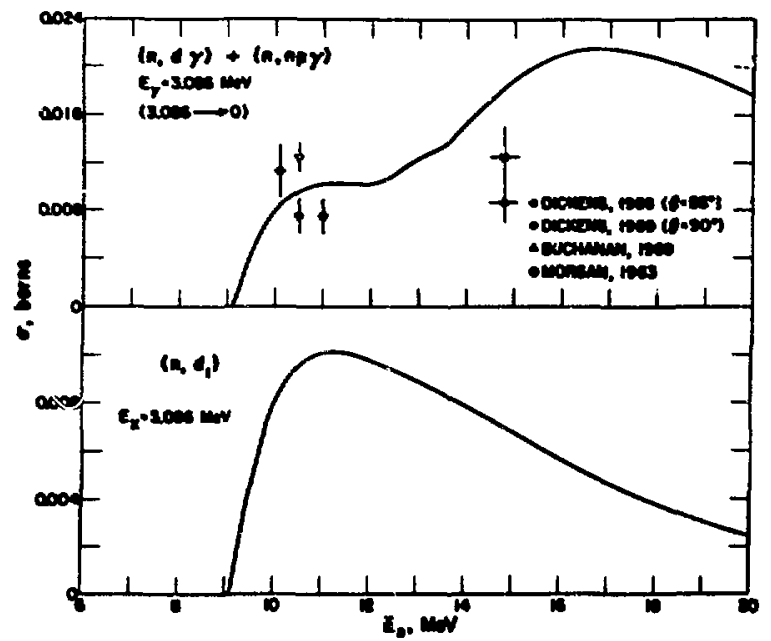

718. 50. Evaluated $\left(n_{1} d_{1}\right)$ crose ection and the photon-production date for the 3.086-itev photon. The rias in the upper curve above 12 unV 1a die to the (n,npY) contribution cu the saie gentention. The lover curve has it calculated ehape normatIred to the photun-production mesurements below the effective $\left(n, n^{\prime} p y\right)$ threahold.

The resulte of our anilyale for the $\left(n_{1} d_{2}\right)$ axcitntion crous section to the 3.684-iteV level and the $\left(n, x_{1}\right)$ crose ecction fur the 3.684-Mv photon are glven in Fis. 51. Again, the rise In the $(u, x y)$ crose section near \$2 MV is due to contributtons frow ( $n, n p Y)$ reactsons. The craluuted curve and the weneurente agree reasonbly well.

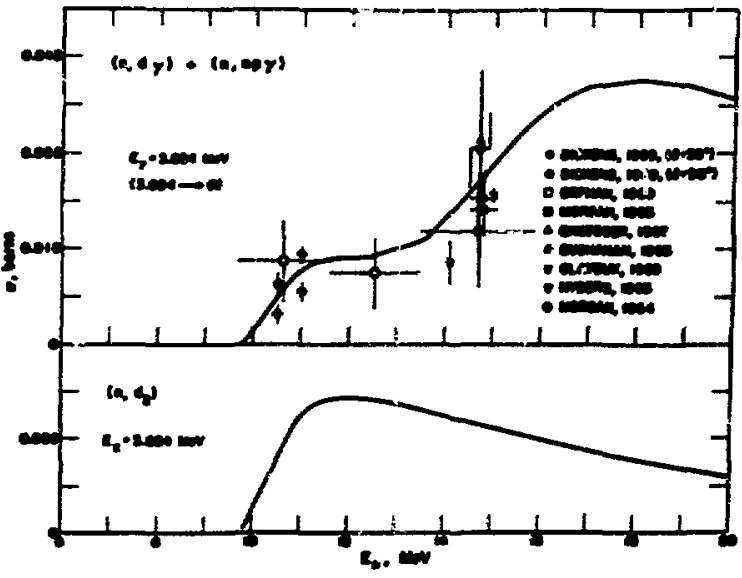

F19. 51. Bualuated $\left(n_{0} d_{2}\right)$ crose enction and the photon-production date for the $3.684-1 i v y$ photon. (See ception to F1s. 50, 
The $\left(n, d_{3}\right)$ cross eection to the 3.854- $\mathrm{HeV}$ level and the $(n, x y)$ cross section for the 3.854-MeV 11re are given in Fig. 52 . The evaluated $(n, x y)$ curve ancl the measurements again agree reasonably well. The sum of our evaluated $\left(n, d_{2}\right)$ and $\left(n, d_{3}\right)$ crosa gectlous $(20 \mathrm{mb})$ agrees well with a rough estimate of this cross saction (15 to $25 \mathrm{mb}$ ) from $\left(n, d_{2}\right)+$ $\left(n, d_{3}\right)$ partial angular distribution measurements by Fessenden and Maxson (Fe67), Zatzick ard Maxson (Za63), and Carlson (Ca57).

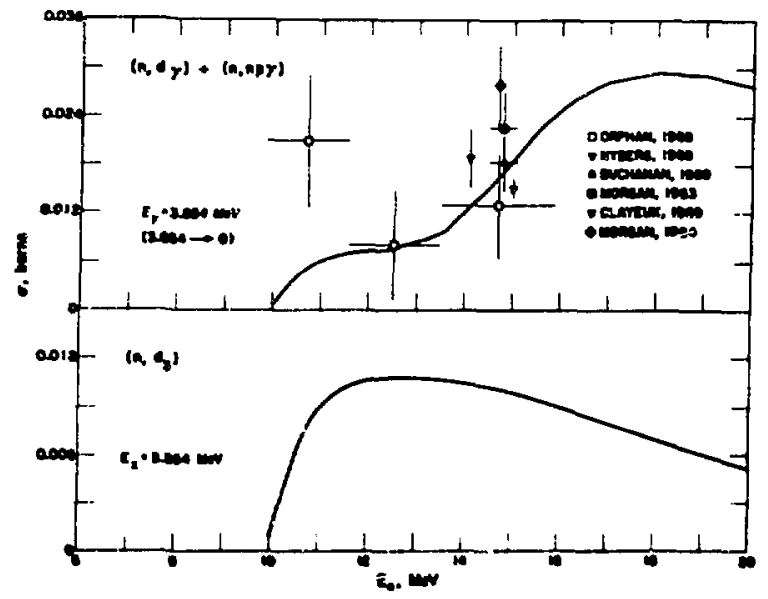

Fig. 52. Evaluated $\left(n, d_{3}\right)$ crosa section and the photoo-production data for the $3.854 \mathrm{MeV}$ photon. (See Caption to Fig. 50.)

The photon-production crose sections for photone of 0.170- and 0.68-5eV energy are given In FIg. 53. The latter is a conposite of 3.684- $\rightarrow 3.086-\mathrm{keV}\left(\mathrm{E}_{\gamma}=\right.$ $0.598 \mathrm{MeV})$ and $3.854-\rightarrow 3.086-\mathrm{HeV}\left(E_{Y}=0.768 \mathrm{keV}\right)$ transitions. In each casa, we conputed the $(n, x y)$ crose sections from the evaluated level-excitation erciss sections.

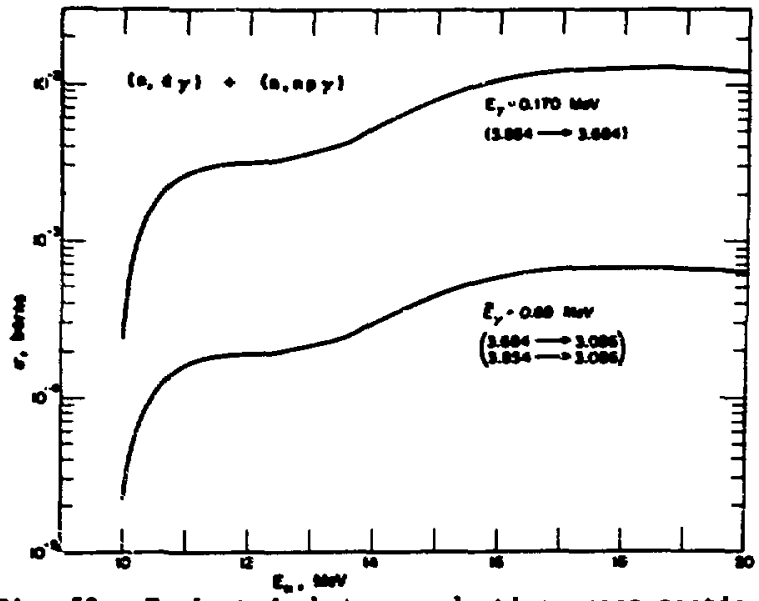

F1s. 53. Evaluated photon-production crose sections for the low-energy gane rays from cascades in $13 \mathrm{C}$, as reconstructed from the level-excitation crose sections.
3.6 The ${ }^{14} \mathrm{~N}(n, t){ }^{12} \mathrm{C}$ and ${ }^{14} \mathrm{~N}(\mathrm{n}, t \gamma)^{12} \mathrm{C}$ Cros B Sections The threshold for the ${ }^{14} N\left(n, t_{0}\right)^{12} c$ reaction occurs at $4.304 \mathrm{MeV}$. The evaluated curve for the $\left(n, t_{0}\right)$ reaction 18 compared to the avallable measurements in Fig. 54. Considering the uncertainties associated with the Gabbard et al, (GaS9) and Scobel et al. (Sc66) measurenenta, the agreement between the experimente is zeasonable. The open triangle at $14.5 \mathrm{MeV} 1 \mathrm{~s}$ our evaluated result $(6.5 \pm$ $1.3 \mathrm{mb})$, based prinarily upon $\left(n, t_{0}\right)$ angular-distribution measurements by Fessenden and Maxson (Fe67) and Rendic (Re67); we also considered LIndeay and Velt's (L167) aeasurement. but it is a factor of 2 lower than the other results.

Also shown in F1g. 54 1a the evaluated curve for the ${ }^{1 i_{N}} \mathrm{~N}\left(n_{0} t_{1}\right)$ reaction to the $4,439-\mathrm{HeV}$ state in ${ }^{12} \mathrm{C}$. The curve is baned upon a compound-nucleus reaction-theory calculation for the $(n, p)$ reacition with a eimilar Q-value (see Appendix A) shich ha been normalized to our evaluntad reeult et $14.5 \mathrm{kgV}$. The eotinated crose uection et $14,5 \mathrm{MeV}$ for the $\left(n, t_{1}\right)$ reaction to $21 \pm 7 \mathrm{~b}$, baend on the Feesenden (Fa67) and Rendic (Re67) meanuremente.

The only particle-stable axcited state in ${ }^{12} \mathrm{C}$ 1s the 4.439-kav level, which decaye entirely by genan-ray entasios co the ground atate of ${ }^{12} \mathrm{C}$. The germe-ray production czose eection for the 4.439MeV line is given In FLg. 55, We obtalned the curve frow the evaluated ${ }^{14} N\left(n, t_{1}\right)^{12} c^{\star}$ crose section and frow an eatiate of the ${ }^{14} \mathrm{~N}\left(n, n^{\prime} d\right)^{1 ?} c^{\star}$ crose section to the firet exclted state if ${ }^{12} \mathrm{C}$. We ande the latter eatinate in the anner described in Sec. 3.5 for the $\left(n, n^{\prime} p Y\right)$ reactions. We obtained the evaluated total $(n, t)$ cross section by sumaing the $\left(n, t_{0}\right)$ and $\left(n, t_{1}\right)$ contributione.

3.7 The ${ }^{14} \mathrm{~N}(\mathrm{n}, x)^{11_{\mathrm{B}}}$ and ${ }^{14} \mathrm{~N}(\mathrm{n}, 0 \mathrm{x})^{11_{\mathrm{B}}}$ Crose sections: The threahold for the $\left(n, \alpha_{0}\right)$ resction occurn at $0.168 \mathrm{HeV}$; the $\left(n, a_{0}\right)$ reaction does not becone algaificant, however, unt1l bove $1.2 \mathrm{keV}$. The evaluated $\left(n, \alpha_{0}\right)$ crose rection fros 1 to $7 \mathrm{MeV}$ is compared to the avallable mensuremente in F18. 56. The curve is based anly on meavurements by Johnson and Barschall (JoSO) at lower energles and on the results of Gabbard et al. (GaS9) at higher energies. The results of haddad (HaS9a) and Manl and Dutt (Ma66) were obtained from mensurenents of the Inverse ${ }^{11_{B}}(a, n)^{14} \mathrm{~N}$ reaction, uaing the reciprocity 


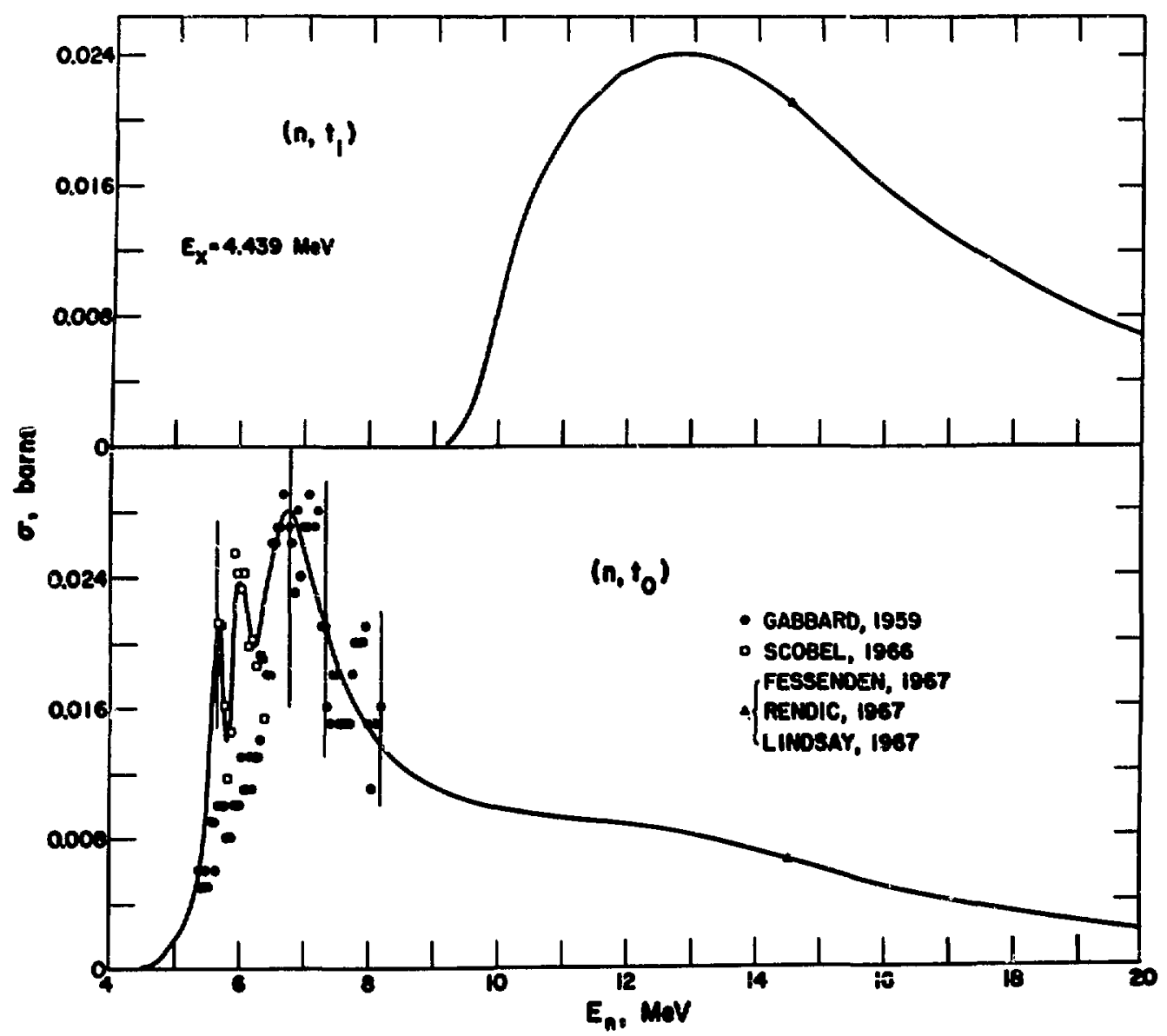

F18. 54. Measured and evaluated $(n, t)$ cross sections to the ground and first excited atates of 12 c.

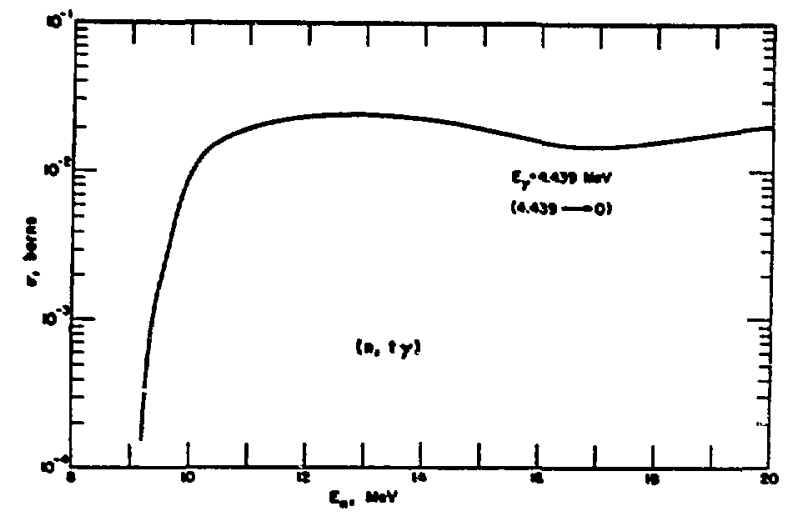

Fig. 55. Evaluated cross section for the photon decay of the firat excited atate in $12 \mathrm{C}$ following $(n, t)$ and $\left(n, n^{\prime} d\right)$ reactions. theorem (B152). As was the case with $\left(n, p_{0}\right)$, we obtained the shape of the $\left(n, \alpha_{0}\right)$ curve over many of the sharper resonances from a Breit-Wigner expresslon, using the resonance energy and width from the total-cross-section analysis and normalizing to the peak area in the $\left(n, \alpha_{0}\right)$ measurements. We used a similar treatment for several peaks in the $\left(n, \alpha_{1}\right)$, $\left(n, \alpha_{2}\right)$, and $\left(n, \alpha_{3}\right)$ reactions described below.

The $\left(n, \alpha_{0}\right)$ cross section from 7 to $20 \mathrm{MeV} 18$ given in Fig. 57. The open triangle at $14.5 \mathrm{MeV} 1 \mathrm{~s}$ the result of our evaluation of $(n, \alpha)$ experiments by Lillie (L:5.2), Leroux et al. (Le68), BachInger and Uhl (Ba68), and Maxson and Murphy (Ma68). L111le's measurement was made with a cloud-chamber, the Leroux and Bachinger data were obtained with nuclear emulslons, and the Haxson measurement emp. uyed a counter telescope. The four measurements do not agree well over the entire spectrum, and our results are a composite of the four, taking into account to a Iimited 


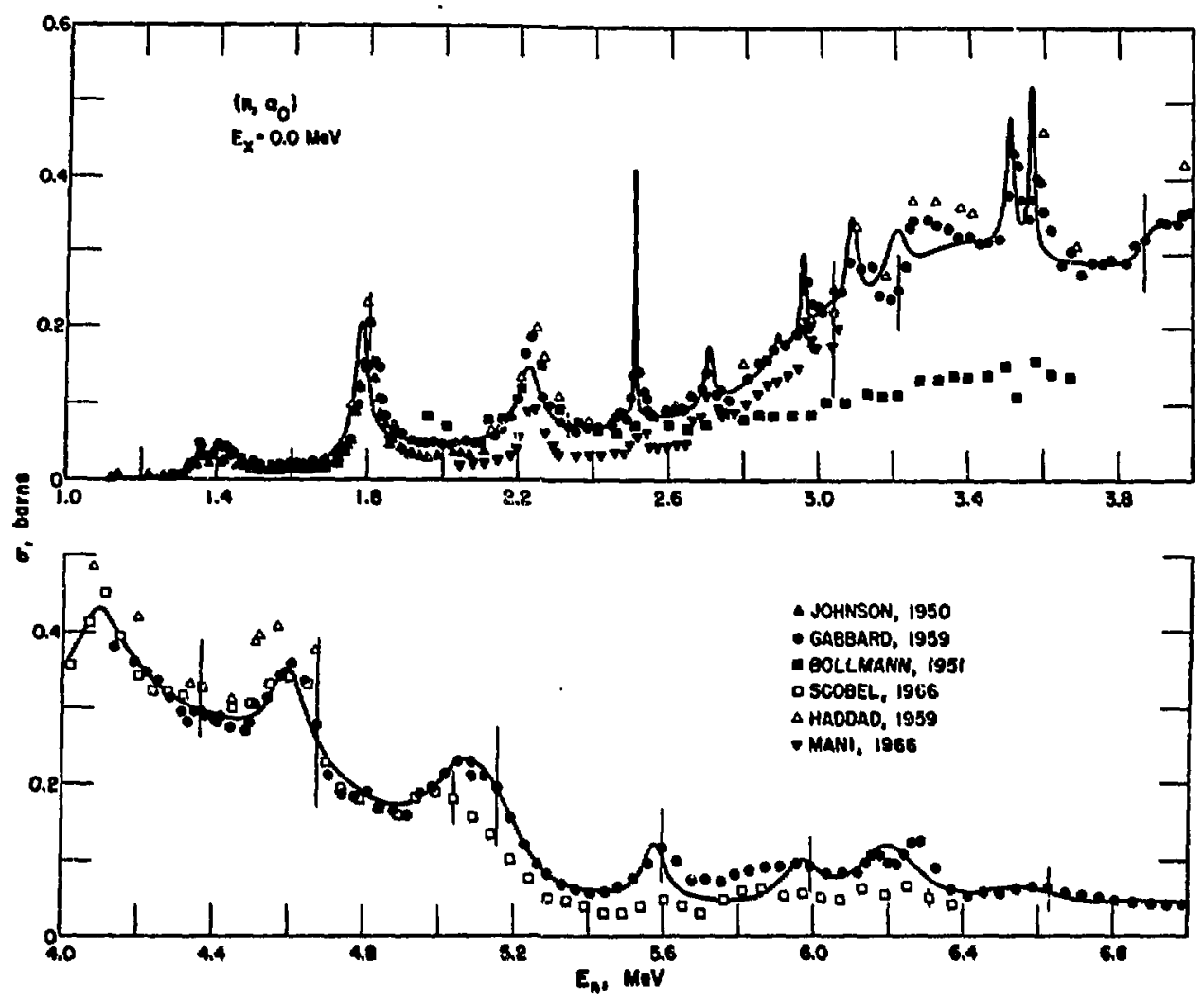

Fig. 56. Measured and evaluated $\left(n, \alpha_{0}\right)$ cross gections from 1 to $7 \mathrm{MeV}$. The resonance energies and total widths for many of the resonances are taken from the total cross section.

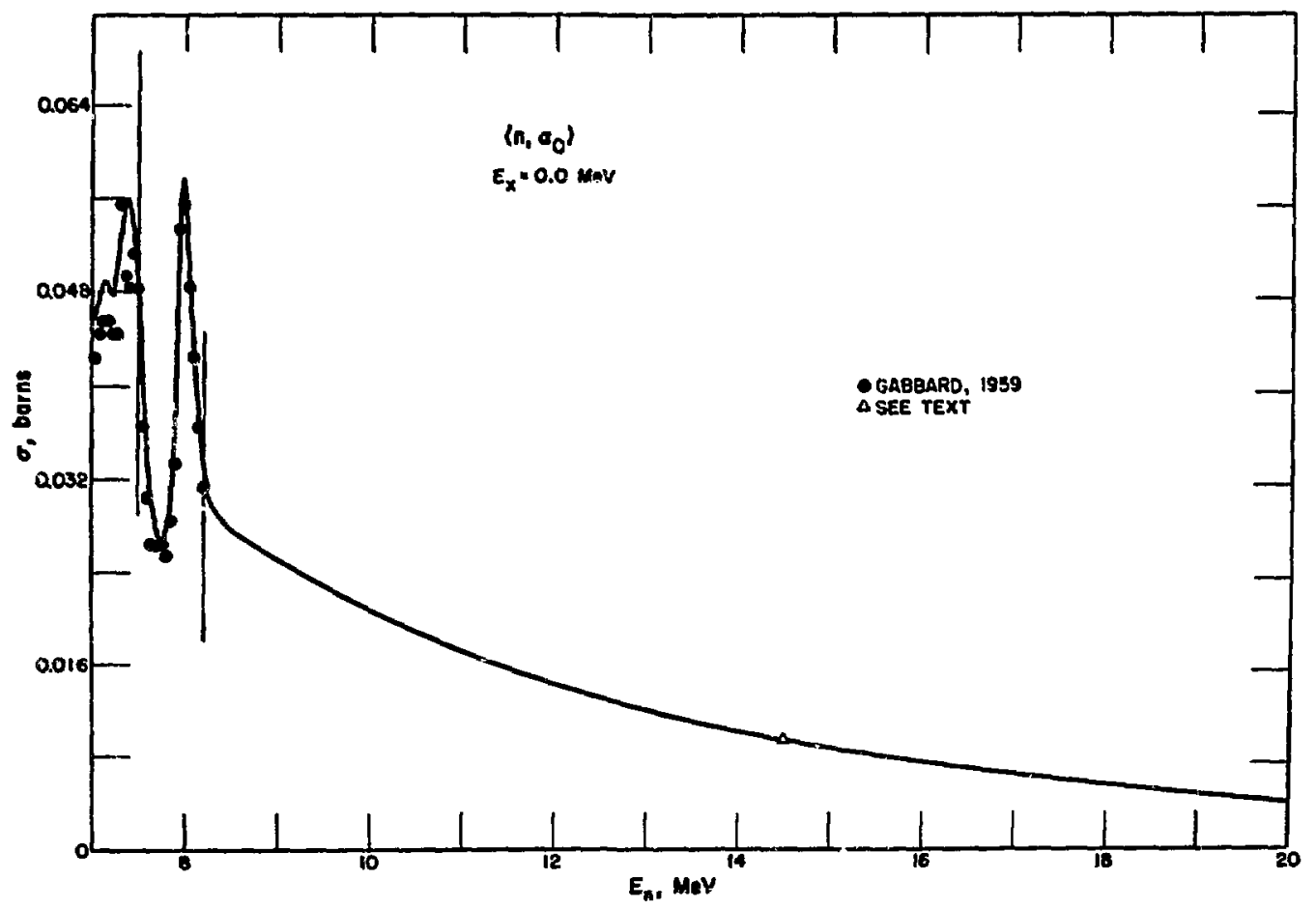

Fig. 57. Measured and evriluated $\left(n, \alpha_{0}\right)$ cross sections from 7 to $20 \mathrm{MeV}$. The triangle at $14 \mathrm{MeV}$ is a composite of four measurements? 
extent the $(n, \alpha \gamma)$ measurements described below. Lillie cltes a value of $100 \mathrm{mb}$ for the integrated $(n, \alpha)$ cross section (L152), whereas Leroux et al, give $60 \mathrm{mb}$ (Le68). Our evaluated spectrum is normalized to $92.5 \mathrm{mb}$ at $14.5 \mathrm{MeV}$. There are no available measurements for the $\left(a, \alpha_{0}\right)$ cross section between 8.2 and $14 \mathrm{MeV}$; we based the shape of the evaluated curve In this region upon the compound-aucleus reactiontheory calculations described in Appendix A. The curve was extrapolated smoothly from 14.5 to $20 \mathrm{MeV}$. The decay scheme for ${ }^{11} B$, which relates the $(n, \alpha \gamma)$ measurements to the $(n, \alpha)$ level excitation cross sections, is given In Fig. 58. The level energies, spins, and parities come from the $A=11$ to 12 energy-level compllation by Ajzenberg-Selove and Lauritsen ( $1 \mathrm{j} 68$ ). The branching ratios that are included in the compilation were obtained mainly

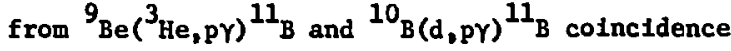
measurements by 01 ness et al. (0165).

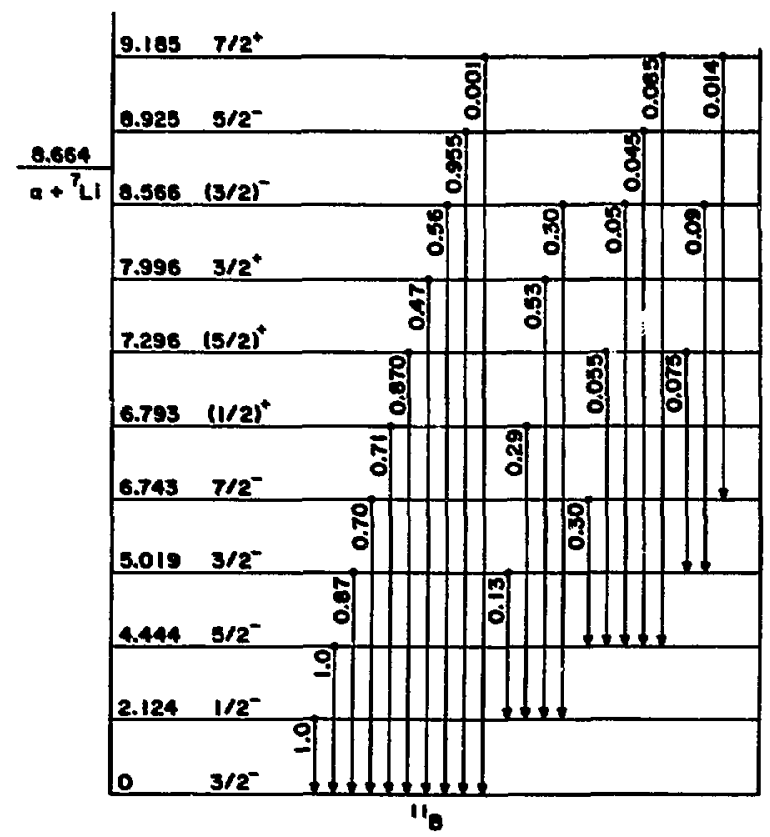

Fig. 58, Decay scheme for ${ }^{11_{B}}$ used in interpreting the $(n, a \gamma)$ measurements.

The probabilittes for gamma-ray emlsotion from the 8.925-MeV level (100\%) and the 9.185-MeV level (10x) are also from the 01ness measurements; all known higher levels have total widths in the keV range and do not decay olgnificantly by gama ray emission. Table VIII sumarizes the gawa-ray tran- sitions that appear in the evaluation; some of the weaker transitions have been combined, as indicated.

TABLE VIII

GAMA RAYS FROM ${ }^{14} \mathrm{~N}(n, \alpha){ }^{11_{B}}$ REACTIONS

\begin{tabular}{|c|c|c|}
\hline $\begin{array}{l}\mathrm{E}_{\mathrm{Y}} \\
(\mathrm{MeV})\end{array}$ & $\begin{array}{c}E_{\text {Inftial }} \\
(\mathrm{MeV}) \\
\end{array}$ & $\begin{array}{r}E_{\text {fInal }} \\
(\mathrm{MeV}) \\
\end{array}$ \\
\hline 8.925 & $\left\{\begin{array}{l}9.185 \\
8.925\end{array}\right.$ & $\left.\begin{array}{l}0 \\
0\end{array}\right\}$ \\
\hline 8.566 & 8.566 & 0 \\
\hline 7.996 & 7.996 & 0 \\
\hline 7.296 & 7.296 & 0 \\
\hline 6.77 & $\left\{\begin{array}{l}6.793 \\
6.743\end{array}\right.$ & $\left.\begin{array}{l}0 \\
0\end{array}\right\}$ \\
\hline 6.442 & 8.566 & 2.124 \\
\hline 5.872 & 7.996 & 2.124 \\
\hline $\begin{array}{l}5.019 \\
4.65 \\
4.444\end{array}$ & $\begin{array}{r}5.019 \\
9.185 \\
6.793 \\
8.925 \\
4.444\end{array}$ & $\left.\begin{array}{c}0 \\
4.444 \\
2.124 \\
4.444\end{array}\right)$ \\
\hline 3.800 & $\left\{\begin{array}{l}8.566 \\
8.566\end{array}\right.$ & $\left.\begin{array}{l}4.4441 \\
5.019\end{array}\right\}$ \\
\hline 2.895 & 5.019 & 2.124 \\
\hline 2.852 & 7.296 & 4.444 \\
\hline 2.30 & $\left(\begin{array}{l}9.185 \\
6.743 \\
7.296\end{array}\right.$ & $\begin{array}{l}6.743 \\
4.444 \\
5.019\end{array}$ \\
\hline 2.124 & 2.124 & 0 \\
\hline
\end{tabular}

The evaluated curves for the $E_{\gamma}=2.124 \mathrm{MeV}$ $(n, \alpha \gamma)$ cross section and the ${ }^{14} N\left(n, \alpha_{1}\right)^{11_{B}{ }^{*}}$ cross section to the $2.124-\mathrm{MeV}$ level are compared to the avallable measurements for $E_{\mathfrak{n}}=4-7 \mathrm{MeV}$ in FIg. 59 . Although there is some cascading to the $2.124-\mathrm{MeV}$ level, the $(n, a \gamma)$ cross section for the ground-state transition is mainly determined by the $\left(n, a_{1}\right)$ excitation cross section. Therefore, the comparison Given in Fig. 59 provides a check on two entirely Independent sets of experimental data, 1.e., the $(n, \alpha r)$ and the $(n, \alpha)$ measurements. The agreement is reasonable considering the error bars on the measurements and gives us confidence in both sets of data.

The same results are given In Fig. 60 for the 7- to 20-MeV neutron-energy region. The open triangle at $14.5 \mathrm{MeV}$ in the lower half of the figure again results from our evaluation of the $(n, \alpha)$ spectru $L$ and cross section from four measurements (L152, $I_{1} 668$, Ba68, Ma68). The overall consistency in the two parts of Fig. 60 ls reasonable, although Hall and Bonner's $(n, a \gamma)$ data (Ha59) are lower than the 


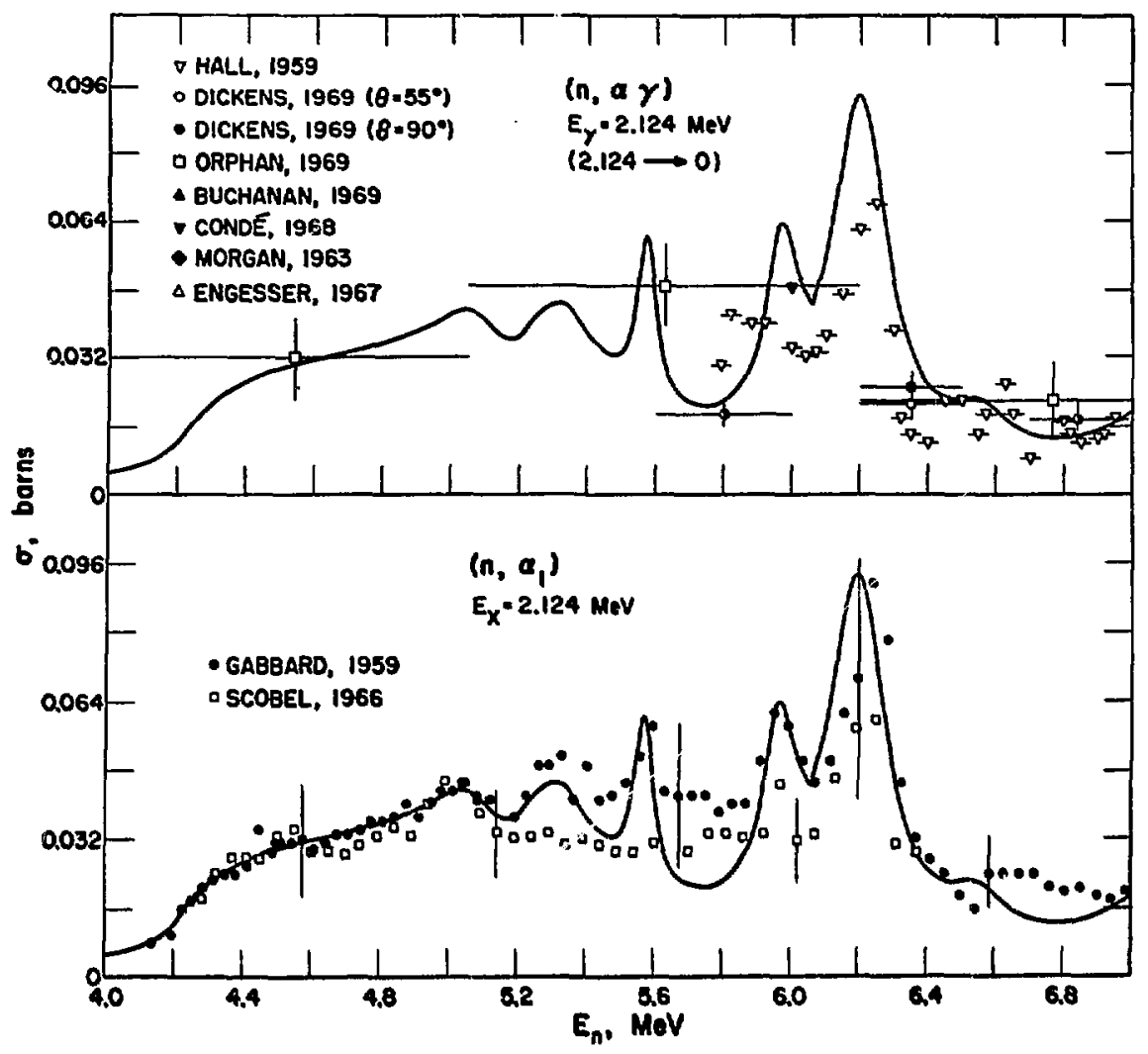

Fig. 59. Neasured and evaluated $\left(n, \alpha_{1}\right)$ and $(n, \alpha y)$ croos aections for the $2.124-$ MeV level and ground-gtate transition for neutron energies between 4 and $7 \mathrm{MeV}$.

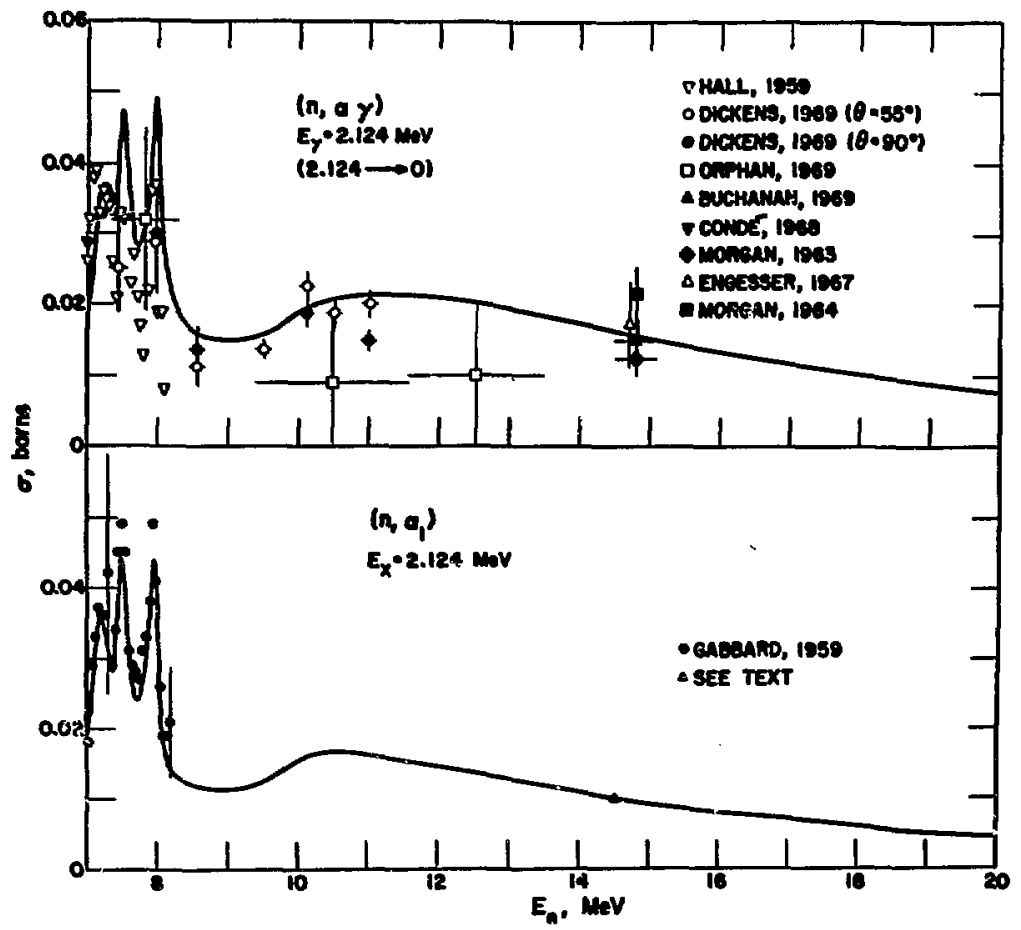

Fig. 60. Measured and evaluated $\left(n, \alpha_{1}\right)$ and $(n, \alpha \gamma)$ cross sections for the 2.124-MeV level and ground-8tate transition. The $14.5-\mathrm{MeV}\left(\frac{1}{n}, \alpha_{1}\right)$ datum is a composite of four measurements. 
evaluation near $8 \mathrm{MeV}$. Further, the new INC compilation (Bu71) glves a value of $30 \mathrm{mb}$ for the $(n, \alpha y)$ cross section at $14.8 \mathrm{MeV}$, compared to their old value of $15 \mathrm{mb}$ (Bu69) and our evaluated result of 16 mb. The measurement by Maslov et al. (Ma68a) for the sum of the 2.124- and 2.313-MeV photons gives a value at $14 \mathrm{MeV}$ that agrees well with the evaluated results.

$$
\text { The }{ }^{14} \mathrm{~N}\left(\mathrm{n}, \alpha_{2}\right)^{11_{\mathrm{B}}} \text { eross section for the 4.444- }
$$

MeV level and the photon production cross section for the 4.444-MeV photon are given in F1g. 61. The dashed curve in the upper half of the f1gure results if the ${ }^{14} \mathrm{~N}(\mathrm{n}, \mathrm{t}, \mathrm{)})^{12} \mathrm{C}$ crose section for the 4.439-MeV game ray is added to the $E_{\gamma}=4.444-\mathrm{MeV}$ cross section. Because these IInes ilffer in energy by only $5 \mathrm{keV}$, they are undoubtedly unresolved in the NaI gamma-ray measurements and are probably unresolved in the Ge(L1) measurements. The open triangle at $14.5 \mathrm{MeV}$ in the lower half of Fig. $61 \mathrm{rem}$ sults from our evaluated opectrum, as described ear- 1ier. The reasonable consistency between the $(n, \alpha)$ and the $(n, a y)$ measurements in Fig. 61 gives us confidence in the branching ratios involved. The fact that the dashed curve rises above the $(n, x y)$ measurement of Dickens and Perey (Di69) near $11 \mathrm{MeV}$ probably Indicates that elther our $\left(n, \alpha_{2}\right)$ cross section or our $\left(n, t_{1}\right)$ cross section to the $4.439-\mathrm{MeV}$ level of ${ }^{12} \mathrm{C}$ is too high in this energy region. We did not discover this inconsistency until the evaluation was completed.

The ${ }^{14} N\left(n_{2} \alpha_{3}\right)^{11}{ }_{B}^{*}$ cross section to the 5.019HeV level and the $(n, a r)$ cross section for the 5.019-MeV photon are given in F1g. 62. We have corrected the $\left(n, \alpha_{3}\right)$ measurements by Gabbard et al. (Ga59) for contributions from the $\left(n, d_{0}\right)$ and $\left(n, p_{1}\right)$ reactions which were not resolved in their experiment. The open triangle at $14.5 \mathrm{MeV}$ in the lower part of Fig. 62 is from our evaluated spectrum. The 5.019- $\mathrm{HeV}$ gamma ray has not been observed in measurements with $\mathrm{Ge}(\mathrm{LI})$ detectors. This is prob-

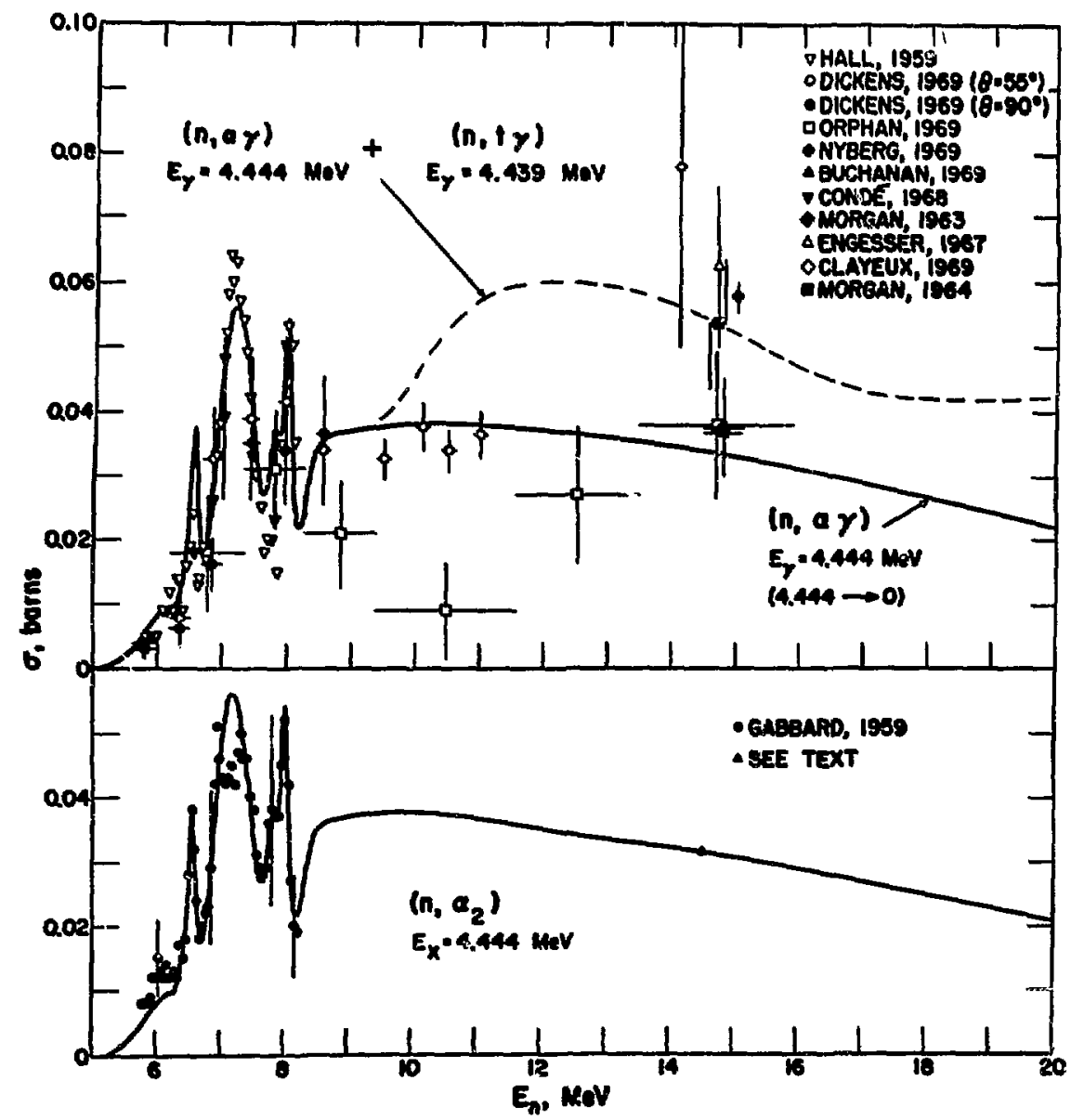

FIg. 61. Heasured and evaluated cross sections for the $\left(n, a_{2}\right)$ ari $(n, 0 \gamma)$ cross sections for the $4.444-\mathrm{NeV}$ level and ground-state transition. The dashed curve includes a contribution from the 4.439-MeV $(n, t \gamma)$ photon. 
ab?y because of Doppler broadening of the gawma rays from the 5.019 $\rightarrow 0-\mathrm{MeV}$ transition, to the extent that they are not observed as peaks in high-resolution Ge(Li) spectra. Th1s broadeiling is too small to affect poorer-resolution NaI or CaI measurements seriously, and we have included the $(n, x y)$ data from these measurements in the upper part of Fig. 62. These results should be compared to the upper evaluated curve, which includes the $\left(n, n^{\prime} \gamma\right)$ cross section for the 5.106-MeV photon, because the 5.106and 5.019-MeV photons are not reaolved in the poorer-resolution measurements.

Reynolds et al. (Re70) have suggested that the "missing" $200 \mathrm{mb}$ in the nitrogen discrepancy near 8 MeV (see Sec. 3.10) might be partially accounted for by the $\left(n_{1} a_{3}\right)$ channel. The results in $\mathrm{H} i_{8} .62$ indicate that the $\left(n, \alpha_{3}\right)$ cross saction can be increased by no more than 20 to $30 \mathrm{mb}$ and atill be consistent with the $\left(n, \alpha_{3}\right)$ and $(n, \alpha \gamma)$ measurements near $8 \mathrm{MeV}$. The evaluated curves and the measurementa in Fig. 62 agree reasonably well. However, the new
TNC compilation (Bu71) quotes an $(n, x y)$ cross sectIon at $14.8 \mathrm{MeV}$ which falls near the Engesser and Thompson (En67) point. Because this new result supersedes the older TNC measurements (Mo63, Mo64, Bu69), the evaluated composite $(n, x y)$ cross section is possibly a little low near $15 \mathrm{MeV}$. Also, the Maslov et al. (Ma69a) measurement at $14 \mathrm{MeV}$, which was inadvertently omitted from the graph, supports a higher cross section in this region.

The evaluated $(n, \alpha)$ level-excitation cross sections for the 4th through 10 th excited levels of ${ }^{11} B$ are given in Fig. 63. We obtained the curves for all levels except those at 8.925 and $9.185 \mathrm{MeV}$ by normalizing the compound-nucleus reaction-theory calculations described in Appendix A to our evaluated spectrum at $14.5 \mathrm{MeV}$ (open triangles). For the cross section to the 8.925- and 9.185-MeV levels, we normalized the calculations by the same factor rer lired for the 8.566-MeV-1evel cross section, becauas estimates for the 8.925- and 9.185-MeV contributions were not ubtained from the spectrum measurementa.

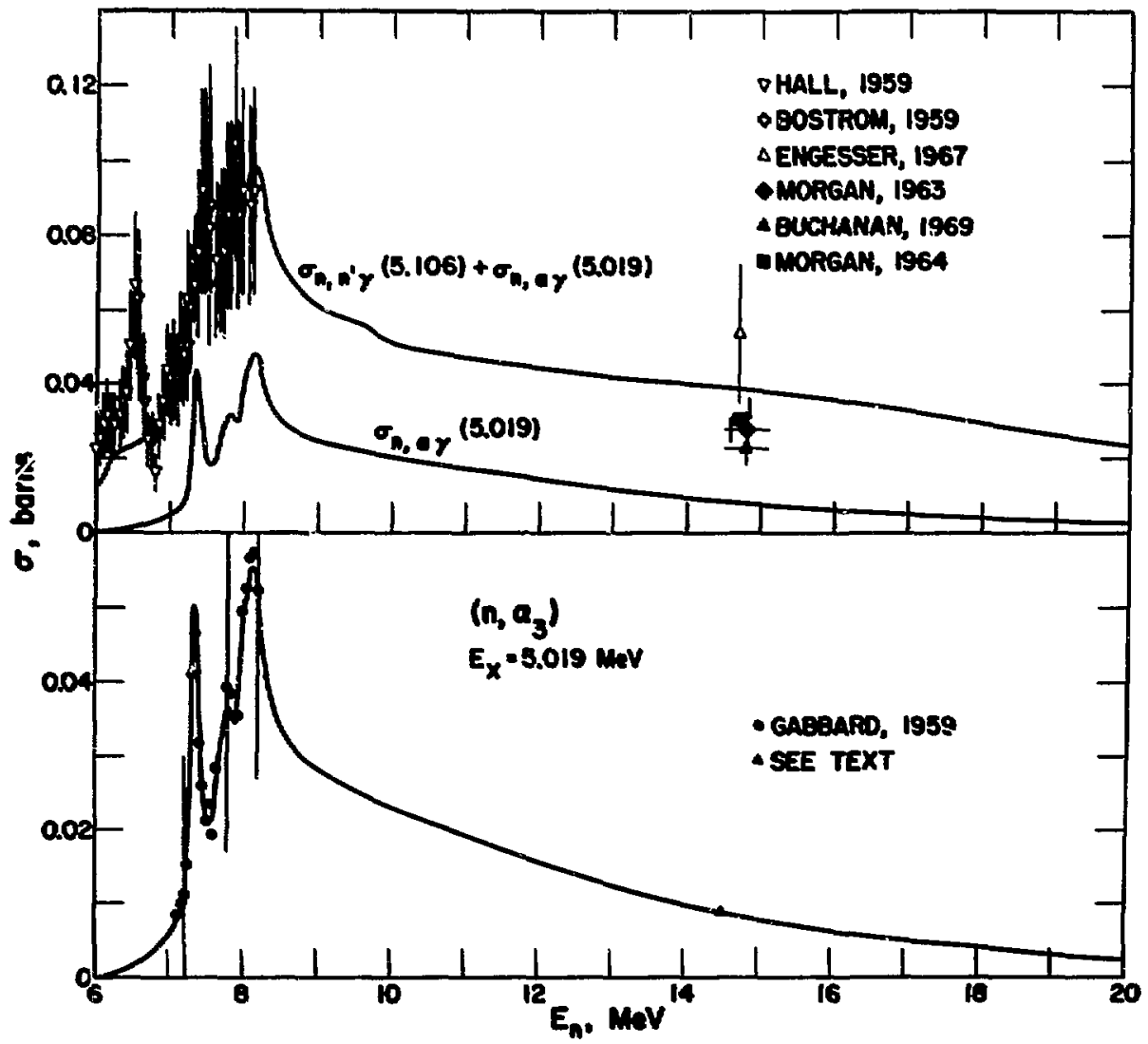

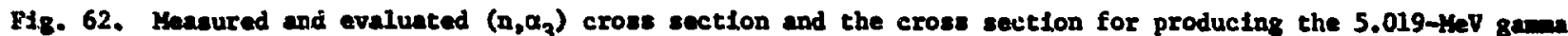
ras fron this renction. The conbined photon-production cross section for the 5. 019- and 5.106-14V photon: is compared to the available kaI mesureaents in the upper part of the figure. 
The ${ }^{14} N(n, \alpha y)^{11} B$ cruss sections that result from excitation of the higher levels in ${ }^{11_{B}}$ are given in Figs. 64 and 65. We obtained the evaluated curves from the foregoing estimatee of the leve:-excitation cross sections using the ${ }^{11_{B}}$ decay scheme given in Fig. 58. Although the existence of these gamma rays Is implied by alpha-spectrum measurements at 14.5 MeV (L152, Le68, Ba68, Ma68), the only direct observation ${ }^{*}$ of the higher-energy photons given in FIg. 65 occurred in an integral experiment by Reynolds and Sperling ( $\operatorname{Re} 71$ ), in which gamma-ray spectra vere measured in a large rank of Ilquid nitrogen pulsed wth 14teV neutrons. Broad penks in the unfolded

*Maslov et al. (Ma68a) report a 9.1-MeV photon at E = 14.1 MeV with a cross section of $8 \pm 4 \mathrm{mb}$ which mighe correspond to the $8.925-\mathrm{KeV}$ line in FIg. 65 . spectrum from this neasurement are probably due to the 6.77-,7.296-, 7.996-, 8.566-, and 8.925-HeV photons indicated in Fig. 65.

We obtained the evaluated total $(n, a)$ cross section In FIg. 5 (Sec. 2) by suning the level-excitation cross sections for the ground and firat 10 excited states of ${ }^{11} 1_{B}$. The excitation cross sections co higher levels in ${ }^{11}$ B are Included in the $(n, 2 \alpha)$ cross section, because these levels decay uninly by alpha emission.

3.8 The ${ }^{14} N(n, 2 a)^{7} L_{1}$ Cross Section

The only experimental data avaflable on the $(n, 2 \alpha)$ cross section are the cloud-chwber meauremente by L1111e (Li52) and Möener et al. (Ho65).

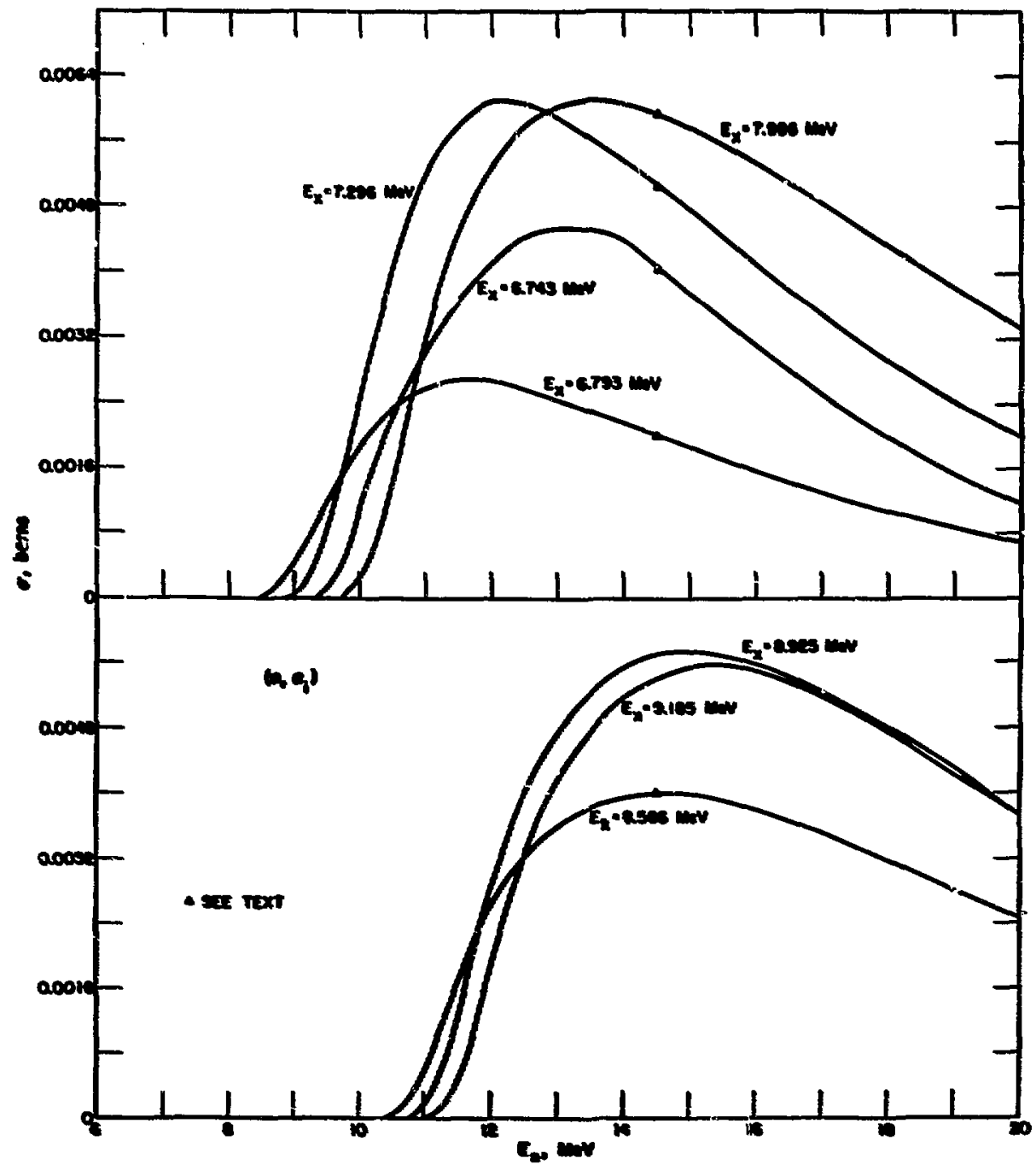

Fis. 63. Draluated croes acctions for the $\left(n, a_{4}\right)$ through $\left(n, a_{9}\right)$ renctions. 
The experinental results are compared with our curve In F18. 66. We crudely estimated the shape of tha curve to $16 \mathrm{MeV}$ by calculating (Appendix A) the contribution fron $(n, a)$ reactions to known states in ${ }^{11}$ B above 9.2-MeV excitation energy relative to the coatrfbution fros states below $9.2 \mathrm{KeV}$, and then applied this ratio to our total $(n, a)$ cross section.
The absolute value of tie calculated curve agreed better with the Mosner (Kob7) datum than is indicated in Fig. 66. We decided, however, to compronise the evaluated curve between the two measurenenta. Above $16 \mathrm{KeV}$, we ade a sooth extrapolation of the curve.

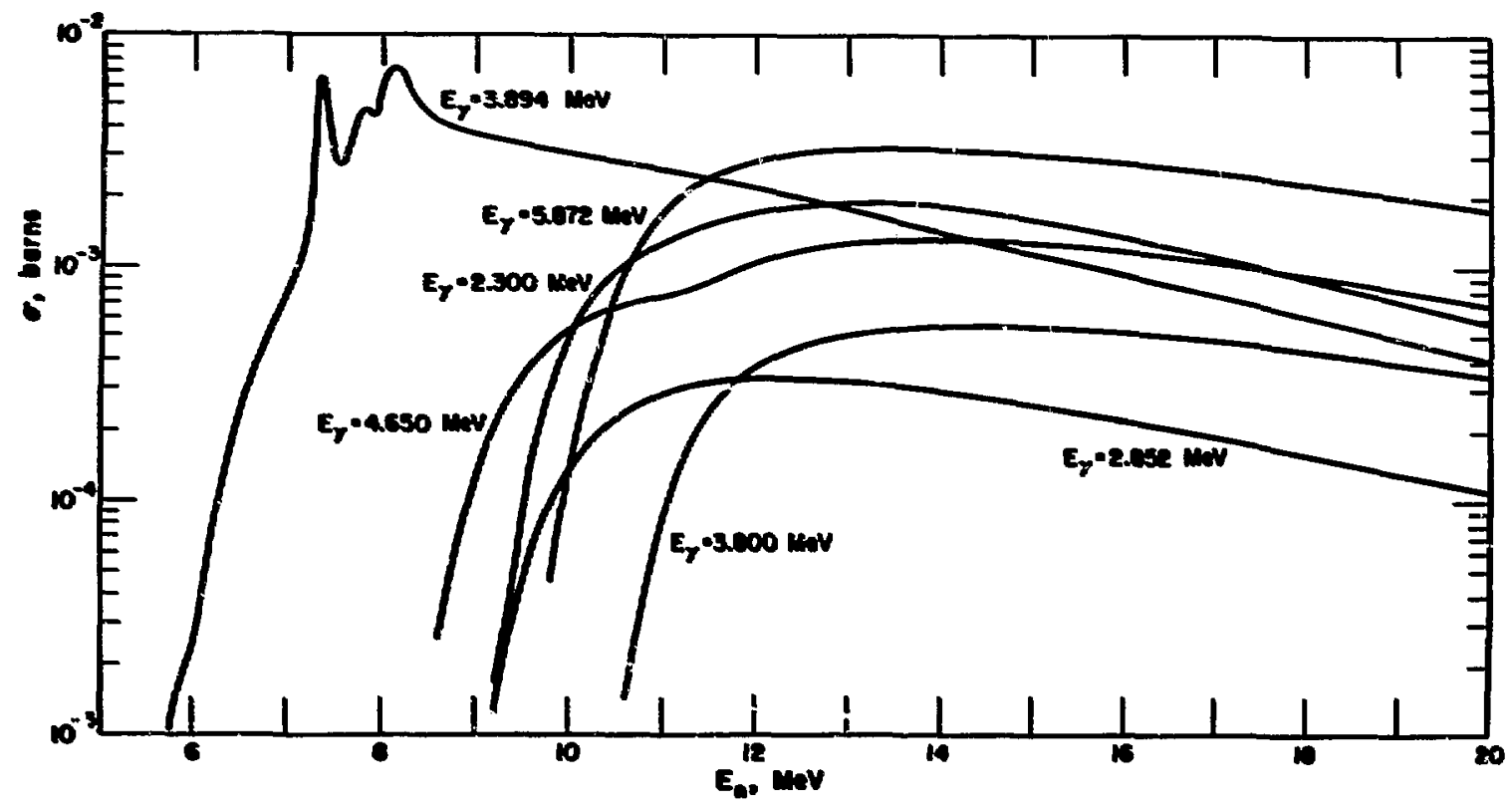

Fi8. 64. Eveluated photon-production cross sections for six of the velker (n,ar) transitions with photon entrgies below $6 \mathrm{MrO}$.

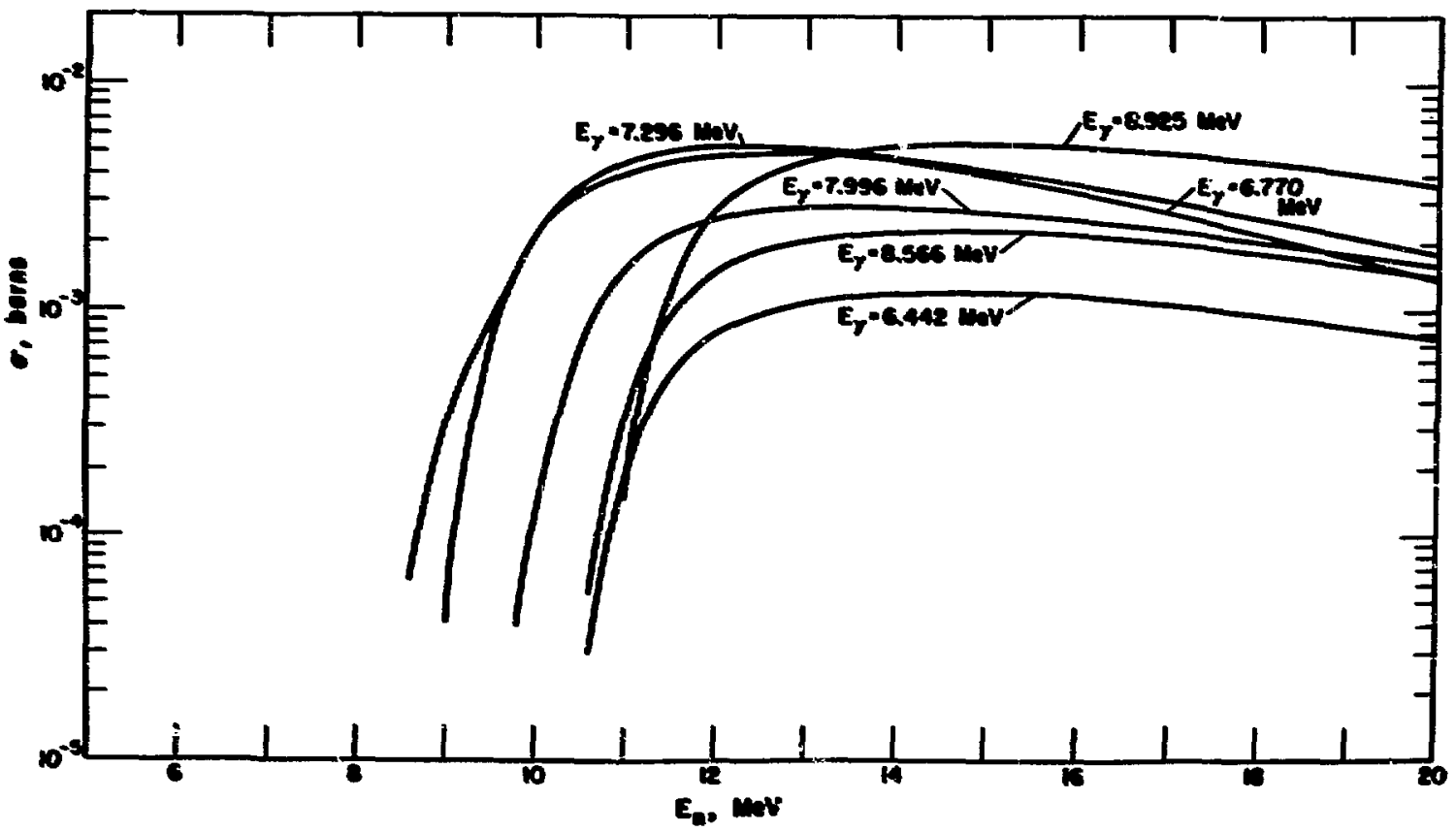

Fis. 65. Eveluated phoson-production cross sections for six of the weaker ( $n$, or) transitions with photon ancestes betwean 6 and 9 kint. 


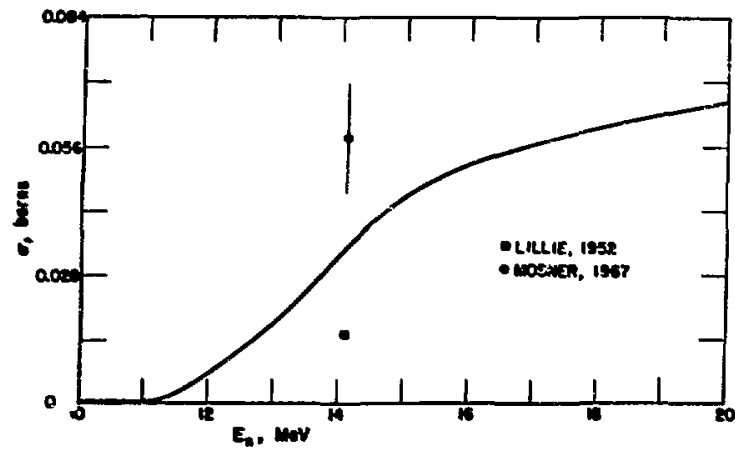

F18. 66. Measured and evaluated $(n, 2 \alpha)$ cross sections.

3.9 The ${ }^{14} \mathrm{~N}(\mathrm{n}, 2 \mathrm{n})^{13} \mathrm{~N}$ Cross Section and Energy Distribution

The thregnold for the ${ }^{14} \mathrm{~N}(\mathrm{n}, 2 \mathrm{n})^{13} \mathrm{~N}$ reaction occurs at $11.31 \mathrm{MeV}$. A number of activation measurewents of the $(n, 2 n)$ cross section have been made using the $10-m i n$ half-21fe posttron decav of ${ }^{13} \mathrm{~N}$. The evaluated $(n, 2 n)$ cross section 18 compared to many of the available measuramente in Fig. 67, " The evaluated curve is based mainly on measuremento by Ferguson et a1. (Fe60), Prud'home et al. (Pr60), and Bormann et al. (Bo65). The $(n, 2 n)$ cross section Is seen to be less than $12 \mathrm{mb}$ at all neutron energles below $20 \mathrm{MeV}$.

There are no measurements of the energy distribution of neutrons from the $(n, 2 n)$ reaction. To estimate the energy distribution, we performed a calculation assuming that the cross section follows a purely phase-space or statistical energy distribution (Oh65); that 1s,

$$
\frac{d^{2} \sigma}{d \Omega_{1} d E_{1}} \propto\left\{E_{1}\left[\frac{14}{15}\left(\frac{14}{15} E_{n}+Q\right)-E_{1}+\frac{2}{15} \sqrt{E_{n} E_{1} \mu_{1}}-\frac{E_{n}}{15^{2}}\right]\right\}^{1 / 2},
$$

where $\Sigma_{1}$ is the laboratory energy of the outgolng peutron, $\mu_{1} 18$ the ccsine of tine laboratory angle, $\Omega_{1}$ is the laboratory solid angle, $E_{n}$ is the incident neutron energy, and $Q$ is the $Q$-value for the $(n, 2 n)$ reaction $(-10.553 \mathrm{MeV})$. We integrated this expression over laboratory solid angle to obtain average energy spectra for various incident-neutron ener81es. Smple resulte are given In Fig. 68, where the spectra are normalised 60 that the area under each curve is unity.

\footnotetext{
Seureral 14-HeV aeasurements (A858, Ce62, C866, Du54, Gr65, Pasj, Pa67, Ra61, St65a) are omitted from Fig. 67 .
}

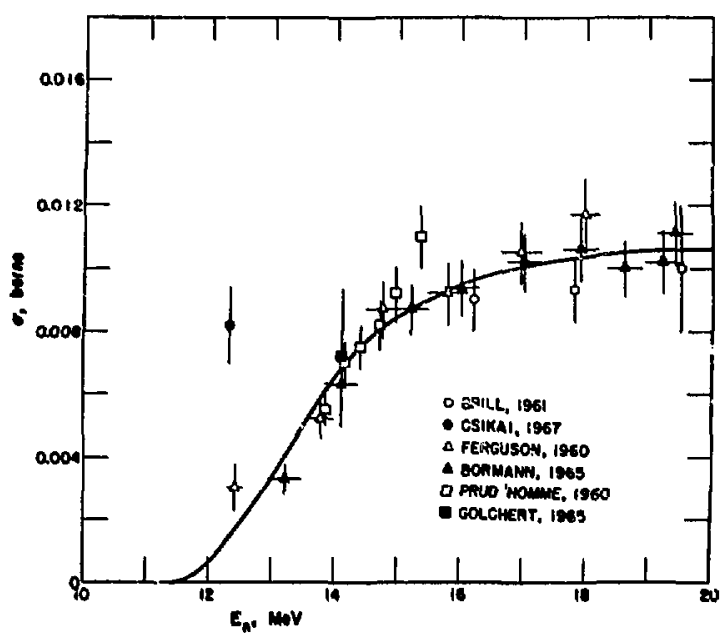

F18. 67. Measured and evaluated $(n, 2 n)$ cross sections. Several one-energy measurements near $14 \mathrm{MeV}$ are not plotted, although they were included in the evalination.

\subsection{The Elestic-Scattering Gross Section}

Our evaluation of the elastic-scattering cross section in the eV energy region, which resulto in a thermal free-atom scattering cross suction of 9.957 barns, is described in the discussion of the total cross section (Sec. 3.1). Aside from the eV region, we determined the elastic cross section for neutron energies below $10 \mathrm{MeV}$ by subtracting the sum of the evaluated partial-reaction cross sections from the evaluated total cross section. The results of this anajysis for neutron energles up to $6 \mathrm{MeV}$ are compared to the avallable elastic measurements in Fig. 69. We obtained the elastic results by fitting our evaluated angular-distribution shapes (Sec, 4.1) to the angular distribution measurements. We arbitrar11y placed error bars of $10 \%$ on the experimental data by Fowler (Fo55, Fo66) and Chase (Ch61); we consider the Bostrom results (Bo57) less accurate and have given them error bars of $20 \%$. The agreement between the evaluated curve and the measurements Is quice good below $3 \mathrm{MgV}$ and reasonably good up to $6 \mathrm{MeV}$.

The relative elastic measurements by Boreil et al. (Bo68) between 4.2 and $6.3 \mathrm{MeV}$ are not included in Fig. 69. These results, obtained using a spherical-shell technique, substantially disagree with our 


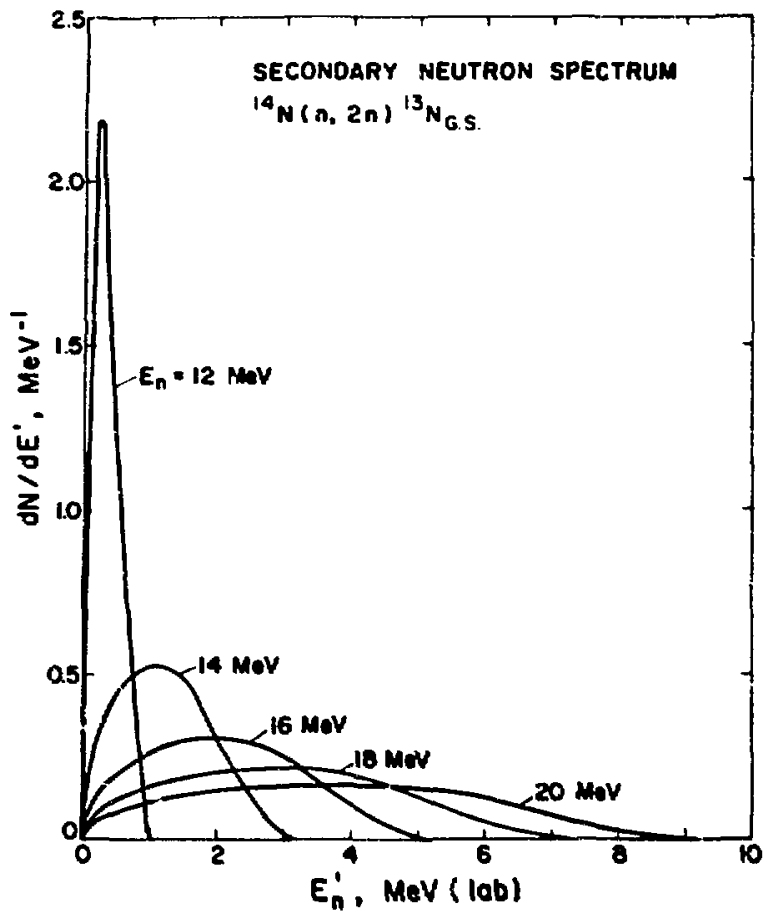

F1g. 69. Evaluated eacondary-neutron energy opectra for the $(n, 2 n)$ reaction foc ceveral laboratory energies of the incldent neutron. evaluated curve, as they ware bormalized to in elasilc cross gection of 0.7 barns at $6.3 \mathrm{keV}$. The shape of their measured curve also does not agree with the eval uated shape above $5.0 \mathrm{MeV}$, principally because of Its overall decrease with Increasing energy relative to the evaluated result. Finaliy, the nonelast1c cross section aeasured in the Borell experiment also d1sagrees substantially with the evaluated nonelastic cross section and is tharefore inconsietent with the sum of the avallable $\left(n, n^{\prime}\right),(n, p)$, and $(n, a)$ measurements at these anergies.

The elestic cross section for the 6- to 20-1feV energy region is given in Fig. 70. As atated earlier, below $10 \mathrm{MeV}$ we determined the evaluated elastic crose section by abtracting the nonelastic fron the total, and above $10 \mathrm{MaV}$ we Joined the evaluated curye amoothly to the axperinantal results.

The enerey range covered in Fig. 70 includes the region of the woll-known diacrepancy in the nitrogen crcus sections (St69, Di69) nuar 8 MoV. The essence of thio problien is that the olastic cross

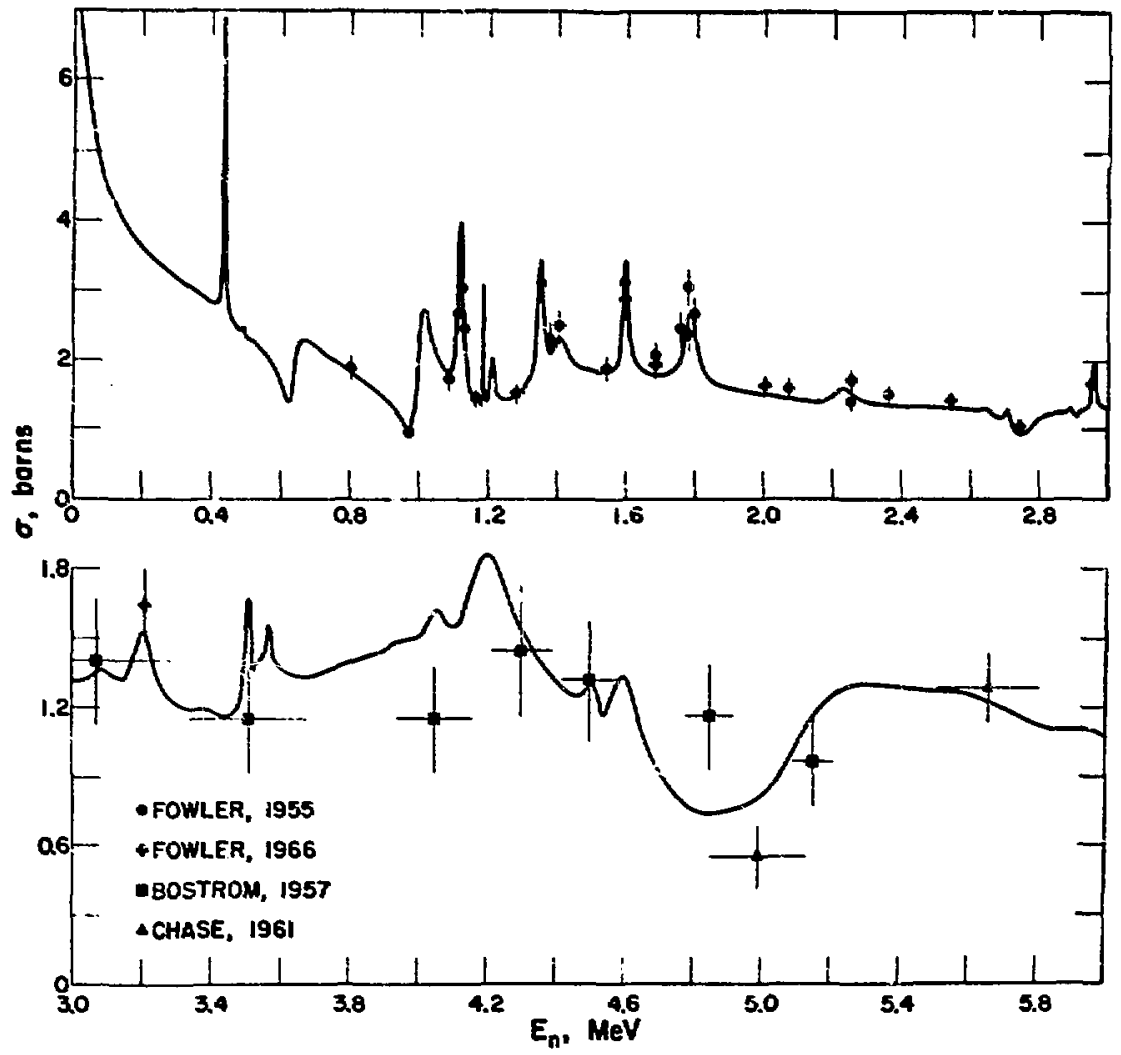

F18. 69. Measured and evaluated cross sections for elastlc scattering between $10 \mathrm{keV}$ and $6 \mathrm{MeV}$. 
section detersined by subtracting the nonelastic crose section frow the total. which is hod we obcalned the evaluated eurve, lien roughiy 200 ob above the elactic measuresenta by Bauer at al. (Ba67). At the time thls ovaluation was completed, the Nelitis et. al. (Ne71) and Percy (Pa71) resubte shown 1xi F1g. 70 were not avallable, and thera was little evidence from elastic mesurseves to eupport the evaluated curve. Our jecision to rely upon thc svaluated norielastc and total croses sectlons rather than the measurements by Bauer et al. (Ba67) was based aninly on two considerations. First, th was difficult to reconclle some of the Bauer resulte at enall angles with Hick's InIt (H143) for the alninu posalble elastic cross section at a sartering angle of $0^{\circ}$. This problen was ade wore severe by prelininary re-

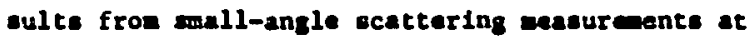
Edgewood (Bu7la) which Indicated that the zero-degree elastc crose aection near $B$ MaV was substantially higher than Wick's 11mit. Second, with our cholce of the elastic crose section it was neceseary to asaure that only one measureant, the Bauer (Ba67) alustic-scattering data, was wrons. If we assuned that the error was in the $\left(n, n^{\prime}\right)$ or $(n, a)$ chanuele,

The prelininary values fros the Nelile experinent, which were avalleble for the evaluation, ware sowe 157 lower than the final resulta gtven in FiR. 70. the crose section frow one of these channels would have to be doubled or the contribution from both reactione would have to be Increased $50 \%$ to account for the "misging" $200 \mathrm{mb}$. This would require asauning substantial errors in several measuremente (see Sec. 3.3 .1 and 3.7).

The new results by Pergy and Kinney (Pe71) and Nellio et al. (Ne71) given In Fig. 70 support our chulce for the elastic crose section. Nthough there Is etill a possibility of error: in this energy reglon, particularly from unknown structure in the crose sections, the altuation has been greatly clarifled by the new measurements, and the evaluated curve appears a reaconable cholce for the elastic crose section at these energies.

We based the elastic crose section near $14 \mathrm{MeV}$ upon a conpostce of the avallable elactc neasuresenta, although the messurament by Bauer et al. (Bal,3) was wolghted heavily in the decision, together with the knowledge that Anderaon and Mcriure's $\left(n, n^{\prime}\right)$ aeasurewents (An64) and the nonelastic atesurements by Flerov and Talyzin (F158) and Degtyarev (De65) sugeest a sosewhst lower elsetic crose section than 1. Indicated by some of the elastic measuremante. The extenuion of the elastic cross section from 14 to $20 \mathrm{MeV}$ is based upon ralative meanureaents

"These reaulta are given in Fig. 70 with the ande norralization used by Borell et al. (Bo68).

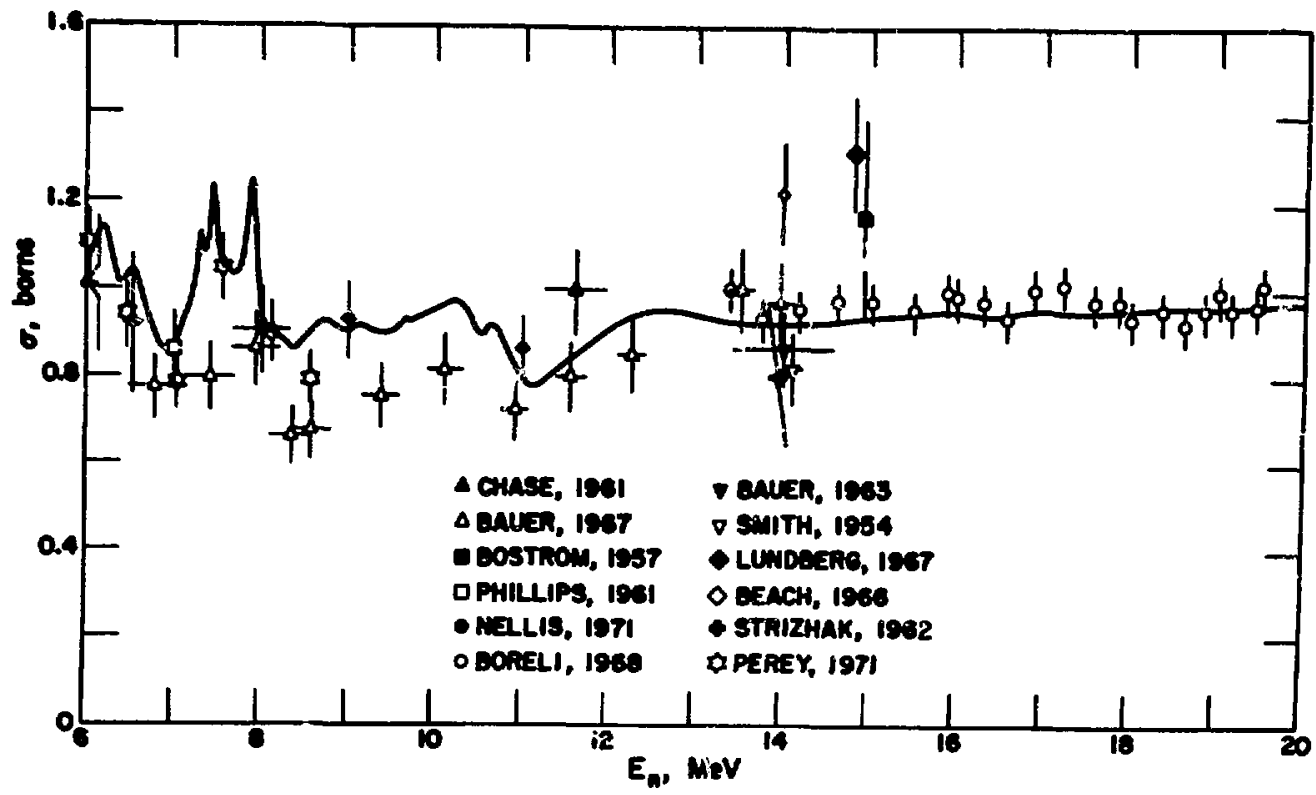

F18. 70. Measured and evaluated elastic scattering cross sections from 6 to 20 MeV. The data of Perey (Pe71) and the revised results of Nellis (Ne71) became avallable after our evaluation (shown by the solid 11ne) was coupleted. 
by Borell et al. (Bo68). The evaluated elasifc and total cruse sectiona at $19.8 \mathrm{MeV}$ result in an evaluated nonelestic crose section of 0.58 barns, ac compared to Degtyarev's measurement of $0.69 \pm 0.05$ barns (De65).

\section{NEUTRON ANGULAR DISTRIBUTIONS}

\subsection{Elaetic-Scatcering Anqular Diatributione}

4.1.1 Elatic Anpular Diatributiona for $E_{n}<8 \mathrm{MeV}$ We determined the elastic-scattering angular diatributione at neutron energies below $8 \mathrm{MeV}$ frow a resonance-theory anelysis that Incorporated the resonance energles and total widthe from our analysis of the total cross section and reaction widthe fron our analysis of the partial crose sections. W1th the resonance parameters fixed, the $\ell=0$ and l - 1 potential phase shifta vere obtained by fitting th, avallable angular diatribution measureaents. We then constructed the final evaluated angular d1atributione from a wooth curve through the fittad potential phase ohifta.

Our resonance-theory parameteriantion 1s bused upon the eingle-level $R$-matrix treatmont by Lune and Thoeas (La58) and is given explicitly in Appendix B. The expressione used to calculate the differential crcise sectione, conotructed from the general equations given by Blatt and Bledenharn (B152a), do not contain terms due to $\neq \bullet^{\prime}$ or $l \neq \ell^{\prime}$, where and $s$ are the Incoming and outgoing channel apina and $l$ and $l^{\prime}$ are the Incoming and outgoing orbital angular momenta. Both these approximations were made to 1imit the number of phase shifts. The resulting expressione, which in general still contaln $81 x$ phase shifts per $\ell$ value, adequately deacribe the aviallable elastic angular-distribution nessurements.

The calculationa were carried out on LASL CDC 6600 computers using a locally written lesst-8quares fitting subroutine (An70). The resonance parameters were entered as fixed Input for each partial wuve, and the s- and p-wave potential phase shifts were obtalned by fitting angular-distribution measurements by Fowler (Fo55, Fo65), Bostrom (B057), Chase (Ch61), and Bauer (Ba67). The d- and f-wave potential phase shifts were set equal to hard-sphere values calculated as described in Appendfx B. This approximation was checked by fitting several distributions near $8 \mathrm{MeV}$ with $\ell=0,1$, and 2 potential phase shifts; the resulting d-wave values are and1 and in raasonable agreement with the hard-ephere calculations.

We Included a total of 33 resonance in the analyola. The resonance paranetera used are given in Table IX. The quantity $E_{R}$ is the resonant energy In the labsratory syaten, $I$ is the total width of the resoriances in the center-of-ass syaten, and $\Sigma_{K}$ is the center-of-anas excitation energy $\mathrm{In}^{15} \mathrm{~N}$ corresponding to $\mathbf{R}_{\mathbf{R}^{*}}$. We obtained the parameters $\mathbf{E}_{\mathbf{R}}$ and $I$ minly by fitting the resonances in the total crose section with Brelt-Wigner shapee above otrsightIIne backgrounds. Exceptions are the parameters of the 0.647 - and $0.996-\mathrm{HeV}$-wave resonances which we obtained from Ajzenberg-Selove's compllation (Aj70). We assuned a radius of $5.1 \times 10^{-13} \mathrm{cn}$ for the a-wave resonances, and used radil of $3.6 \times 10^{-13} \mathrm{~cm}$ for all higher waves, We selected the larger value for the owave rsdlue so that the calculated hard-aphere phese shifte at lower energy roughly agreed with the fitted potential. phase shifte.

The ratios of the neutron width to the total width $\left(\Gamma_{n} / \Gamma\right)$ for the varlous resonancee are based upon several conelderations. We estinated this racto for vany of the resonanced by comparing the areas under the resonance peaks in the $(n, p)$ and $(n, \alpha)$ cross sections to the areas under the peaks In the total cross section. We also obtained information on $\Gamma_{\mathbf{n}} / \Gamma$ from Afzenberg-Selove's compllation $(A\} 70)$. The change in total cross section $\left(\Delta \sigma_{T}\right)$ over a resonance 18 also related to $\Gamma_{n} / \Gamma$ through the expression (W163)

$$
\Delta \sigma_{T}=\frac{2 \pi \hbar^{2}}{3} \quad(2 J+1) \frac{\Gamma_{n}}{\Gamma},
$$

where $J 18$ the total angular momentum of the resonance and $\pi$ is the reduced wavelength for the Inc1dent neutron beam. Where $\Gamma_{\mathbf{n}} / \Gamma$ was uncertain, we chose the ratio to be consistent with the angular momentum of the resonance and with the measured value of $\Delta \sigma_{T}$. often, the reverse situation occurred, and we chose the unknown spin J to be consistent with the avallable Information on $\Gamma_{n} / \Gamma$.

We took the spins and parities for many of the resonances below $3 \mathrm{MeV}$ from an analysis like ours performed by Fowlex and Johnson (Fo55) or from Ajzenberg-Selove's compllation (A:70). Sometimes, 
TABLE IX

NITROGEN RESONANCE PARAMETERS

\begin{tabular}{|c|c|c|c|c|c|}
\hline $\begin{array}{l}\mathrm{E}_{\mathrm{R}} \\
(\mathrm{MeV})\end{array}$ & $\begin{array}{l}E_{X} \\
(\mathrm{MeV}) \\
\end{array}$ & $\Omega$ & $\begin{array}{l}\text { Resonant } \\
\text { Phage } \\
\text { Sh1ft } \\
\end{array}$ & $\begin{array}{c}\Gamma \\
(\mathrm{MeV}) \\
\end{array}$ & $\Gamma_{n_{/ \Gamma}}$ \\
\hline .4336 & 11.239 & $3 / 2^{-}$ & & 0.0051 & 1.0 \\
\hline 0.4926 & 11.294 & $1 / 2^{-}$ & & 0.0087 & 0.29 \\
\hline 0.647 & 11.438 & $1 / 2^{+}$ & & 0.041 & 0.70 \\
\hline 0.996 & 11.764 & $3 / 2^{+}$ & & 0.040 & 0.95 \\
\hline 1.1164 & 11.876 & $5 / 2^{-}$ & & 0.0159 & 0.99 \\
\hline 1.1840 & 11.939 & $3 / 2^{+}$ & & 0.0019 & 1.0 \\
\hline 1.2090 & 11.963 & $1 / 2^{-}$ & & 0.0146 & 0.99 \\
\hline 1.3490 & 12.093 & $5 / 2^{+}$ & & 0.0173 & 0.92 \\
\hline 1.406 & 12.146 & $3 / 2^{-}$ & & 0.044 & 0.61 \\
\hline 1.5974 & 12.325 & $5 / 2^{-}$ & & 0.0172 & 0.99 \\
\hline 1.784 & 12.499 & $5,2^{+}$ & & 0.041 & 0.85 \\
\hline 2.229 & 12.914 & $1 / 2^{*}$ & & 0.070 & 0.70 \\
\hline 2.5105 & 13.177 & $9 / 2^{-}$ & & 0.0038 & 0.15 \\
\hline 2.7081 & 13.361 & $1 / 2^{+}$ & & 0.0164 & 0.50 \\
\hline 2.75 & 13.40 & $1 / 2^{+}$ & & 0.075 & 0.50 \\
\hline 2.9576 & 13.594 & $7 / 2^{+}$ & & 0.0116 & 0.84 \\
\hline 3.097 & 13.714 & $3 / 2^{+}$ & & 0.032 & $0.2{ }^{\circ}$ \\
\hline 3.205 & 13.824 & $3 / 2^{+}$ & & 0.064 & 0.78 \\
\hline 3.5101 & 14.109 & $7 / 2^{+}$ & & 0.0219 & 0.74 \\
\hline 3.5689 & 14.164 & $7 / 2^{-}$ & & 0.0143 & 0.40 \\
\hline 4.055 & 14.617 & $1 / 2^{+}$ & & 0.059 & 0.60 \\
\hline 4.195 & 14.748 & $5 / 2^{+}$ & & 0.183 & 0.8 \\
\hline 4.515 & 15.046 & $3 / 2^{+}$ & & 0.072 & 0.7 \\
\hline 4.599 & 15.125 & $7 / 2^{+}$ & & 0.112 & 0.8 \\
\hline 4.85 & 15.36 & $3 / 2^{+}$ & & 0.32 & 1.0 \\
\hline 5.30 & 25.59 & $5 / 2^{-}$ & & 0.18 & 0.8 \\
\hline 5.572 & 16.032 & $3 / 2^{+}$ & & 0.071 & 0.3 \\
\hline 5.965 & 16.399 & $5 / 2^{+}$ & & 0.112 & 0.3 \\
\hline 6.198 & 1.6 .616 & $7 / 2^{+}$ & & 0.192 & 0.4 \\
\hline 6.550 & 16.945 & $3 / 2^{+}$ & & 0.207 & 0.55 \\
\hline 7.295 & 17.640 & $1 / 2^{+}$ & & 0.041 & 0.7 \\
\hline 7.437 & 17.772 & $5 / 2^{-}$ & & 0.122 & 0.8 \\
\hline .883 & 18.188 & $512^{-}$ & & 0.149 & 0.9 \\
\hline
\end{tabular}

however, we chose values in disagreement with one or both of these sources in order to produce better overall agreement with the estimates of $\Delta \sigma_{T}$ and with the angular-distribution measurements.

Very little is known about the spins and parities of resonances above $3 \mathrm{MeV}$ in nitrogen, and all such values in Table IX are from our analysis. We made these assignments on the basis $c f \mathcal{A}_{T}$ and the avallable angular-distribution measuremencs, requirIng that t'.e potential phase shifts vary smoothly with energy. For many resonances, hosever, there vere no angular-distribution data or the resolution of the avallable measurement was too broad to be useful. Then we were forced to estimate the value of $\ell$ from the total width of the resonance, so uncertaintles in most of the assignments abo ve $3 \mathrm{MeV}$ are falrly large. The actual fits to the experimental angular distributions, however, remain reasonably good out to $8 \mathrm{MeV}$.

The s- and j-wave potential phase shifta resultIng from this analysis are given in F18. 71. The angular-distribution messurements used in determining the various phase shifts are Indicated by the different aymbols. The Fowler (Fo55, Fo66) measurements were the only high-resolution data avallable for nitrogen. * From 3.5 to $5.5 \mathrm{MeV}$ we encountered considerable difficulty in obtaining satisfactory aimultaneous fits for the $l=0$ and $l=1$ phase shifts. Consequently, in this region we fitted the s-wave phase shifts to the measurements while holding the $p-$ wave phese shifts fixed at the values given by the $\ell=1$ curve.

The elastic-scattering angular diatributions are represented in the evaluation with Legendre coefficients. The coefficients from 0 to $4 \mathrm{MeV}$ are given in Fig. 72, The values shown were calculated from the smooth curves through the fitted s- and

\footnotetext{
* Perey and Kinney (Pe71) have recently nade new measurements with good resolution near $7 \mathrm{MeV}$.

** Throughout this eva! iation the Legendre coefficients are given using the: ENDF normalization 80 that $\mathrm{do} / \mathrm{d} \Omega=$

$\frac{\sigma}{2 \pi} \sum_{\ell=0}^{\ell} \frac{2 \ell+1}{2} \mathrm{f}_{\ell} P_{\ell}(\cos \theta)$, with $\mathrm{f}_{0} \equiv 1$ and $\left|\mathrm{E}_{\ell}\right|<1$.
} 
p-wave potential phase shifis of Fig. 71. The effects of the many resonances in nirrogen below $4 \mathrm{MeV}$ are evident in the Legendre coefficients. The coefficlents from 4 to 8 LeV are included In F1g. 73. Here, the coefficients vary more smoothly with energy, although some structure is st111 present.

In Figs. 74-79 the evaluated elastic angular distributions are compared to the experimental results used in obtalning the s- and p-wave potential phase shifts. The solid curve given with each measurement represents the evaluated shape averaged over the energy resolution (assumed rectangular) of the measurement and normalized to the experimental data; the dashed curve represents the same shape normalized to the evaluated elastic cross section, also sultably corrected for the resolution of the measurements. The arrowe on the left-hand scale below each curve Indicate W1ck's $1 \mathrm{Im} 1 \mathrm{t}$ (W143) for the minimum differential cross section at $0^{\circ}$. The values for Wick' a limit, which are based on the evaluated total cross section, have also been averaged over the quoted resolution of the measurements.

The elastic angular-distribution measurements of Fowler (Fo55, Fo66) between 0.8 and $1.35 \mathrm{MeV}$ are compared to the evaluation In F18. 74. The evaluated and measured angular distributions agree well except for the three distributions near the 1.1164-MeV resonance. This disagreement occurs because of the $\mathrm{J}=5 / 2$ assignment for this resonance, as much better fits to the angular distribution can be obtained with $\mathrm{J}=3 / 2$, which is the assigrment given by Fowler and Johnson (Fo55). The change in Carlson and Cerbone's total cross section ( $\mathrm{Ca} 7 \mathrm{O}$ ) ovor this resonance, however. Is inconststent with the $\mathrm{J}=3 / 2$ assignment and suggests $\mathrm{J}>5 / 2$, which 1.8 the basis for our assignment. A possible explanation for the discrepancy between the evaluated and experimental angular distributions might be that the enerigy epread in the

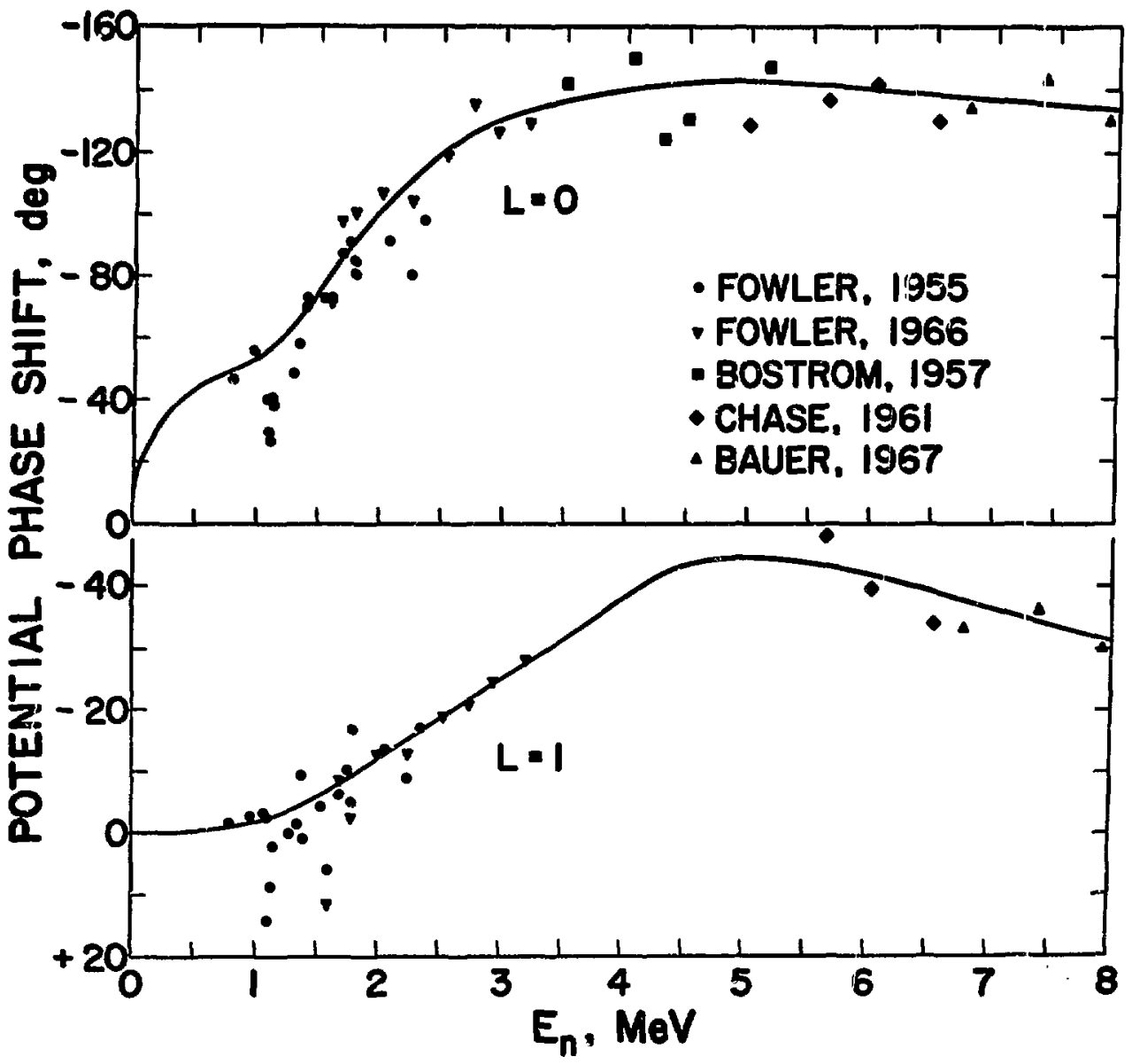

F1g. 71. Potent1al-scatter1ng phase shifts up to $8 \mathrm{MeV}$ deduced from fits to elastic angular distributions. 


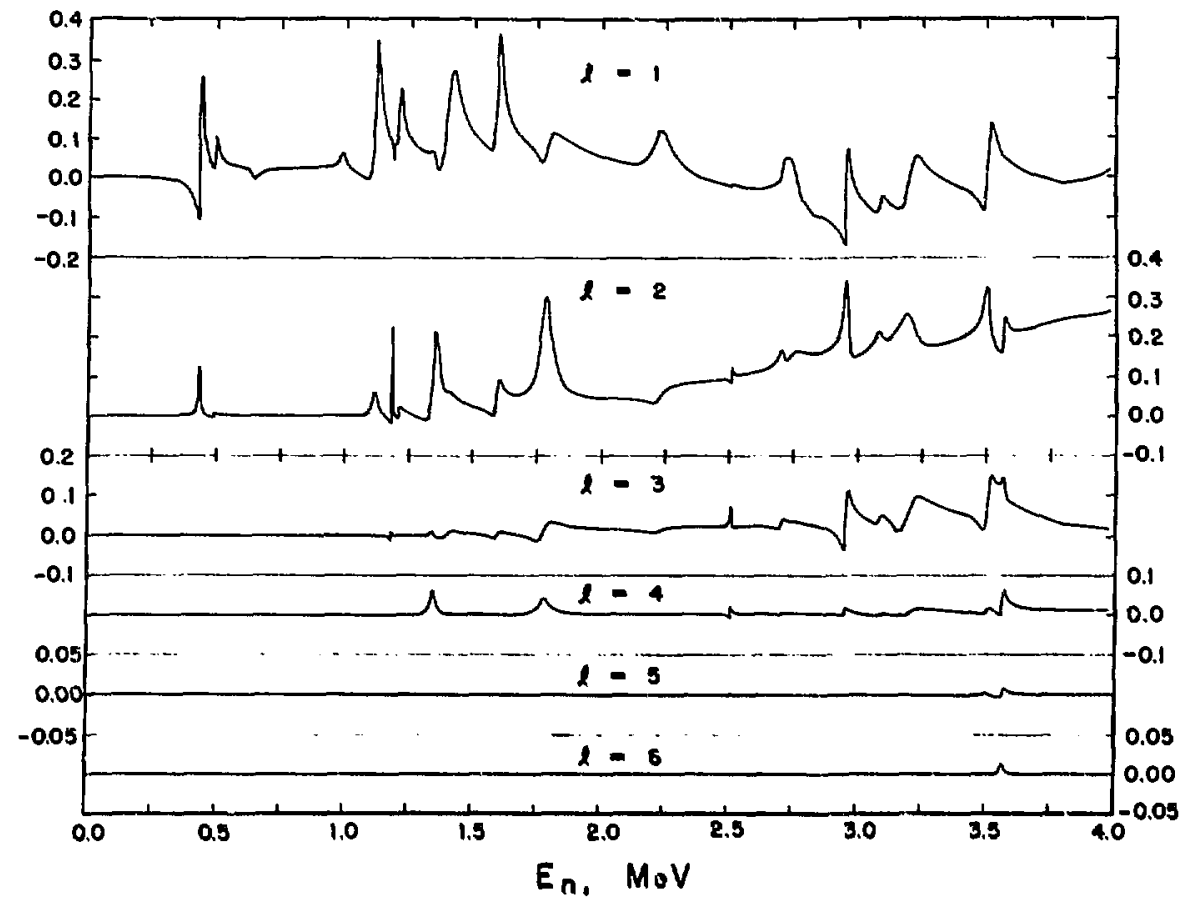

F1g. 72. Legendre coefficlente deduced ueing the phase ahifta of Fig. 11 for elastic scattering below $4 \mathrm{MeV}$. Thi coefficients are normalized accordir 3 to the ENDE/B definition.

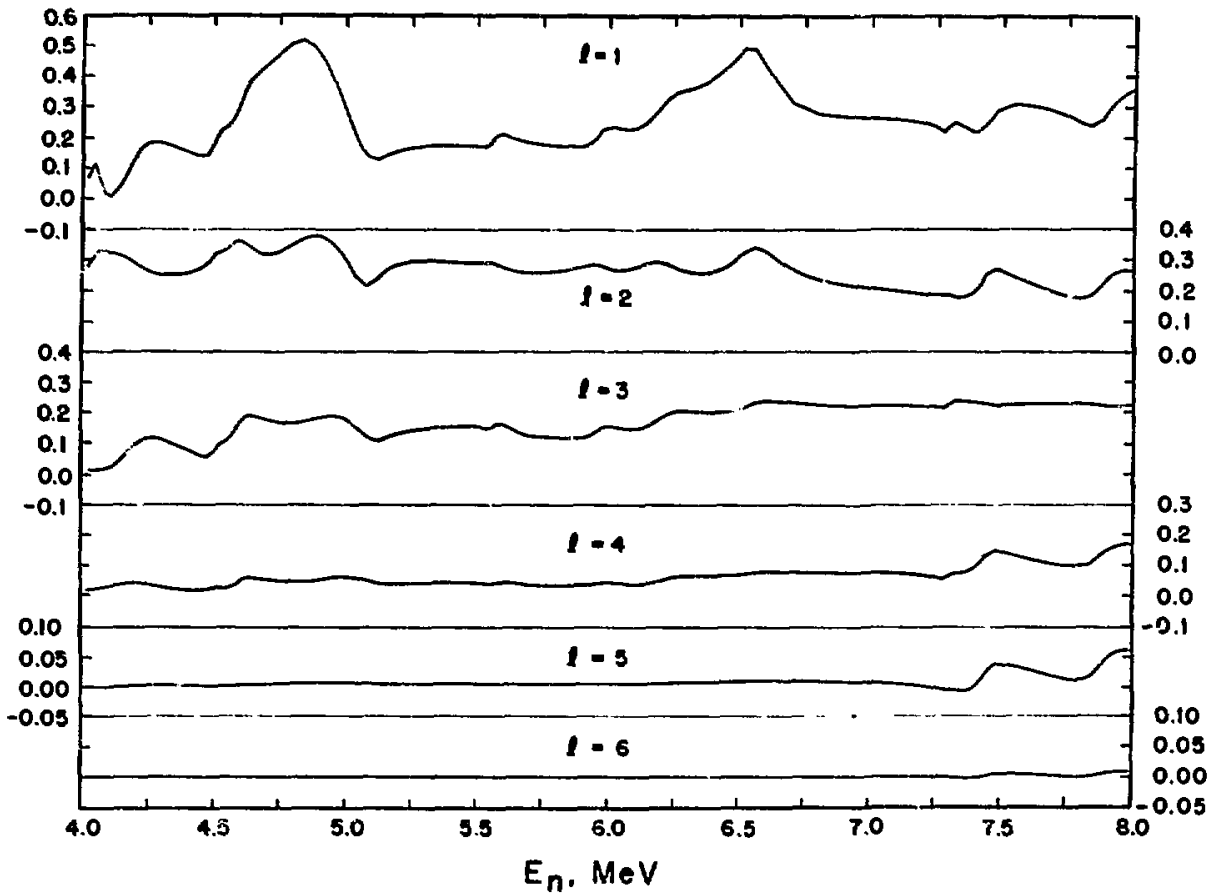

Fig. 73. Legendre coefficlants deduced using the phase shifts of Fig. 7]. for elastic scattering from 4 to $8 \mathrm{MeV}$. The coefficlents follow the ENDF/B definition. 

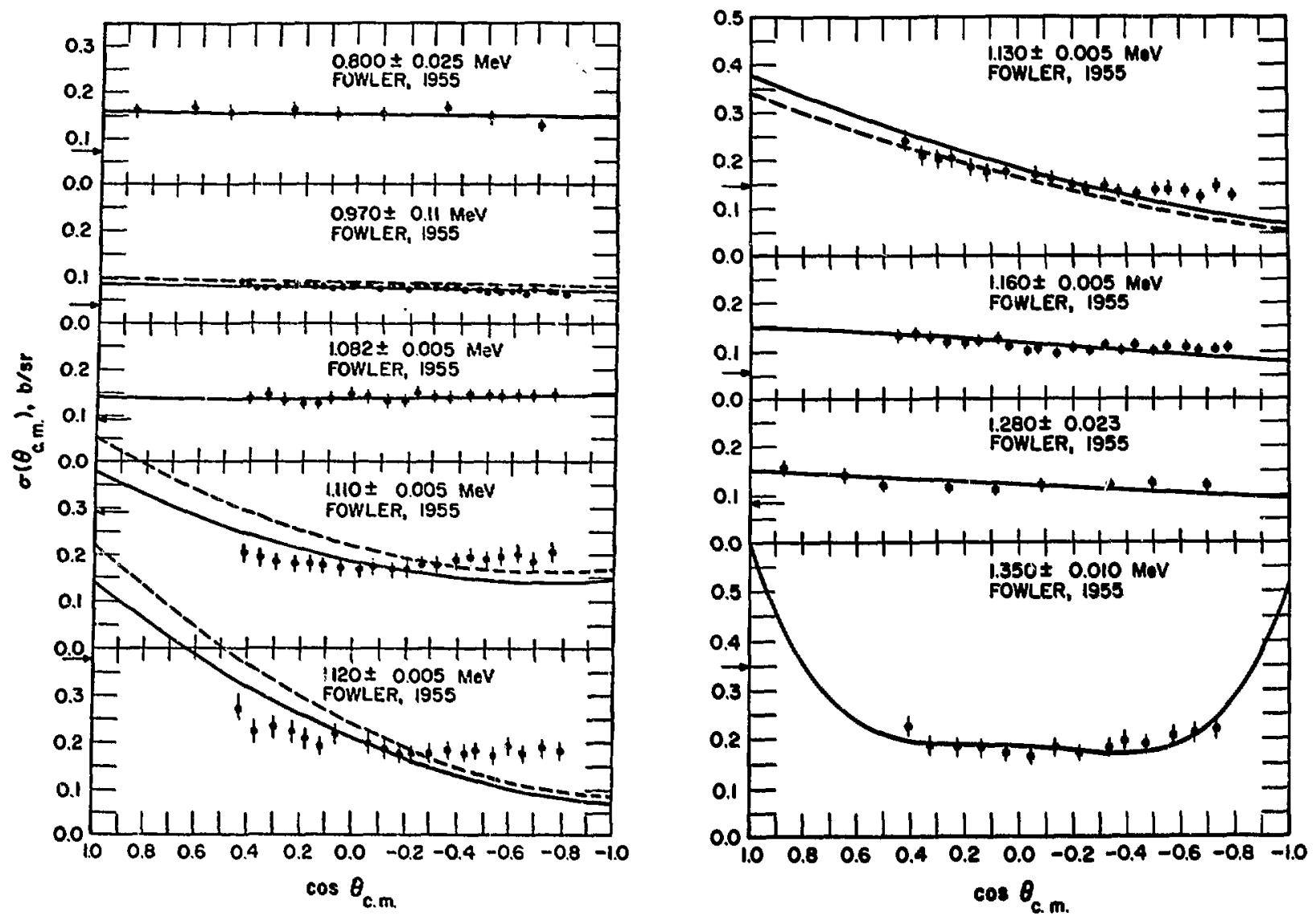

Fig. 74. Measured and evaluated differential cross sections for elastic scattering from nitrogen up to $1.35 \mathrm{MeV}$.

neutron beam used in the measurement was greater than realized.

The good agreement between the measurements at 0.97 and $1.35 \mathrm{MeV}$ and the evaluated results in F18. 74 supports the $\mathrm{J}^{\pi}$ assigments in Table IX for the 0.996- and 1.349-MeV resonances. The measurements in Fig. 74 provide no information on the resonances at $0.4336,0.4926,0.647,1.184$, and $1.209 \mathrm{MeV}$. Except for the 1.184-MeV resonance, we obtained the parameters in Table IX for these resonances from Afzenberg-Selove's compilation (Af70). The 1.184 $\mathrm{MeV}$ resonance was assumed to be d-wave from its narrow width, and the assignment $J=3 / 2$ is consistent with the observed $\Delta \sigma_{\mathrm{T}}$ and $\Gamma_{\mathrm{n}} / \Gamma=1$. However, because this resonance is very sharp (1.9-keV wide), it may have a substantial reaction width not observed in measurements and a higher value of $\mathrm{J}$.

The evaluated results are compared in FIg. 75 to the Fowler measurements (Fo55, Fo66) between 1.377 and $1.756 \mathrm{MeV}$. The evaluated and measured shapes agree well in this region and support the $J^{\pi}$ assignments in Table IX for the 1.406- and 1.5974-MeV resonances .

The elfstic measurements between 1.779 and 2.54 $\mathrm{MeV}$ are compared to the evaluated curves in Fig. 76 , The comparisons for the $1.779 \mathrm{MeV}$ measurements support the $5 / 2^{+}$assignment for the $1.784-\mathrm{MeV}$ resonance. Our choice of $\mathrm{J}^{\pi}=1 / 2^{-}$for the $2.229 \mathrm{MeV}$ resonance disagrees with the Fowler (Fo55) assignment of $J^{\pi}=3 / 2^{-}$; in fact, there was little to choose between our $\mathrm{J}^{\pi}=1 / 2^{-}$and $\mathrm{J}^{\pi}=3 / 2^{-}$fits for the 2.25 -MeV measurement, and the $3 / 2^{-}$assigment is a suitable alternative. No information on the $2.5105-\mathrm{MeV}$ level is provided by the measurements in Fig. 76, and our $\mathrm{J}^{\pi}$ assignment for this level is based on its narrow width and on the observed $\Delta \sigma_{T}$ together with our estimate of $\Gamma_{\mathbf{n}} / \Gamma$.

Figure 77 includes the evaluated and experimental results between 2.742 and $4.30 \mathrm{MeV}$. Our assignments of $7 / 2^{+}$for the $2.9576-\mathrm{MeV}$ resonance and $3 / 2^{+}$for the 

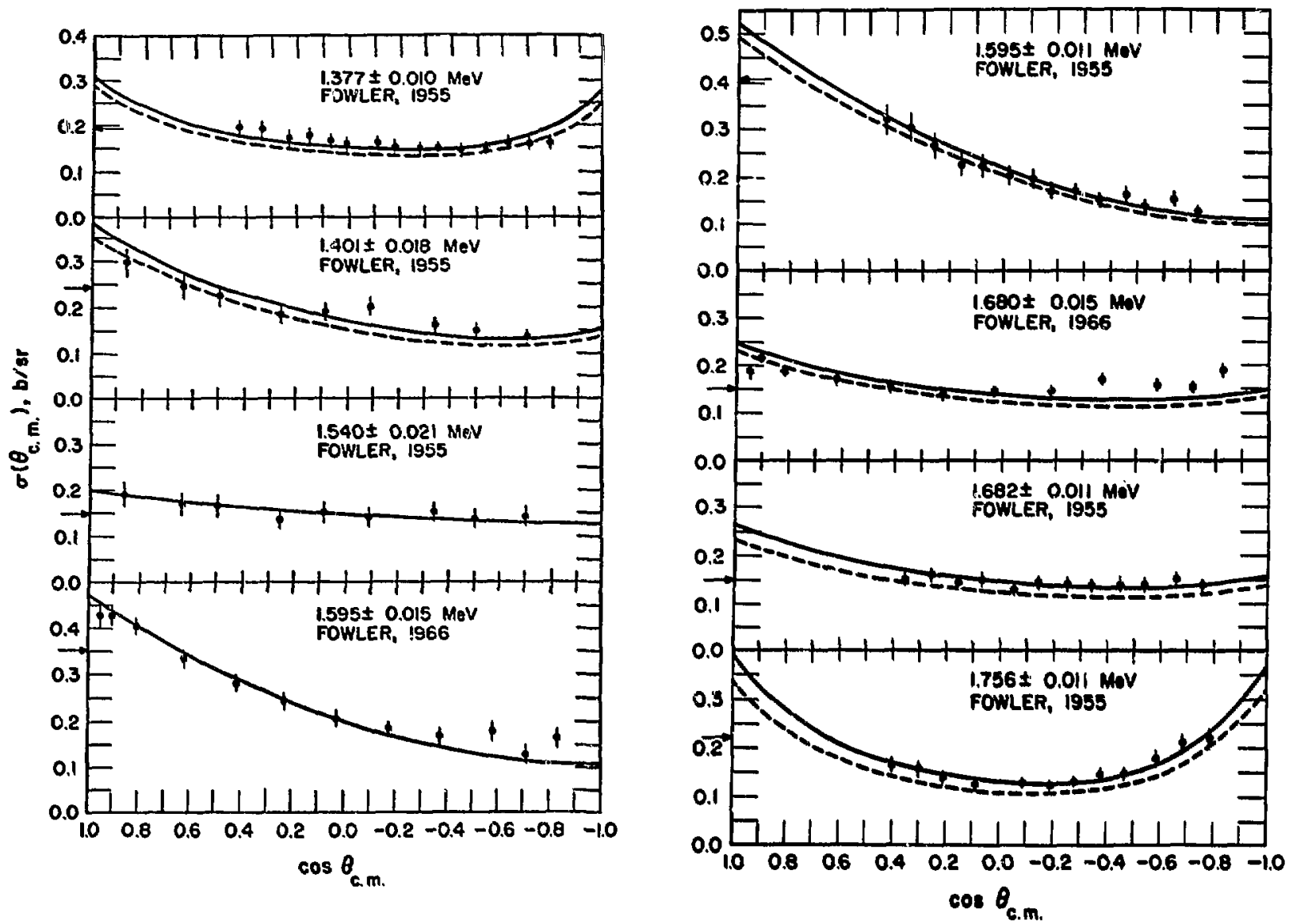

Fig. 75. Measured and evaluated differential cross sections for elastic scattering from 1.37 to 1.76 MeV.

3.205-MeV resonance are supported by the good agreeinent between the evaluation and the Fowler (Fo66) data at 2.95 and $3.207 \mathrm{MeV}$. The assignments for other resonances in this energy region are uncertain and are not discussed in detail. They are generally based upon estimates of $\Delta \sigma_{T}$ and $\Gamma_{n} / \Gamma$ consistent with reasonable fits to the angular-distribution results. The large errors and energy spread in the Bostrom (Bo57) measurements make precise assignments difficult.

The evaluated and experimental results for $E_{n}=$ 4.5 to $6.78 \mathrm{MeV}$ are given in Fig. 78. Again, the precise $J^{\pi}$ assignments in this region are uncertain and are not discussed in detail. The general d-wave character of the resonances he:e seems to be supported by the measurements, particularly above $5.5 \mathrm{MeV}$.

Finally, the elastic angular distribution results between 7.11 and $7.93 \mathrm{MeV}$ are given in Fig. 79 . Bauer's measurements at 7.41 and $7.93 \mathrm{MeV}$ are a little difficult to reconcile with Wick's Iimit, and we included artificial points at $0^{\circ}$ in fitting potential phase shifts to these data. The dashed curves in Fig. 79 (and Fig. 78) indicate the significant renormalizations used in the evaluation at these energles.

\section{1 .2 Ejastlc Angul ar Distribution for $E_{n} \geq 8 \mathrm{MeV}$}

We obtained the elastic angular distributions above $8 \mathrm{MeV}$ by fitting the available measurements with Legendre expansions and then drawing smooth curves through the fitted Legendre coefficients. We augmented the experimental data with several fictitlous points to anchor the fits at front and back angles. He estimated the supplementary points used near $180^{\circ}$ (usually just one point per distribution) from optical-model fits to the measurements. At forward angles, we anchored the fits by a single point at $0^{\circ}$ based upon Wick's (W143) 1imit, $\sigma_{w}\left(0^{\circ}\right)$, which was varied from $(1.4 \pm 0.2) \sigma_{w}\left(0^{\circ}\right)$ between 7 and $11 \mathrm{MeV}$ to $(1.05 \pm 0.05) \sigma_{\mathrm{w}}\left(0^{\circ}\right)$ near $14 \mathrm{MeV}$. We included the indicated standard deviations with the $0^{\circ}$ points 80 that the fitted $0^{\circ}$ cross sections were not dictated by the fictitious points but were strongly influenced by them. Our decision to use values greater 

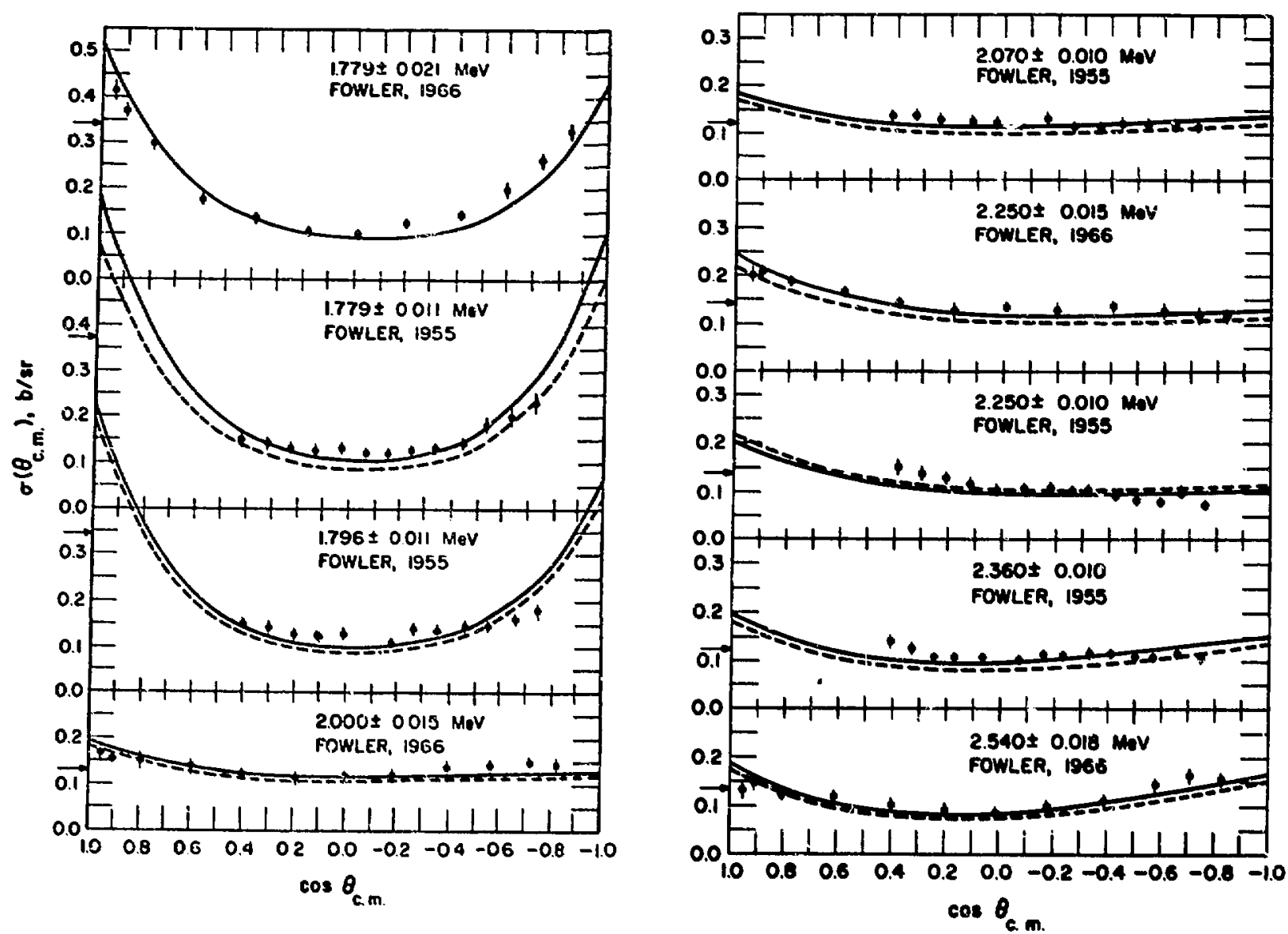

Fig. 76. Measured and evaluated differential crose sections for el zstic scattering from 1.78 to 2.54 MeV.

than Wick's 1 Imit at $0^{\circ}$ was based upon preliminary information from Edgewood Arsenal, where neasurements of elastic scattering at very amall angit:a (2.5-15 $)$ were in progress. The final results (Bu71a) of this experiment indicate that the $0^{\circ}$ cross sections for nitrogen at $7.55 \pm 0.06 \mathrm{MeV}$ and $9.50 \pm 0.05 \mathrm{MeV}$ are 40 and $20 \%$ greater than Wick's 1Imit, respectively. The ovaluated croas sections at $0^{\circ}$ agree with the final Edgewood results to within about 107.

The Legendre coefficients from 8 to $20 \mathrm{NeV}$ that resulted from this analysis are amooth functions of energy and are shown in Fig. 80. We based the extrapolation of the curves from 15 to $20 \mathrm{KeV}$ upon op: "cal-model calculations using parameters obtained from the 14-KeV measurements by Bauer et al. (Ba63). We adjugted the coefficlents to produce pogreement with Wick's 11 mit at all energies.

The elastic angular-distribution measurements between 8.0 and $10.1 \mathrm{MeV}$ are compared to the eraluated curves in Fig. 81. The inclusion of the points at $0^{\circ}$ tended to "stretch" the shape obtained from the Bauer (Ba67) results at small angles. The Nellis results (Ne70) at $9 \mathrm{MeV}$ are preliminary and have since been increased approximately 15\% (Ne71) so that now they agree very well with the integrated elastic cross section used in the evaluation (see Fig. 70 of Sec. 3.10).

The elastic angular-distribution results from 10.93 to $13.5 \mathrm{MeV}$ are included in F1g. 82. In this region the shapes of the Bauer (Ba67), Nellis (Ne70), and Chase (Ch61) measurements are quite consistent. The final Nellis results (Ne71) at $11 \mathrm{MeV}$ are again roughly 157 higher than the data (Ne70) In Fig. 82.

F1g. 83 shows the angular-distribution results near $14 \mathrm{MeV}$. Wick's limit in this and subsequent figures is given by the intersection of the dashed line and the cross-section axis at $0^{\circ}$. At this energy we emphasized the 1963 measurement by Bauer et al. (Ba63) In the evaiuation. The resulting shape agrees well with the 1967 Bauer result:s (Ba67) and the 1966 Beach measurement (Be66) but not with the Strizhak data (St62) or, to a lesser extent, the Lundberg 

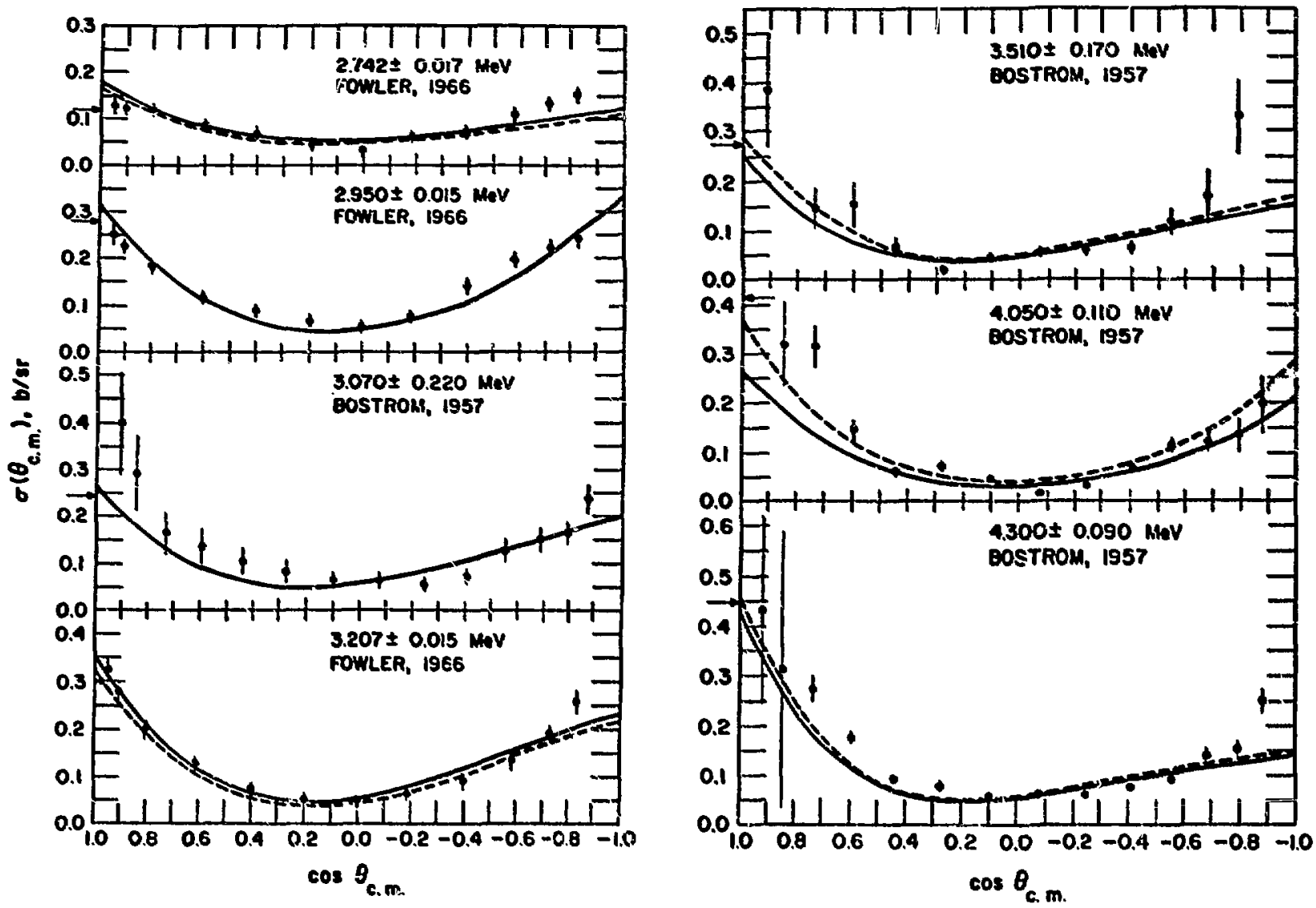

F1g. 77. Heasured and evaluated differentisl crose sectlons for elestic scettering fron 2.74 to 4.30 keV.

result (Lu67) at: $14.8 \mathrm{KeV}$. Further, a algaiflcant normalization difference between the evaluation and the Beach and Lundberg results is evident. The Bostrom measurementa (BO57) at 14.32 and $15.83 \mathrm{MeV}$ given in FiB. 84 exhibit sidj.ar differences in shape and normalization; however, these results are not expected to be as accurate as more nodern mensurements.

Finally, the calculated differential cross sectioris at 16, 18, and $20 \mathrm{KeV}$ are given in F18. 85. These curves sere extrapolated from the 14-MeV mecsurements using opticul-midel parameters, as noted rbove.

\subsection{Inelastic Neutron Angular Diatributions}

The only direct measurements of ${ }^{14} N\left(n, n^{\prime}\right)$ angular distributions available when this evaluation was completed were the 14-Mev results of Bauer et al. (Ba63) and Bobyr et al. (Bo62;. Therefore, at rost neutron energies we based our evaluated $\left(n, n^{\prime}\right)$ angular distributions upon measured $\left(p, p^{2}\right)$ angular dis- tributions. The near-equality of $\left(n, n^{\prime}\right)$ and $\left(P, P^{\prime}\right)$ differential cross sectlons for charge-conjugate reactions has been pointed out by Luts and Anderson (Lu66; also see An67) and 1/ based upon the charge oymetry of the nuclear two-body force. Th1 arguaent is expected so be vaids for Inelastic reactions to low-lying states, where the outgelng froton energy 18 high en ugh that Coulomb penetrability effecta are ama11. The approximation 18 probably best at higher neutron energles where diract interactions are dominivnt.

We used the $\left(p, p^{\prime}\right)$ measurements by Oda et al. $(\operatorname{Od} 60)$, Donovan et al, (Do64), Freemantle (Fr54), and Hansen (Ha70) in the analya1s. We did not incorporate the extensive $\left(p, p^{p}\right)$ data by Borell et 91 . (Bo68) in the study, but their results are qualitatively very similar to the measurements used. We determined the mintimum odd number of cosffictents required to produce a statistically acceptable fit to the $\left(p, p^{\prime}\right)$ data for all levelo below 8.5-MeV excitetion in ${ }^{14} \mathrm{~N}$. We then plotted the resulting, coefficients as a func- 

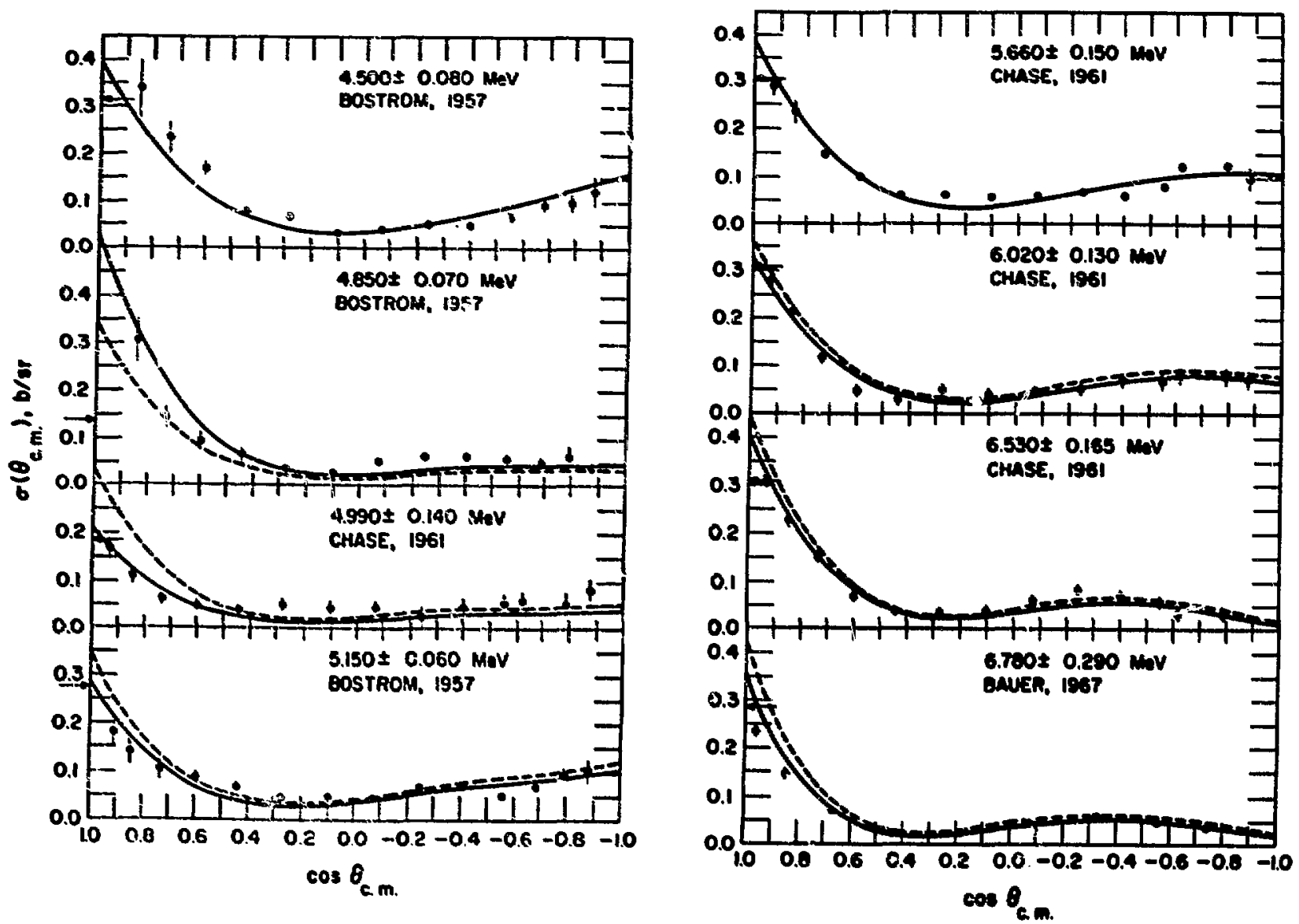

Fis. 78. Measured and evaluated differenilal crosa aections for elactic ecattering from 4.59 to 6.78 keV.

tiwn of lacident energy, and dres swooth curve: through the points. Because there are no measure-. aents below 7 HeV for any level and because the sinilarity between $\left(a, z^{\prime}\right)$ and $\left(p, p^{\prime}\right)$ cross sections is prubably least at the lowest energies, we estinated the variation of the coefficleats near threshold fros Hau: sr-Feahbach calculations using an energydependent locel optical model. The extrapolation of the coefficients from 15 to 20 giev was also besed partly on these calculations. The (P,P') data kera insufficient to determine the cross section for the 8.061- and 8.589-MeV levels at back angles, so we assumed these angular distributions to be sywotric about $90^{\circ}$. We tested the smoothed coefficients at all Incident energies to Insure nonnegativity of the resulting angular distributions before adopting them in the evaluation.

The evaluated $\left(n, n^{\prime}\right)$ angular distributions for the 2.313-ifeV level of ${ }^{14} \mathrm{~N}$ are compared in F18. 86 to the $\left(p, p^{\prime}\right)$ measurements upon which they are hased. The solid curves are the evaluated shapes normallzed to the messurenents; the deshed curves are the evaluated ehapes normalized to our $\left(n, n^{\prime}\right)$ exoss sections and are ohown only where the waximu difference occurred. The 14.15-keV measureant by Bener et al. (Ba63) Is the on'y $\left(n, n^{\prime}\right)$ experiment includind in. F18. 86. The shape detuced from the (P,P') data of Oda et al. (Od60) at $14.10 \mathrm{keV}$ agraes uicely with the Biver $\left(n, n^{\prime}\right)$ seasurement.

Similar results axe given In Fig. 87 for the inelaseic angular distributions to the 3.945-MeV level of ${ }^{14} \mathrm{~N}$. (The solid and dashed curves are as In Fig. 86.) Again, the shape of the angular distr1bution obtained from the 14.10-MeV (P,P') data of Oda et al. (Od60) sgrees well with the $\left(n, n^{\prime}\right)$ measurement by Bauer et al. (Ba63) at $14.15 \mathrm{MeV}$.

Complete grapis of the evaluaced legendre soefficlents as functions of neutron energy are included in Appendix $C$ for all states in ${ }^{14} \mathrm{~N}$ below 8.5-MeV excitation energy. Sample angular distributlons are also given for each level at various incident neutron energies. The angular distributions 

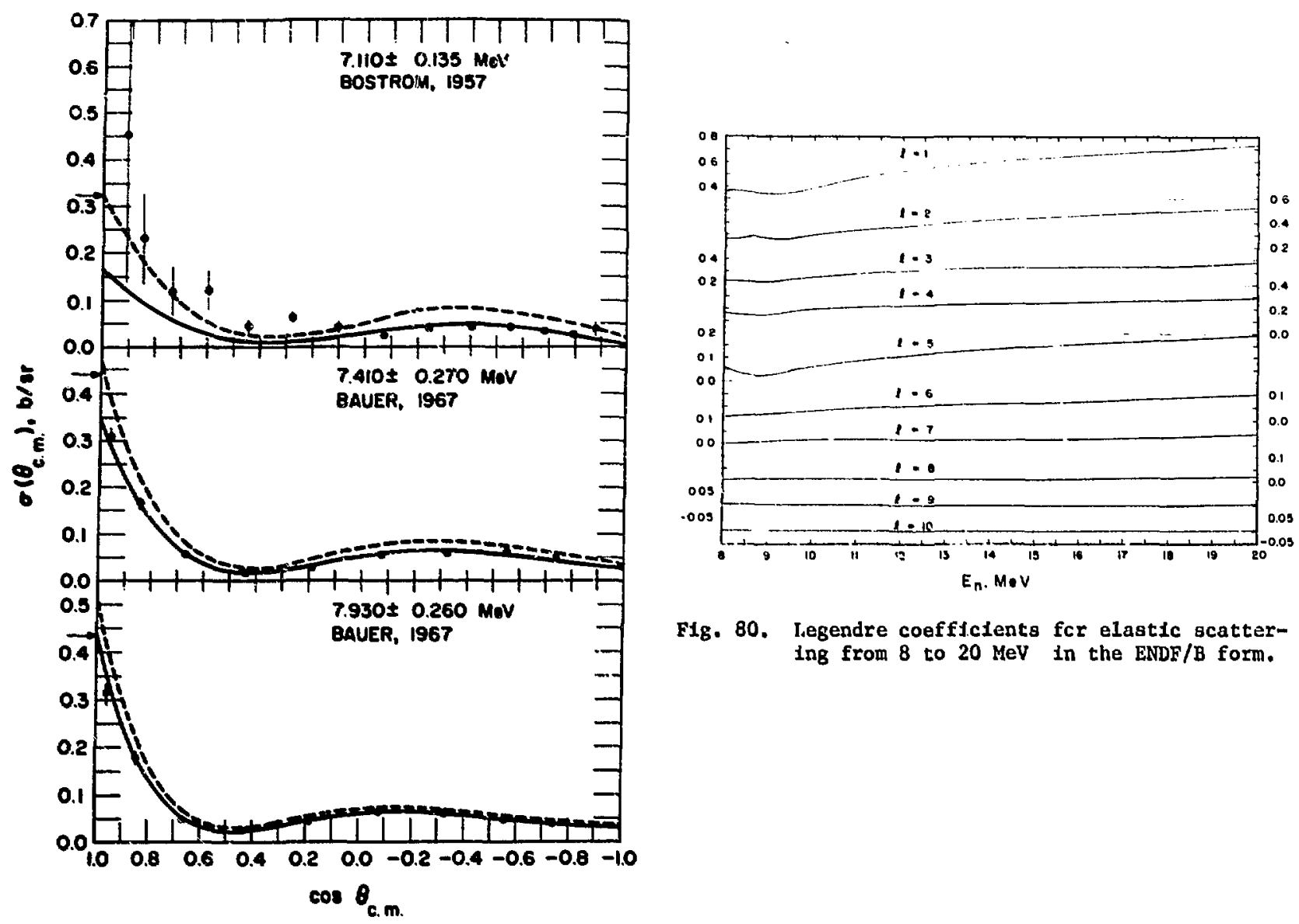

F18. 80. I egendre coefffclents fic elastic scattering from 8 to $20 \mathrm{MeV}$ in the $\mathrm{ENDF} / \mathrm{B}$ form.

F18. 79. Heasured and evaluated differential cross sections for elestic scattering from 7.11 to $7.93 \mathrm{MeV}$.
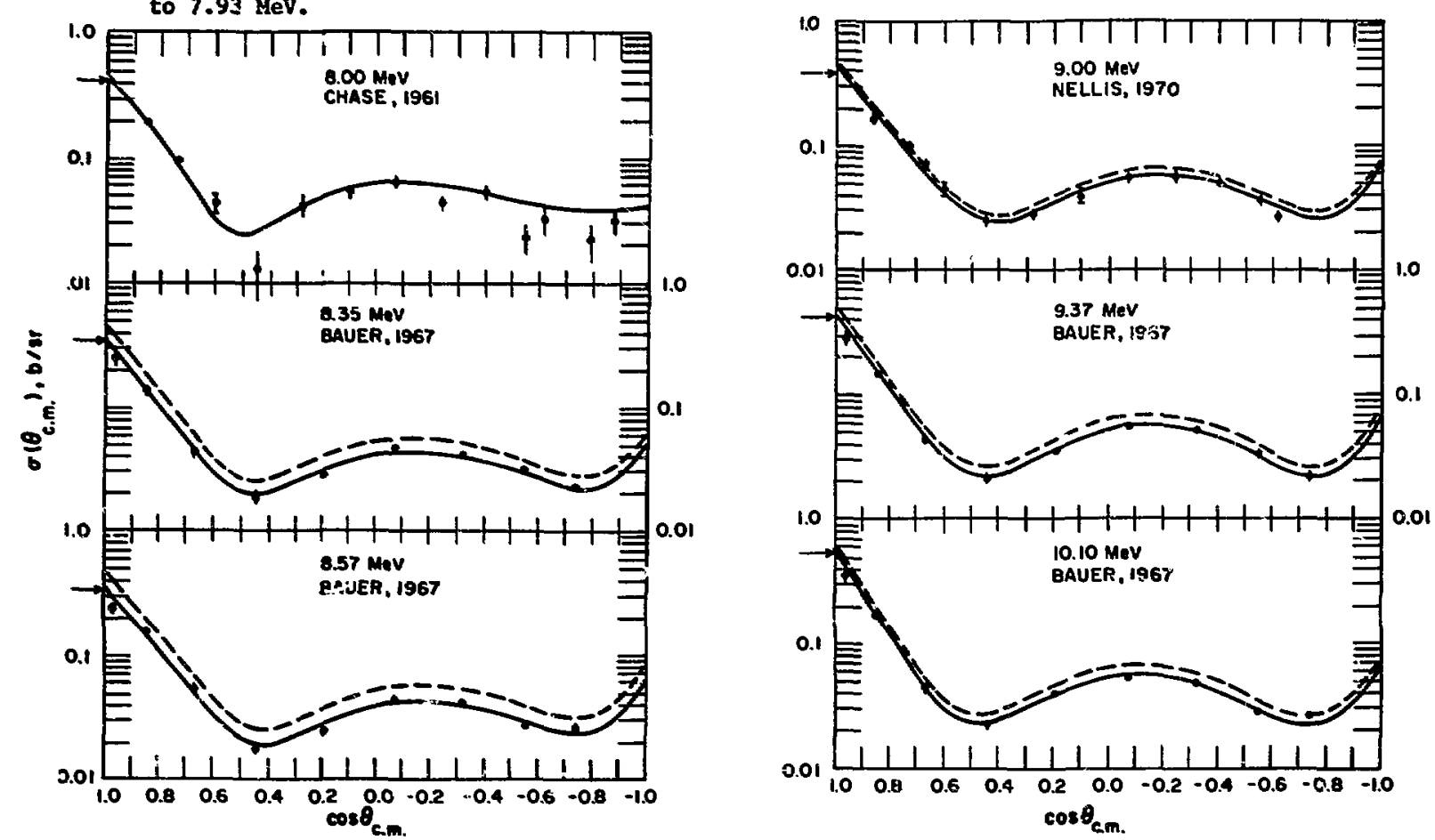

Fig. 81. Measured and evaluated differential cross sections for elastic scattering from 8.00 to 10.1 MeV. 

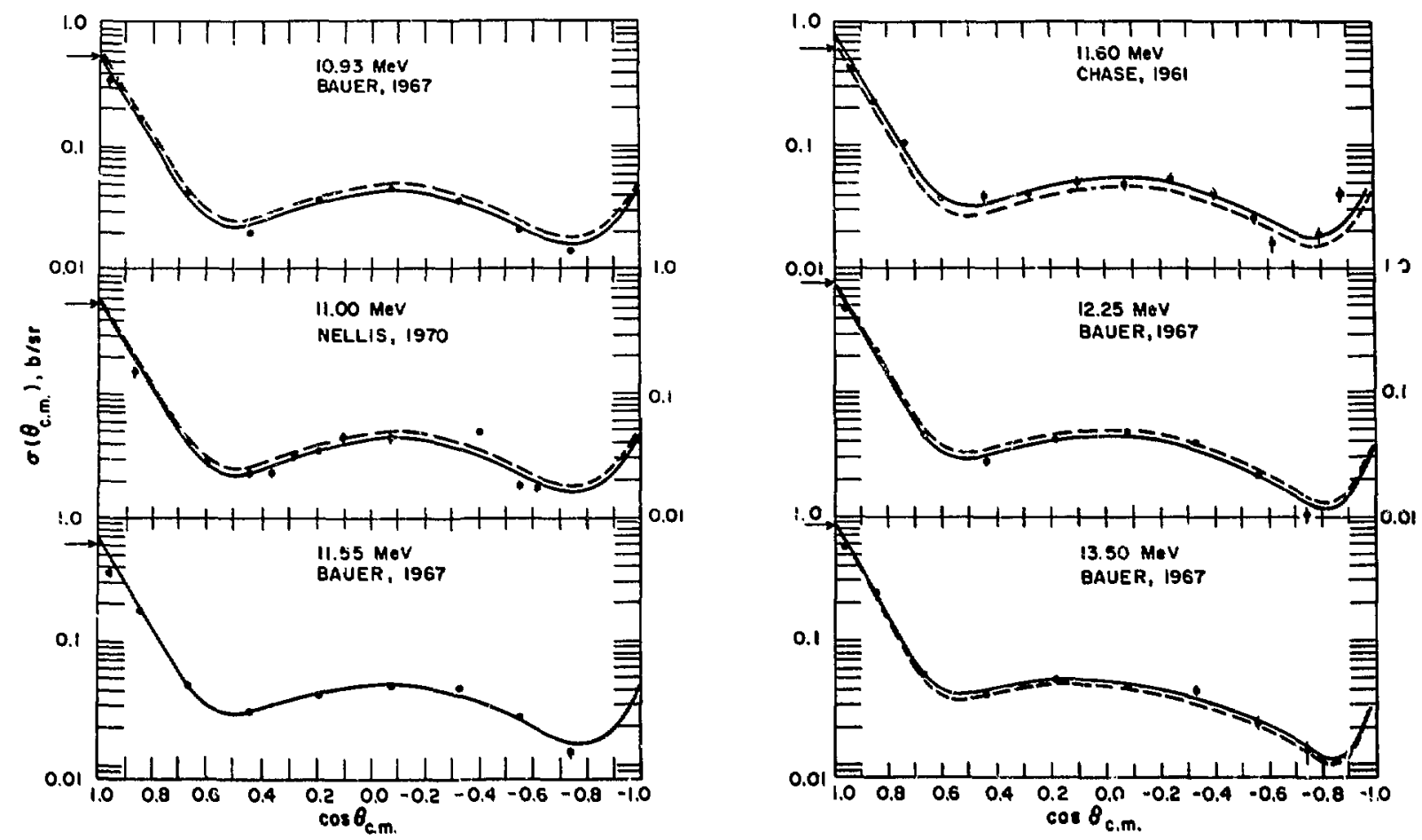

Fig. 82. Measured and evaluated differential cross sections for elastic scattering from 10.9 to 13.5 MeV.
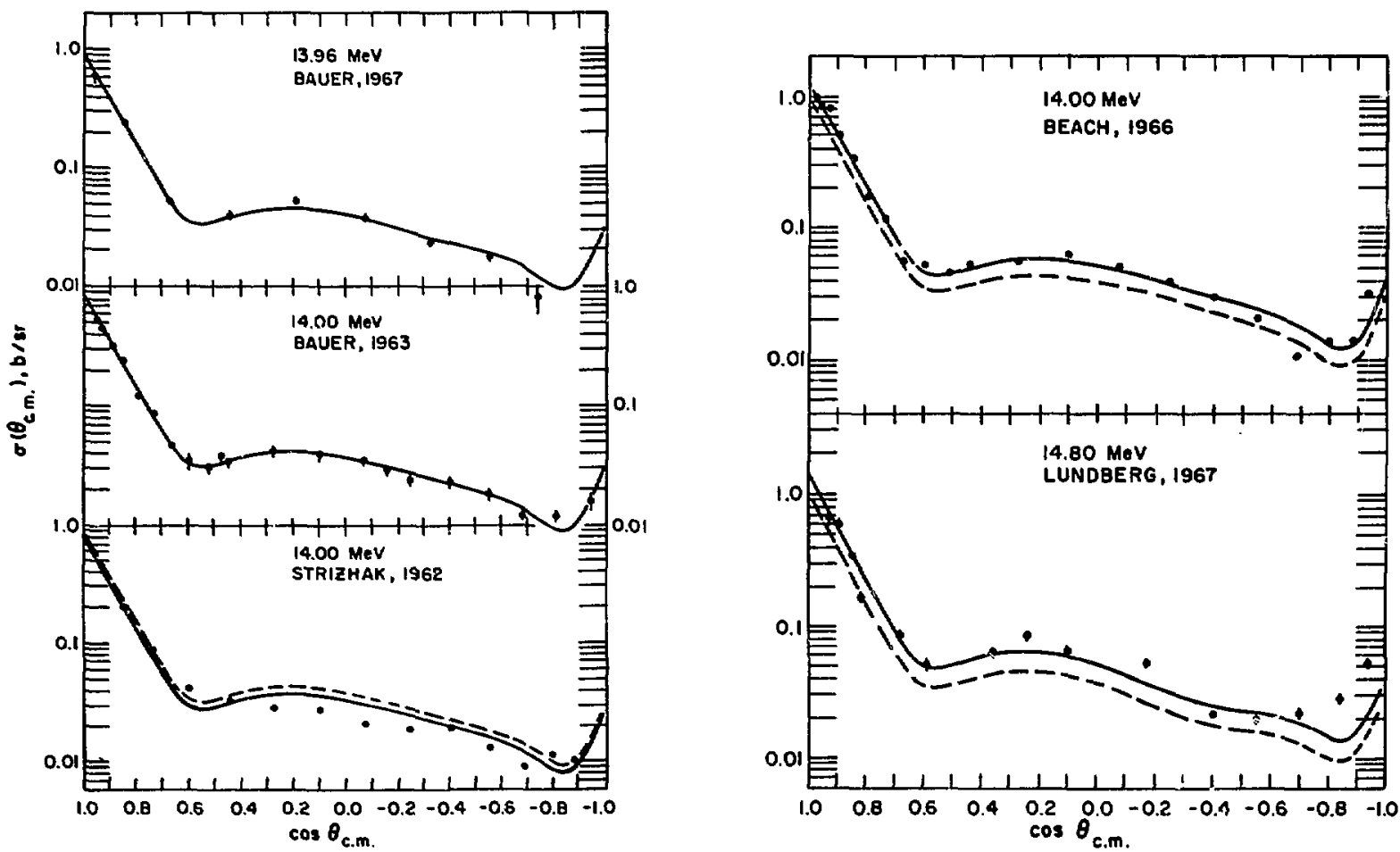

Fig. 83. Measured and evaluated differential cross sections for elastic scattering from 13.9 to $14.8 \mathrm{MeV}$. 


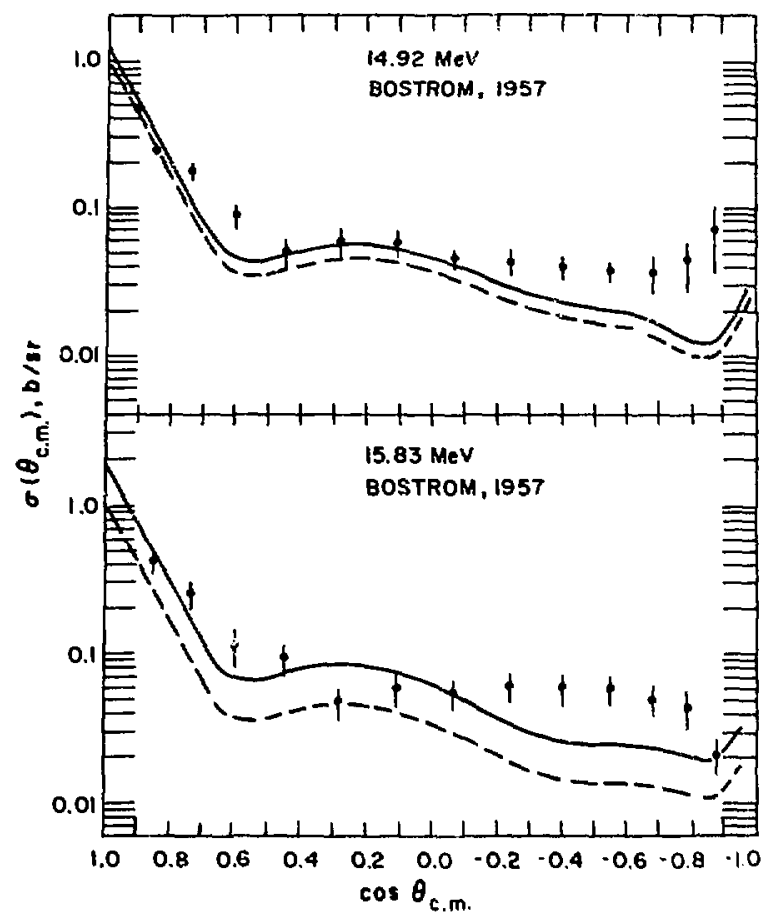

Fig. 84. Measured and evaluated differential cross sections for elastic scattering at 14.92 and $15.83 \mathrm{MeV}$.

for all states with excitation energy higher than $8.5 \mathrm{MeV}$ are assumed to be isotropic in the center-ofmass reference system.

The excellent agreement between the 14-MeV ( $\left.p, p^{\prime}\right)$ and $\left(n, n^{\prime}\right)$ results should not be assumed necessarily to hold true at lower energies, particularly within a few MeV of the threshold for particular reactions. The agreement between the integrated ( $\left.p, p^{\prime}\right)$ cross sections and the $\left(n, n^{\prime}\right)$ cross sections deduced from $\left(n, n^{\prime} y\right)$ measurements is no better than semiquantitative. Therefore, although we expect the evaluated shapes to be reasonably good, calculations that depend critically on the inelastic angular distributions below, say, $10 \mathrm{MeV}$ should be treated with some skepticism.

\subsection{Angular Distributions for the ${ }^{14} N(n, 2 n)^{13} N$ Reaction}

The cross section for the $(n, 2 n)$ reaction is small at all neutron energies ( $<12 \mathrm{mb})$, so no great effort was expended in estimating the neutron angular distribution from this reaction. We obtained the evaluated angular distributions by simply integrating the phase-space expression for the differential cross section used In Sec. 3.9 over outgoing neutron energy. The resulting average angular distribtulons are shown In Fig. 88 .

5. PHOTON ANGUI.AR DISTRIBUTIONS

The thermal-capiure gamma rays from the ${ }^{14} \mathrm{~N}$ $(n, \gamma)^{15} \mathrm{~N}$ reaction are assumed to have isotropic anguiar distributions. This should be a good approxination as the first p-wave resonance does not occur until $434 \mathrm{keV}$, and s-wave cafture must be dominant at lower energies. The single ground-state transition from the ${ }^{14} \mathrm{~N}(n, \gamma)$ reaction in the $\mathrm{MeV}$ region is given the same highly anisotropic angular distribution oliserved by Kuan et al. (Ku70) for the ${ }^{14} N(p, y)$ reaction, with an appropriate adjustment of the energy scale as described in Sec. 3.2.

The only avaflable measurements of gamma-ray angular distributions from $(n, x y)$ reactions at more than two angles are the results of Morgan et al. (Mo64) at $14.8 \mathrm{MeV}$. These measurements indicate that most of the angular distributions are essenthally isotropic, and the only anisotroplc distributions entered into the evaluated files were for the $1.632-$ and $4,913-\mathrm{MeV}$ gamma rays from the $\left(n, n^{\prime} \gamma\right)$ reaction and for the $3.854-\mathrm{MeV}$ gamma ray from the $(n, d y)$ reaction. We obtained the evaluated angular distributions by fitting the $14.8-\mathrm{MeV}$ measurements with even-order Legendre coefficients and then allowing the evaluated coefficients to vary linearly from

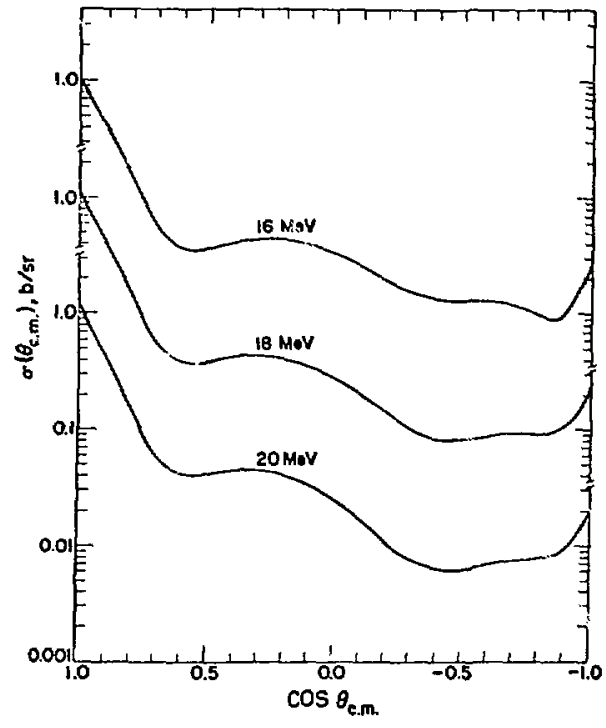

Fig. 85. Differential cross sections for elastic scattering between 16 and $20 \mathrm{MeV}$, calculated from an optical model fitted to the 14-MeV data. 


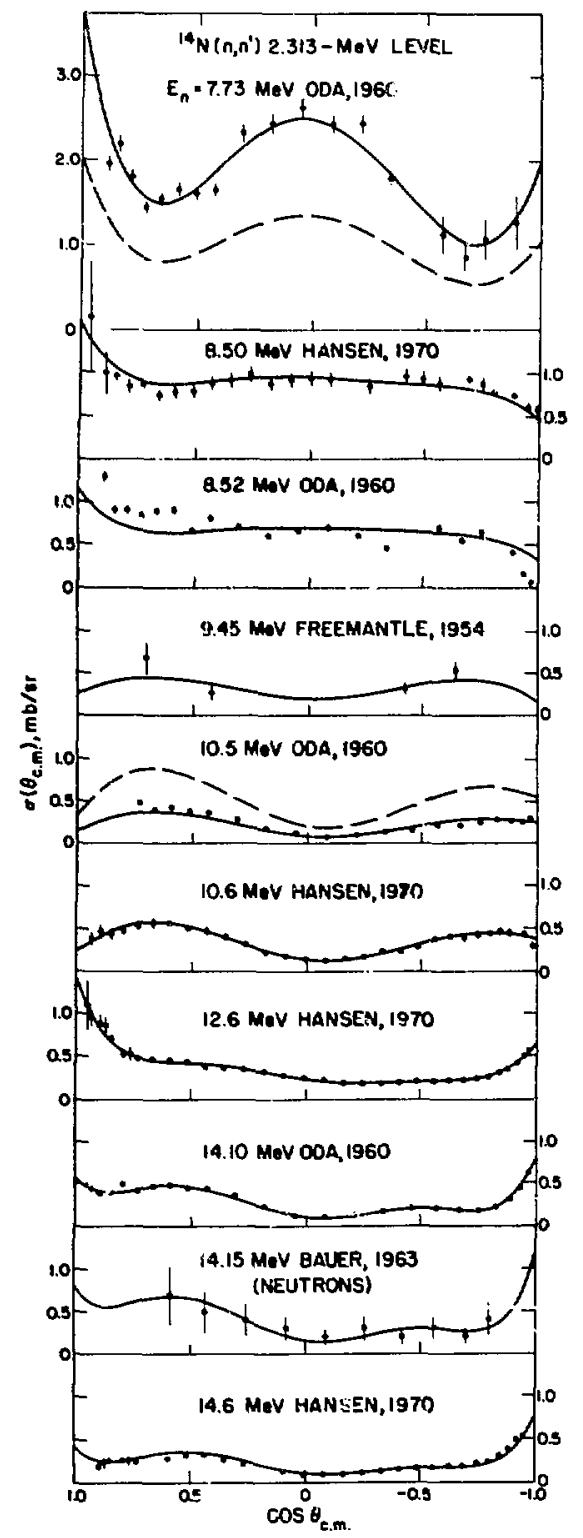

Fig. 86. Comparison of the evaluated $\left(n, n^{\prime}\right)$ angular distributions for the 2.313-MeV level in $14 \mathrm{~N}$ to the $\left(\mathrm{p}, \mathrm{p}^{\prime}\right)$ measurements on which they are based. A single $\left(n, n^{\prime}\right)$ measurement at $14.15 \mathrm{MeV}$ is included.

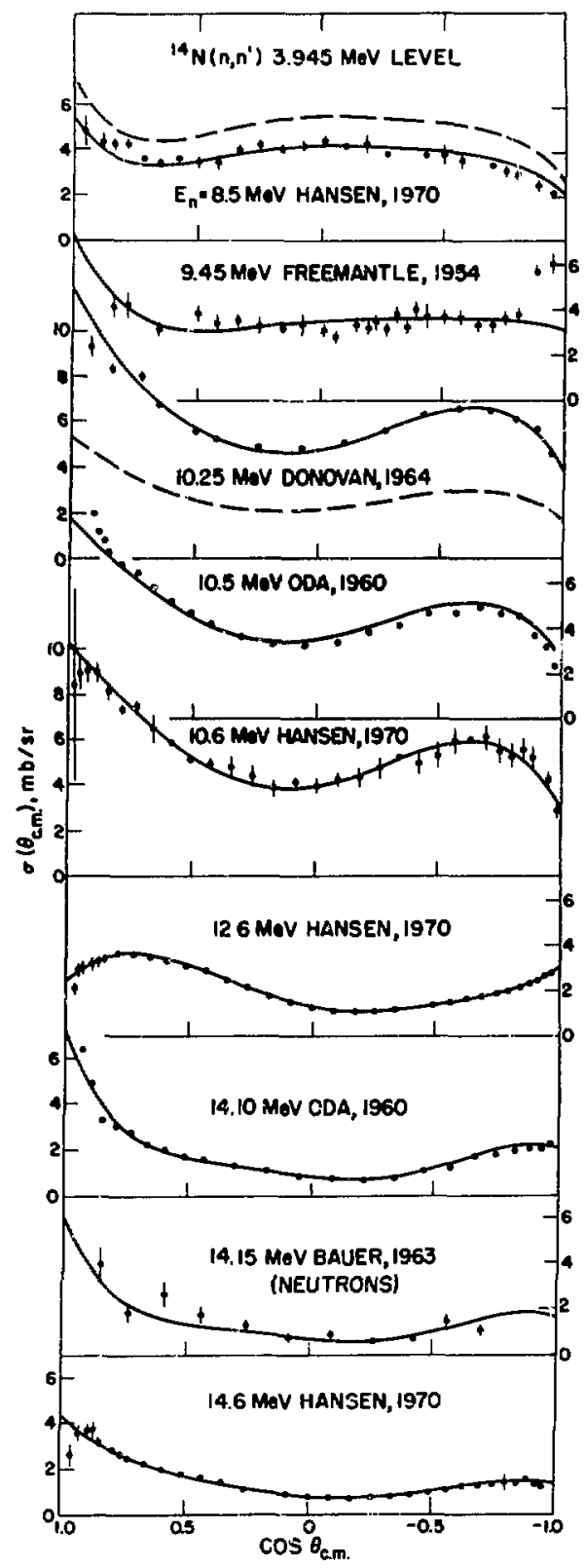

Fig. 87. Evaluated angular distributions for inelastic scattering to the $3.945-\mathrm{MeV}$ leve1 in $14_{\mathrm{N}}$, compared to the $\left(\mathrm{p}, \mathrm{p}^{\prime}\right)$ measurements on which they are based. A single $\left(n, n^{\prime}\right)$ measurement at $14.15 \mathrm{MeV}$ is included. 


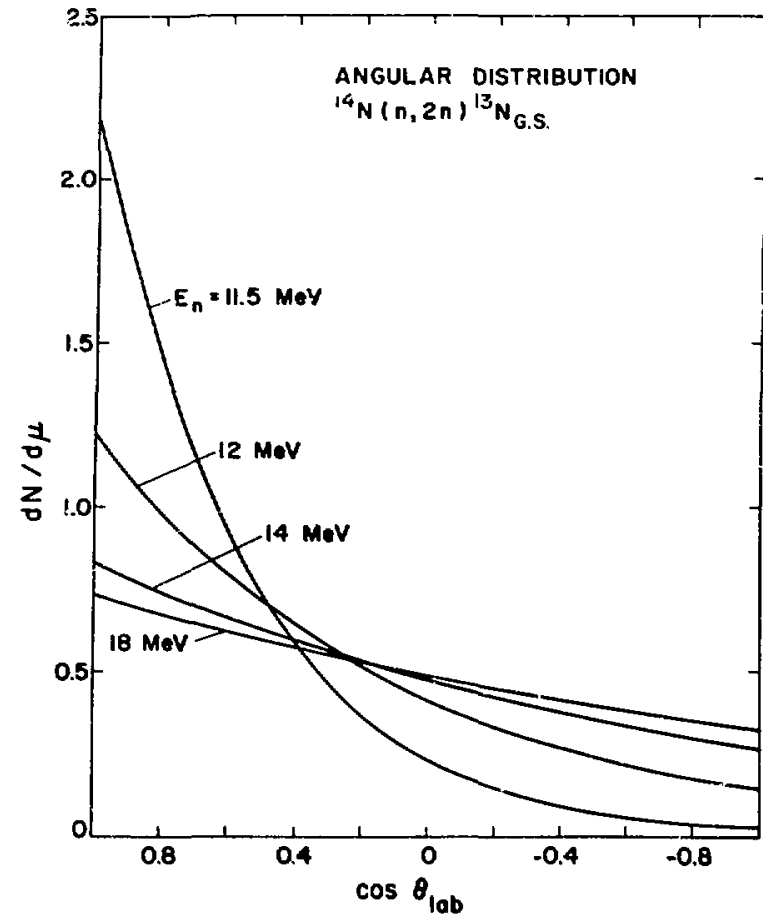

Fig. 88. Eveluated laboratory angular distributions for the $(n, 2 n)$ reaction. The curves are normalized to untt area and averaged over outgoing neutron energy, as described in the rext.

zero at threshold up to the measured value at 14.8 $\mathrm{MeV}$. At higher energies the coefficients are held constant at the $14.8 \mathrm{MeV}$ values. The ratio of $\sigma\left(0^{\circ}\right) / \sigma\left(90^{\circ}\right)$ for the three anisotropic photons is approximately 1.3 at $14.8 \mathrm{MeV}$. The new TNC compllation (Bu?1), which supersedes the Morgan et al. (Mo64) results, states that all gamma rays at $14.8 \mathrm{MeV}$ are isotropic to within $10 \%$.

The $(n, x y)$ measurements made by Dickens and Perey (D169), whIch Include data at $55^{\circ}$ and $90^{\circ}$, provide further information on the anisotroples in the photon angular distributions. These results are generally consistent with the assumption that the anisotropy in the angular distributions is smail, although there are occasional exceptions. A better set of evaluated angular distributions could probably be obtained by a theoretical analysis, but we did not attempt such a study in this evaluation.

\section{DISCUSSION}

While preparing this report, we have found several areas where the evaluation might be improved. The most obvious possibilities for improvement come from the new measurements (Buila, Ne71, Pe71, Yo69) that were unavallable for the evaluation. Although these measurements generally agree with our results, some improvement could be made by their inclusion. A second area that mignt be improved is the theoretical calculations used in the evaluation. Speclfically, all the partial cross sections above 15 $\mathrm{MeV}$ and perhaps some it lower energles could be estimated better with recently improved nucleartheory codes. Similarly, our estimates of the $\left(n, n^{\prime} p \gamma\right)$ and $\left(n, n^{\prime} d \gamma\right)$ cross sectlons could be Improved by better calculations, and a more-complete resonancetheory analysis might be made, although significant improvement in the elastic angular distributions would probably require additional information on states in ${ }^{15} \mathrm{~N}$. Finally, the angular distributions of photons from $(n, x y)$ reactions could be estimated better using existing theorles.

It is useful in many practical applications to be able to estimate the effects of uncertainty in nuclear data on measurements or calculations of various quantities. As an ald to such estimates, we have summarized in Table $X$ the uncertaintles associated with most of the cross sections evaluated for nitrogen at several selected neutron energles. Note that these are semiquantitative estimates that are not expected to hold true in great detall. Further, the errors are averaged over the structure in the cross section, and no allowance for the effect of unknown structure is included. Where posstble, the uncertaintles are based on quoted errors in the experimental measurements, although in several instances we have modified the originai estimates. The errors near threshold for the negative- $Q$ reactions are much larger than those given in Table $\mathrm{x}$. The evaluated elastic angular distributions are expected to have relative errors of the order of $10 \%$. The Inelastic angular distributions are substantially less well known, and thelr accuracy is difficult to estimate. Above $10 \mathrm{MeV}$ the distributions probably have relative errors of about $20 \%$, and at lower energies the accuracy is undoubtediy worse. For the thermal $(n, \gamma)$ photon spectrum, we estimate the relative error for the strong lines to be about $5 \%$, rising to $\sim 20 \%$ for moderately weak lines and a factor of 2 for the very weak lines. 
TABLE $X$

ESTIMATED ERRORS IN THE EVALUATED NITROGEN CROSS SECTIONS

\begin{tabular}{|c|c|c|c|c|c|c|c|c|c|c|c|}
\hline Cross Section & $\begin{array}{c}\text { ENDF/B } \\
\text { Des1gnation } \\
\end{array}$ & $10^{-5} \mathrm{ev}$ & Therma1 & $\underline{0.1 \mathrm{HeV}}$ & $1 \mathrm{MeV}$ & $2 \mathrm{KeV}$ & $5 \mathrm{MeV}$ & $8 \mathrm{MeV}$ & $11 \mathrm{HeV}$ & $14 \mathrm{MeV}$ & $20 \mathrm{MeV}$ \\
\hline Total & $M F-3, M T=1$ & \pm 82 & \pm 37 & \pm 37 & \pm 12 & \pm 18 & \pm 17 & \pm 17 & \pm 18 & \pm 17 & \pm 18 \\
\hline Elastic & $M F=3, M T=2$ & 37 & 37 & 37 & 17 & 17 & $10 x$ & $10 x$ & $15 \%$ & $10 \%$ & 127 \\
\hline Nonelastic & $\mathrm{MF}=3, \mathrm{MT}-3$ & $5 \pi$ & 57 & $30 z$ & $30 \%$ & $30 x$ & $30 z$ & $20 \%$ & $20 \%$ & $15 \%$ & $20 \%$ \\
\hline Total $\left(n, n^{\prime}\right)$ & $M F=3, M T=4$ & - & - & - & - & - & $30 \pi$ & $20 z$ & $20 \%$ & 207 & $25 \%$ \\
\hline $\begin{array}{l}\text { Discrete }\left(n, n^{\prime}\right) \\
E_{x}\left(14_{N}\right)<8.5 \mathrm{MeV}\end{array}$ & $\begin{array}{l}M F=3 \\
M T=5 x-62\end{array}$ & - & $\therefore$ & - & - & - & $30 z$ & $\begin{array}{l}\text { Strong } \\
\text { levels } \\
15 \% \\
\text { Heak } \\
\text { levele } \\
30 \%\end{array}$ & $\begin{array}{l}\text { Strong } \\
\text { levelg } \\
15 \% \\
\text { Weak } \\
\text { levelo } \\
30 \%\end{array}$ & $\begin{array}{l}\text { Strong } \\
\text { levels } \\
15 \% \\
\text { Weak } \\
\text { levelo } \\
30 \%\end{array}$ & $\begin{array}{l}\text { Factor } \\
\text { of } 2\end{array}$ \\
\hline $\begin{array}{l}\text { Discrete }\left(n_{0} n^{\prime}\right) \\
E_{x}(14 N)>8,5 \mathrm{MeV}\end{array}$ & $\begin{array}{l}\text { MF }=3 \\
\text { MT }=63-82\end{array}$ & - & - & - & - & - & - & $=$ & $50 \%$ & $50 \%$ & $50 \%$ \\
\hline$(n, Y)$ & $M F=3, M T-102$ & $10 \%$ & $10 \%$ & $\begin{array}{l}\text { Eactor } \\
\text { of } 4\end{array}$ & $\begin{array}{l}\text { Factor } \\
\text { of } 4\end{array}$ & $\begin{array}{l}\text { Eactor } \\
\text { of } 4\end{array}$ & $\begin{array}{l}\text { Bactor } \\
\text { of } 2\end{array}$ & $\begin{array}{l}\text { Factor } \\
\text { of } 2\end{array}$ & $\begin{array}{l}\text { Factor } \\
\text { of } 2\end{array}$ & $\begin{array}{l}\text { Factor } \\
\text { of } 2\end{array}$ & $\begin{array}{l}\text { Factor } \\
\text { of } 2\end{array}$ \\
\hline $\begin{array}{l}\text { Toral }(n, p) \\
(n, d) \text { and }(n, t)\end{array}$ & $\begin{array}{l}\text { MF-3 } \\
M T=103,104,105\end{array}$ & 57 & 58 & $30 \pi$ & $30 \%$ & $30 \%$ & $30 \%$ & $40 \%$ & 407 & 307 & $\begin{array}{l}\text { Factor } \\
\text { of } 2\end{array}$ \\
\hline Total $(a, a)$ & $M F=3$, MTS-107 & - & $=$ & - & - & $40 \%$ & $30 z$ & $30 \pi$ & $30 \%$ & 307 & $\begin{array}{l}\text { Factor } \\
\text { of } 2\end{array}$ \\
\hline$(n, 2 \alpha)$ & $M T=3, M T=108$ & - & - & - & - & - & - & - & - & $50 x$ & $50 z$ \\
\hline$(n, 2 n)$ & $M F=3, M T=16$ & - & - & - & - & - & - & - & - & $20 \%$ & $20 z$ \\
\hline Total $(n, x y)$ & $\begin{array}{l}\text { MFm13 Sum of } \\
\text { MT-4, 103-107 }\end{array}$ & - & - & - & - & - & $30 \%$ & $20 \%$ & $20 \%$ & $20 \%$ & $25 \%$ \\
\hline $\begin{array}{l}\text { Individual } \\
(n, x y) \text { lines }\end{array}$ & $\begin{array}{l}\text { MFI }=13 \\
\text { FI }=4,103-107\end{array}$ & - & - & - & - & - & $30 z$ & $\begin{array}{l}\text { Strong } \\
\text { levele } \\
157 \\
\text { Weak } \\
\text { levele } \\
30 \%\end{array}$ & $\begin{array}{l}\text { Strong } \\
\text { levele } \\
15 z \\
\text { Weak } \\
\text { levele } \\
30 \%\end{array}$ & $\begin{array}{l}\text { Strong } \\
\text { levels } \\
15 z \\
\text { Weak } \\
\text { levels } \\
30 z\end{array}$ & $\begin{array}{l}\text { Pactor } \\
\text { of } 2\end{array}$ \\
\hline
\end{tabular}

\section{ACKONOWLEDGMENTS}

It is a pleasure to thank $M$. Meissner, D. M. McClellan, and C. I. Baxanan for their gracious cooperation in performing the many clerical tasks needed for this evaluation, and $M$. L. Stein for assistance in plotting much of the data. We also thank $L$. Stewart, F. G. Perey, and M. K. Drake for many informative discussions and comments. Finally, we graiefully acknowledge the many authors who provided us their experimental results in advance of publication. Without their cooperation, this evaluation would have been substantlally reduced in content.

\section{REFEERENCES}

A 368 F. Ajzenberg-Selove and T. Leuritsen, "Energy Levels of Light Nucle1 (VII). A=ll-12," Nucl. Phys. All 4, 1 (1968).

Aj70 F. Ajzenberg-Selove, "Energy Levels of Light Nuclei A=13-15," Nucl. Phys. Al52, 1 (1970).

Al66 D. E. Alburger, A. Gallmann, J. B. Nelson, J. T. Sample, and E. K. Warburton, "Properties of Excited States in $\mathrm{C}^{14}$," Phys. Rev. 148, 1050 (1966).
An64 J. D. Anderson and J. W. Mcclure, "Inelast1c Scattering of $14 \mathrm{MeV}$ Neutrons from Nitrogen," WASH-1048, p. 48 (1964).

An67 J. D. Anderson, C. Wong, and V. A. Madsen, "Application of Charge Independence to Neutron Inelast1c Scattering," Lawrence Lfvermore Laboratory report UCRL-50197 (1967).

An70 W. Anderson, private comanication (1970).

As58 v. J. Ashby, H. C. Catron, L. L. Newkirk, and C. J. Taylor, "Absolute Meesurement of $(n, 2 n)$ Cross Sections at 14.1 MeV," Phys. Rev. 11l, 616 (1958).

Au62 E. H. Auerbach, "Abacus-2 (Revised Version)," Brookhaven National Laboratory rejort BNL-6562 (1962).

Ba49 R. Batchelor and B. H. Flowers, "Thermal Neutron Capture in Nitrogen, " Harwell Laboratory report AERE-N/R-370 (1949).

Ba57 G. A. Burtholomew and P. J. Camplon, "Neutron Cepture Germe Rays from Lithium, Boron, and Nitrogen," Can. J. Phys. 35, 1347 (1957).

Ba63 R. W. Bauer, J. D. Anderson, and L. J. Christensen, "Scattering of $14 \mathrm{MeV}$ Neutrons from Nitrogen and Oxygen, "Nucl. Phys. 47, 241 $(1963)$. 
Ba67 R. W. Bauer, J. D. Anderson, H. F. Lutz, C. Wong, J. W. McClure, and B. A. Pohl, "Elastic Scattering for 7 to $14 \mathrm{MeV}$ Neutrons from $\mathrm{N1}$ trogen," Nucl. Plays. A 93,673 (1967).

Ba68 R. Bachinger and M. Uhl, "Die Reaktion ${ }^{14} \mathrm{~N}$ $(n, \alpha)$ I mit 14.1 MeV Neutronen, "Nucl. Phys. A116, 673 (1968).

Be56 R. L. Becker ard H. H. Barschall, "Total Cross Sections of Light Elements for $(\alpha, n)$ Neutrons," Phys. Rev. 102, 1384 (1956).

Be63 R. E. Benenson and B. Yaramis, $" C^{13}(\alpha, n) N^{14}$ and $0^{18}(d, n) F^{19}$ Differential Cross Sections at $3.9 \mathrm{MeV}$ Bombarding Energy, "Phys. Rev. 129, 720 (1963).

Be66 P. L. Beach, R. W. Finlay, R. D. Koshel, and R. L. Cassola, "Elastic Neutron Scattering from $\mathrm{N}, \mathrm{O}$, and $\mathrm{Ar}$ at $14.1 \mathrm{MeV}$, Bull. Am. Phys. Soc. 11, 471 (1966).

Be68 R. A. I. Bell, R. D. G1ll, B. C. Robertson, J. S. Lopes, and H. J. Rpse, "Electromagnetic Transitions in ${ }^{1 l_{B}}$ and ${ }^{1}{ }_{C}, "$ Nucl. Phys. All8, 481 (1968).

B159 E. G. Bilpuch, L. W. Weston, C. D. Bowman, and H. W. Newson, "Recent Total Neutron Cross Sections for $\mathrm{LI}, \mathrm{N}, \mathrm{C}, \mathrm{Cl}, \mathrm{Co}, \mathrm{Sr}$, and $\mathrm{Pb}$," Bull. Am. Phys. Soc. 4, 42 (1959).

B162 B. G. Bilpuch, J. A. Farrell, G. C. Kyiker, P. B. Parks, and H. W. Newron, private conmun1cation to R. J. Howerton (1962).

Bl52 J. M. Blatt and V. F. Weisskopf, Theoretical Nuclear Physics, John Wiley and sons, N. Y. (1952).

Bl52a J. M. Biatt ¿ L. C. Biedenharn, "The Angular Distribution of Scattering and Reaction Cross Sections," Rev. Mod. Phys. 24, 258 (1952).

Bo51 W. Bollmen and $W$, Zünt1 $1_{\text {"WIrkungsquerschnitt }}$ messungen des $\mathrm{N}^{14}(n, \alpha) \mathrm{B}^{11}$ - und des $\mathrm{N}^{14}(n, p) \mathrm{C}^{14}$. Prozesses mit monochromatischen D-D-Neutronen," Helv. Phys. Acta 24, 517 (1951).

Bo57 N. A. Bostrom, I. L. Morgan, J. T. Prud 'homne, and A. R. Sattar, "The Elastic Scattering of Fast Neutrons from Oxygen and Nitrogen, " Wright A1r Development Center report WADC-TR-57-446 (1957).

Bo59 N. A. Bostrom, I. L. Morgan, J. T. Prud 'homme, P. L. Okhuysen, and 0 . M. Hudson, Jr., "Interaction of Fast Neutrons in Iron, Lead, Oxygen, and Nitrogen, "Wright Air Development Center report WADC-IR-59-.3]. (1959).

Bo62 V. V. Bobyr, L. Ye. Grona, and V. I. Strizhak, "Anguiar Distribution of 14-Mey Neutrons Inelastically Scatter:d on Carbon, Nitrogen, and Sulfur," Soviet Phys.-JETP 14, 18 (196?).

Bo65 M. Bormann, E. Fretwurst, P. Schehka, G. Wrege, H. Büttner, A. Lindner, and H. Meldner, "Some Excitation Functions of Neutron Induced" Reactions in the Energy Range 12.6-19.6 MeV," Nucl. Phys. 63, $438(1965)$.
Bo68 F. Borel1, P. N. Shrivastava, B. B. Kinsey, and V. D. Mistry, "Proton and Neutron Resonances in Nitrogen," Phys. Rev. 174, 1221 (1968); University of Texas deport ORO-2972-47 (1967).

Br61 0. D. Brill, N. A. Vlasov, S. P. Kalinin, and L. S. Sokolov "Cross Section of the $(n, 2 n)$ Reaction in $\mathrm{C}^{12}, \mathrm{~N}^{14}, \mathrm{O}^{16}$, and $\mathrm{F}^{19}$ in the Energy Interval 10-37 Mev," Soviet Phys.Doklady 6, 24 (1961).

Br64 G. Breit, "Definitions of Comoound States," Rev. Mod. Phys. 36, 1072 (196ї).

Buó9 P. S. Buchanan, "A Compllation of Cross Sections and Angular Distributions of Gamma Rays Produced by Neutron Bombardment of Various Nuclei," Texas Nuclear Corporation report ORO-2791-28 (1969).

Bu71 P. S. Buchanen, D. O. Nellis, and W. E. Tucker, "A Compilation of Cross Sections and Anguler Distributions of Gamma Rays Produced by Neu. tron Bombardment of Verlous Nucle1," Texas Nuclear Corporation report ORO-2791-32 (1971).

Bu7la W. P. Bucher, C. E. Hollandeworth, R. D. Lamoreaux, A. Niller, R. R. Sankey, and D. Eccleshall, "Smail-Angle Elastis Scattering of 7.55 and $9.50 \mathrm{MeV}$ Neutrons from $\mathrm{C}, \mathrm{N}$, and 0 ," Ballistic Research Laboratory report BRL R 1562 (1971).

Ca57 R. R. Carlson, "Cross Sections :'or Plckup Reactions of $14-\mathrm{MeV}$ INeutrons with $\mathrm{N}^{14}$, "Phys. Rev. 107, 1094 (1957).

Ca66 R. R. Carlson, "Branching Rations in $\mathrm{C}^{14}$ and $\mathrm{N}^{14}$," Phys. Rev. 148, 991 (1966).

Ca70 A. D. Carlson and R. J. Cerbone, "High Resolution Measurements of the Total Neutron Cross Sections of Nitrogen and Iron," Nucl. Sci. Eng. 42, 28 (1970).

Ce62 M. Cevolant and S. Petralia, "Cross Section Measurement of $(n, 2 n)$ Reactions on $14.1-\mathrm{MeV}$ Neutrons, " Nuovo Cimento 26, 1328 (1962).

Ch6l L. F. Chase, Jr., R. V. Smith, R. G. Johnson, F. J. Vaughn, and M. Walt, "Fast Neutron Cross Sections of Oxygen and Nitrogen," Air Force Special Weapons Center report AFSWC-TR-61-15 (1961).

Cl69 G. Clayeux and G. Grenier, "Spectres de renvo1 des gammas produits par des neutrons de 14.1 $\mathrm{MeV}, "$ Centre d'Etudes de Limell report CEA$\mathrm{R}-3807$ (1969).

Co49 J. H. Coon and R. A. Hobles, "D1sintegration of $\mathrm{He}^{3}$ and $\mathrm{N}^{14}$ by Thermal Neutrons," Phys. Rev. 75, 1358 (1949).

Co49a L. J. Cook, E. M. McMillan, J. M. Peterson, and D. C. Sewell, "Total Cross Sections of Ruclei for 90-Mev Neutrons," Phys. Rev. 75, 7 (1949).

Co52 J. H. Coon, E. R. Graves, and H. H. Barschall, "Total Cross Sections for $14 \mathrm{MeV}$ Neutrons," Phys. Rev. 88, 562 (1952). 
Co68 H. Conde', I. Bergquist, and G. Hyström, "Gamma-Rays from Inelastic Neutron Scattering in Nitrogen, "Neut. Cross Sect. and Tech. Conf. Wash., n. c., (7.68), p. 763 .

Cs56 J. Csikaj, "Fluctuations in the Total Cross Sertions of $(n, 2 n)$ Reactions, "Conference on the Stuly of Nucl. Structure with Neutrons, Antwerp, 1965 North-Holland Publishing Co., Amsterdam, 1966i) p. 537.

CsGT J. Csikai and S. Nagy, "Sone $(n, p)$ Reaction Cross Sections f'or 14.7 MeV Neutrons," Nucl. Phys. A91, 222 (1967).

Cs67a J. Csikai and G. Peto, "Influence of Direct Inelastic scattering on $(n, 2 n)$ Cross Sections, " Acte Phys. Aced. Se1. Hung. 23, 87 (1967).

Cu51 P. cüer, J.-P. Lonchamp, and S. Gorodetzky, "Determination de la section de desintegration de l'azote sous l'action des neutrons thermiques," J. Phys. Radium 12, $6 \mathrm{~s}$ (1951).

De50 J. DeJuren and N. Knable, "Nuclear Cross Sections for 95-Mev Neutrons," Phys. Rev. 77, $606(1950)$.

De65 Yu. G. Degtyarev, "Cross Sections for the Inelastic Interaction of Neutrons with Nuclei of $\mathrm{H}^{7}, \mathrm{C}^{12}, \mathrm{~N}^{14}, \mathrm{Al}^{27}, \mathrm{Fe}^{56}, \mathrm{Cu}, \mathrm{Pb}, \mathrm{U}^{235}$, $\mathrm{U}^{238}$, and Pu239," Soviet J. At. Energy 19, 1426 (1965).

Di69 J. K. Dickens and F. G. Perey, "The I is $y(n, x \gamma)$ Reection for $5.8 \leq \mathrm{I}_{\mathrm{p}} \leq 8.6 \mathrm{MeV}$," Nucl. Sc1. Fiag. 36, $280(1969)$.

Do64 P. F. Dronovan, J. F. Mollenauer, and E. K. Harburton, "Inelastic Scattering of $10.2 \mathrm{-MeV}$ Protons by N14," Phys. Rev. 133, B113 (1964).

Du54 J. D. Dudiey and C. M. Class, $" 14 n(n, 2 n) 13 N$ Cross-Section Measurement with $14 \mathrm{MeV} \mathrm{Neu-}$ trons," Phys. Rev. 94, 807 (1954).

En67 F. C. Engesser and W. E. Thompson, "Ganme Rays Resulting from Interactions of $14.7 \mathrm{MeV}$ Neutrons with Verious Elements," J. Nucl. Energy 21, 487 (1967).

Fe6o J. M. Fergusin and W. E. Thompson, "Cross Sections for the $(n, 2 n)$ Reaction in $\mathrm{N}^{14}, \mathrm{p}^{31}$, $\mathrm{Cu}^{63}$, and $\mathrm{Pr}^{141}$," Phys. Rev. 118, 228 (1960).

Fe67 P. Fessenden and D. R. Maxson, "N $\mathrm{H}^{1}+(n, d) \mathrm{C}^{13}$, $\mathrm{N}^{14}(\mathrm{n}, \mathrm{t}) \mathrm{C}^{\mathrm{l} 2}$, and $\mathrm{N}^{\mathrm{i}}(\mathrm{n}, \mathrm{d}) \mathrm{C}^{14}$ near $\mathrm{E}_{\mathrm{n}}=14 \mathrm{MeV}, "$ Phys. Rev. 158, 948 (1967).

Fe68 J. M. Ferguson, "A Code for Calculating Neutron Compound-Nucleus Cross Sections and Angular Distributions: JANE," Naval Radiological Defense Laboratory report NRDL-CP-68-4 (1968).

F158 N. N. Flerov and V. M. Talyzin, "Cross Section for Inelastic Interactions of $14.5 \mathrm{MeV}$ Neutrons with Various Elements," Soviet J. At. Energy 1, 617 (1958).

Fo55 J. I. Fowler and C. H. Johnson, "Differential Elastic Scattering Cross Section for Neutrons on Nitrogen," Phys. Rev. 98, 728 (1955).
Fo66 J. L. Forler, C. H. Johnson, and R. L. Kernell, "Differential Elastic Scattering of Neutrons from Nitrogen," Neut. Cross Sect. and Tech. Conf. Wash., D. C. $(1968)$, p. 553 .

Fo71 D. G. Foster, Jr., and D. W. Glasgow, "Neutron Total Cross Sections 2.5-15 MeV. I. Experimental," Phys. Rev. C 3, 576 (1971).

Fr54 R. G. Freemantle, D. J. Prowse, and J. Rotblat, "Scattering of $9.5-\mathrm{MeV}$ Protons by Nitrogen," Phys. Rev. 96, 1268 (1954).

Ga59 F. Gabbard, H. Bichsel, and T. W. Bonner, "The Disintegration of Nitrogen by Fast Neutrons," Nucl. Phys. 14, 277 (1959).

Ga63 F. Gabbard, private communication to the Sigma Center at the Broolchaven National Laboratory (1963).

Ga66 A. Gullmann, P. Fintz, J. B. Nelson, and D. E. Alburger, "Study of Excited States in $\mathrm{N}^{15}$

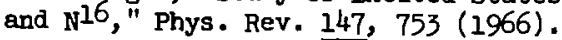

Ga67 A. Gallmann, F. Hass, and B. Heusch, "study of Unbound Levels in $\mathrm{N}^{14}$ by the $\mathrm{C}^{12}\left(\mathrm{He}^{3}, \mathrm{py}\right) \mathrm{N}^{14}$ Reaction," Phys. Rev. 164, 1257 (1967).

G159 J. K. Gibbons and R. J. Macklin, "Yotal Neutron Yields from Light Nucle1 under Proton and Alphe Bombardment," Phys. Rev. 114, 571 (1959).

Go65 N. W. Golchert, D. O. Gardner, and J. Sedlet, "Cross Section of Some Reactions of 99 , with 14.1 MeV Neutrons," Nucl. Phys. 73, 349 (1965)。

Go66 S. Gorodetzky, R. M. Freeman, A. Galimann, and F. Haas, "Angular-Correlation Studies" the Reactions $\mathrm{O}^{16}\left(\mathrm{He}^{3}, \mathrm{\alpha r}\right) \mathrm{O}^{15}, \mathrm{C}^{12}\left(\mathrm{He}^{3}, \mathrm{pr}\right) \mathrm{N}^{14}$ and $c^{12}(d, p y) c^{13}$," Phys. Rev. 149, 801 (1966).

Gr65 B. Grimeland, E. KJellsby, and J. Vines, "Cross Sections of Some Reactions Induced in Nitrogen, Phosphorus, Copper, and Bromine with Neutrons of Energy 14.8 MeV," Phys. Rev. 137. B878 (1965).

Gr68 R. C. Greenwood, "Observation of a $9.15 \mathrm{MeV}$ Doublet Level in $15 \mathrm{~N}$ from a Study of the $14 \mathrm{~N}$ $(n, y) 15$ N Reaction, "Phys. Letters 27B, 274 (1968).

Ha52 W. Hauser and H. Feshbach, "The Inelastic Scattering of Neutrons," Phys, Rev. 87, 366 (1952).

Ha59 H. E. Hall and T. W. Bonner, "Ganma Radiations from Inelastic Scattering of Fast Neutrons in $\mathrm{C}^{12}, \mathrm{~N}^{14}$, and $0^{16}$," Nucl. Phys. 14, 295 (1959).

Ha 59 E. Haddad, quoted as private communication by Ge59.

Ha6l G. C. Hanna, D. B. Primeau, and P. R. Tunnicliffe, "Thermal Neutron Cross Sections and Resonance Integrals of the Reactions $0^{17}(n, \alpha)$ Cl4, $\operatorname{Ar} 36(n, \alpha) s^{33}$, and $\mathbf{N}^{14}(n, p) c^{14}, "$ Can. J. Phys. 39, 1784 (1961).

Ha70 L. F. Hansen, private communication (1970). 
He60 D. F. Hebbard and J. L. Vogl, "Elastic Scattering and Radiative capture of Protons by c13," Nucl. Phys. 21, 652 (1960).

He70 H. T. Heaton, II, R. B. Schwartz, and R. A. Schrack, "Total Cross Section of Nitrogen in the MeV Region," Bull. Am. Phys. Soc. 15, 568 (1970).

H150 R. H. Hildebrand and C. E. Leith, "Total Cross Sections of Nucle1 for 42-MeV Neutrons," Phys. Rev. 80, B4t2 (1950).

Hi52 J. J. Hinchey, P. H. Stelson, and W. M. Preston, "The Total Neutron Cross Section of N1trogen," Phys. Rev. 86, 483 (1952).

H154 P. Hillman, R. H. Stahl, and N. F. Ramsey, "Total Cross Sections of Liquefied Gases for High-Energy Neutrons," Phys. Rev. 96, 115 (1954).

Hu6l C. M. Huddleston and F. P. Mooring, "Total Neutrc 1 iross Section of Nitrogen and oxygen from $1 \mathrm{keV}$ to $450 \mathrm{keV}$, "Argonne National Iaboratory report ANL-6376, 13 (1961).

Jo50 C. H. Johnson and H. H. Barschall, "Interaction of Fast Neutrons with Nitrogen," Phys. Rev. 80, 818 (1950).

Jo5l C. H. Johnson, B. Petree, and R. K. Adair, 'Total Cross Section of Nitrogen for Fast Neutrons; Phys. Rev. 84, 775 (1.951).

$J 052$ C. H. Johnson, H. B. Willard, J. K. Bair, and J. D. Kington, "Total Neutron Cross Sections of $\mathrm{NI}^{4}$, Ge, Se, Cd, and hs," Onk Ridge National Laboratory report ORNL-1365, p. 1 (1952).

Jo68 C. H. Johnson, F. X. Haas, J. L. Fowler, F. D. Mart in, R. L. Kernell, and H. O. Cohn, "Total Neutron Cross Sections of $9 \mathrm{Be}, 14 \mathrm{~N}$, and $16_{0}$," Neutron Cross Sections and Technology Conf. Wash., D. C., (1908) p. 851 .

Jo69 L. Jonsson and R. Hardell, "Energies and Intensities of Gamma Rays from Slow Neutron Capture in Nitrogen, " International Symposium on Neutron Capture Gamma-Ray Spectroscopy, Studsvik, 1969 (to be published).

Ju63 E. T. Jurney and H. T. Mots, "Thermal Neutron Capture in D and 016," Argonne National Laboratory report ANL-6797, p. 236 (1963).

Ka60 J. V, Kane, R. E. Pixley, and D. H. Wilkinson, "Isotopic Spin Selection Rules XIV: Transi. tions between Mirror States in $13 \mathrm{C}$ and $1 \hat{J}_{\mathrm{N}}$," Ph11. Mag. 5, 365 (1960).

KuTO H. M. Kuan, M. Hasinoff, W. J. O'Connell, and S. S. Hanna, "The Giant Dipole Resonences in ${ }^{1} \mathrm{l}_{\mathrm{C}}$ and 150 observed with the Reactions $10_{\mathrm{B}}$ $(p, \gamma) 1 l_{C}$ and $14_{N}(p, \gamma) 150$, "Nucl. Phys. Al51, 129 (1970).

LA58 A. M. Lane and R. G. Thomes, "R-Matrix Theory of Nuclear Reactions," Rev. Mod. Phys. 30, 257 (1958).
Le68 B. Leroux, K. El-Hammami, J. Dalmas, R. Chastel, G. Lamot, C. Fayard, and J. HajJboutros, "Etudes des reactions $(n, 0 !)$ sur les noyaux 160 et $14 \mathrm{~N}$ a $14.9 \mathrm{MeV}, "$ Nucl. Phys. Al16, 196 (1968).

Li52 A. B. Lille, "The Disintegration of Oxygen and Nitrogen by 14.1-MeV Neutrons," Phys. Rev. 87, 716 (1952).

Li67 R. H. Lindsay and J,J. Veit, "N14 $(n, t)$ and $\mathrm{N}^{4}(\mathrm{n}, \mathrm{d})$ Anglular Distributions at $14.7 \mathrm{MeV}$," Phys. Rev. 157, 933 (1967).

Lu66 H. F. Lutz and J. D. Anderson, "Neutron Cross Sections Inferred from Charged Particle Data," Lawrence LIvermore Laboratory report UCRL14568 ( 1.966 ).

Lu67 B. Lundberg, S. Schwarz, and H. O. Zetterstrom, "Elastic Scattering of $14.8 \mathrm{MeV}$ Neutrons from $14 \mathrm{~N}$ and ${ }^{16}$ o, "Arkiv Fysik 34, 247 (1967).

Maj6 R. J. Mackin, Jr., W. R. Mills, Jr., and J. Thirion, "Radiation from Excited States of Carbon-13," Phy's. Rev. 102, 802 (1956).

Ma65 J. H. E. Mattauch, W. Thlele, and A. H. Wapstra, "1964 Atomic Mass Table," Nucl. Phys. 67, 1 (1965).

Ma66 G. S. Man1 and G. C. Putt, "Reaction Mechanism for the ${ }^{1 l_{B}(\alpha, n)} 14_{N}$ Reaction, "Nucl. Phys. 78,613 (1966).

Ma68 D. R. Maxson and R. D. Murphy, $" 160(n, \alpha)^{13} \mathrm{C}$ Reaction at $14.1 \mathrm{MeV}$, Nucl. Phys. Allo, 555 (1968).

Ma68a G. N. Maslov, F. Nasyrov, and N. F. Paghkin, "r-Radiation in the Interaction of $14 \mathrm{MeV}$ Neutrons with the Nuclei of B, C, N, I, F, and Al Atoms," Soviet J. At. Energy 24, 704 (1968).

Ma69 R. E. Maerker and F. J. Muckenthaler, "GammaRay Spectra Arlsing from Thermal-Neutron Capture in Elements Found in Solls, Concretes, and Structural Materlals," Oak Ridge National Laboratory report ORNL-4382 (1969).

Mc66 L. Mcradden and G. R. Satchler, "Optical-Model Analysis of the Scattering of $24.7 \mathrm{MeV}$ Alpha Particles," Nucl. Phys. 84, 177 (1966).

Me49 E. Melkonian, "Slow Neutron Velocity Spectrometer Studies of $\mathrm{O}_{2}, \mathrm{~N}_{2}, \mathrm{~A}, \mathrm{H}_{2}, \mathrm{H}_{2} \mathrm{O}$, and Seven Hydrocarbons," Phys. Rev. 76, 1750 (1949).

Me53 R. Meler, R. Ricamo, P. Scherrer, and $W$. Zünti, "Totale Wirkungsquerschnitte der Elemente $\mathrm{N}$, $\mathrm{Na}, \mathrm{Al}$ und Si fïr Neutronen von 1.9-3.8 MeV," Helv. Phys. Acta 26, 451 (1953).

Me66 D. F. Measday and J. N. Palmiert, "Neutron Total Cross Sections in the Energy Range 80 to $150 \mathrm{MeV}$," Nucl. Phys. 85, 129 (1966).

Mi68 D. Miljanic, G. Paic, B. Antolkoyic, and $P$. Tomas, "( $\mathrm{n}, \mathrm{d})$ Reactions on $14 \mathrm{~N}, 35 \mathrm{Cl}, 3 \mathrm{~K}_{\mathrm{K}}$, $40 \mathrm{Ca}$, and $75 \mathrm{As}$ at $14.4 \mathrm{MeV}$," Nucl. Phys. Al 06 , 401 (1968). 
Mo62 H. T. Motz, R. E. Carter, and W. D. Barfield, "Thermal-Neutron Capture Gamma-Rays from Beryllium arid Nitrogen," Pile Neutron Research in Physics (International Atomic Fnergy Agency, Vienna, 2962), p. 225.

Mo63 I. L. Morgan, $J$ n B. Ashe, R. W. Benjamin, 0. M. Hudson, Jr., S. C. Hathur, D. O. Nellis, C. V. Parker, and W. E. Tucker, Annual Progress Report, (Texas Nuclear Corp., Austin, 1963T, p. 68.

Mo64 I. L. Morgan, J. B. Ashe, and D. O. Nellis, "Angilar Distributions of Gamma Rays from C, 0 , and $\mathrm{N}$ at $\mathrm{E}_{\mathrm{r}}=14.8 \mathrm{MeV}$, Nuclear Physics Division Annual Progress Report (Texas Nuclear Corp., Austin, 1964), p. 156 .

Mo64a P. A. Moldauer, "Statistical Theory of Nuclear Collisiou Cross Sections," Phys. Rev. 135, B642 (1964).

Mo67 J. Mösner, G. Schaidt, and J. Schintlmeister, "Four-Particle Disintegration of Nitrogen by Fast Neutrons," Nucl. Phys. Al03, 238 (1967).

Ne54 N. E. Nereson and S. Darden, "Average Neutron Total Cross sections in the 3- to $12-\mathrm{MeV} \mathrm{Re}-$ gion," Phys. Rev. 94, 1678 (1954).

Ne70 D. 0. Nellis, private communication (1970).

Ne7l D. O. Nellis, F. S. Buchanan, T. C. Martin, W. E. Tucker, G. H. WIlliams, and A. J. Wolfram, "Neutron Scattering and Canma-Ray Production Cross Sections for $\mathrm{N}, \mathrm{O}, \mathrm{Al}, \mathrm{Si}$, Ca, and Fe," private communication (1971).

Ny69 K. Nyberg, private cormunication to L. Stewart (1969).

od60 Y. Oda, M. Takeda, N. Takano, T. Yanizak1, C. Ku, K. Kikuch1, S. Kobayash1, K. Matsuda, and Y. Nagahara, "Elastic and Inelastic Scattering of Protons from $\mathrm{N}, \mathrm{Ne}, \mathrm{Mg}, \mathrm{Si}, \mathrm{S}$, and $\mathrm{A}$ in the Energy Range from $7.6 \mathrm{MeV}$ to $14.2 \mathrm{MeV}$," J. Phys. Soc. Japan 15, 760 (1960).

Oh65 G. G. Ohlsen, "Kinematic Relations in Reactions of the Form $A+B \rightarrow C+D+E$, "Nucl. Instr. Methods 37, 240 (1965).

0165 J. W. Olness, E. K. Warburton, D. E. Alburger, and J. A. Becker, "Studies of Electromagmetic Transitions in $\mathrm{B}^{11}$ and $\mathrm{C}^{\mathrm{ll}}$," Phys. Rev. 139, B512 (1965).

or69 V. J. Orphan and C. G. Hoot, "Weutron Cross Section Data for Radiation Transport Calculations," Gulf General Atomic report GA-8005 (1969).

Or70 V. J. Orphan, N. C. Rasmussen, and T. L. Harper, "Line and Continuum Gama-Ray Yields from Thermal-Neutron Capture in 74 Elements, "Gulf General Atomic report $G A-30248$ (1970).

Pa53 E. B. Paul and R. L. Clarke, "Cross-Section Heasurements of Reactions Induced by Weutrons of 14.5-MeV Energy," Can. J. Phys. 31, 267 (1953).
Pa67 A. Pasquarelli, "Measurements of Cross Sections for $\left(n, 2_{n}\right),(n, p)$, and $(n, \alpha)$ Reactions at $14.7 \mathrm{MeV}$," Nucl. Phys, A93, 218 (1967).

Pe60 J. M. Peterson, A. Bratenahl, and J. P. Stoering: "Neutron Total cross Sections in the 17- to 29-MeV RegIon," Phys. Rev. 120, 521 $(1960)$.

Pe7l F. G. Perey and W. E. Kinney, private communication (1971).

Ph6l D. D. Phillips, private cormunication to $R$. J. Howerton (1961).

Ph67 G. W. Phillips, F. C. Young, and J. B. Marion, "Bnergy Levels and Electromagnetic Transitions in $\mathrm{N}^{15}$ from the $\mathrm{C}^{13}\left(\mathrm{He}^{3}, \mathrm{p} \gamma\right) \mathrm{N}^{15}$ Reaction," Phys. Rev. 159, 891 (1967).

Pi6o R. E. Pixley, J. V. Kane, and D. H. Wilkinson, "Rare E2 Transition in C13," Phys. Rev. 120, $943(1960)$.

Po5e H. L. Poss, E. O. Salant, G. A. Snow, and L. c. L. Yuan, "Total Cross Sections for 14-Mev Neutrons," Phys. Rev. 87, 11 (1952).

Pr60 J. T. Prud 'homme, I. L. Morgan, J. H. Mccrary, J. B. Ashe, and O. M. Hudsun, Jr., "A Study of Neutrons and Camma Rays from Neutron Induced Reactions in Several Elements," A1r Force Speclal Weapons Center repnrt AFSWCTR-60-30 (1360).

RaGl L. A. Rayburn, "14.4-MeV ( $n, 2 n)$ Cross Sections," Phys. Rev. 122, 168 (1.961).

Re67 D. Rendic, "The Reaction $14 \mathrm{~N}(\mathrm{n}, \mathrm{t}){ }^{12} \mathrm{C}$ at $\mathrm{E}_{\mathrm{n}}=$ $14.4 \mathrm{MeV}$," Nucl. Phys. A91, 604 (1967).

Re70 G. M. Reynolds, S. M. Sperling, and W. E. Selph, "Secondary Gamma-Ray Production and Transport in Liquid Nitrogen," Nucl. Sct. Eng. 42, 324 (1970).

Re71 G. M. Reynolds and S. M. Sperling, "A Re-analysis of Secondary Gamma-Ray Spectra Produced in Liquid Nitrogen by $14 \mathrm{MeV}$ Neutrons, " Sctence Applications Irc. report SAI-71-550-LJ (1971).

ro65 L. Rosen, J. G. Beery, A. S. Goldhaber, and E. H. Auerbach, "Elastic Scattering of 10.5and 14.5-MeV Polarized Protons from Nuclel and the optical Model Potential at Intermediate Energies," Ann. Phys. (N.Y.) 34, 96 (1965).

Sc66 W. Scobel, R. W. Fink, and M. Bormann, "The Reactions $\mathrm{N}^{14}(n, \alpha) \mathrm{B}^{12}$ and $\mathrm{N}^{14}(n, t) \mathrm{C}^{12}$ observed with a Gridded Ionization Chamber, " $z$. Physik 197. 124 (1966).

S169 H. E. Siefken, P. M. Cockburn, and R. W. Krone, "Levels in 15 N Resulting from the Proton Capture of ${ }^{14} \mathrm{C}$, "Nucl. Phys. Al28, 162 (1969).

Sm54 J. R. Smith, "Scattering of 14.1-MeV Meutrons in Hellum, Hydrogen, and Nitrogen, "Phys. Rev. 95, 7.30 (1954). 
St62 V. I. Strizhak, V. V. Bobyr, and L. Ya. Grona, "Angular Distributions for Elastic Scattering of 14-MeV Neut_ons," Soviet Phys. - JETP 14, 225 (1962).

Stós L. Stewart, private communication from J. D. Anderson (1,065).

St65a J. F. Strain and W. J. Ross, "14-MeV Neutron Reactions," Cak Ridge National Laboratory report ORIL-3672 (1965).

St69 L. Stewart, private communication (1969).

Th67 G. E. Thomas, D. E. Blatchley, and L. M. Bollinger, "High-Sensitivity Neutron-Capture Gama-Ray Facility," Nucl. Instr. Methods 56, 32? (1967).

Wa64 E. K. Warburton, J. W. Olness, D. E. Alburger, D. J. Bredin, and L. F. Chase, Jr., "Studies of Blectromgnetic Transitions in $\mathrm{N}^{14}$ by Means of the $\mathrm{C}^{12}(\mathrm{he} 3, \mathrm{p}) \mathrm{N}^{14}$ Reaction, "Phys. Rev. $134, B 338$ (1964).

Wa65 E. K. Warburton, J. S. Lopes, R. W. Ollerhead, A. R. Polett1, and M. F. Thomas, "AngularCorrelgtion studies for the $\mathrm{C}^{12}\left(\mathrm{He}^{3}, \mathrm{cor}\right) \mathrm{Cl}^{\mathrm{ll}}$, $\mathrm{c}^{12}\left(\mathrm{He}^{3}, \mathrm{p \gamma}\right) \mathrm{N}^{14}$ and $\mathrm{O}^{18}(\mathrm{p}, \alpha \gamma) \mathrm{N}^{15}$ Reactions," Phys. Rev. 138, Blo4 (1965).

Wa65a E. K. Warburton, J. W. Olness, and D. E. Alburger, "Studies of Electromagnetic Transitions in $\mathrm{N}^{15}$ and $0^{15}$, Phys. Rev. 140, B1202 (1965).

We66 E. K. Warburton and J.W. Qlness, "Angular Correlations in the $\mathrm{C}^{i 3}\left(\mathrm{He}^{3}, \mathrm{pr}\right) \mathrm{N}^{15}$ Reaction: Levels of $\mathrm{N}^{15}$," Phys. Rev. 14\%, 698 (1966).
Wa71 A. H. Wapstra and N. B. Gove, "The 1971 Atomic Mass Evaluation," Nucl. Data T'ables 9, 267 (1971).

Wi43 G. C. Wick, Atti reale accad. Italia, Mem. classes sci. fis., mat. e nat. 13, 1203, (1943); see also J. H. Coon, R. W. Davis, H. E. Felthauser, and D. B. Nicodemus, "Scattering of 14.5-MeV Neutrons by Complex Nuclei," Phys. Rev. 112, 250 (1958), and L. Stewart, "Evaluated Neutron Cross Sections for Tritium, "Los Alamos Scientific Laboratory report $L A-3270$ (1965).

Wi63 H. B. Willard, L. C. Biedenharn, P. Huber, and E. Baumgartner, "Resonunce Processes with Fast Neutrons," in Fast Neutron Physics, Part II: Experiments and Theory edited by J. B. Marion and J. L. Fowler, (John Wiley and Sons, Inc., New York, 1963), p. 1284.

Wc67 C. Wong, J. D. Anderson, J. Mcclure, B. Pohl V. A. Madsen, and F. Schmittroth, ${ }^{1} \mathrm{C}^{14}(p, n) \mathrm{N}^{14}$ Reaction and the Two-Body Force," Phys, Rev. 160,769 (1967).

Yo69 F. C. Young, G. W. Phillips, and J. B. Marion, private communication to F. Ajzenberg-Selove (1969); see Ad70.

Z063 M. R. Zatzick and D. R. Maxson, "Angular Dis trfbutions of $(n, d)$ Pickup Reactions in $\mathrm{N}^{14}$, p 31 and $\mathrm{s}^{32}$ at $14 \mathrm{MeV}, "$ Phys. Rev. 129 , 1728 (1963).

Z139 W. H. Zinn, S. Seely and V. W. Cohen, "Collision Cross Sections for D-D Neutrons, "Phys. Rev. 56, 260 (1939).

\section{APPENDIX A}

\section{COMPOUND-NUCLEUS REACTION-THEORY CALCULATIONS}

We used the computer code JANE (Fe68) to calculate the $\left(n, n^{\prime}\right),(n, p)$, and $(n, \alpha)$ level-excitation cross sections used to supplement experfmental data as described in Sec. 3. This code, which is based on the optical model of the nucleus and on the compound-nucleus theory of reactions, computes partialreaction cross sections using transmisolon coeff:cients generated from the opticai model as input for the Hauser-Feshbach (Ha52) calculations, which include refinements by MoIdauer (Mo64a, Br64). Before using the code, we made several minor corrections and checked the cross-section calculations agalnst calculations made with ABACUS (Au62) for several different neutron energles. In addition, the code was modifted to handle up to 50 levels for $\left(n, n^{\prime}\right)$ reactions and 25 levels for $(n, p)$ and $(n, \alpha)$ reactions.
This was sufficient for the $n+{ }^{14} \mathrm{~N}$ calculations ud to a laboratcry neutron energy of - $14 \mathrm{MeV}$. The form of the optical potential uged in the JANE code is

$$
-V_{r}=V f(r)+1 W g(r)+V_{s 0}\left(\dot{b} \cdot \vec{s}^{-} .\right)+2 w(r),
$$
where the usual real, Imaginary, spin-orblt, and Coulomb terms are included.

The reai part is the usial Saxon potential, $f(r)=\{1+\exp [(r-R) / a]\}^{-1}$.

The Imaginary part is a mixture of a volume potentlal and a Saxon-derivative potential,

$$
g(r)=v f(r)+(1-v)(-4 b) \frac{d}{d r}\{1+\exp [(r-R) / b]\}^{-I} \text {. }
$$
where $v$ is a mixing parameter and, normally, $0<v \leqslant 1$. 
The usual spin-orbit term,

$$
h(x)=-\frac{2}{x} \frac{d}{d x}\left\{1+\operatorname{\omega xp}\left[\left(r-R_{s o}\right) / a\right]\right\}^{-1},
$$

is included.

We usually renormalized the calculated cross sections to fit experimental measurements, so we made no particular effort to optimize the optical parameters used in th: calculations. The opticalmodel parameters, which are summartzed in Table AI, were obtained from the work of Bauer et al. (Ba67) for the $n+{ }^{14} \mathrm{~N}$ channel, RcBen et al. (Ro6j) for the $p+{ }^{14} \mathrm{C}$ channel, anč McF'adden and Satchler (Mc66) for the $a+{ }^{11} B$ channel. The Bauer parmeters were obtalned from an optical-model study of $n+{ }^{14} N$ elastic scattering, the Rosen paratueters are from an analysis of many proton scattering and polarization measurements, and the McFadden parameters were obtained from a study of $a+{ }^{27} \mathrm{Al}$ elastic scattering.

TABLE AI

OP'TICAL-MODEL PARAMETERS USED IN THE CROSS-SECTION CALCULATIONS

\begin{tabular}{|c|c|c|c|}
\hline Parameter & $\begin{array}{l}n \cdot r^{14} \mathrm{~N} \\
\text { Channe: }\end{array}$ & $\begin{array}{l}\mathrm{p}+{ }^{14} \mathrm{C} \\
\text { Channel }\end{array}$ & $\begin{array}{l}\alpha+^{11_{B}} \\
\text { Channel }\end{array}$ \\
\hline$v(\mathrm{MeV})$ & $52.7-0.28 \mathrm{E}$ & $53.8-0.33 \mathrm{E}$ & 49.1 \\
\hline $\begin{array}{l}\text { W }(\mathrm{MeV}) \\
\mathrm{v} \\
\mathrm{R}(\mathrm{F}) \\
\mathrm{a}(\mathrm{F}) \\
\mathrm{b}(\mathrm{F}) \\
\mathrm{v}_{\text {so }}(\mathrm{MeV}) \\
\mathrm{R}_{\text {So }}(\mathrm{F})\end{array}$ & $\begin{array}{l}5.0 \\
0 . \\
2.89 \\
0.65 \\
0.47 \\
7.0 \\
2.99\end{array}$ & $\begin{array}{l}7.5 \\
0 . \\
3.01 \\
0.65 \\
0.70 \\
5.5 \\
3.01\end{array}$ & $\begin{array}{l}7.34 \\
1 \\
4.10 \\
0.57 \\
0.57 \\
0 \\
4.10\end{array}$ \\
\hline
\end{tabular}

The energy levels of ${ }^{14} \mathrm{~N}$ used in the $\left(n, n^{\prime}\right)$ calculations are descrthed in Table AII. We obtained the level parameters from the $A=13-15$ compilation by Ajzenberg-Selove (Aj70). The parentheses in Table AII indicate limited uncertainty in the parameters, whereas a bracket means that no Information was avallable, and the value in the table was arbitrarily chosen. To account for the different isotopic spins of the states, we multiplied the $\left(n, n^{\prime}\right)$ cross sections computed with JANE by $(2 \mathrm{~T}+1)^{-1}$.

The energy levels of ${ }^{14} \mathrm{C}$ used in the $(n, p)$ calculations are described in Table AlII. These we also obtalned from Ajzenberg-Selove's compilation (Af70). The levels of ${ }^{i 1_{B}}$ used in the $(n, \alpha)$ calculations are given in Tahle AIV. We obtained these values from the earlier $A=11-12$ coinpilation of $A j z e n b e r g-S e i n v e$ and Lauritsen (Aj68).
TABLE AII

${ }^{14} \mathrm{~N}$ LEVEL PARAMETERS USED IN THE COMPOUNDNUCLEUS REACTION-THEORY CALCULATIONS

\begin{tabular}{|c|c|c|c|c|c|}
\hline $\mathrm{E}_{\mathrm{x}}$ & $\mathrm{J}^{\pi}$ & $\underline{\mathbf{T}}$ & $E_{x}$ & $\underline{\mathrm{s}}^{\pi}$ & $\mathbf{T}$ \\
\hline $\begin{array}{l}0 \\
2.313 \\
3.945 \\
4.913 \\
5.106\end{array}$ & $\begin{array}{l}1+ \\
0+ \\
1+ \\
(0)- \\
2-\end{array}$ & $\begin{array}{l}0 \\
1 \\
0 \\
0 \\
0\end{array}$ & $\begin{array}{l}10.10 \\
10.228 \\
10.434 \\
10.56 \\
10.809\end{array}$ & $\begin{array}{l}(2)+ \\
1(-) \\
2+ \\
1= \\
4+\end{array}$ & $\begin{array}{c}{[0]} \\
0 \\
1 \\
{[0]} \\
0\end{array}$ \\
\hline $\begin{array}{l}5.691 \\
5.833 \\
6.198 \\
6.444 \\
7.028\end{array}$ & $\begin{array}{l}1- \\
3- \\
1+ \\
3+ \\
2+\end{array}$ & $\begin{array}{l}0 \\
0 \\
0 \\
0 \\
0\end{array}$ & $\begin{array}{l}11.04 \\
11.051 \\
11.246 \\
11.374 \\
11.516\end{array}$ & $\begin{array}{l}1+ \\
{[5+]} \\
3- \\
1+ \\
3+\end{array}$ & $\begin{array}{c}0 \\
{[0]} \\
1 \\
0 \\
{[0]}\end{array}$ \\
\hline $\begin{array}{l}7.966 \\
8.061 \\
8.489 \\
8.617 \\
8.800\end{array}$ & $\begin{array}{l}2(-) \\
1- \\
(4-) \\
0+ \\
0-\end{array}$ & $\begin{array}{l}0 \\
1 \\
0 \\
1 \\
1\end{array}$ & $\begin{array}{l}11.66 \\
11.75 \\
11.81 \\
11.95 \\
12.23\end{array}$ & $\begin{array}{l}(2-) \\
1+ \\
(2+) \\
2+ \\
3-\end{array}$ & $\begin{array}{l}{[0]} \\
{[0]} \\
{[0]} \\
{[0]} \\
{[0]}\end{array}$ \\
\hline $\begin{array}{l}8.907 \\
8.963 \\
8.979 \\
9.129 \\
9.9 .22\end{array}$ & $\begin{array}{l}3- \\
5+ \\
2+ \\
2- \\
2+\end{array}$ & $\begin{array}{l}1 . \\
0 \\
(0) \\
0 \\
1\end{array}$ & $\begin{array}{l}12.29 \\
12.414 \\
12.47 \\
12.504 \\
12.608\end{array}$ & $\begin{array}{l}{[2+]} \\
4- \\
{[5+]} \\
{[4 \div]} \\
3+\end{array}$ & $\begin{array}{l}{[0]} \\
{[0]} \\
{[0]} \\
{[0]} \\
{[0]}\end{array}$ \\
\hline $\begin{array}{r}9.388 \\
9.508 \\
9.702 \\
10.063\end{array}$ & $\begin{array}{l}2- \\
2- \\
1+ \\
{[3+]}\end{array}$ & $\begin{array}{l}0 \\
1 \\
{[0]} \\
0\end{array}$ & $\begin{array}{l}12.689 \\
12.793 \\
12.825 \\
12.853 \\
12.942\end{array}$ & $\begin{array}{l}3- \\
4+ \\
4- \\
{[5+]} \\
4[-]\end{array}$ & $\begin{array}{l}{[0]} \\
{[0]} \\
{[0]} \\
{[0]} \\
{[0]}\end{array}$ \\
\hline
\end{tabular}

TABLE AIII

${ }^{14} \mathrm{C}$ LEVEL PARAMETERS USED IN THE COMPOUNDNUCLEUS REACTION-THEORY CALCULATIONS

\begin{tabular}{|c|c|c|c|}
\hline $\begin{array}{l}E_{x} \\
(\mathrm{MeV}) \\
\end{array}$ & $\mathrm{J}^{\pi}$ & $\begin{array}{l}E_{x} \\
(M e V) \\
\end{array}$ & $\mathrm{J}^{\pi}$ \\
\hline 0 & $0^{+}$ & 10.433 & $(2)^{[-]}$ \\
\hline 6.094 & $1^{-}$ & $10.4: 53$ & {$\left[3^{-}\right]$} \\
\hline 6.583 & $0^{+}$ & 10.740 & {$\left[3^{+}\right]$} \\
\hline 6.728 & $3^{-}$ & 11.350 & {$\left[2^{-}\right]$} \\
\hline 6.894 & $0^{-}$ & 11.660 & {$\left[2^{+}\right]$} \\
\hline 7.012 & $2^{+}$ & 11.900 & {$\left[1^{-}\right]$} \\
\hline 7.337 & $2^{-}$ & 12.601 & {$\left[3^{+}\right]$} \\
\hline 8.318 & $(1)^{+}$ & 12.854 & {$\left[4^{-}\right]$} \\
\hline 9.801 & $(1)^{[-]}$ & 12.958 & {$\left[3^{+}\right]$} \\
\hline
\end{tabular}


TABLE AIV

$11_{\text {B LEVEL PARAMETERS USED IN THE COMPOUND- }}$ NICLEUS REACTION-THEORY CALCULATIONS

$\mathrm{E}_{\mathrm{X}}$

(MeV)

0

2.124

4.444

5.019

6.743

6.793

7.296

7.996

8.566

8.925

9.185

9.274

9.87

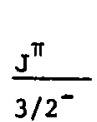

$1 / 2^{-}$

$5 / 2^{-}$

$3 / 2^{-}$

$7 / 2^{-}$

$(1 / 2)^{+}$

$(5 / 2)^{+}$

$3 / 2^{+}$

$(3 / 2)^{-}$

$5 / 2^{-}$

$7 / 2^{+}$

$5 / 2^{+}$

$3 / 2^{+}$
$\mathbf{E}_{\mathbf{x}}$ (MeV) $10.25 \quad\left(3 / 2^{-}\right)$

$10.33 \quad 5 / 2^{-}$

$10.595 \quad 7 / 2^{+}$

$11.00 \quad 5 / 2^{-}$

$11.266 \quad(9 / 2)^{+}$

$11.462 \quad\left[7 / 2^{+}\right]$

$11.60 \quad\left[5 / 2^{-}\right]$

$11.834 \quad\left(5 / 2^{+}\right)$

$12.00 \quad\left[3 / 2^{+}\right]$

12.565

13.00

$\left[3 / 2^{-}\right]$

$1 / 2^{-}$

13.15

$(11 / 2)^{+}$

APPENDIX B

RESONANCE-THEORY PARAMETERIZATION

Tiss reso.zance treatment used to derive the elastic-scattering angular distributions (Sec. 4.1.1) Is based on the single-level approximation to $R-$ matrix theory, as described by Lane and Thomas (La58). We took the nuclear-scattering phase shifts, $\delta^{\prime}$, as complex to a.counc for the reaction chandels, so that a general element of the collision matrix is given by

$$
U_{n n}=\exp \left(2 i 0^{\circ}\right)=\tau \exp (21 \delta),
$$

where $\delta$ is the real part of $\delta^{\prime}$ and $\tau$ is related to the inaginary part, $\nu$, of $\delta^{\prime}$ by $\tau=\exp (-2 \nu)$ and must lie in the range $0 \leq \tau \leq 1$. The real part of the phase shift was divided into resonant $(B)$ and potential scattering ( $\phi$ ) components, as

$$
\delta_{\lambda}=\phi_{\ell}+\beta_{\lambda},
$$

where $\lambda$ designates the quantum numbers assoctated with yarticular partial waves and $\ell$ is the orbital angular momentum of the incoming neutron. We assumed the potential scattering phase shifts to be functions of $\ell$ and incldent neutron energy only.

The parameters $\tau_{\lambda}$ and $\beta_{\lambda}$ can be related to the usual resonance parameters through the expression (La58):

$$
\begin{aligned}
u_{n \mathbf{n}}^{\lambda} & =\tau_{\lambda} \exp \left(21 \beta_{\lambda}\right) \exp \left(21 \phi_{\ell}\right) \\
& =\left[1+\frac{1 \Gamma_{\lambda n}}{E_{\lambda}} \frac{\lambda}{+\Delta_{\lambda}-i-1 \Gamma_{\lambda} / 2}\right] \exp \left(21 \phi_{\ell}\right),
\end{aligned}
$$

where $\Gamma_{\lambda n}, \Gamma_{\lambda}, E_{\lambda}$, and $\hat{\varepsilon}_{\lambda}$ are the partial neutron width, the trtal width, the energy elgenvalue, and the level shift, respectively, for the $\lambda^{\text {th }}$ level in tha compound system, and $E$ Is the energy of relative motion in the center-of-mass sysiem. After performIng the necessary algetra, one can represent the quantities $\tau_{\lambda}$ and $\beta_{\lambda}$ as

$$
{ }_{\lambda}=\left[1-\frac{\Gamma_{\lambda n}\left(\Gamma_{\lambda}-\Gamma_{\lambda n}\right)}{\left(E_{\lambda}+\Delta_{\lambda}-E\right)^{2}+\Gamma_{\lambda}^{2} / 4}\right]^{1 / 2}
$$

and

$$
\tan B_{\lambda}=\frac{\Gamma_{\lambda n}\left(E_{\lambda}+\Delta_{\lambda}-E\right)}{\left[\left(E_{\lambda}+\Delta_{\lambda}-E\right)^{2}+\Gamma_{\lambda}^{2} / 4\right]\left(\tau_{\lambda}+1\right)-\Gamma_{\lambda} \Gamma_{\lambda n^{\prime}}{ }^{2}} .
$$

We constiucted expressions relating the differential-scattering cross section $\sigma(\theta)$ to the phase shifts $\delta_{\lambda}$ ' from the generai equations given In Blatt and Bledenharn (B152a). Terms correspondIng to $\ell \neq \ell^{\prime}$ and $s^{\prime} \neq s^{\prime}$, where $\ell$ and $\ell^{\prime}$ are the 
Incoming and outgoing angular momenta and $s$ and $s$ ' are the incoming and outgoing channel spins, were omitted from the expressions to reduce the number of parameters. In the computer code used to fit the measured distributions, the resonance parameters were treated as fixied input and $\phi_{\ell}$ for the $\ell=0$ and $\ell=1$ potential phase shifts were varied to f1t the measurements.

The potential phase shifts for $l=2$ and $l=3$ were represented by hard-sphere values, given by

$$
\phi_{\ell}=-\arctan \left[F_{\ell}(k a) / G_{\ell}(k a)\right],
$$

where $k$ is the wave number for the incident neutrons, $a$ is the nuclear radius used in the calculations, and $F_{Q}$ and $G_{\ell}$ are the regular and irregular neutron wave functions, as given in Lane and Thomas (La58). The energy dependences of the $\Gamma_{\lambda}$ and $\Delta_{\lambda}$ used in the calculations were represented in the usual manner by

$$
\begin{aligned}
& \Gamma_{\lambda}=2 \gamma_{\lambda}{ }^{2} \mathrm{ka} /\left(\mathrm{F}_{\ell}{ }^{2}+\mathrm{G}_{\ell}{ }^{2}\right) \\
& \Delta_{\lambda}=-\gamma_{\lambda}{ }^{2} \mathrm{ka}\left(\mathrm{F}_{\ell} \mathrm{F}_{\ell}{ }^{\prime}+\mathrm{G}_{\ell} \mathrm{G}_{\ell}{ }^{\prime}\right) /\left(\mathrm{F}_{\ell}{ }^{2}+\mathrm{G}_{\ell}{ }^{2}\right),
\end{aligned}
$$

where $\gamma_{\lambda}^{2}$ is the reduced width of the level designated by $\lambda$. We obtained the values for $\gamma_{\lambda}{ }^{2}$ and $E_{\lambda}$ from the resonance widths and energles derived from the total cross-section measurements.

\section{APPENDIX $\mathrm{C}$}

\section{IEGENDRE COEFFICIENTS AND ANGULAR DISTRIBUTIONS FOR NEJTRON INELASTIC SCATTERING}

Complete graphs of the evaluated Legendre coefficients as functions of neutron energy are given In this appendix for angular distributions of $\left(n, n^{\prime}\right)$ reactions to the first 12 excited states in $14 \mathrm{~N}$. We have used the ENDF definitions of the coefficlents throughout [1.e., the "natural" coefficients divided by $(2 \ell+1)]$. Sample angular distributions are also given for each of the levels at several neutron energies. The Legendre coefficlents are presented in the odd f1gures, $\mathrm{Cl}$ through $\mathrm{C23}$; the sample angular distributions are given in the even figures, c2 through c24. The calculated angular distributions have been normalized to the eppropriate level-exc1tation cross sections. Almost all of the input data consisted of $\left(p, p^{\prime}\right)$ rather than $\left(n, n^{\prime}\right)$ measurements. None of the observed distributions that was adequately defined experimentally for $\theta>90^{\circ}$ was observed to be symetric about $90^{\circ}$, as required by Hauser-Feshbach theory. Nevertheless, for lack of data to determine the complete distributions, we assumed the last two levels to have symmetric distributions. 


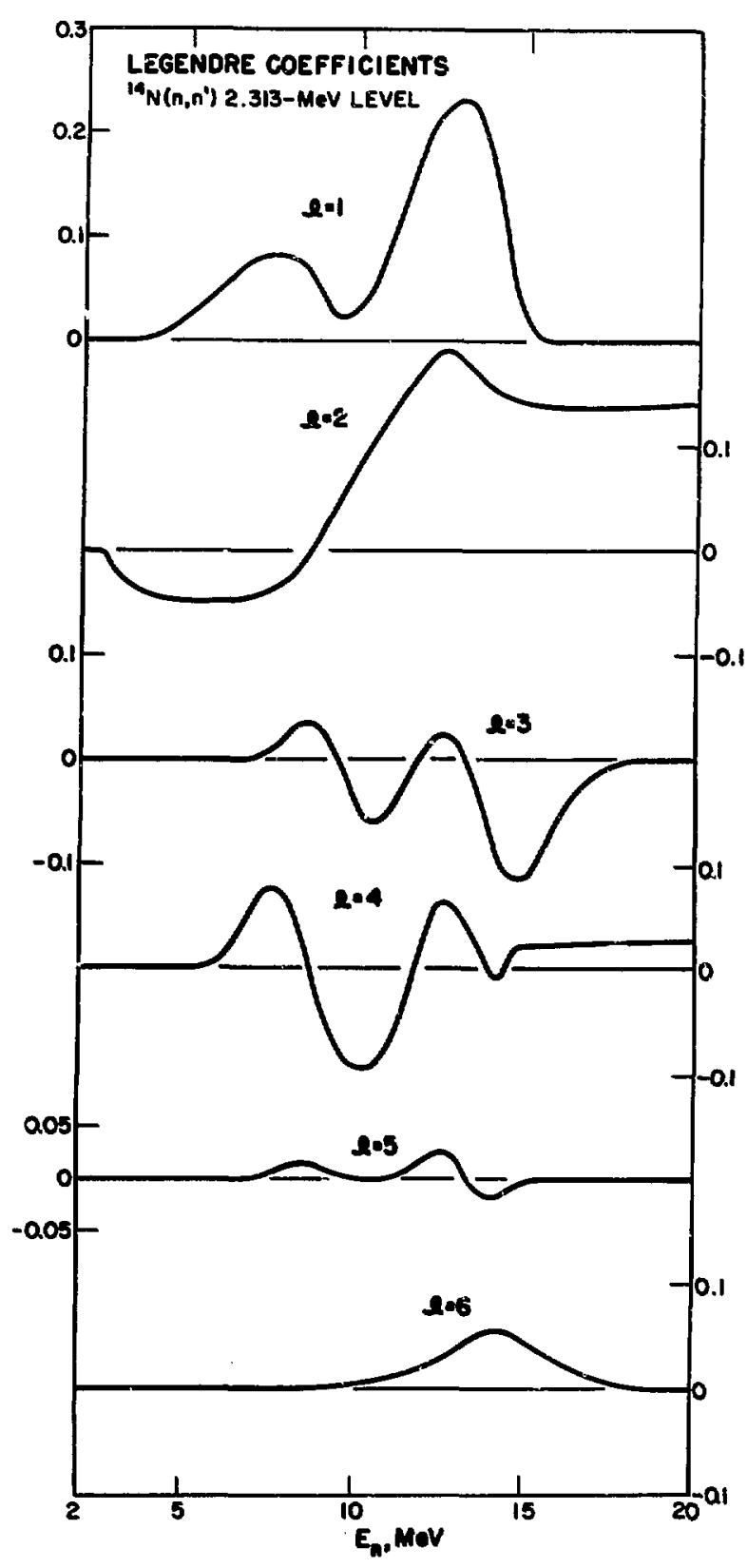

Fig. Cl: Evaluated Legendre coefficients for inelastic scattering to the 2.313-MeV level in $14 \mathrm{~N}$.

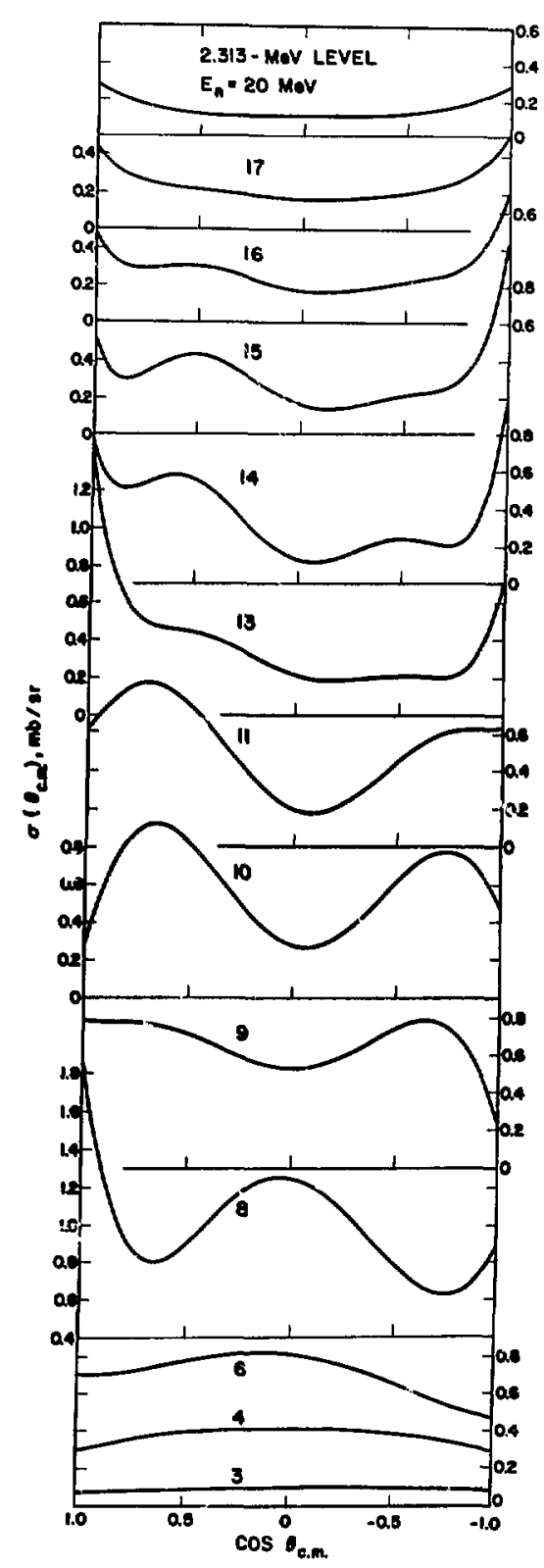

Fig. C2. Evaluated differential cross sections at selected energies for inelagtic scattering to the 2.313-MeV Ievel in $14 \mathrm{~N}$. Note that the 8-MeV curve has a suppressed zero. 


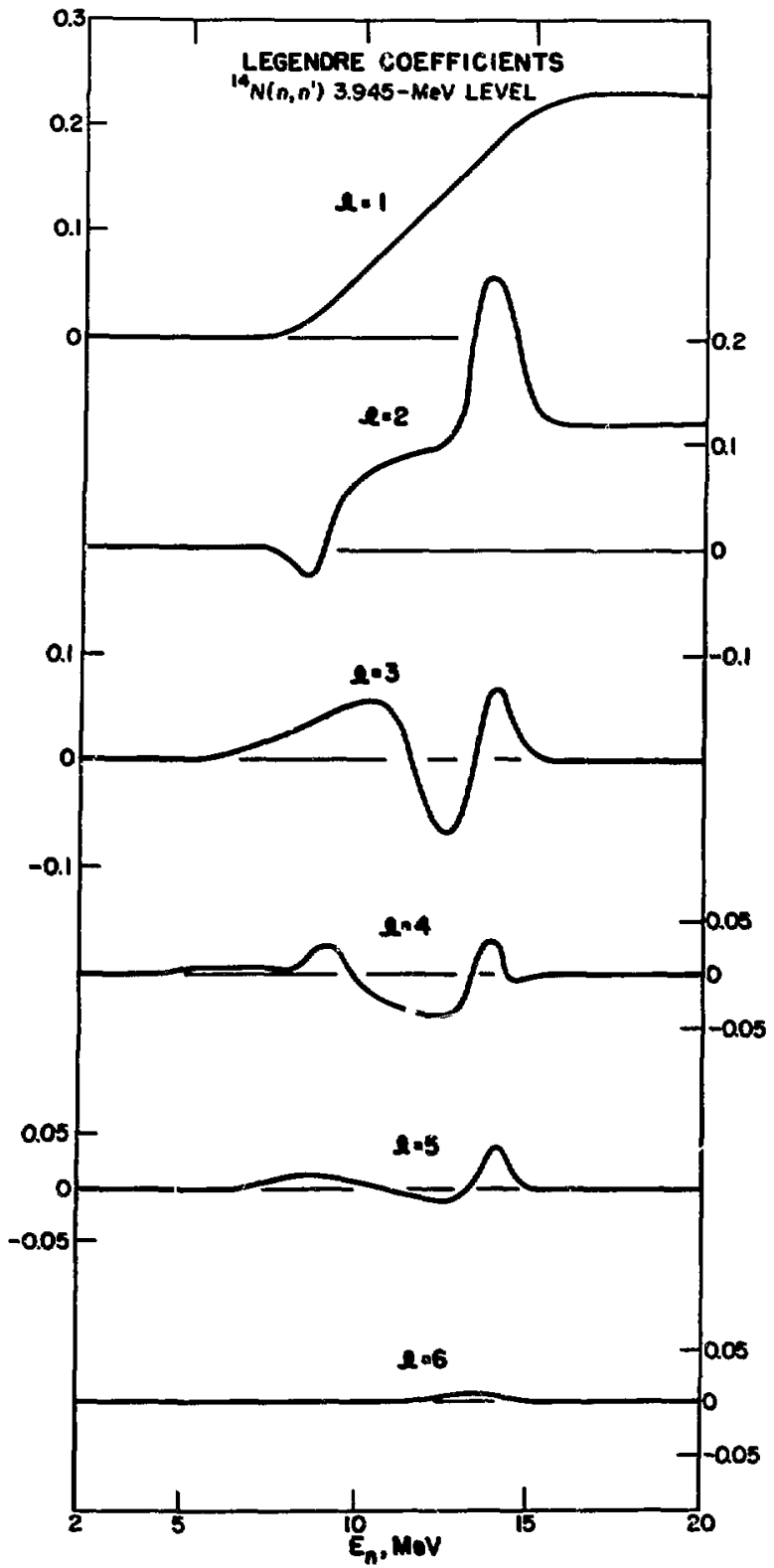

Fig. C3. Evaluated Legendre coefficients for inelastic scattering to the $3.945-\mathrm{MeV}$ level in $14 \mathrm{~N}$. This transition exhibits the lergest $\ell=2$ coefficient of any inelastic channel for nitrogen.

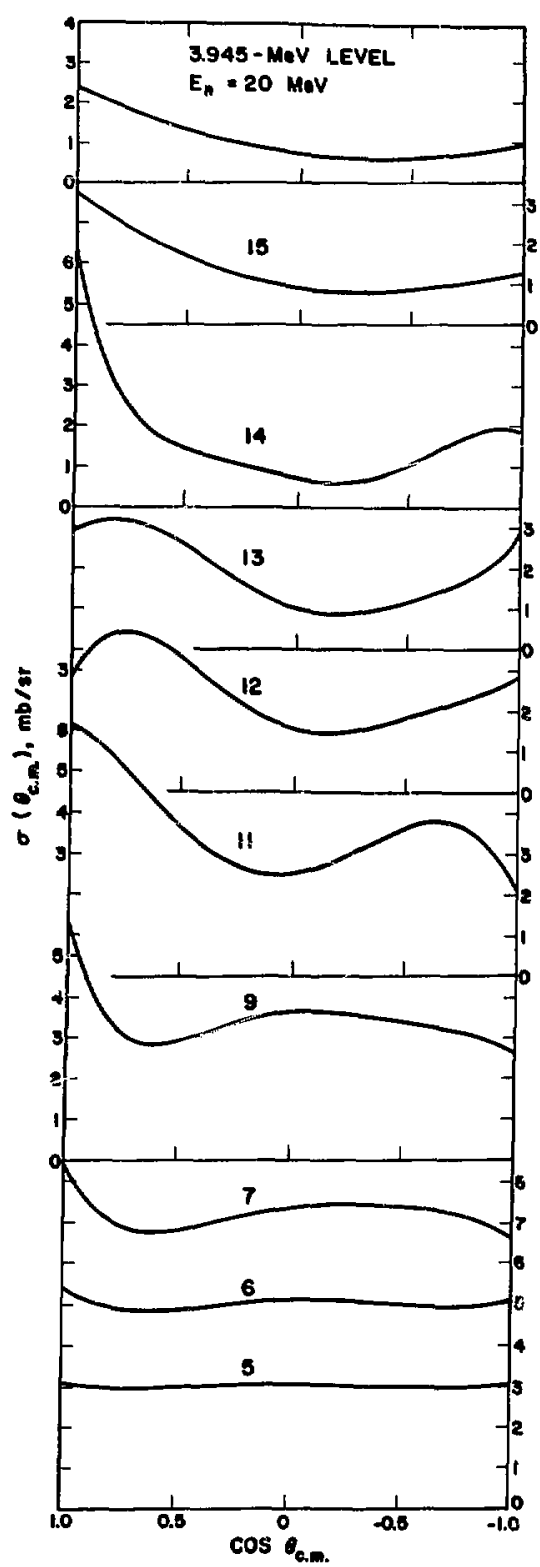

Fig. C4. Evaluated differential cross sections at selected energies for inelastic scattering to the $3.945-H$ eV level in $14 \mathrm{~N}$. 


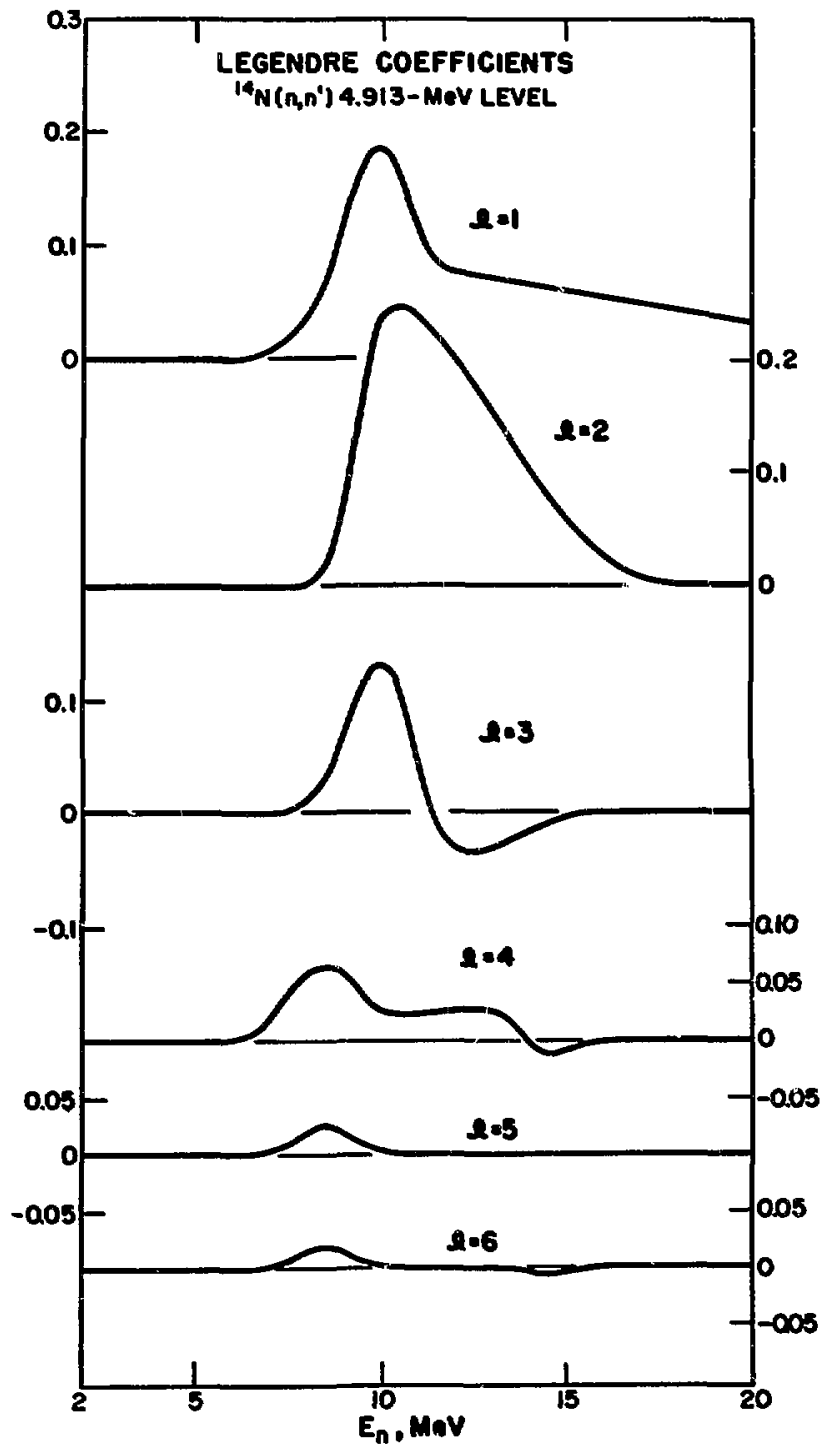

Fig. C5. Evaluated Legendre coefficients for inelastic scattering to the 4.913-MeV level in $14 \mathrm{~N}$.

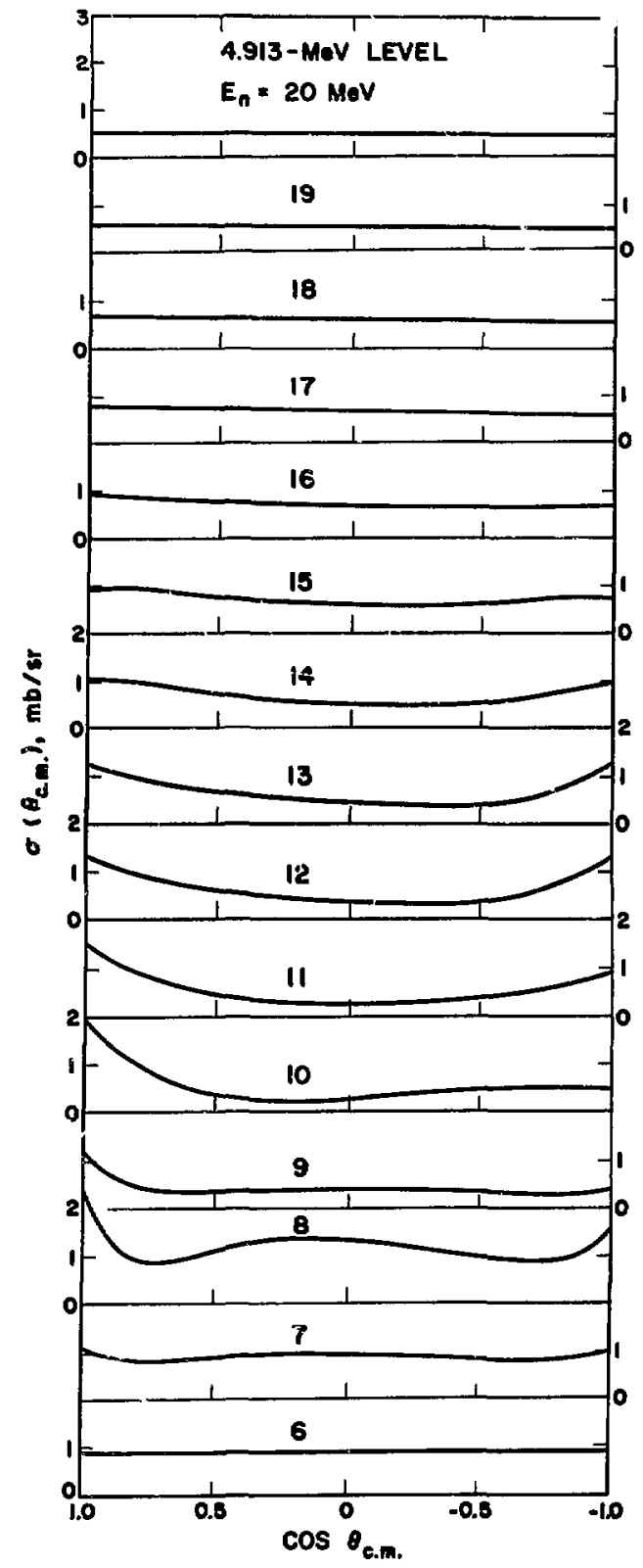

Fig. C6. Evaluated differential cross sections at selected energies for inelastic scattering to the $4.913-\mathrm{MeV}$ level in $14 \mathrm{~N}$. 


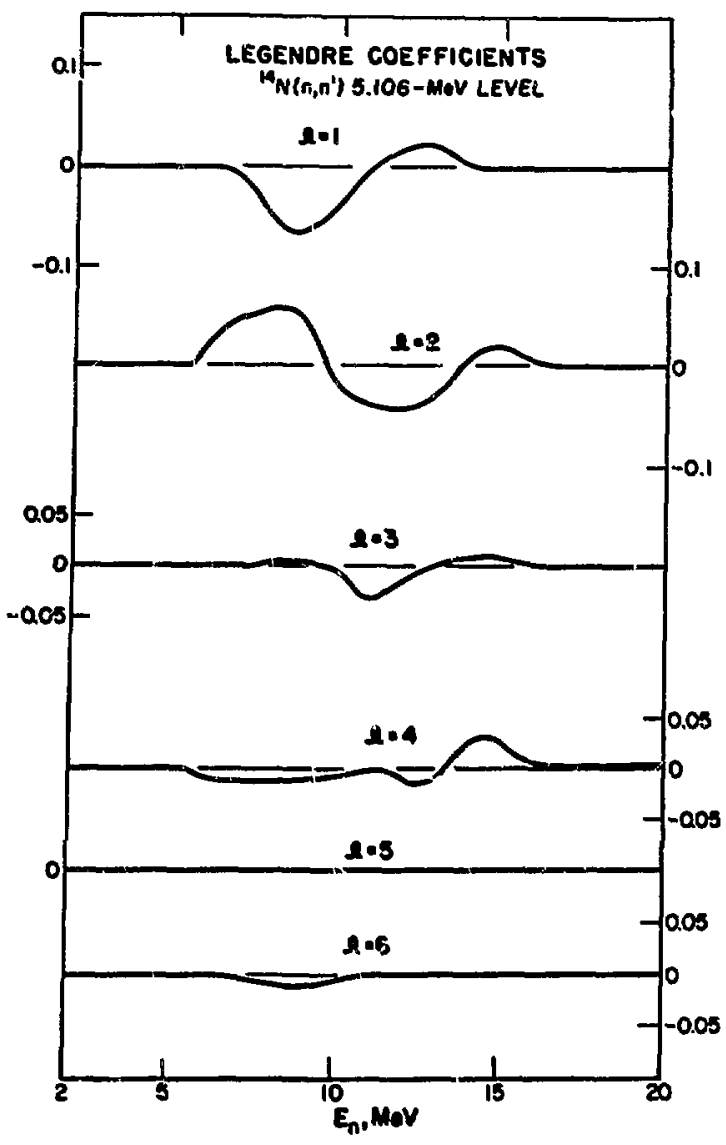

F18. C7. Evaluated Legendre coefficlents for Inelastlc scattering to the 5.106-MeV level in $14 \mathrm{~N}$.

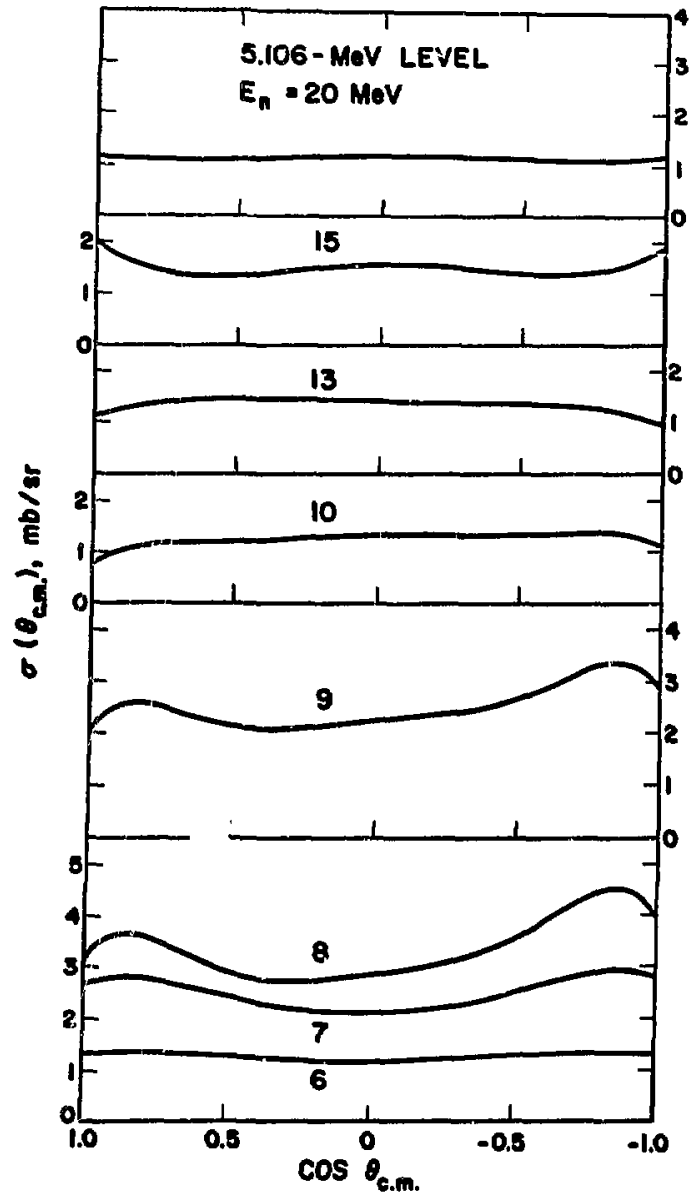

Fig. C8. Evaluated differential cross sections at selected energies for Inelast tc scattering to the $5.106-\mathrm{MeV}$ level in $14 \mathrm{~N}$. 


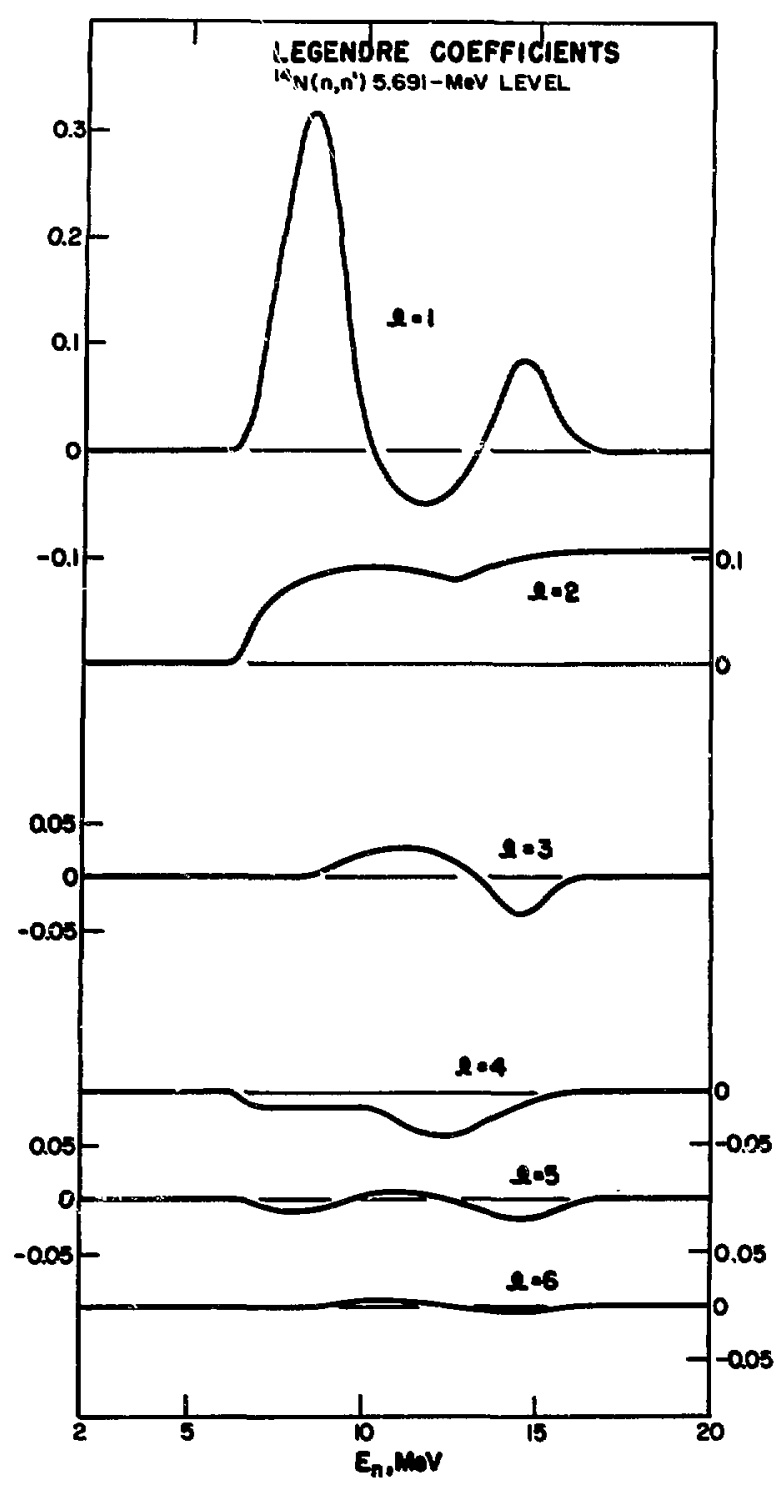

FIg, C9. Evaluated Legendre coefficients for Inelastlc scattering to the 5.691-MeV level In 14 .

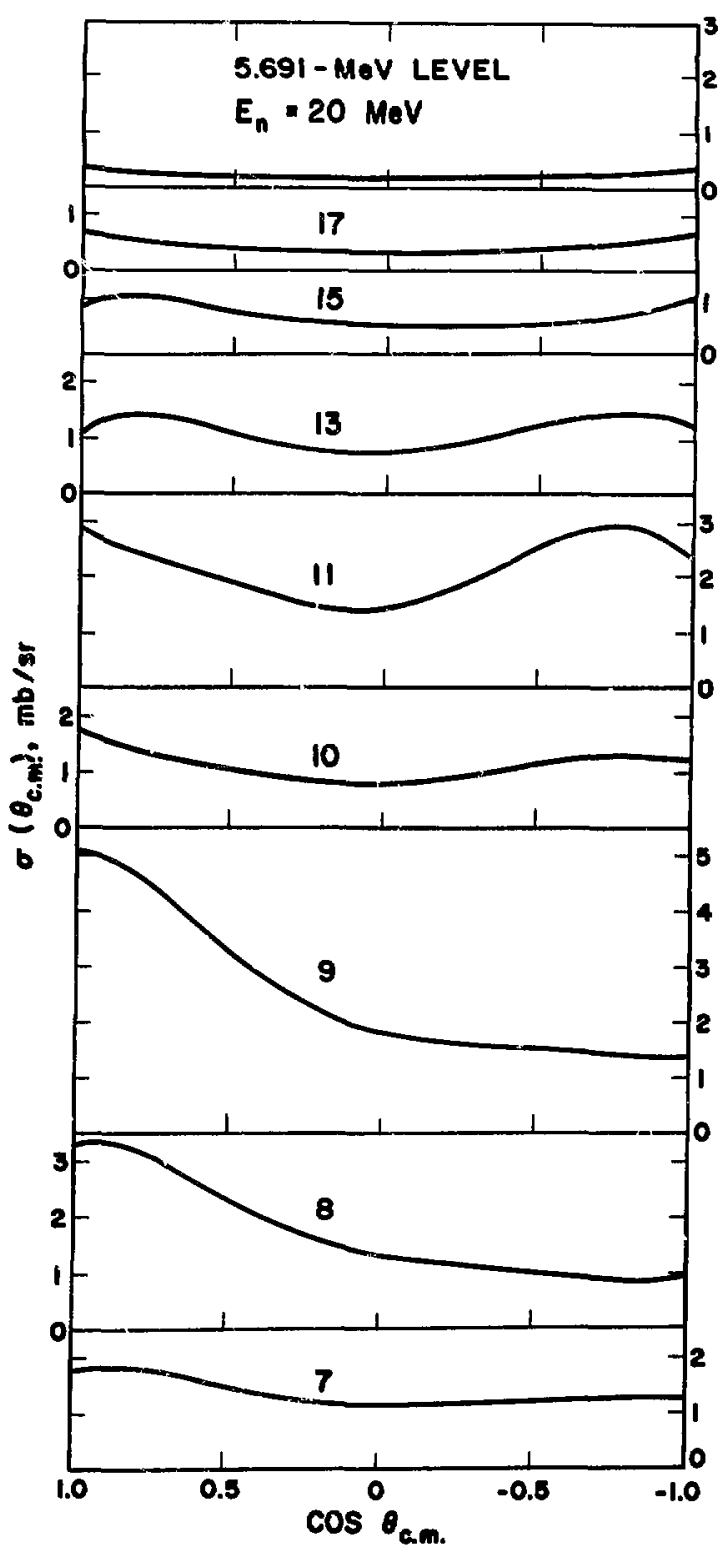

Fig. C10. Evaluated differential cross sections at selected energies for Inelagtic scattering to the $5.691-\mathrm{HeV}$ level in $14 \mathrm{~N}$. 


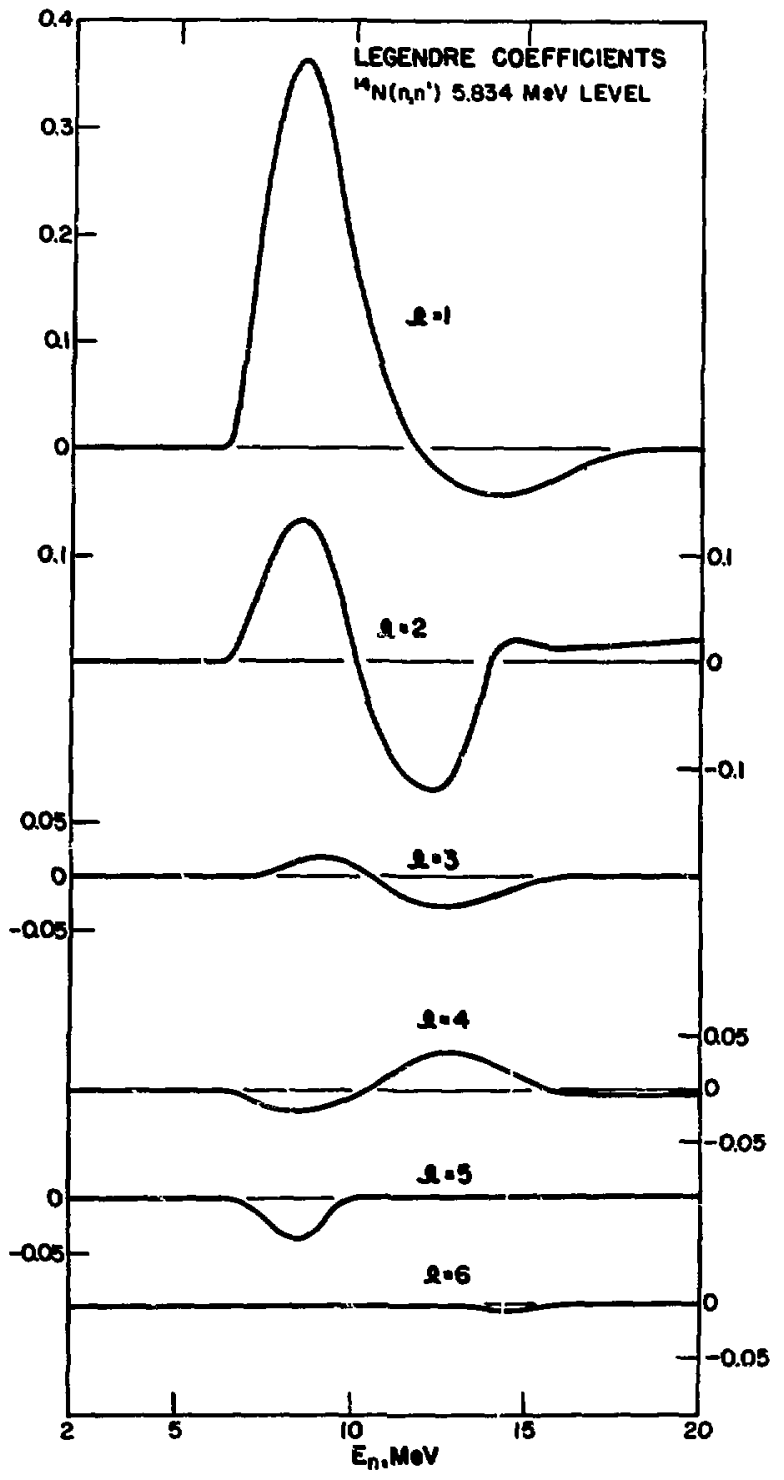

Fig. C11. Evaluated Legendre coefficients for inelastic scattering to the 5.834- $\mathrm{HeV}$ level in $14 \mathrm{~N}$. This transition exhibits the largest $\ell=1$ coefficient of any of the inelastic channels for nitrogen.

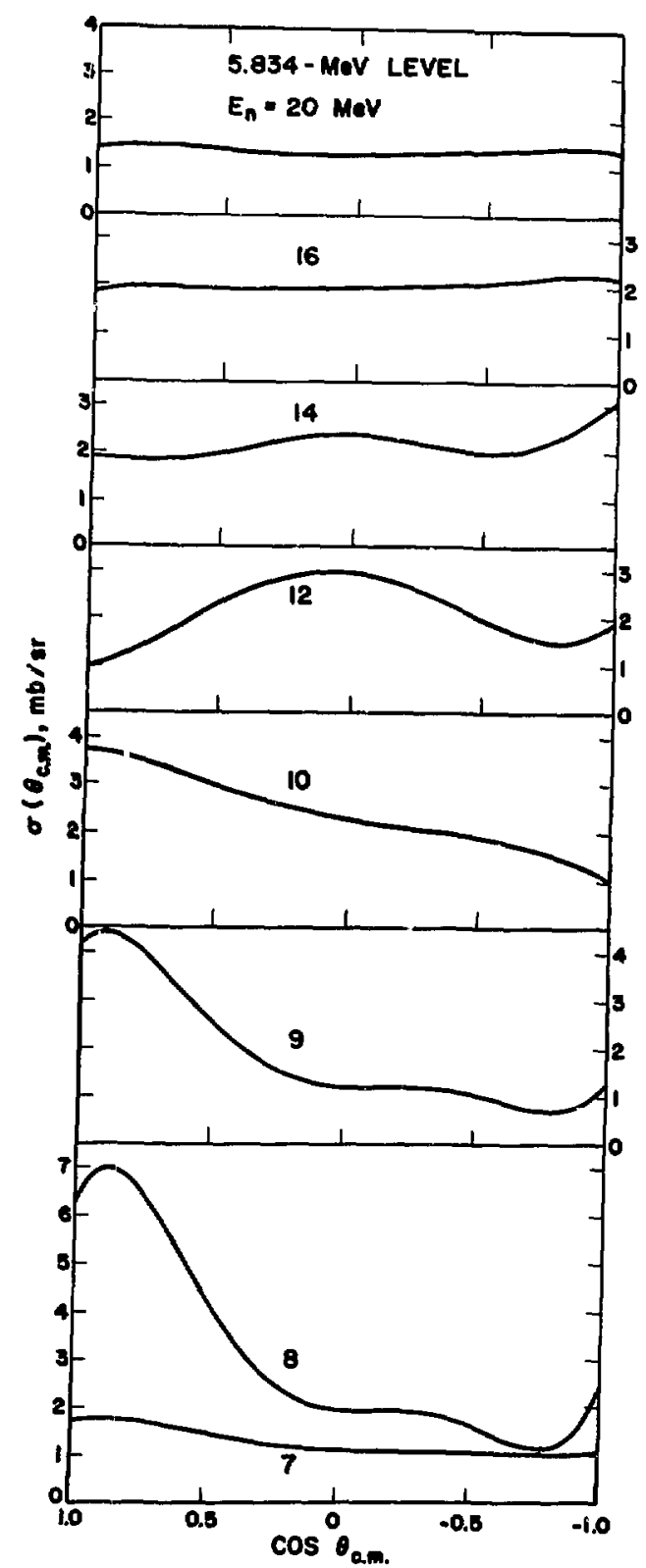

Fig. C12. Evaluated differenttal cross sections at selected energies for Inelastic scattering to the $5.834-\mathrm{MeV}$ level in ${ }^{14} \mathrm{~N}$. Note that the maximum/minimum cross-section ratio is close to 7 . 


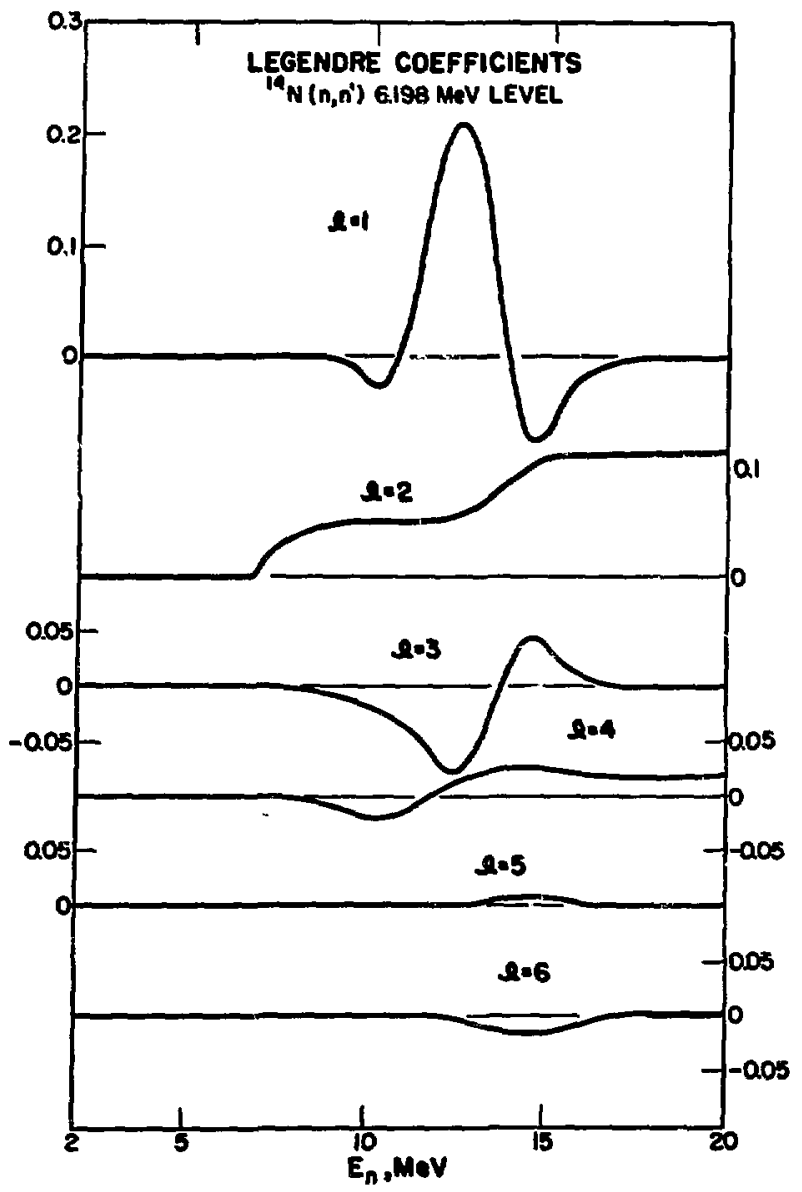

Fig. C13. Evaluated Legendre coefficlents for Inelastic scattering to the 6.198-MeV level In $14 \mathrm{~N}$.

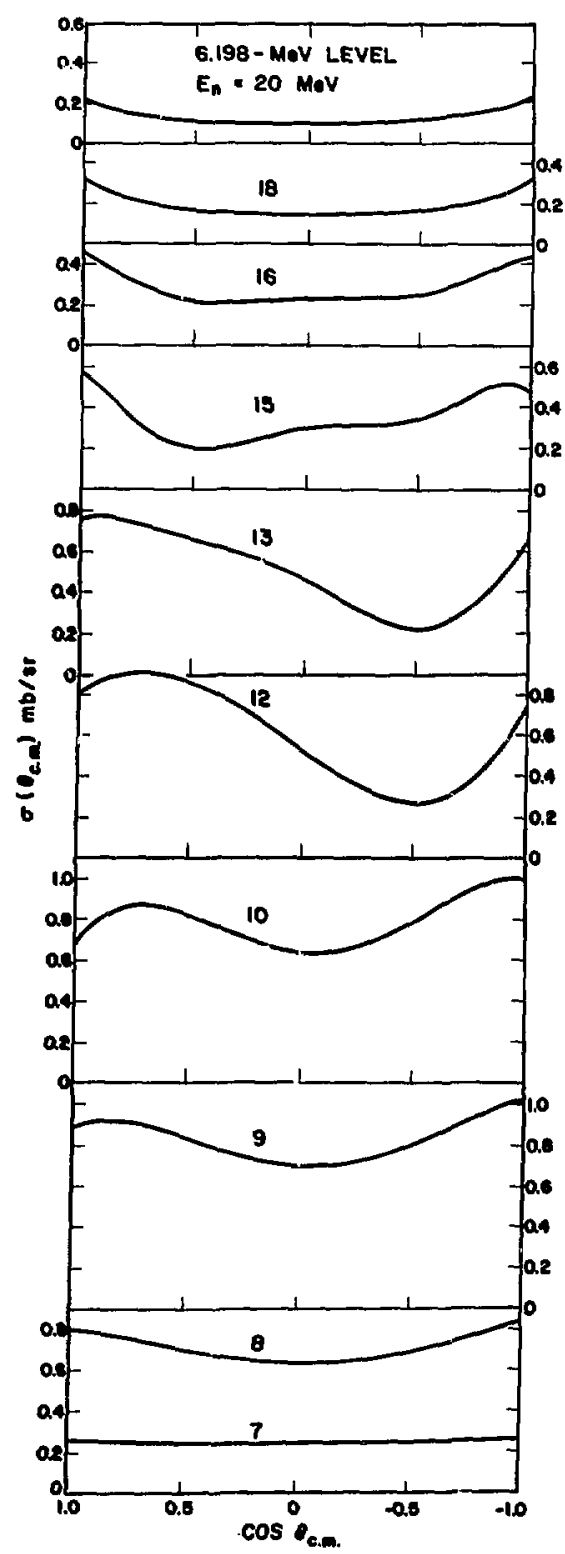

Fig. C14. Evaluated differential cross sections at selected energies for inelastic scatterIng to the $6.198-\mathrm{MeV}$ level in $14 \mathrm{~N}$. 


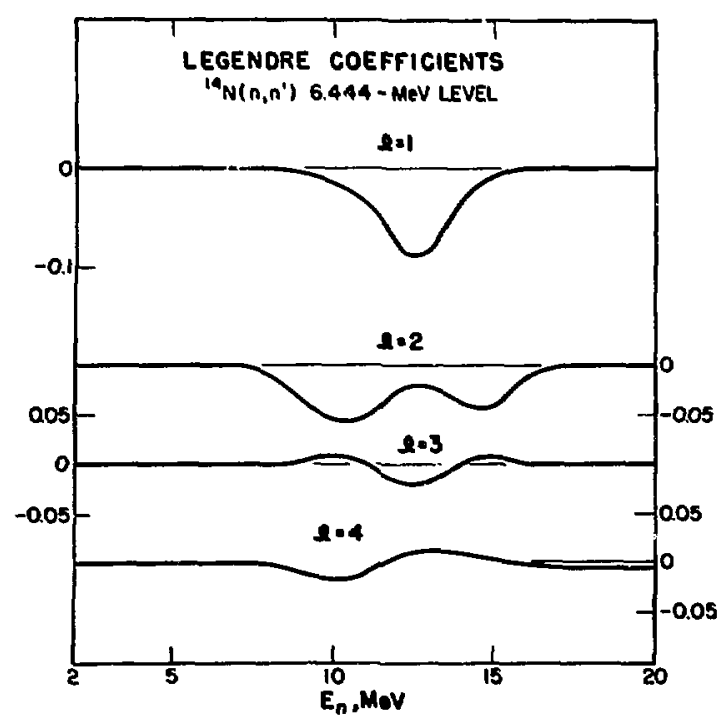

Fig. C15. Evaluated Legendre coefficients for inelastic scattering to the 6.444-MeV level in 14 .

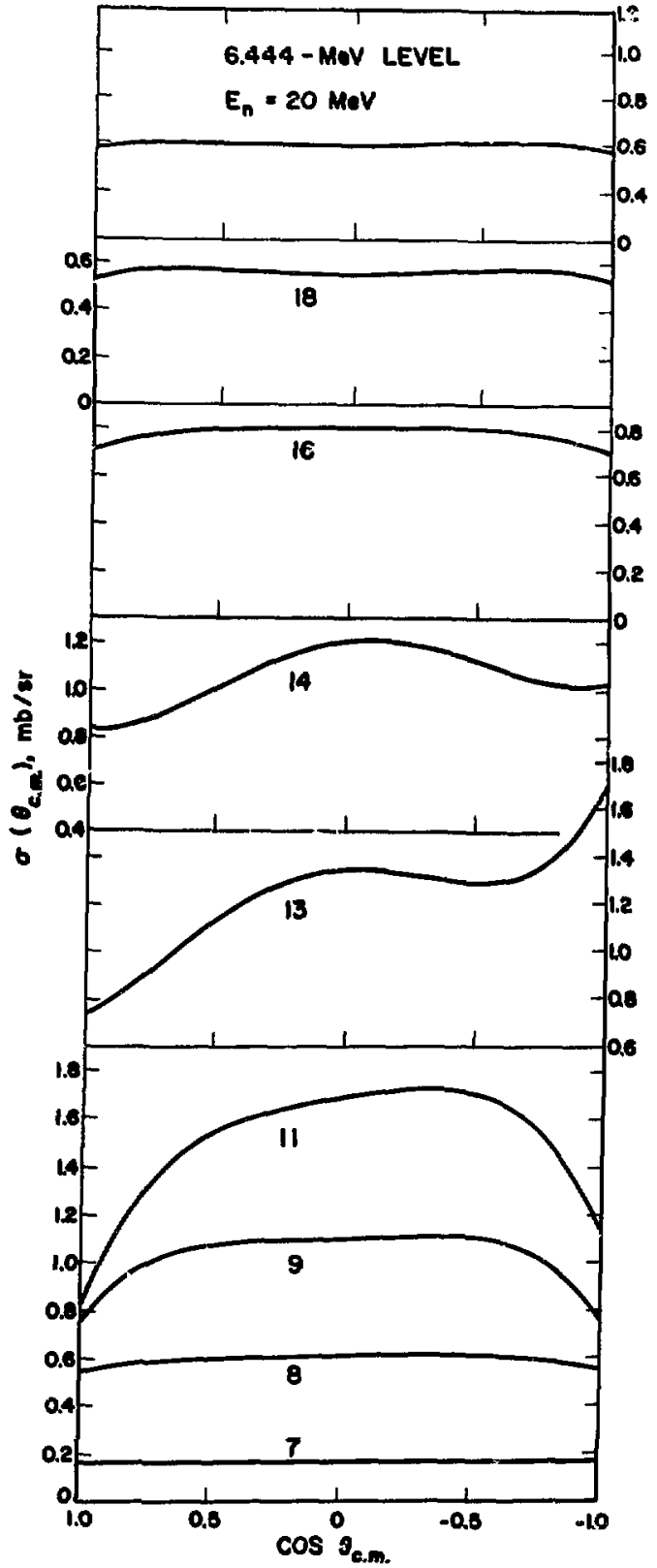

Fig. Cl6. Evaluated differential cross sections at selected energiles for inelast Ic scattering to the 6.444-MeV level in $14 \mathrm{~N}$. Note the suppressed zero for the $13-\mathrm{MeV}$ curve. 


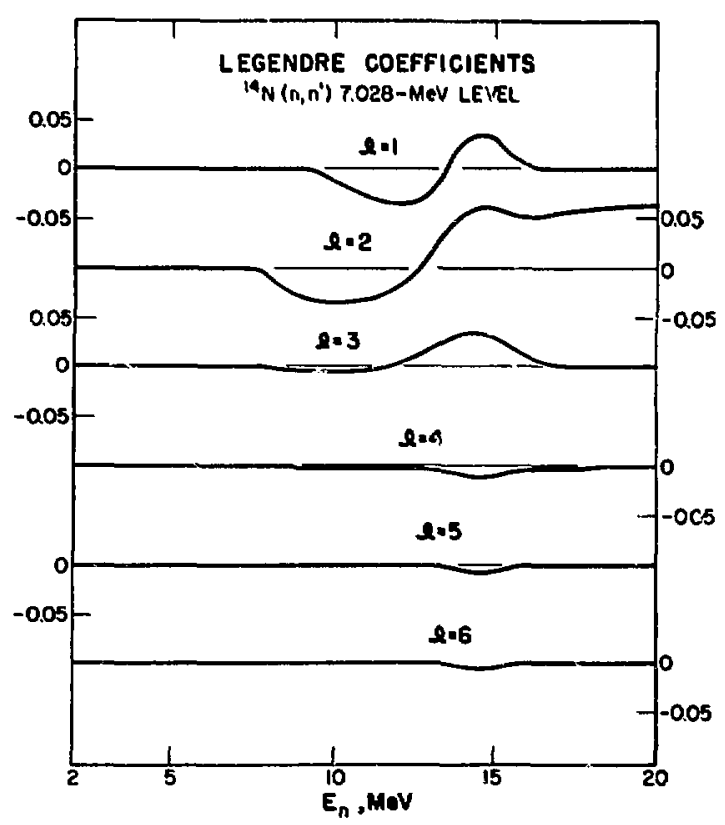

Fig. C17. Evaluated Legendre coefificlents for inelastic scattering to the 7.028-MeV level III $14 \mathrm{~N}$.

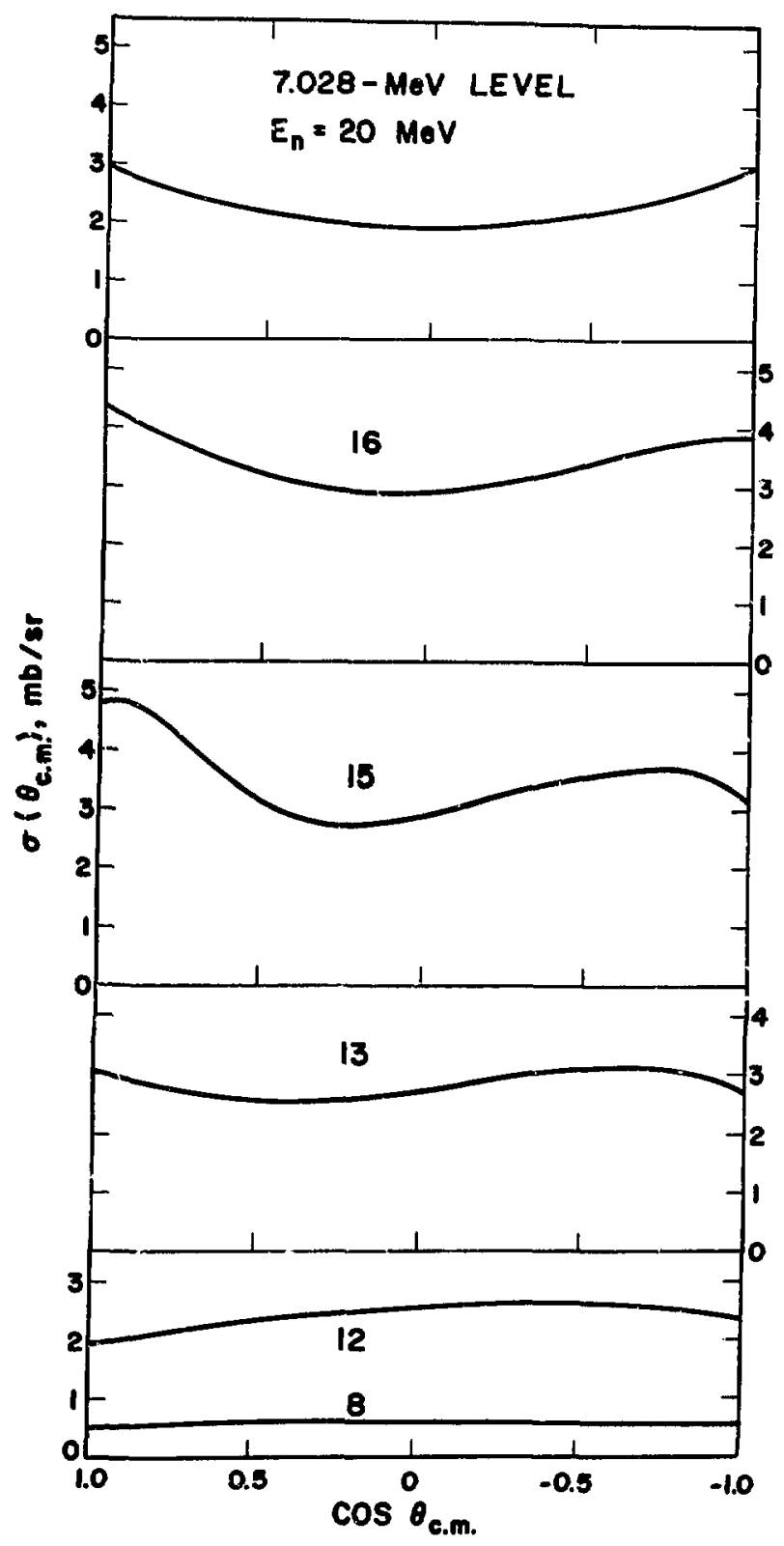

Fig. C18. Evaluated differential cross sections at selected energies for inelastic scattering to the $7.028-\mathrm{MeV}$ level in $14 \mathrm{~N}$. 


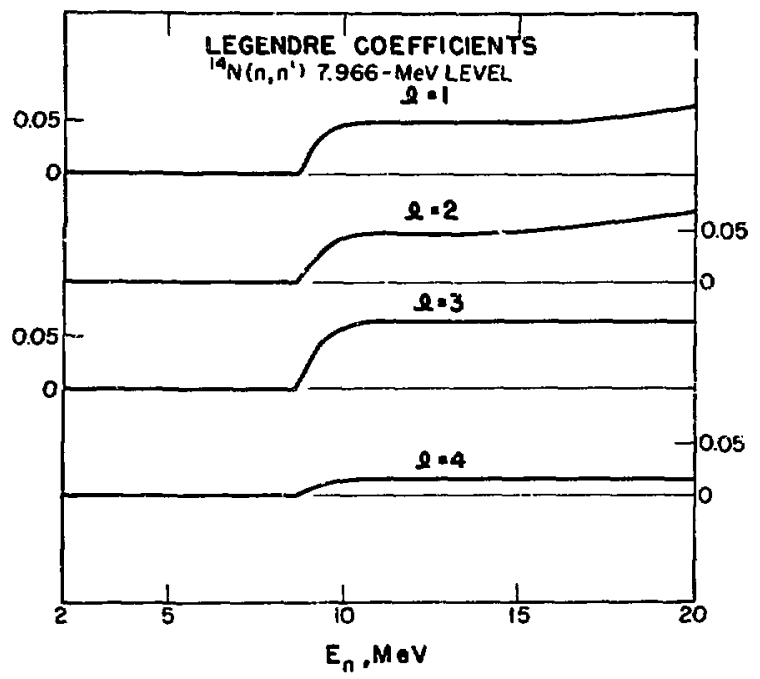

Fig. C19. Evaluated Legendre coeficients for inelastic scattering to the 7.966-MeV level in $14 \mathrm{~N}$.

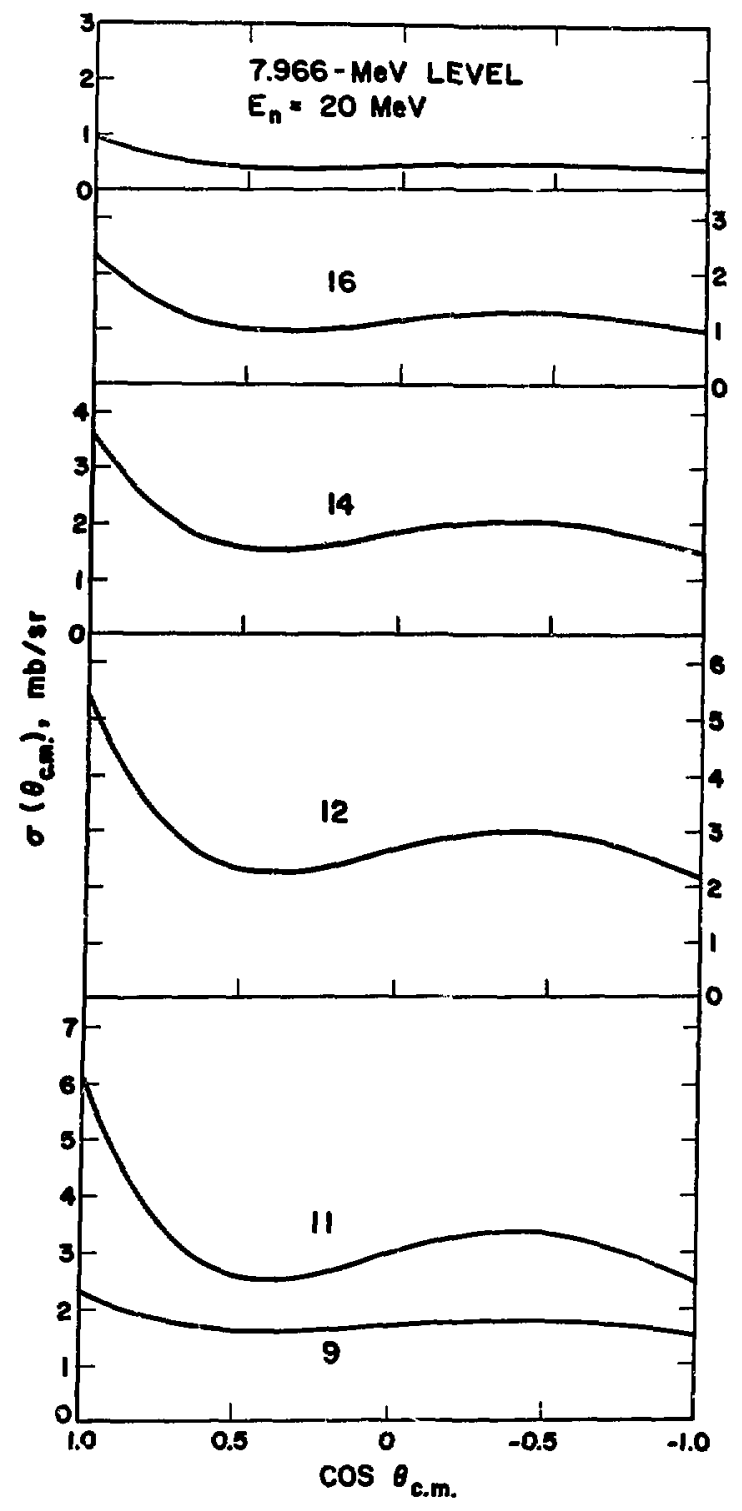

F1g. C20. Evaluated differential cross sections at selected energies for inelastic scattering to the $7.966-\mathrm{MeV}$ level in ${ }^{14} \mathrm{~N}$. 


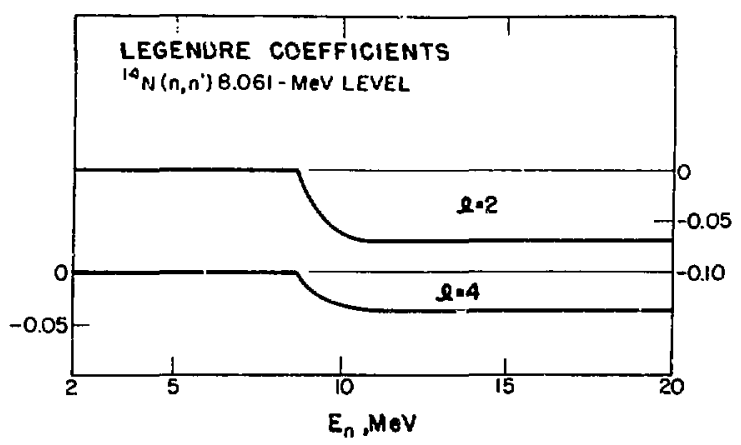

F1g. C21. Evaluated Legendre coeffictents for inelastic scattering to the $8.061-\mathrm{MeV}$ level in $14 \mathrm{~N}$. There were not enough measured points at back angles in the $\left(p, p^{\prime}\right)$ data from which these curves were constructed to define the cross sections beyond $90^{\circ}$, so the distributions were assumed symmetric.

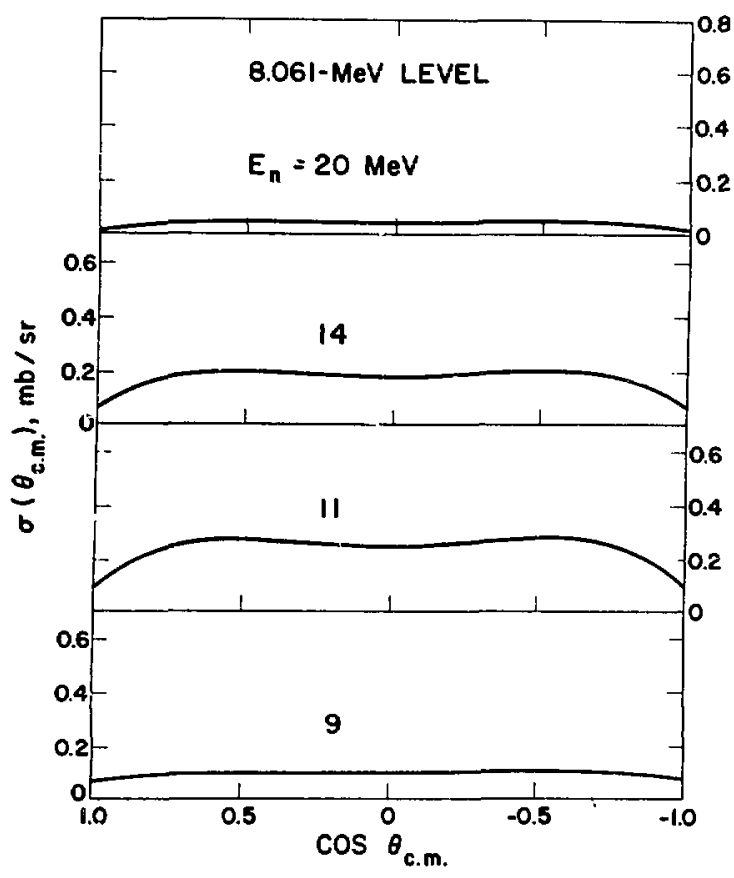

F1g. C22. Evaluated differential cross sections at selected energies for inelastic scatterIng to the $8.061-\mathrm{MeV}$ level in $14 \mathrm{~N}$, assumed symmetric about $90^{\circ}$ in the absence of sufficient data to determine the entire distribution.

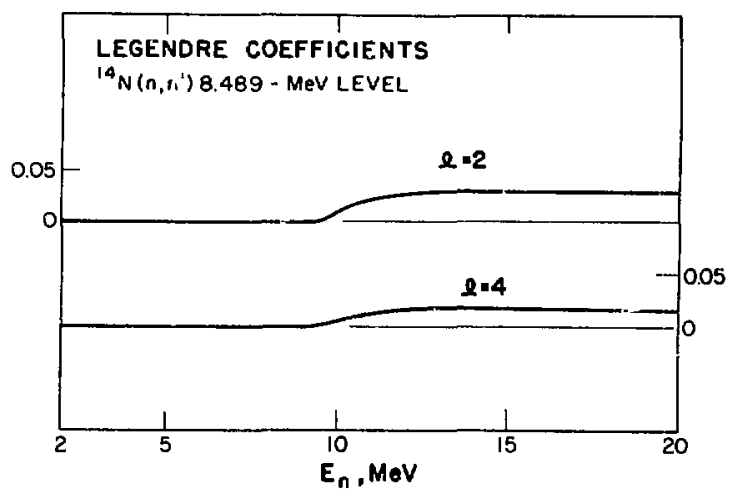

$\mathrm{Fig}$. C23. Evaluated Legendre coefficlents for inelastic scattering to the $8.489-\mathrm{MeV}$ level in $14 \mathrm{~N}$, assumed symetric in the absence of adequate data.

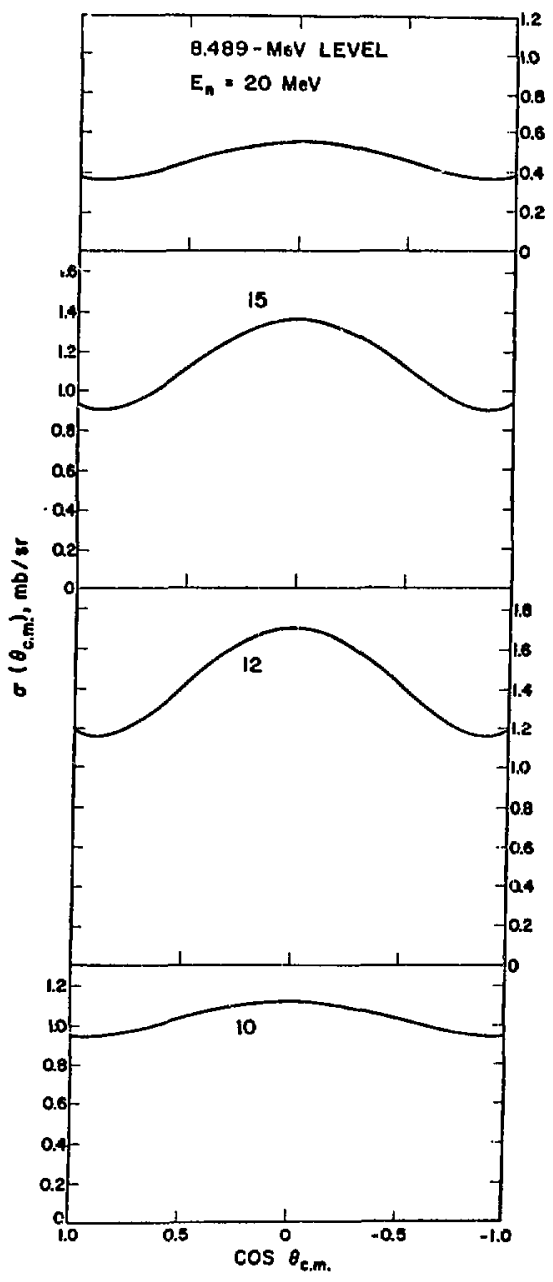

F1g. C24. Evaluated differential cross sections at selected energies for inelastic scattering to the $8.489-\mathrm{MeV}$ level in $14 \mathrm{~N}$. Symmetry about $90^{\circ}$ has been assumed. 